\section{CSIC}

CONSEJO SUPERIOR DE

INVESTIGACIONES

CIENTÍFICAS

ESTACIÓN AGRÍCOLA EXPERIMENTAL

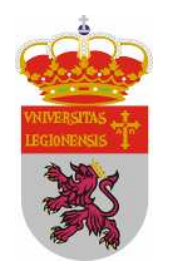

UNIVERSIDAD DE LEÓN

DEPARTAMENTO DE PRODUCCIÓN ANIMAL

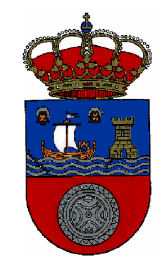

GOBIERNO DE

CANTABRIA

CONSEJERÍA DE DESARROLLO RURAL, GANADERÍA, PESCA Y BIODIVERSIDAD

\title{
INVASIÓN DE PASTOS DE MONTAÑA POR LECHERINA (EUPHORBIA POLYGALIFOLIA): ESTUDIOS DIRIGIDOS AL DESARROLLO DE UN SISTEMA DE CONTROL BIOLÓGICO BASADO EN EL PASTOREO
}

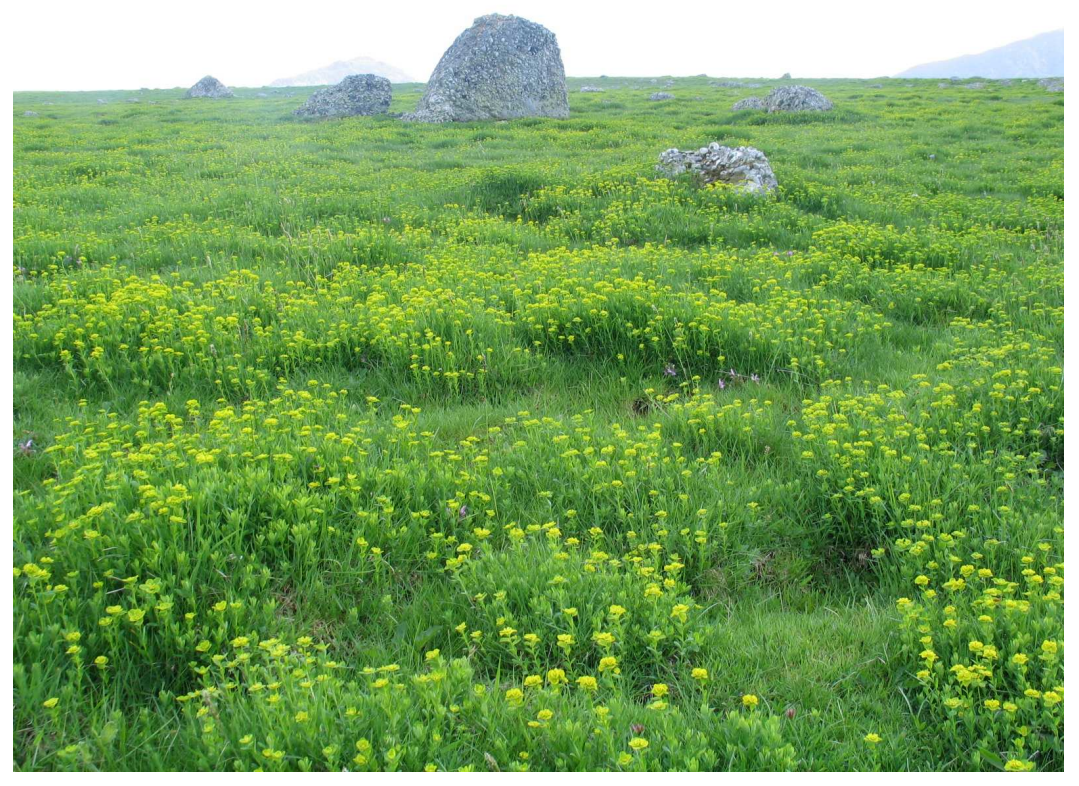

Manuel José Mora Martínez

León, Noviembre 2008 



\title{
INVASIÓN DE PASTOS DE MONTAÑA POR LECHERINA (EUPHORBIA POLYGALIFOLIA): ESTUDIOS DIRIGIDOS AL DESARROLLO DE UN SISTEMA DE CONTROL BIOLÓGICO BASADO EN EL PASTOREO
}

\author{
Memoria de Tesis Doctoral presentada por \\ Manuel José Mora Martínez
}

dirigida por

Dra. Pilar de Frutos Fernández y Dr. Juan Busqué Marcos

para acceder al grado de Doctor dentro del Programa de Doctorado "Producción y Sanidad Ovina" de la Universidad de León. 

El autor de esta memoria disfrutó de una beca predoctoral del Programa I3P (Itinerario Integrado de Inserción Profesional) del Consejo Superior de Investigaciones Científicas (CSIC) y, posteriormente, de una beca predoctoral del Instituto Nacional de Investigación y Tecnología Agraria y Alimentaria (INIA) y de una beca de formación del Gobierno de Cantabria.

Este trabajo se encuadra en los proyectos RTA02-027 y CSI 06A07 financiados por el INIA y la Junta de Castilla y León respectivamente. 

Deseo expresar un sincero agradecimiento a todas las personas e instituciones que han puesto a nuestra disposición sus conocimientos y los medios necesarios para la realización de este trabajo. 

A Manuel y Josefa, mis padres

por luchar tanto para ofrecerme las

oportunidades que vosotros no tuvisteis

\section{A Virginia}

por tu apoyo y comprensión en los momentos menos buenos 



\section{PAISAJE CON FIGURA}

Calveros de España

y rocas

$y$ arenas blancas,

en la inmensidad

un hombre

solo

guarda unas cabras.

Arriba los anchos mundos,

sus matemáticas,

Platones y Galileos

y Pitágoras.

Abajo, en el entremedio

del abismo y de la nada,

las cabras lamen y rumian

un rastro de yerba rala.

Julio Maruri 

ÍNDICES 



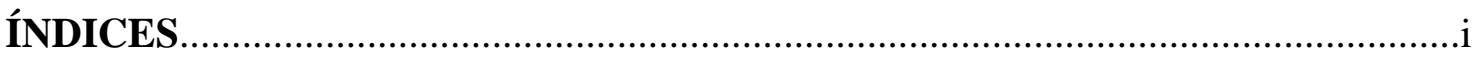

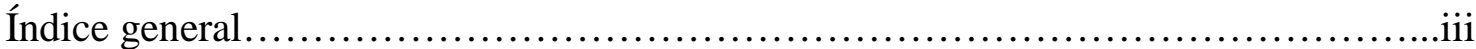

Índice de tablas..............................................................vii

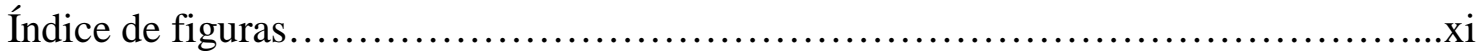

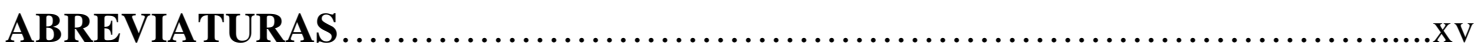

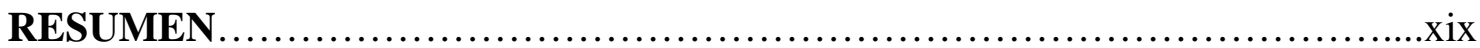

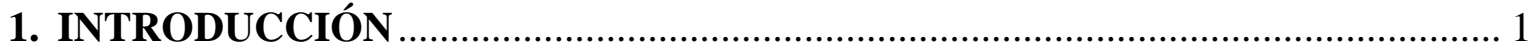

2. El sistema pastoral en la montaña cantábrica. El caso de los puertos de Sejos........ 7

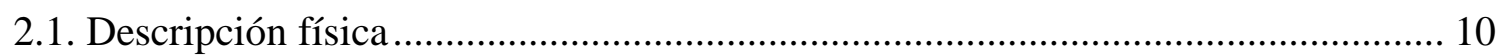

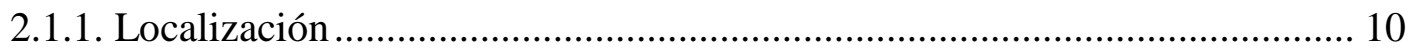

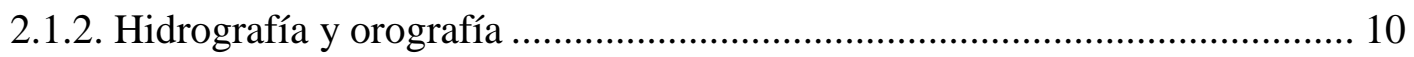

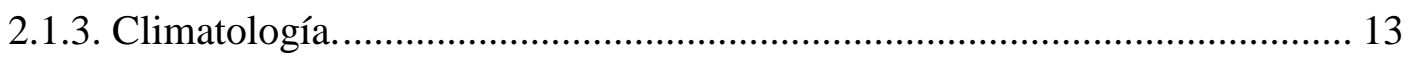

2.1.4. Geología, geomorfología y edafología.................................................... 15

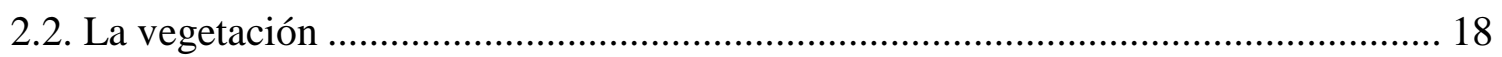

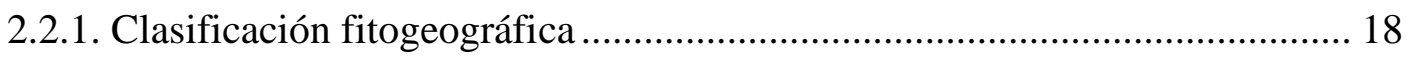

2.2.2. Tipificación de los pastos de Sejos ............................................................. 18

2.2.3. La lecherina (Euphorbia polygalifolia)............................................... 27

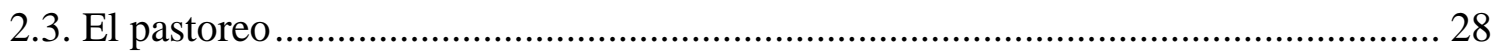

2.3.1. Origen histórico y gestión tradicional..................................................... 28

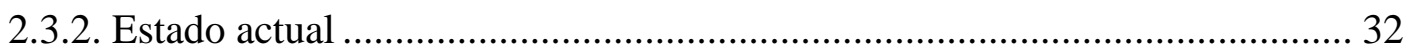

3. REVISIÓN BIBLIOGRÁFICA. Relación pasto-herbívoro: pautas y

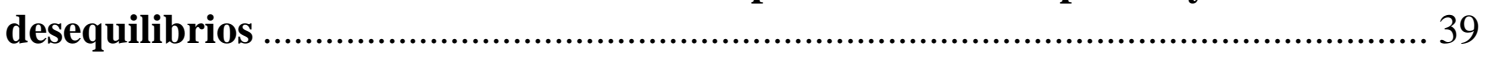

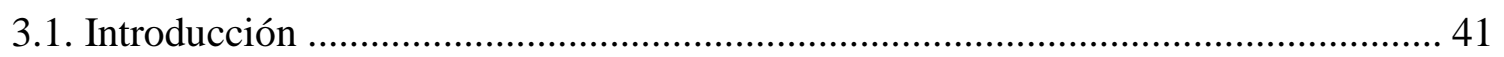

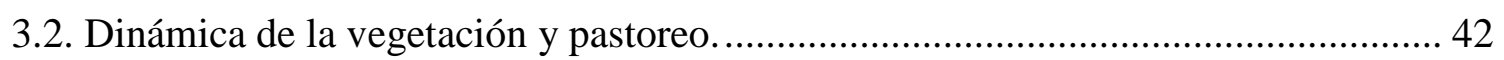

3.2.1. Dinámica de la vegetación..................................................................... 42

3.2.2. Efectos directos del pastoreo sobre las plantas ........................................ 45

3.2.3. Estrategias de las plantas de evasión del pastoreo....................................... 48

3.2.4. Dinámica de la vegetación asociada al pastoreo ........................................ 49

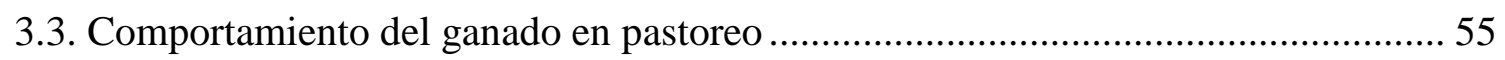

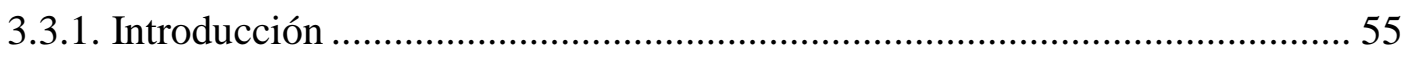

3.3.2. Escalas en el estudio del comportamiento en pastoreo............................... 56

3.3.3. Factores que afectan al comportamiento en pastoreo. ............................... 59

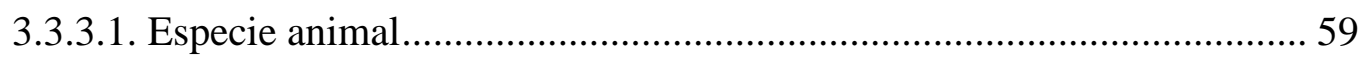

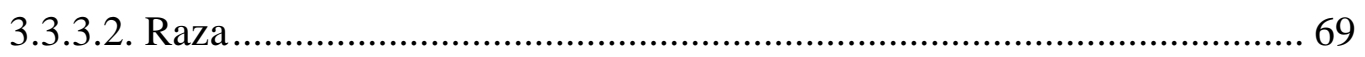

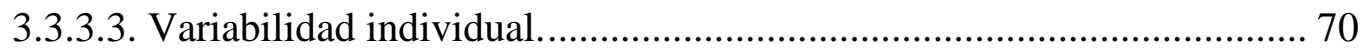


3.3.3.4. Aprendizaje postingestivo.

3.3.3.5. Factores sociales: actuaciones humanas, aprendizaje social y competencia del ganado. .73

3.3.3.6. Vegetación: disponibilidad, valor nutritivo y estructura.........................74

3.3.3.7. Distancia a puntos de agua.................................................................. 76

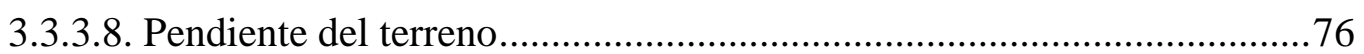

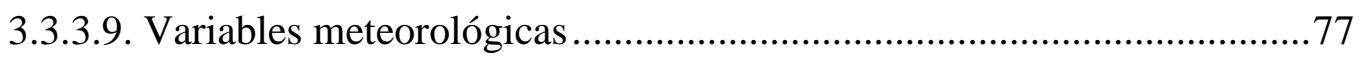

4. PRUEBA 1. Composición botánica y química y utilización digestiva de pastos

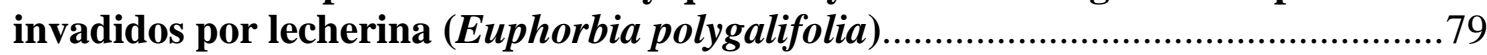

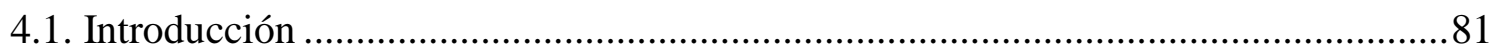

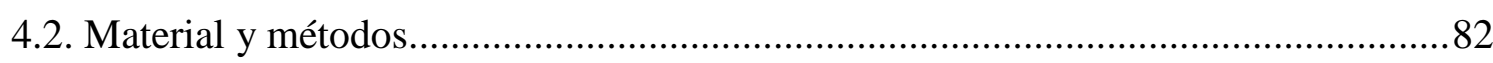

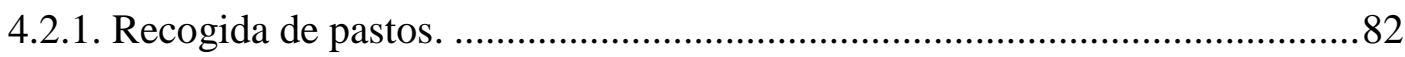

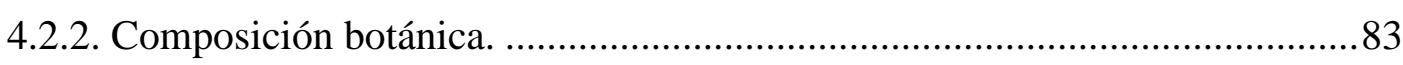

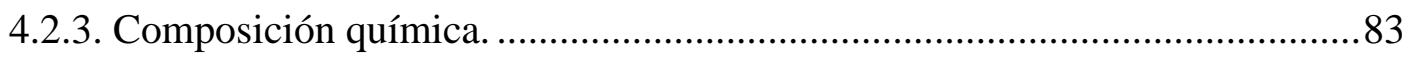

4.2.4. Cultivos discontinuos de microorganismos ruminales: producción de gas

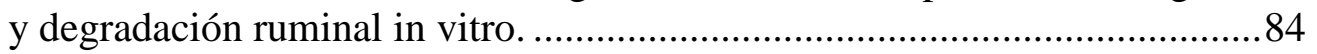

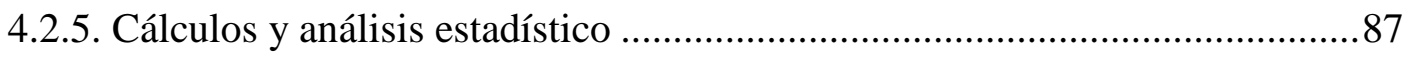

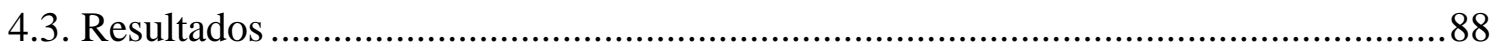

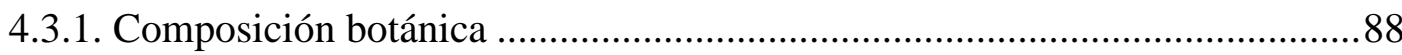

4.3.2. Composición química ........................................................................... 92

4.3.3. Cultivos discontinuos de microorganismos ruminales: producción de gas

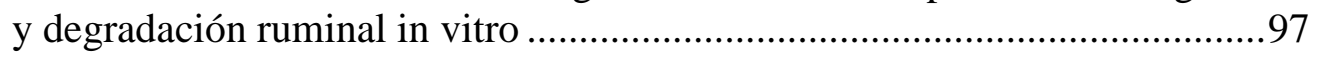

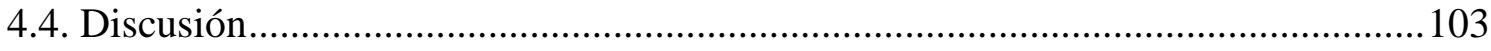

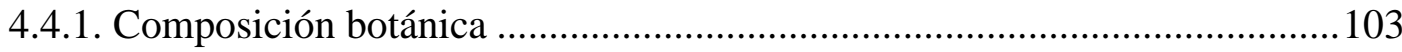

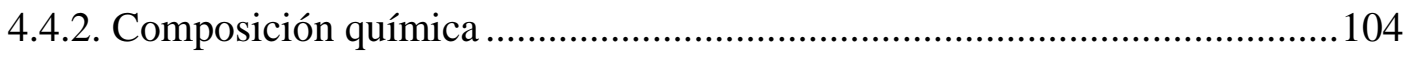

4.4.3. Cultivos discontinuos de microorganismos ruminales: producción de gas

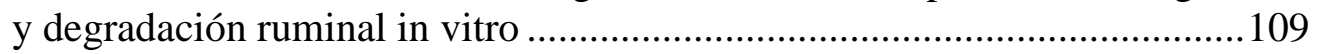

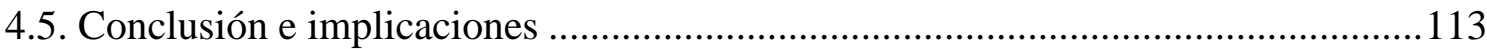

5. PRUEBA 2. Características del pastoreo estival del ganado vacuno y caballar en un puerto de la cordillera cantábrica invadido de lecherina (Euphorbia

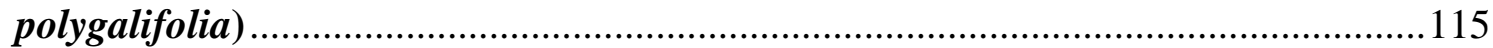

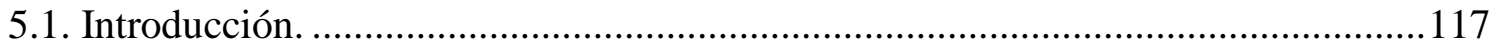

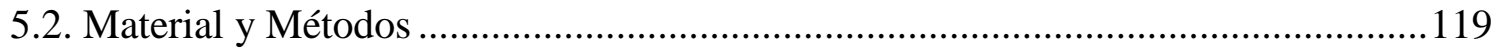

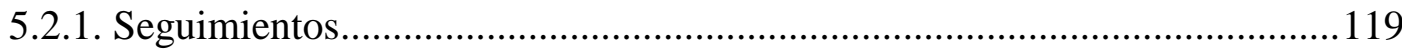

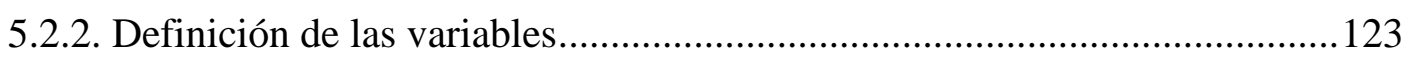

5.2.2.1. Características generales de las rutas diurnas ....................................124

5.2.2.2. Características de las actividades del ganado: pastoreo y descanso .... 125 
5.2.2.3. Características del pastoreo en relación con el tipo de pasto ............... 126

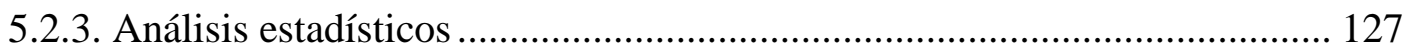

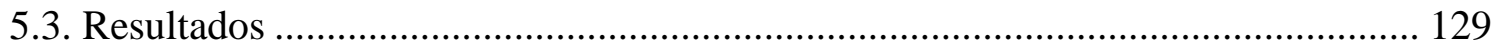

5.3.1 Características generales de las rutas diurnas ............................................ 129

5.3.2. Características de las actividades del ganado: pastoreo y descanso ........... 132

5.3.3. Características del pastoreo en relación con el tipo de pasto...................... 139

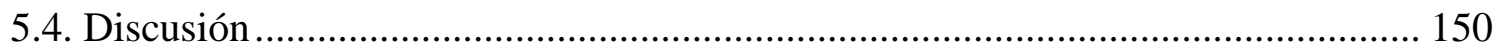

5.4.1. Características generales de las rutas diurnas ............................................ 151

5.4.2. Características de las actividades del ganado: pastoreo y descanso ............ 153

5.4.3 Características del pastoreo en relación con el tipo de pasto....................... 155

5.4.4. Extrapolación de los resultados a todo el puerto........................................ 161

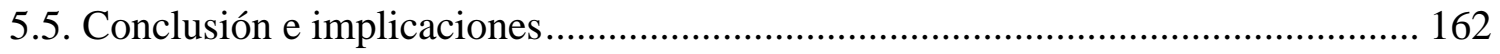

\section{PRUEBA 3. Degradación ruminal de pastos de puerto invadidos por lecherina} en el ganado vacuno y ovino: efecto del pastoreo previo en zonas invadidas ....... 165

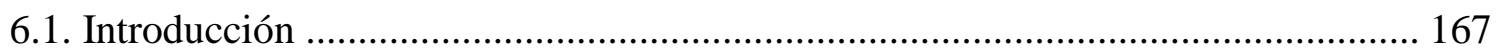

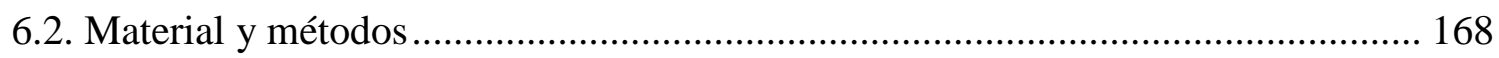

6.2.1. Animales y diseño experimental................................................................ 168

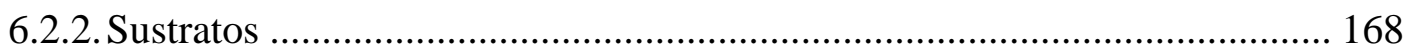

6.2.3. Cultivos discontinuos de microorganismos ruminales: producción de gas y degradación ruminal in vitro .......................................................... 169

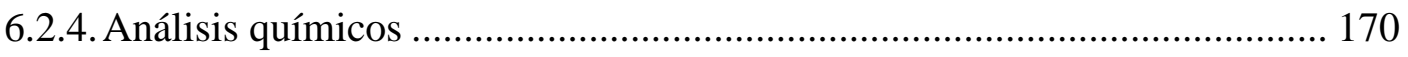

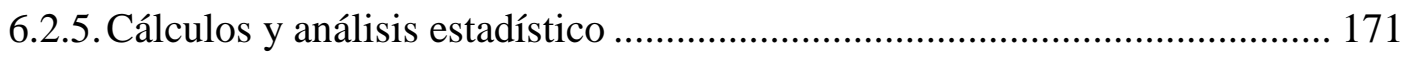

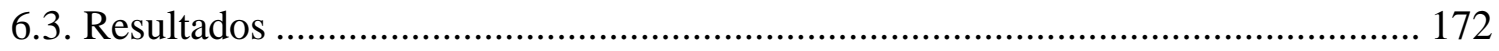

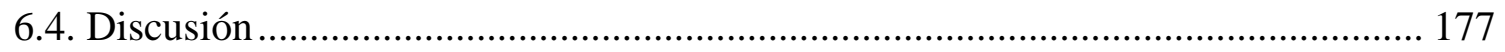

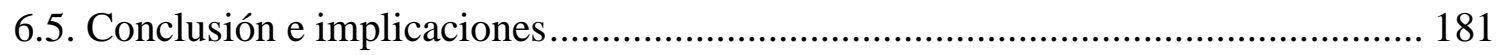

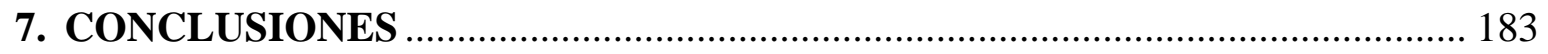

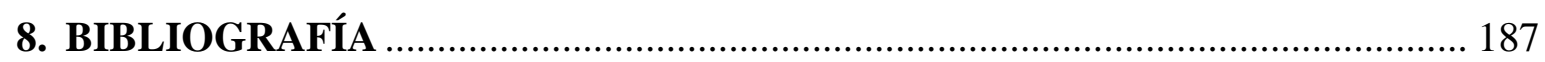



Tabla 2.1. Superficie y porcentaje de la superficie total ocupada por las distintas comunidades vegetales de Sejos.

Tabla 2.2. Evolución en el número de vacas marcadas para subir a la Mancomunidad Campoo Cabuérniga por municipios (años 1982, 1991 y 2002) y censo de caballar en 2002. Entre paréntesis $n^{\circ}$ de cabañas ganaderas.

Tabla 3.1. Efectos negativos del sobrepastoreo versus posibles efectos positivos del pastoreo moderado en la fisiología de los pastos (adaptado de Holechek et al., 2004).

Tabla 3.2. Ejemplos de utilización forrajera crítica en diferentes tipos de pastos (adaptado de Holechek et al. [2004] y Rickert [1996]).

Tabla 3.3. Mecanismos de evasión de las plantas para resistir el pastoreo (adaptado de Briske, 1996).

Tabla 3.4. Jerarquización ecológica del pastoreo de grandes herbívoros (adaptado de Senft et al., 1987).

Tabla 3.5. Atributos de las escalas espaciotemporales que describen el pastoreo de los grandes herbívoros (adaptado de Bailey et al., 1996).....

Tabla 3.6. Comparación morfo-fisiológica de los sistemas digestivos de dos tipos extremos de rumiantes: selectores de dietas con escaso desarrollo de la pared celular y consumidores de herbáceas y forrajes bastos (adaptado de Hoffman, 1988)

Tabla 3.7. Comparación del tiempo dedicado a la actividad de pastoreo por el ganado vacuno y caballar.

Tabla 4.1. Composición botánica (\%MS) de pastos invadidos por lecherina, pastos no invadidos y pastos invadidos por lecherina a los que se les ha sustraído la lecherina (invasinlech), a lo largo de la estación de pastoreo.

Tabla 4.2. Composición química (\%MS; materia orgánica, proteína bruta, fibra neutro detergente y fibra ácido detergente) de la lecherina, pastos invadidos por lecherina, pastos no invadidos y pastos invadidos por lecherina a los que se les ha sustraído la lecherina (invasinlech), a lo largo de la estación de pastoreo.

Tabla 4.3. Contenido de taninos totales en la lecherina ( $\mathrm{g}$ de equivalentes de ácido tánico/kgMS) e incremento en la producción de gas a las 24 horas cuando se incuba in vitro con PEG (dPEG; \%), a lo largo de la estación de pastoreo..

Tabla 4.4. Lípidos identificados en la lecherina (mg/kg MS).

Tabla 4.5. Producción de gas asintótica ( $\left.A, \mathrm{~mL} \mathrm{~g}^{-1} \mathrm{MO}\right)$, ritmo fraccional de producción de gas $\left(c, \mathrm{~h}^{-1}\right)$, desaparición de materia seca (DMS, $\left.\mathrm{g} \mathrm{kg}^{-1}\right)$, ritmo medio de fermentación (RMF, $\mathrm{mL} \mathrm{h}^{-1}$ ) y extensión de la degradación en el rumen $(\mathrm{ED}, \mathrm{g}$ $\mathrm{kg}^{-1}$ ) de los sustratos lecherina, pastos invadidos por lecherina, pastos no invadidos y pastos invadidos por lecherina a los que se les ha sustraído la lecherina (invasinlech), a lo largo de la estación de pastoreo.

Tabla 4.6 Concentración de amoniaco $\left(\mathrm{NH}_{4} \mathrm{mg} \mathrm{L}^{-1}\right)$, producción de ácidos grasos volátiles (AGV totales $[\mathrm{AGVt}]$, acético $[\mathrm{A}]$, propiónico $[\mathrm{P}]$, butírico $[\mathrm{B}]$ y "otros" $\left.\mathrm{AGV} ; \mathrm{mmol} \mathrm{L}^{-1}\right)$, relación acético:propiónico (A:P, mol:mol), producción estimada de metano $\left(\mathrm{CH}_{4}, \mu \mathrm{mol}\right)$ y relación $\mathrm{CH}_{4}$ : $\mathrm{AGV}$ totales $(\mu \mathrm{mol}: \mu \mathrm{mol})$ en incubaciones in vitro de 24 horas de los sustratos lecherina, pastos invadidos por lecherina, 
pastos no invadidos y pastos invadidos por lecherina a los que se les ha sustraído la lecherina (invasinlech), a lo largo de la estación de pastoreo.

Tabla 5.1. Seguimientos diurnos realizados en el estudio y características del pastoreo en el puerto de Sejos.

Tabla 5.2. Datos descriptivos correspondientes al ejemplo de seguimiento de la figura 5.3 (ver descripción de parámetros indicados en el apartado 5.2.2).

Tabla 5.3. Valores mínimos, medios y máximos de cobertura de lecherina (\%) en pastos de Festuca-Agrostis agrupados según su grado de invasión.

Tabla 5.4. Características generales de las rutas diurnas recorridas por el ganado. Nivel de significación estadística (P) de los efectos fijos especie (Esp: vacuno y caballar) y época (Ep: inicio, medio y final) y de su interacción.

Tabla 5.5. Selección en los percentiles 0-33\%, 33-67\% y 67-100\% de altitud y de pendiente en las rutas diurnas del ganado. Nivel de significación estadística $(\mathrm{P})$ de los efectos fijos especie animal (Esp: vacuno y caballar) y época (Ep: inicio, medio y final), de la covariable coeficiente de asimetría de las altitudes o pendientes de las áreas disponibles (cov) y de sus interacciones.

Tabla 5.6. Características de las rutas diurnas según la actividad desarrollada (pastoreo y descanso). Nivel de significación estadística (P) de los efectos fijos especie (Esp: vacuno y caballar) y época (Ep: inicio, medio y final) y de su interacción.

Tabla 5.7. Características de las rutas diurnas del ganado vacuno según la actividad desarrollada (pastoreo y descanso). Nivel de significación estadística (P) del efecto fijo raza (tudanca y otras razas), de la covariable días desde el inicio del estudio (días) y de su interacción.

Tabla 5.8. Selección en los percentiles 0-33\%, 33-67\% y 67-100\% de altitud y de pendiente en las rutas diurnas del ganado según la actividad desarrollada (pastoreo y descanso). Nivel de significación estadística (P) de los efectos fijos especie (Esp: vacuno y caballar) y época (Ep: inicio, medio y final), de la covariable coeficiente de asimetría de las altitudes o pendientes de las áreas disponibles (cov) y de sus interacciones.

Tabla 5.9. Correlaciones significativas $(\mathrm{P}<0,05)$ existentes entre disponibilidades, utilizaciones y selecciones de los distintos tipos de pastos estudiados y la diversidad vegetal (PD: proporción de pasto disponible; PU: proporción de pasto utilizado, estimado por tiempo de pastoreo; IJ: índice de selección de Jacobs del tipo de pasto; SPD: Índice de Shannon para las comunidades vegetales en el área disponible; SPU: Índice de Shannon para las comunidades pastadas en la ruta)

Tabla 5.10. Disponibilidad de los distintos tipos de pastos en las rutas diurnas de pastoreo. Nivel de significación estadística (P) de los efectos fijos especie (Esp: vacuno y caballar) y época (Ep: inicio, medio y final) y de su interacción.

Tabla 5.11. Disponibilidad de los distintos tipos de pasto en las rutas diurnas de pastoreo del ganado vacuno. Nivel de significación estadística (P) del efecto fijo raza de vacuno (tudanca y otras razas), de la covariable días desde el comienzo del estudio (días) y de su interacción.

Tabla 5.12. Utilización de los distintos tipos de pasto por el ganado en sus rutas de pastoreo diurnas. Nivel de significación estadística (P) de los efectos fijos especie (Esp: vacuno y caballar), época (Ep: inicio, medio y final) y su interacción, así 
como de la covariable disponibilidad de cada componente vegetal analizado en las áreas disponibles en cada ruta (cov).

Tabla 5.13. Utilización de los distintos tipos de pasto por el ganado vacuno en sus rutas de pastoreo diurnas. Nivel de significación estadística $(\mathrm{P})$ del efecto fijo raza (tudanca y otras razas) y de las covariables: días desde inicio del estudio (días) y tipos de pastos en las áreas disponibles en cada ruta (cov2).

Tabla 5.14. Selección de los distintos tipos de pasto por el ganado en sus rutas de pastoreo diurnas. Nivel de significación estadística (P) de los efectos fijos especie (Esp: vacuno y caballar) y época (Ep: inicio, medio y final), de la covariable disponibilidad de los tipos de pasto analizados en las áreas disponibles (cov) y de sus interacciones.

Tabla 5.15. Selección de los distintos tipos de pasto por el ganado vacuno en sus rutas de pastoreo diurnas. Nivel de significación estadística $(\mathrm{P})$ del efecto fijo raza (tudanca y otras razas), de la covariable días desde el comienzo de la prueba (días) y de su interacción.

Tabla 5.16. Selección de los pastos de Festuca-Agrostis según su grado de cobertura de lecherina dividido en tres percentiles de igual superficie disponible (cobertura baja, media y alta; ver tabla 5.3). Nivel de significación estadística (P) de los efectos fijos especie (Esp: vacuno y caballar) y época (Ep: inicio, medio y final), de la covariable proporción de pasto de Festuca-Agrostis sobre el total de pasto herbáceo en el área disponible (cov) y de sus interacciones.

Tabla 5.17. Altitudes y pendientes medias de los tipos de vegetación analizados en el estudio (datos de la cartografía de vegetación de Sejos [Busqué et al., 2006]).

Tabla 5.18. Selección de los principales tipos de vegetación estimados para toda el área del puerto de Sejos con utilización ganadera de vacuno y caballar (con pendientes menores a $35 \%$ ).

Tabla 6.1. Composición química de los sustratos pasto invadido por lecherina y pasto no invadido ( $\mathrm{g} / \mathrm{kg} \mathrm{MS})$.

Tabla 6.2. Producción asintótica de gas $\left(A, \mathrm{~mL} \mathrm{~g}^{-1} \mathrm{MO}\right)$, ritmo fraccional de producción de gas $\left(c, \mathrm{~h}^{-1}\right)$, tiempo de retardo $(\mathrm{Lag}, \mathrm{h})$, ritmo medio de fermentación (RMF, $\mathrm{mL} \mathrm{h}^{-1}$ ), desaparición de materia seca (DMS, $\mathrm{g} \mathrm{kg}^{-1}$ ) y extensión de la degradación en el rumen ( $\mathrm{ED}, \mathrm{g} \mathrm{kg}^{-1}$ ) de dos sustratos (pastos invadidos vs. no invadidos por lecherina) incubados in vitro durante 120 horas con inóculo ruminal de vacuno y ovino que habían pastado previamente (+EP) o no (-EP) en parcelas invadidas por lecherina.

Tabla 6.3. Concentración de amoniaco $\left(\mathrm{mg} \mathrm{L}^{-1}\right)$, producción de ácidos grasos volátiles (AGV, mmol $\left.\mathrm{L}^{-1}\right)$, relación acético:propiónico (A:P, mol:mol), producción estimada de metano $\left(\mathrm{CH}_{4}, \mu \mathrm{mol}\right)$ y relación $\mathrm{CH}_{4}$ :AGV totales $(\mu \mathrm{mol}: \mu \mathrm{mol})$ en incubaciones in vitro a 24 horas de dos sustratos (pastos invadidos vs. pastos no invadidos por lecherina) con inóculo ruminal de vacuno y ovino que habían pastado previamente (+EP) o no (-EP) en parcelas invadidas por lecherina. 

Figura 2.1. Localización de Sejos dentro de la Mancomunidad Campoo Cabuérniga (Cantabria).

Figura 2.2. Hidrografía de los Puertos de Sejos y sus alrededores (adaptado de Ferrer i Marco et al., 2006).

Figura 2.3. Mapa de altitudes de los Puertos de Sejos y sus alrededores (adaptado de Ferrer i Marco et al., 2006).

Figura 2.4. Mapa de pendientes de los Puertos de Sejos y sus alrededores (adaptado de Ferrer i Marco et al., 2006).

Figura 2.5. Mapa de orientaciones de los Puertos de Sejos y sus alrededores (adaptado de Ferrer i Marco et al., 2006).

Figura 2.6. Mapa de precipitaciones medias anuales de los Puertos de Sejos y sus alrededores (adaptado de Gutiérrez et al., 2005).

Figura 2.7. Mapa de temperaturas medias anuales de los Puertos de Sejos y sus alrededores (adaptado de Gutiérrez et al., 2005).

Figura 2.8. Mapa de temperaturas mínimas medias del mes más frío de los Puertos de Sejos y sus alrededores (adaptado de Gutiérrez et al., 2005).

Figura 2.9. Mapa de agrupaciones funcionales de suelos de los Puertos de Sejos y sus alrededores (adaptado de Ferrer i Marco et al., 2006).

Figura 2.10. Ortofoto representando el área cartografiada de los puertos de Sejos.

Figura 2.11. Mapas de las comunidades vegetales herbáceas más representativas de los puertos de Sejos.

Figura 2.12. Mapas de las comunidades vegetales arbustivas más representativas de los puertos de Sejos.

Figura 2.13. Distribución espacial de la vegetación de Sejos según el dominio superficial de uno de los tres grandes grupos de vegetación existente: herbáceo, arbustivo y arbóreo.

Figura 2.14. Superficie de Sejos ocupada por lecherina (izquierda) y por la comunidad vegetal de pastos herbáceos de Festuca-Agrostis (derecha), según sus porcentajes de cobertura.

Figura 2.15. Localización de los pueblos con derechos históricos de aprovechamiento en la finca de la Mancomunidad Campoo Cabuérniga. (Gómez Sal et al., 1995).....

Figura 2.16. Distribución espacio-temporal actual de los pastos de la Mancomunidad Campoo Cabuérniga con indicación de los pueblos con derechos de pastoreo en cada época y zona (Gómez Sal et al., 1995)....

Figura 2.17. Localización de los seles en los puertos de Sejos dentro de la Mancomunidad Campoo Cabuérniga (Busqué et al., 2006).

Figura 2.18. Distribución de los tamaños de las cabañas de vacuno que subieron a la Mancomunidad Campoo Cabuérniga en 2002.

Figura 2.19. Distribución de los tamaños de las cabañas de caballar que subieron a la Mancomunidad Campoo Cabuérniga en 2002.

Figura 2.20. Zonificación de las zonas pastorales de la Mancomunidad Campoo Cabuérniga (izquierda) y del área de estudio de los puertos de Sejos (derecha). 
Figura 2.21. Evolución del número de ejemplares de vacuno (eje vertical izquierdo) y caballar (eje vertical derecho) pastando en los puertos de Sejos en el verano-otoño de 2003.

Figura 2.22. Estimación de la utilización forrajera total de los pastos del tipo FestucaAgrostis por el pastoreo de vacuno y caballar en los puertos de Sejos (Mancomunidad-Campoo Cabuérniga) en la estación de pastoreo de 2003 (Busqué et al., 2006).

Figura 3.1. Triángulo de estrategias extremas de las plantas (C: competitivas; S: tolerantes al estrés; R: ruderales) en función de las condiciones de perturbación y estrés (Hodgson et al., 1999).

Figura 3.2. Modelo conceptual de la dinámica de invasión de Euphorbia polygalifolia (lecherina) en los pastos de diente de los puertos de Sejos según el esquema de estrategias CSR (Grime, 1979). Paso 1: la festuca (Festuca nigrescens) sustituye al cervuno (Nardus stricta) cuando aumenta la intensidad de pastoreo por vacuno y caballar (aumento de perturbación [defoliación] y disminución de estrés [fertilización]). La incidencia de descensos acusados en la disponibilidad de recursos (p.ej. sequías; paso 2) o de perturbaciones puntuales muy fuertes (p.ej. más defoliación o hozaduras o toperas; paso 3), o de combinaciones de ambas, desplaza la situación a condiciones inviables para la vida vegetal (formación de huecos). Paso 4: los huecos son colonizados posteriormente por propágulos de lecherina que, en su estado adulto (paso 5) cambian las características del hábitat (aseguran la disponibilidad de recursos por la mayor profundidad de las raíces y evitan la defoliación por vacuno y caballar mediante la producción de defensas químicas).

Figura 3.3. Interrelaciones entre planta y animal en los sistemas de pastoreo. Las líneas y flechas en negrita indican los flujos y la partición de la materia a través del sistema; los factores que son alterados por las decisiones del manejo del pastoreo y que influyen en el ritmo de los procesos (crecimiento, consumo, etc.) se inscriben en círculos; las líneas sencillas indican impactos y relaciones (adaptado de Grant y Maxwell, 1988).

Figura. 3.4. Interpretación funcional de la dinámica de vegetación de pastos herbáceos mesotróficos representados por dos tipos funcionales de plantas: $A$ y $B$ (adaptado de Briske, 1996).

Figura 3.5. Modelo conceptual de la abundancia de plantas herbáceas y leñosas en ecosistemas pastorales (adaptado de Archer, 1996).

Figura 3.6. Gradiente de la capacidad selectiva de la dieta de distintos herbívoros (adaptado de Hoffman, 1988).

Figura 4.1. Evolución de la composición botánica de los pastos invadidos por lecherina, los pastos no invadidos y los pastos invadidos por lecherina a lo que se les ha sustraído la lecherina, a lo largo de la estación de pastoreo.

Figura 4.2. Evolución de la composición química (MO, PB, FND y FAD) de la lecherina, los pastos invadidos por lecherina, los pastos no invadidos y los pastos invadidos por lecherina a los que se les ha sustraído la lecherina, a lo largo de la estación de pastoreo.

Figura 4.3. Cromatograma del extracto lipofílico total de la lecherina. An: alcanos, Aln: aldehidos, OHn: alcoholes (n corresponde al número de átomos de carbono).......96 
Figura 4.4. Evolución de la producción de gas asintótica $\left(A, \mathrm{~mL} \mathrm{~g}^{-1} \mathrm{MO}\right)$, ritmo fraccional de producción de gas $\left(c, \mathrm{~h}^{-1}\right)$, desaparición de materia seca (DMS, $\mathrm{g} \mathrm{kg}^{-1}$ ) y extensión de la degradación en el rumen (ED, $\mathrm{g} \mathrm{kg}^{-1}$ ) de los sustratos lecherina, pastos invadidos por lecherina, pastos no invadidos y pastos invadidos por lecherina a los que se ha sustraído la lecherina, a lo largo de la estación de pastoreo.

Figura 4.5. Evolución de la concentración de amoniaco $\left(\mathrm{NH}_{4} \mathrm{mg} \mathrm{L}^{-1}\right)$, producción de ácidos grasos volátiles ( $\mathrm{mmol} \mathrm{L}^{-1}$; $\mathrm{AGV}$ totales, acético y propiónico) en incubaciones a 24 horas in vitro de los sustratos lecherina, pastos invadidos por lecherina, pastos no invadidos y pastos invadidos por lecherina a los que se les ha sustraído la lecherina, a lo largo de la estación de pastoreo.

Figura 5.1. Localización de las posiciones de las 15 yeguas objeto de seguimiento diurno en los puertos de Sejos. Los puntos de igual color corresponden a un mismo seguimiento

Figura 5.2. Localización de las posiciones de las 18 vacas objeto de seguimiento diurno en los puertos de Sejos. Los puntos de igual color corresponden a un mismo seguimiento. La línea roja delimita el área disponible definida para el seguimiento marcado con puntos rojos (ver figura 5.3 y apartado 5.2.2).

Figura 5.3. Ejemplo de un seguimiento diurno de ganado vacuno: en la imagen superior los puntos de igual color representan una actividad concreta del animal objeto de seguimiento (rojo: pastoreo; verde: descanso; azul: desplazamiento). La línea roja delimita el área disponible estimada para el pastoreo en ese seguimiento (ver apartado 5.2.2); la figura inferior recoge el transecto altitudinal del mismo seguimiento a lo largo del día.

Figura 5.4. Selección en los percentiles 0-33\%, 33-67\% y 67-100\% de las altitudes de las áreas disponibles según la época (inicio, medio y final). Las barras verticales señalan los intervalos de confianza con $\mathrm{P}=95 \%$.

Figura 5.5. Selección en los percentiles 0-33\%, 33-67\% y 67-100\% de las pendientes de las áreas disponibles según la especie (vacuno y caballar). Las barras verticales señalan los intervalos de confianza con $\mathrm{P}=95 \%$.

Figura 5.6. Características de las actividades de pastoreo y descanso en las rutas diurnas (proporción de tiempo empleado, pendiente media utilizada y variación de la pendiente utilizada en la ruta) según la especie (vacuno y caballar). Las barras verticales señalan los intervalos de confianza con $\mathrm{P}=95 \%$ correspondientes a los análisis de cada actividad por separado.

Figura 5.7. Variación intra-ruta de la altitud utilizada (m) en la ruta diurna para las actividades de pastoreo y descanso según la época de la estación de pastoreo (inicio, medio y final). Las barras verticales señalan los intervalos de confianza con $\mathrm{P}=95 \%$ correspondientes a los análisis de cada actividad por separado.

Figura 5.8. Proporción de tiempo diurno empleado en las actividades de pastoreo y descanso según la raza de ganado vacuno (tudanca y otras razas). Las barras verticales señalan los intervalos de confianza con $\mathrm{P}=95 \%$ correspondientes a los análisis de cada actividad por separado.

Figura 5.9. Selección en los percentiles 0-33\%, 33-67\% y $67-100 \%$ de las altitudes de las áreas disponibles según la época (inicio, medio y final) para la actividad 
pastoreo. Las barras verticales señalan los intervalos de confianza con $\mathrm{P}=95 \%$ correspondientes a los análisis de cada percentil por separado.

Figura 5.10. Selección en los percentiles 0-33\%, 33-67\% y 67-100\% de las pendientes de las áreas disponibles según la especie (vacuno y caballar) para la actividad de pastoreo. Las barras verticales señalan los intervalos de confianza con $\mathrm{P}=95 \%$ correspondientes a los análisis de cada percentil por separado.

Figura 5.11. Disponibilidad de los distintos tipos de pastos en las rutas diurnas de pastoreo. Valores significativamente diferentes $(\mathrm{P}<0,05)$ según la especie (vacuno y caballar). Las barras verticales representan el intervalo de confianza al $95 \%$

Figura 5.12. Disponibilidad de los distintos tipos de pasto en las rutas diurnas de pastoreo del ganado vacuno. Las barras verticales representan el intervalo de confianza con $\mathrm{P}=95 \%$.

Figura 5.13. Utilización de los distintos tipos de pasto por el ganado en sus rutas de pastoreo diurnas. Las barras verticales representan el intervalo de confianza con $\mathrm{P}=95 \%$.

Figura 5.14. Evolución de la utilización de cervunal sobre pasto herbáceo en vacas y yeguas a lo largo de la estación de pastoreo. Las barras verticales señalan los intervalos de confianza con $\mathrm{P}=95 \%$.

Figura 5.15. Evolución temporal de la utilización en pastoreo de dos tipos de pasto por las vacas tudancas (izquierda: utilización del pasto arbustivo respecto al pastoreo total; derecha: utilización del cervunal respecto al pastoreo sobre pasto herbáceo). El coeficiente de regresión $\mathrm{R}^{2 *}$ corresponde a la regresión lineal sin la observación del día 73.

Figura 5.16. Selección de los distintos tipos de pasto según la especie (vacuno y caballar) y la época de la estación de pastoreo (inicio, medio y final) en sus rutas de pastoreo diurnas. Las barras verticales señalan los intervalos de confianza con $\mathrm{P}=95 \%$.

Figura 5.17. Selección de los distintos tipos de pasto según la raza de ganado vacuno (tudanca y otras razas) en sus rutas de pastoreo diurnas. Las barras verticales señalan los intervalos de confianza con $\mathrm{P}=95 \%$.

Figura 5.18. Evolución temporal de la selección del pasto arbustivo por las vacas de raza tudanca. El coeficiente de regresión $\mathrm{R}^{2^{*}}$ corresponde a la regresión lineal sin la observación del día 73.

Figura 6.1. Curvas de producción de gas de los pastos invadidos y no invadidos por lecherina en vacas y ovejas sometidas a pastoreo previo en zonas invadidas o libres de la invasión. 

A

Act

AGV

arcsen

AT

$c$

$\mathrm{CH}_{4}$

$\mathrm{CO}_{2}$

Cov

DMS

d.e.

E

ED

e.e.d.

Esp

Ep

FAD

FND

FS

FT

$g_{1}$

G

GC

GC/MS

GPS

Inter.

invasinlech

IJ

$\mathrm{K}_{\mathrm{p}}$

Lag

MCC

MO

MS producción asintótica de gas

actividad

ácidos grasos volátiles

arco seno

ácido tánico

ritmo fraccional de producción de gas

metano

dióxido de carbono

covariable

desaparición de materia seca

desviación estándar

escala

extensión de la degradación en el rumen

error estándar de la diferencia

Especie

Época

fibra ácido detergente

fibra neutro detergente

fenoles simples

fenoles totales

coeficiente de asimetría

tasa de producción de gas

cromatografía de gases

cromatografía de gases/espectrometría de masas

Sistema de Posicionamiento Global

interacción

pasto invadido por lecherina al que se le sustrae la lecherina

Índice de selección de Jacobs

ritmo de paso

tiempo de retraso (lag time)

Mancomunidad Campoo Cabuérniga

materia orgánica

materia seca 
$\mathrm{N}$

$\mathrm{NH}_{3}$

ns

$\mathrm{P}$

PB

PD

PEG

Perc

PU

PVPP

r

$\mathrm{RMF}$

$\mathrm{R}^{2}$

SAS

SPSS

Sig.

SPD

SPU

TT

UGM

UTM nitrógeno

amoniaco

diferencias no significativas

probabilidad (nivel de significación estadística)

proteína bruta

proporción de pasto disponible

polietilenglicol

percentil

proporción de pasto utilizado

polivivilpolipirrolidona

coeficiente de correlación

ritmo medio de fermentación

coeficiente de determinación

Statistical Analysis System

Statistical Package for the Social Sciences

Significación

Ìndice de Shannon para las comunidades vegetales en el área disponible

Índice de Shannon para las comunidades pastadas en la ruta taninos totales

Unidad de Ganado Mayor

Universal Transverse Mercator 
RESUMEN 

Los pastos de puerto acidófilos de la Cordillera Cantábrica dominados por Festuca nigrescens y Agrostis capillaris y, en especial, los pastos objeto de estudio en este trabajo (Puertos de Sejos; Mancomunidad Campoo Cabuérniga; Cantabria), están sufriendo en los últimos años una invasión por la especie endémica Euphorbia polygalifolia, conocida comúnmente como lecherina. Esta planta es rechazada por el ganado vacuno y caballar, mayoritario en la zona, produciendo su expansión una reducción de la utilización pastoral y la diversidad vegetal de los pastos de puerto afectados. Con la asunción general de que el pastoreo es un factor determinante en la dinámica del proceso de invasión de la lecherina, este trabajo se realizó con el objetivo final de fundamentar una estrategia de control de la invasión basada en el estudio de la propia planta y de sus interacciones con el pastoreo por distintos ungulados. Para alcanzar dicho objetivo general, y después de una descripción del sistema pastoral de la zona de estudio (capítulo 2), se desarrollaron tres pruebas experimentales (recogidas en los capítulos 4, 5 y 6).

La primera prueba (capítulo 4) se planteó con la intención de explicar por qué el ganado presente en los puertos de Sejos rechaza consumir los pastos de Festuca-Agrostis invadidos por E. polygalifolia. En este sentido, se partió de la siguiente hipótesis: los pastos invadidos por lecherina presentan, a lo largo de la estación de pastoreo, un menor valor nutritivo que los pastos libres de la invasión. Esta diferencia podría deberse a la presencia de lecherina en el pasto, o a los cambios en los demás componentes botánicos de los pastos invadidos respecto a los pastos sin invadir. Con el fin de contrastar la hipótesis planteada, se estudió la evolución temporal de algunos parámetros indicativos del valor nutritivo (composición botánica y química y utilización digestiva) de los siguientes sustratos: pasto invadido por lecherina; pasto invadido por lecherina al que se le sustrae la lecherina; pasto libre de la invasión y plantas de lecherina. Para ello, se recogieron muestras de cada tipo de pasto mensualmente (desde mayo hasta septiembre) en tres zonas representativas de los puertos de Sejos.

Los resultados mostraron diferencias en la composición botánica de los pastos invadidos y los no invadidos por lecherina no sólo atribuibles a la elevada presencia de $E$. polygalifolia en los invadidos (44,5\%) sino también a cambios en los demás componentes relacionados con la propia invasión (mayor presencia de graminoides y menores contenidos de leguminosas y otras latifoliadas en los pastos invadidos a los que se le sustrae la lecherina que en los no invadidos). A su vez, se encontraron diferencias en la composición química (contenidos superiores de materia orgánica e inferiores de proteína 
bruta y de fibra neutro detergente en los pastos invadidos respecto a los no invadidos) y en la utilización digestiva de los mismos (con valores significativamente superiores de producción de gas, ritmos de fermentación y degradación de la materia seca in vitro, así como de la extensión de su degradación en el rumen en los pastos libres de la invasión). Sin embargo, dichas diferencias no justificarían por sí mismas el acusado rechazo del ganado hacia los pastos invadidos. En cambio, la presencia en la lecherina de taninos y terpenoides sí podría explicar dicho rechazo, mediante el desarrollo por el ganado de aversiones condicionadas hacia los alimentos que contienen estos compuestos secundarios.

Por lo tanto, aunque en esta prueba no fue posible realizar una valoración nutritiva sensu stricto (energética y proteica), nuestros resultados de composición y utilización digestiva sugieren que los pastos invadidos por lecherina presentarían, a lo largo de la estación de pastoreo, un menor valor nutritivo que los pastos libres de la invasión, lo cual apunta hacia la verificación de la hipótesis de partida.

En la segunda prueba (capítulo 5) se estudiaron los patrones de pastoreo estival del ganado vacuno y caballar de los puertos de Sejos, especialmente en referencia al aprovechamiento de los pastos de Festuca-Agrostis invadidos o susceptibles ser invadidos por la lecherina. Para ello, se partió de dos hipótesis: la primera fue que el ganado caballar concentra más su actividad en los pastos de Festuca-Agrostis, y la segunda que a lo largo del verano la utilización y selección de los pastos de Festuca-Agrostis varía en función de la carga ganadera. La prueba consistió en el seguimiento diurno de un total de 18 vacas (de razas tudanca, limusina y charolesa) y 15 yeguas en 3 épocas del verano de 2004 (juniojulio, agosto y septiembre). En cada seguimiento se anotó la posición geográfica, actividad (pastoreo, descanso o desplazamiento) y el tipo de pasto donde el animal se encontraba a intervalos de 20 minutos, desde el amanecer hasta la noche. Los datos de los seguimientos se cruzaron con información digital georreferenciada de la topografía y la vegetación del puerto para definir las áreas disponibles en cada ruta y, de esta manera, calcular la selección de la topografía y de la vegetación dominante del puerto. Aunque en el análisis general se comparó la respuesta del ganado vacuno con la del caballar, también se llevaron a cabo análisis distinguiendo entre vacas tudancas y de otras razas, para poder explicar mejor la diversidad en los patrones de pastoreo encontrados. Los resultados permitieron verificar la hipótesis de la alta concentración del ganado caballar en los pastos de FestucaAgrostis, y en las situaciones topográficas con más riesgo de invasión de lecherina, concretamente en las pendientes inferiores al 25\%. El ganado vacuno de razas foráneas 
también seleccionó de forma muy acusada los pastos de Festuca-Agrostis, aunque en rangos de pendientes más altos. En las vacas tudancas, sin embargo, la selección de este tipo de pasto fue menor. Respecto a la segunda hipótesis, cada tipo de ganado presentó una evolución diferente de su utilización y selección de los pastos de Festuca-Agrostis. El caballar mostró selecciones altas durante todo el verano, que incluso aumentaron al final, cuando rechazaron los cervunales. En el vacuno, las tudancas incrementaron su utilización de los pastos arbustivos, disminuyendo progresivamente su selección de los pastos de Festuca-Agrostis y de los cervunales. Por el contrario, los animales de razas foráneas no mostraron cambios significativos con el tiempo en los índices de selección de estos pastos. Los patrones de selección descritos y el gradiente observado en el porcentaje de tiempo diurno en pastoreo de cada tipo de animal (vacas tudancas 56\%, otras vacas $69 \%$ y yeguas $82 \%$ ), ponen en evidencia la fuerte presión de pastoreo que soportan los pastos con riesgo de invasión por lecherina. Además, permiten cuantificar la responsabilidad atribuible a cada tipo de ganado habitual en el puerto, paso imprescindible para gestionar adecuadamente este problema. En este sentido, es destacable el papel que pueden desempeñar las vacas tudancas, dada su capacidad para utilizar de forma más homogénea los recursos pastables disponibles.

La última prueba (capítulo 6) se llevó a cabo con el objetivo final de dotar de fundamento a una posible estrategia de control biológico de la invasión de lecherina basada en la introducción de ganado ovino en los puertos afectados. En ella, se realizó un estudio comparativo, vacas vs. ovejas, de la utilización digestiva de los pastos de Festuca-Agrostis invadidos o no por la E. polygalifolia y se contrastaron dos hipótesis: la primera era que la microbiota ruminal de las ovejas posee una mayor capacidad para degradar los pastos de puerto invadidos por lecherina que la microbiota del rumen de las vacas. La segunda hipótesis planteaba que la degradación ruminal de este tipo de pastos por distintos rumiantes (en este caso ovino y vacuno) podría ser regulada, al menos parcialmente, mediante su consumo, a través de una adaptación de la población microbiana del rumen. Para estudiar estas hipótesis, se llevó a cabo un experimento con 8 ovejas y 6 vacas distribuidas en 4 tratamientos según un diseño factorial 2x2 (2 especies x 2 tratamientos de pastoreo previo [pastoreo en zonas invadidas o en zonas no invadidas]). Tras un periodo de 17 días, se extrajo fluido ruminal de todos los animales y se estudió la fermentación ruminal in vitro de dos sustratos (pasto invadido y pasto no invadido) mediante la técnica de producción de gas y cultivos discontinuos de microorganismos ruminales. Los 
resultados de producción de gas, extensión de la degradación en el rumen, concentración de amoniaco y producción de ácidos grasos volátiles en las incubaciones de los pastos invadidos sugieren una mejor fermentación de este sustrato en las ovejas que en las vacas, verificando la primera hipótesis. La ausencia de diferencias destacables en las incubaciones del pasto no invadido demostraría además que las diferencias entre las dos especies de rumiantes fueron debidas fundamentalmente a la presencia de E. polygalifolia. El efecto positivo del pastoreo previo en zonas invadidas sobre los ritmos de producción de gas y la extensión de la degradación en el rumen apoyaría la segunda hipótesis, es decir, que la capacidad de los rumiantes para degradar los pastos invadidos por lecherina podría ser mejorada a través de su consumo previo, seguramente mediante la adaptación de la microbiota del rumen. Estos resultados respaldarían el uso del ganado ovino como una herramienta biológica para restaurar los pastos de montaña invadidos por E. polygalifolia, siempre que se asegure previamente que no existe ningún efecto tóxico sobre los animales y que su rendimiento productivo no se ve perjudicado. 
1.INTRODUCCIÓN 

El cambio en el paisaje producido por la propagación de especies vegetales con tendencia a la dominancia es un grave problema que actualmente afecta negativamente a la biodiversidad, funcionalidad ecológica y productividad de diversos ecosistemas pastorales (Allen et al., 1991; Scott et al., 2001; Dullinger et al., 2003). En el caso de las plantas tóxicas para el ganado se añade el efecto negativo sobre los animales, directamente por la ocurrencia de envenenamientos o descensos de la productividad, o indirectamente por la menor disponibilidad de pasto apetecible. Este es el caso de la invasión de pastos de puerto por la lecherina (Euphorbia polygalifolia Boiss. \& Reut. ex Boiss.), especie endémica de la Cordillera Cantábrica, cuyo hábitat común son los matorrales acidófilos montanos: brezales y escobales (Díaz y Fernández Prieto, 1994).

Desde hace décadas, los ganaderos usuarios de muchos puertos de montaña de Cantabria han observado cómo la lecherina se está propagando de forma alarmante en los pastos herbáceos denominados "brañas", principal fuente de alimentación estival del ganado vacuno y caballar en las comarcas de montaña de la región. Las brañas que están sufriendo esta invasión tienen por sí mismas un gran valor ecológico, correspondiendo en su mayoría a comunidades de cervunal seco de alto interés de conservación, tal como queda recogido en la Directiva Europea Habitat (92/43/CEE). Este interés radica en la singularidad de su composición botánica y en su gran adaptación ecológica al pastoreo y a las perturbaciones características de las zonas de alta montaña. Por otro lado, y a una escala espacial diferente, el paisaje del que forman parte, un mosaico de brañas y comunidades diversas de matorral, tiene también un interés medioambiental muy alto, siendo el hábitat idóneo de numerosas especies animales necesitadas de este tipo de mosaicos para desarrollar sus distintas funciones vitales. Además, constituye un paisaje agroecológico, donde la cultura ganadera tradicional de la montaña consiguió desarrollar un sistema de pastoreo sostenible en el sentido de compatibilizar la producción ganadera con una rica vida silvestre.

El peligro que supone la invasión de la lecherina en los pastos de puerto silicícolas de Cantabria tiene su exponente más claro en el puerto de Sejos (Mancomunidad Campoo Cabuérniga). Este puerto es muy conocido en la región por su peculiar sistema de aprovechamiento ganadero, compartido entre cuatro municipios de la montaña de Cantabria (Ruente, Valle de Cabuérniga y los Tojos, dentro de la cuenca cantábrica del río Saja, y la Hermandad de Campoo de Suso, mayoritariamente en la cabecera del Ebro) y con un sistema de aprovechamiento histórico, al menos desde el siglo XV (Gómez Sal et 
al., 1995). La gravedad de la invasión de lecherina en Sejos fue puesta de manifiesto hacia el año 2000 por los ganaderos usuarios del puerto, que percibieron una disminución significativa de la superficie de pasto de braña de buena calidad, con las consiguientes repercusiones sobre el tiempo de permanencia del ganado en el puerto. En este sentido, los ganaderos constataron que la lecherina no era consumida por el ganado vacuno y caballar (únicos representados en Sejos), con lo que toda la superficie ocupada por esta planta era superficie perdida al pastoreo. El sistema pastoral practicado en Sejos en la actualidad se describe en detalle en el capítulo 2.

Con estos antecedentes, se comenzó en 2002 en el Centro de Investigación y Formación Agrarias de Cantabria (CIFA) un proyecto de investigación titulado "Determinación de las causas y selección de un sistema de control sostenible de la invasión de los pastos de montaña por la lecherina (Euphorbia polygalifolia)", financiado principalmente por el Instituto Nacional de Investigación y Tecnología Agraria (INIA; RTA02-027), cuyo objetivo de estudiar las causas de la invasión por lecherina se enfocó siempre en relación con la comunidad vegetal invadida, considerando cómo actúan distintos factores (el pastoreo, el clima, los aportes de nutrientes, etc.).

El presente trabajo de tesis doctoral se enmarcó dentro de este proyecto y de otro más reciente, financiado por la Junta de Castilla y León, titulado "Invasión de puertos de montaña por lecherina (Euphorbia polygalifolia): evolución del valor nutritivo de los pastos y posibles efectos anti-nutritivos para el ganado ovino" (CSI 06A07), que se desarrolla en la Estación Agrícola Experimental del CSIC (León).

En dichos proyectos, se consideró como hipótesis general que el pastoreo es un factor determinante en la dinámica del proceso de invasión de lecherina y, por ello, para esta tesis, se llevaron a cabo una serie de estudios encaminados a comprender mejor las interacciones entre los pastos susceptibles de ser invadidos y el ganado que los aprovecha.

Tras este primer capítulo, de introducción, el segundo trata de caracterizar el área objeto de estudio: los Puertos de Sejos. Se aborda inicialmente su descripción física tratando aspectos relacionados con su localización, hidrografía, orografía, climatología, geología, geomorfología y edafología. A su vez, recopila información sobre las características de la vegetación de la zona, focalizando la atención en la lecherina (Euphorbia polygalifolia). Se describen también los aspectos más relevantes del pastoreo 
histórico y actual, incidiendo en las características que han evolucionado de forma más acusada.

El capítulo tercero recoge una revisión bibliográfica del estado actual de conocimientos sobre las relaciones pasto-herbívoro en sistemas extensivos. En concreto, revisa las interacciones entre el pastoreo y la dinámica de la vegetación, así como los principales factores que afectan al comportamiento del ganado.

A través de los capítulos cuarto y quinto, se pretendió comprender mejor las causas de la invasión de lecherina mediante el estudio de los pastos afectados y de su utilización espacio-temporal por el ganado. Para ello, en el capítulo cuarto se estudian las características botánicas y químicas, así como distintos parámetros relacionados con la utilización digestiva, tanto de los pastos herbáceos de Festuca-Agrostis invadidos y no invadidos por lecherina como de la propia Euphorbia polygalifolia. Por su parte, el capítulo quinto recoge la comparación de la utilización de los pastos en la zona de estudio por el ganado vacuno y caballar a lo largo de la estación de pastoreo, estudiando aspectos como sus patrones de actividad diarios y la selección de la localización del pastoreo en función de la comunidad vegetal, la presencia de lecherina o la pendiente del terreno.

Finalmente, en el capítulo sexto se lleva a cabo un estudio comparativo, vacuno vs. ovino, de la utilización digestiva de los pastos objeto de estudio, con el objetivo final de poder llegar a fundamentar una posible estrategia de control de la invasión de lecherina basada en la introducción de ganado ovino. 

2. El sistema pastoral en la montaña cantábrica. El caso de los puertos de Sejos 

El aprovechamiento transterminante de las superficies pastables es una práctica ganadera ancestral en los valles cantábricos. Los ganados pastorean los fondos de valle a la salida del invierno, ganando altura a medida que avanza la primavera y utilizando, ya en los meses de verano, los pastos altitudinalmente más elevados. Estos pastos altos, también conocidos como puertos estivales, son normalmente de propiedad comunal y suponen, aún en nuestros días, un recurso forrajero trascendental para gran parte de las cabañas ganaderas de aptitud cárnica de la montaña cantábrica (Corbera, 2006).

El área de estudio de los trabajos descritos en esta tesis, los puertos de Sejos, es un ejemplo de puerto estival dentro del valle del río Saja. Su extensión (1200 ha) y su valor pastoral han provocado que sea, históricamente, un recurso de interés para muchos ganaderos y, por ello, su gestión ha sido y sigue siendo compleja. Hasta hace unas décadas, esa gestión se basaba en una repartición espacio-temporal muy bien definida del pastoreo de las cabañas ganaderas (principalmente de vacuno de raza tudanca).

Sin embargo, desde la segunda mitad del siglo $\mathrm{XX}$ se vienen produciendo cambios radicales en los sistemas ganaderos de la montaña cantábrica en general y de la comarca del Saja en particular: proliferación de la maquinaría agrícola; apertura de pistas de acceso a los puertos; descenso brusco de la disponibilidad de mano de obra en ganadería; llegada de las ayudas de la Unión Europea; cambios en la base animal de las cabañas ganaderas... Estos cambios han afectado profundamente el uso pastoral de los puertos de Sejos, detectándose desequilibrios espaciales notables en forma de infra- y sobre-pastoreo.

En este contexto, los ganaderos que aprovechan los puertos de Sejos manifestaron su preocupación, ya iniciado el siglo XXI, por la expansión de una especie vegetal conocida localmente como lecherina. (Euphorbia polygalifolia Boiss. \& Reut. ex Boiss.), que es rechazada activamente por el ganado vacuno y caballar. Esta planta, endémica de la Cordillera Cantábrica, está proliferando de forma alarmante en pastos de puerto acidófilos como Sejos, produciendo una disminución drástica de su valor pastoral y ecológico (Busqué et al., 2003). Actualmente se ha cuantificado en más de 180 ha la superficie de pasto herbáceo de Sejos afectado gravemente por excesiva cobertura de lecherina. 


\subsection{Descripción física}

\subsubsection{Localización}

Los trabajos de campo de las pruebas experimentales descritas en los posteriores capítulos estuvieron localizados en los puertos de Sejos. Situados en la cabecera del valle de Cabuérniga (Cantabria), los puertos de Sejos pertenecen administrativamente a la Mancomunidad Campoo Cabuérniga (MCC), que limita con el municipio de Valle de Cabuérniga por el norte, Los Tojos por el norte y este, la Hermandad de Campoo de Suso por el este y sur, así como con Polaciones y Tudanca por el oeste (figura 2.1). El alto valor paisajístico y ecológico de Sejos ha merecido su inclusión en varias figuras oficiales de protección: Red Natura 2000 (Valles Altos del Nansa y Saja y Alto Campoo (ES1300021)); Parque Natural Saja-Besaya; Reserva Nacional de Caza de Saja y Zona de Influencia del Oso Pardo.

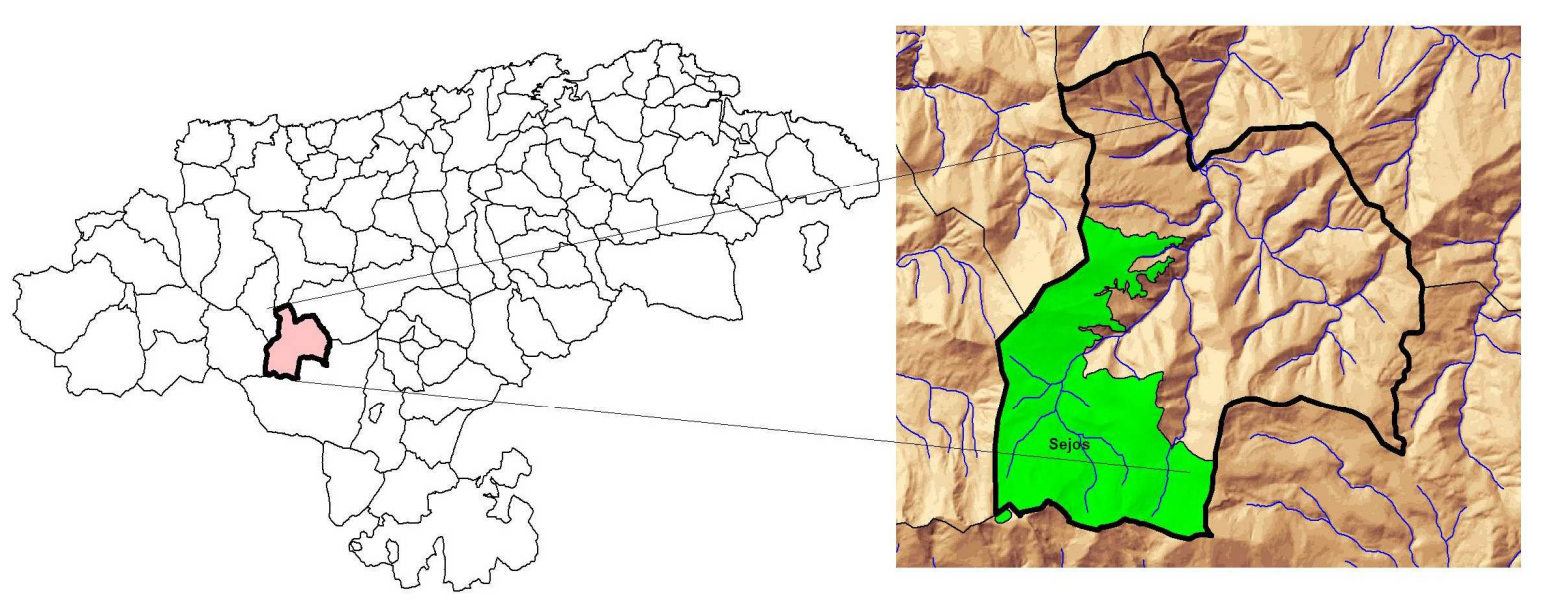

Figura 2.1. Localización de Sejos dentro de la Mancomunidad Campoo Cabuérniga (Cantabria).

\subsubsection{Hidrografía y orografía}

Los puertos de Sejos están situados en la vertiente norte de la Cordillera Cantábrica en la cabecera de la cuenca del río Saja. Concretamente, en la sierra del Cordel nacen los ríos Bijoz, o Diablo, y Cureñas, o Infierno, que atraviesan Sejos de norte a sur (figura 2.2). Estos ríos rodean Monte Redondo (1757 m) hasta encontrarse en Tramburríos, momento a partir del cual adoptan su definitivo nombre de Saja. 
El rango altitudinal de Sejos se extiende desde unos $1300 \mathrm{~m}$ en los tramos finales del Cureñas y Bijoz hasta cotas superiores a los 2000 m (pico Hiján 2085 m) (figura 2.3). No obstante, predominan las cotas situadas entre los 1500 y los $1800 \mathrm{~m}$ de altitud. La figura 2.4 revela la existencia de un amplio rango de pendientes que incluye grandes zonas con pendientes superiores al 30\% y también zonas muy accesibles con terreno prácticamente 1lano. En cuanto a las orientaciones del terreno, la figura 2.5 muestra un claro dominio de las orientaciones norte y noroeste en Sejos. Las orientaciones este y oeste son menos abundantes y las orientaciones sur muy minoritarias.

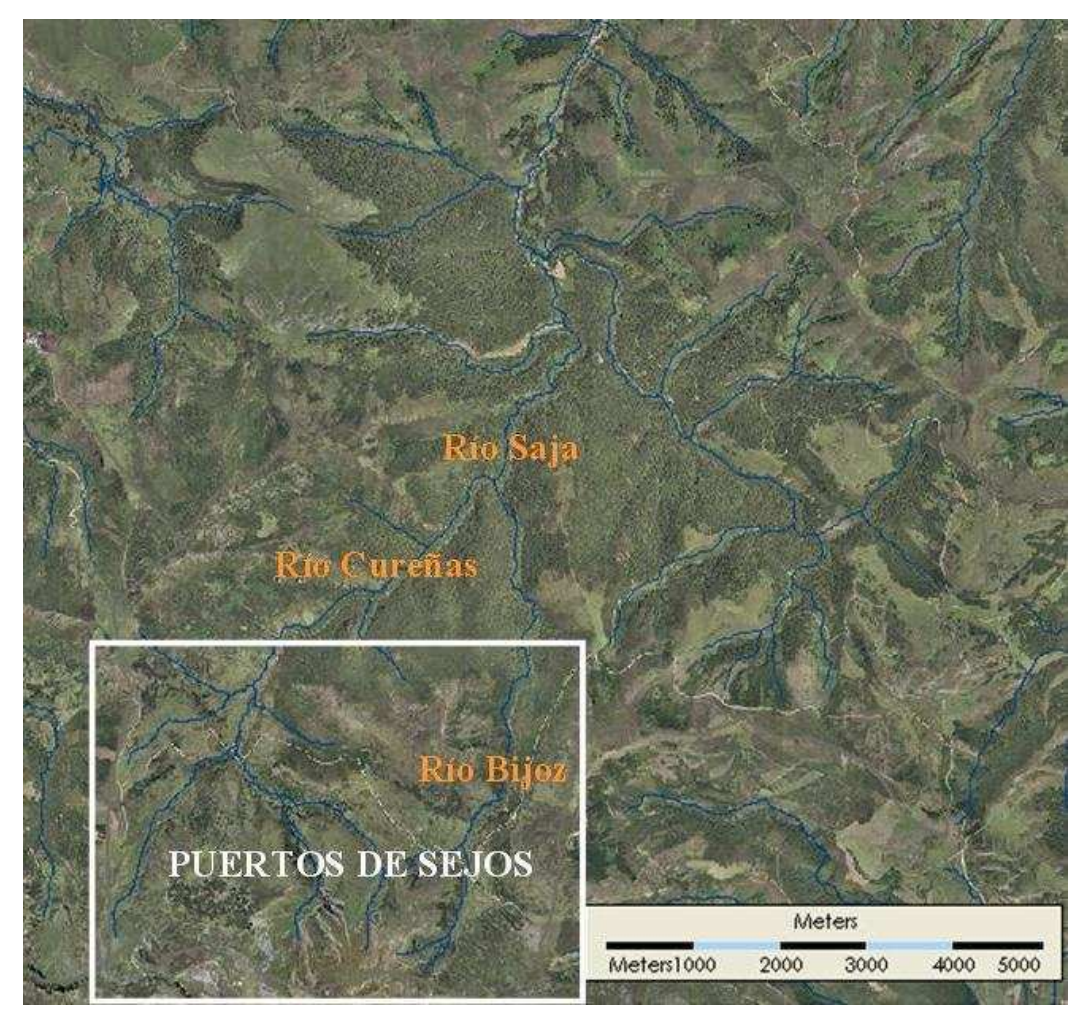

Figura 2.2. Hidrografía de los Puertos de Sejos y sus alrededores (adaptado de Ferrer i Marco et al., 2006). 


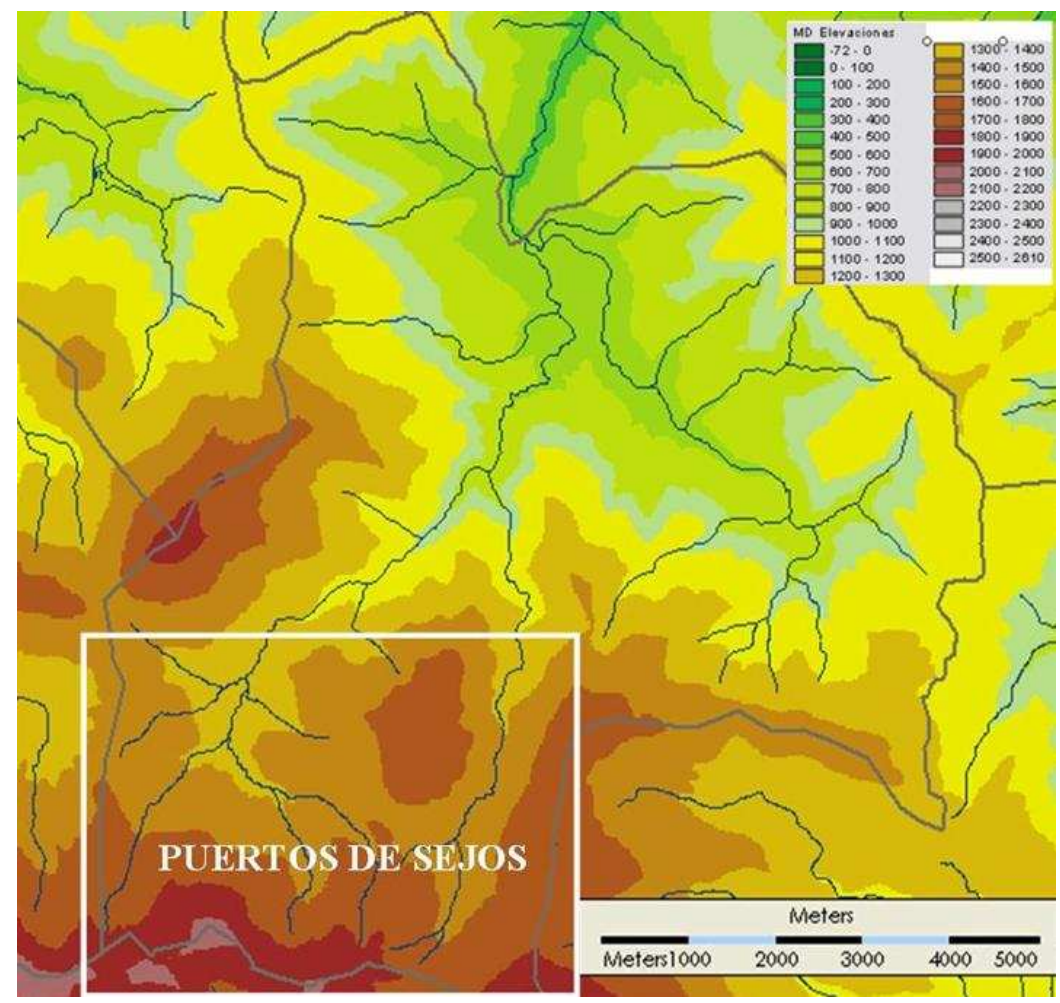

Figura 2.3. Mapa de altitudes de los Puertos de Sejos y sus alrededores (adaptado de Ferrer i Marco et al., 2006).

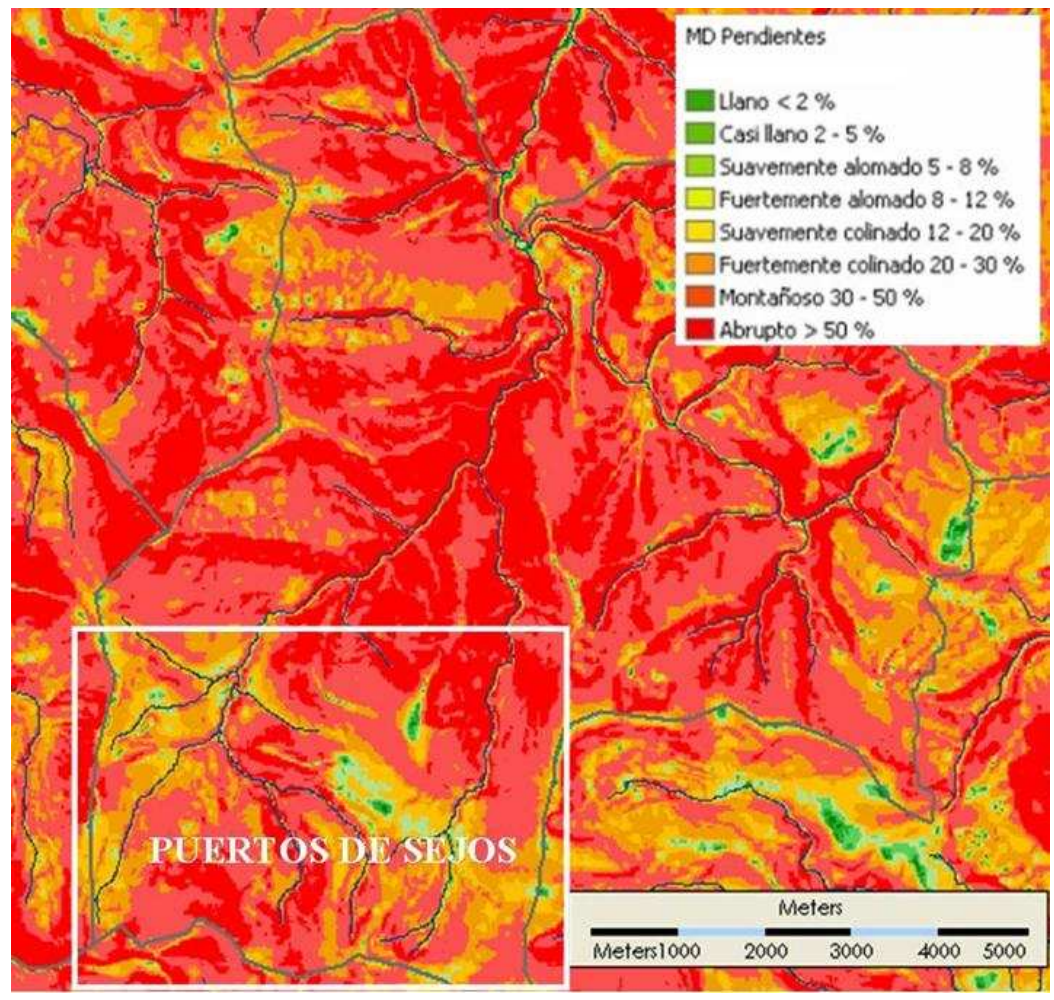

Figura 2.4. Mapa de pendientes de los Puertos de Sejos y sus alrededores (adaptado de Ferrer i Marco et al., 2006). 


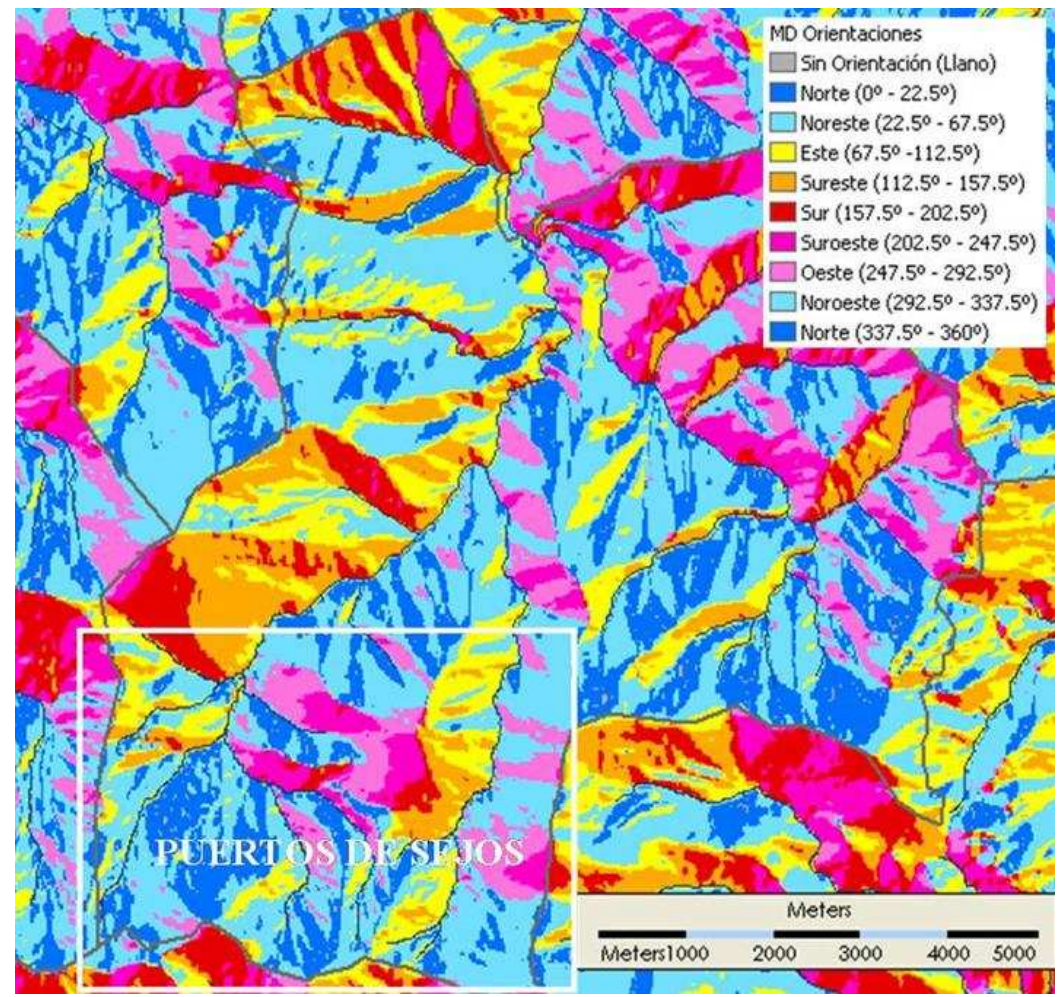

Figura 2.5. Mapa de orientaciones de los Puertos de Sejos y sus alrededores (adaptado de Ferrer i Marco et al., 2006).

\subsubsection{Climatología.}

Sejos se caracteriza por un clima templado-húmedo atlántico con abundancia de lluvias, que aportan una precipitación media anual estimada de entre 1100 y $1300 \mathrm{~mm}$ (figura 2.6), aunque no es infrecuente la existencia de periodos secos prolongados durante el verano. Las temperatura media anual en la zona se encuentra entre los 8 y $\operatorname{los} 10^{\circ} \mathrm{C}$ (figura 2.7) alcanzándose temperaturas medias de mínimas en invierno de $-9^{\circ} \mathrm{C}$ (figura 2.8). El periodo medio libre de heladas se extiende a un rango de entre 60 y 90 días. Dada su proximidad al mar y la ausencia de barreras importantes que lo separen de éste, la niebla es un fenómeno meteorológico habitual en la zona. 


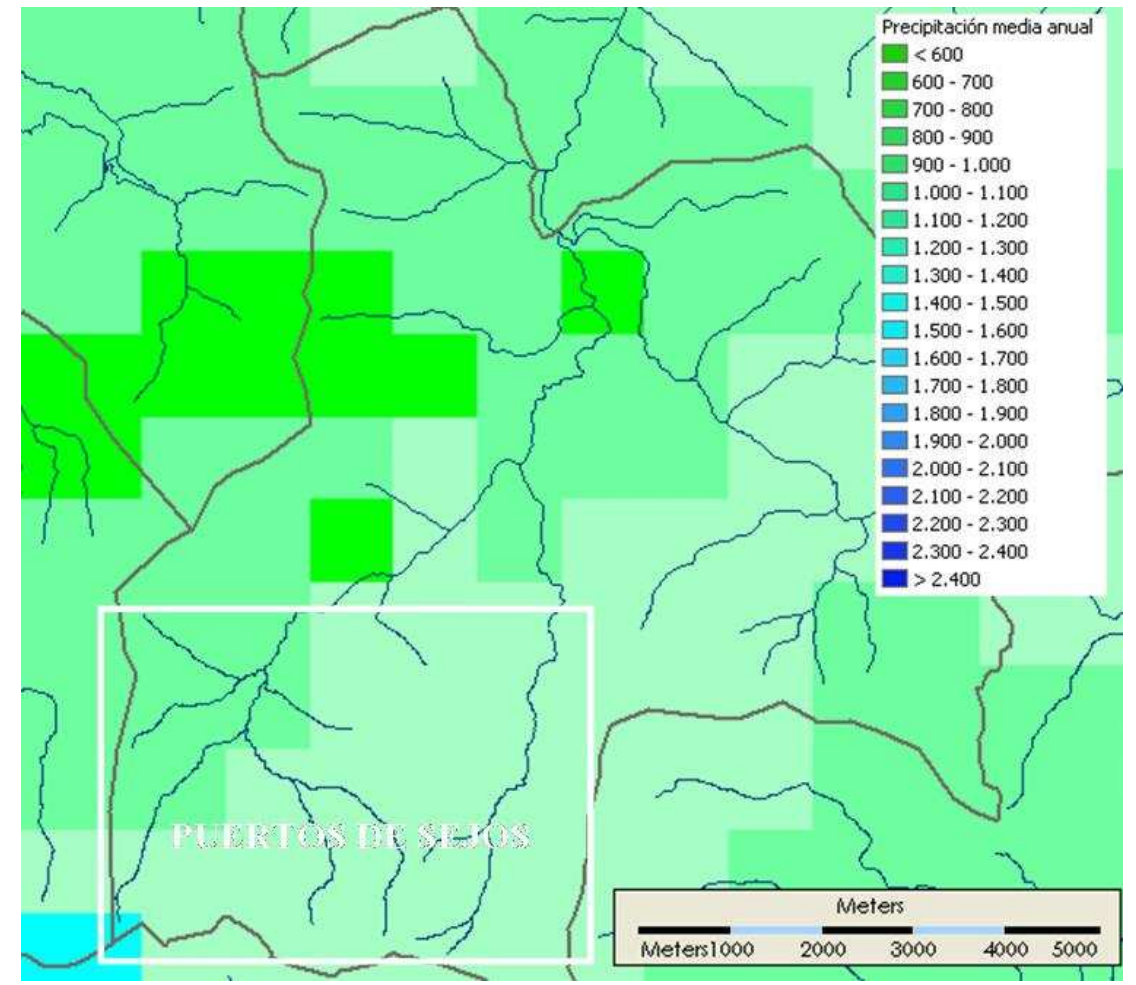

Figura 2.6. Mapa de precipitaciones medias anuales de los Puertos de Sejos y sus alrededores (adaptado de Gutiérrez et al., 2005).

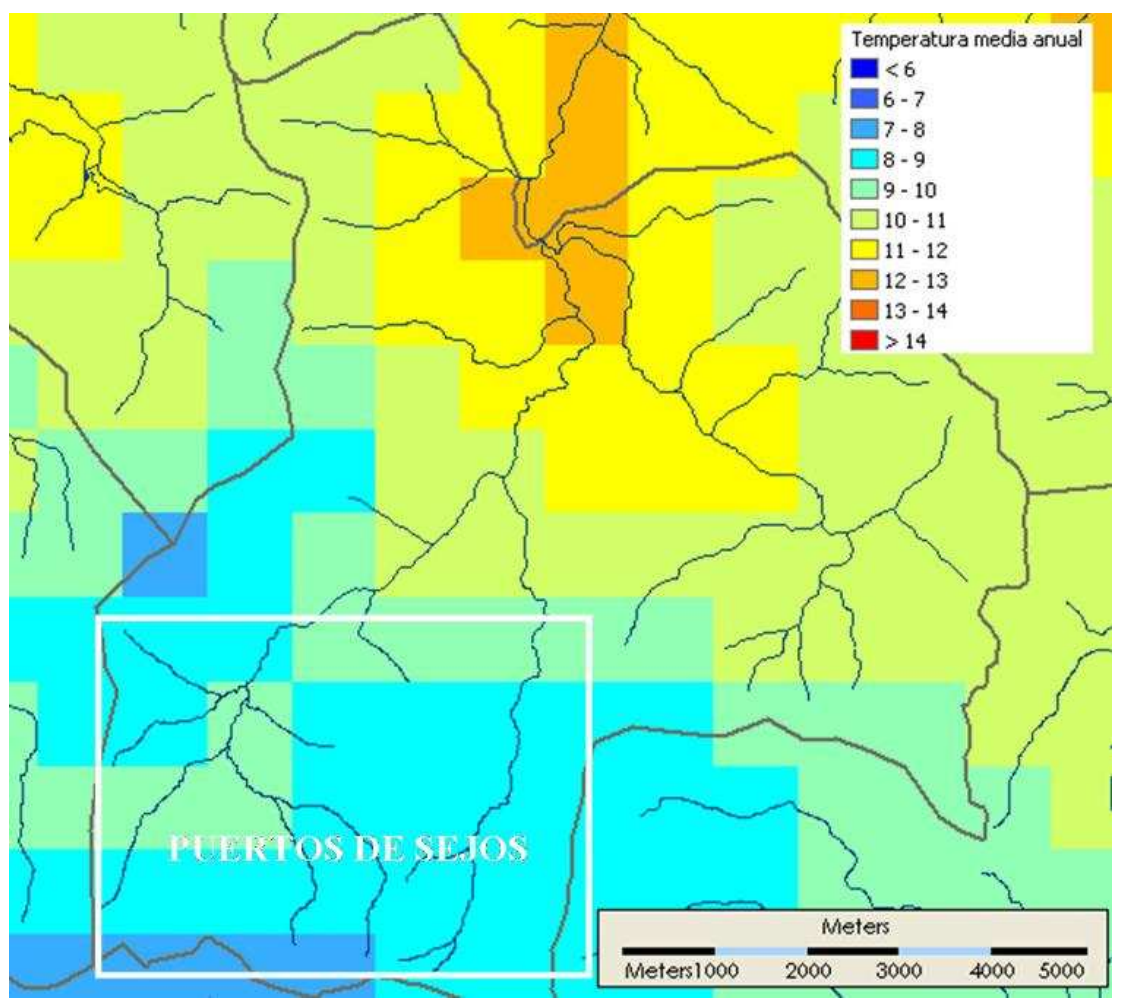

Figura 2.7. Mapa de temperaturas medias anuales de los Puertos de Sejos y sus alrededores (adaptado de Gutiérrez et al., 2005). 


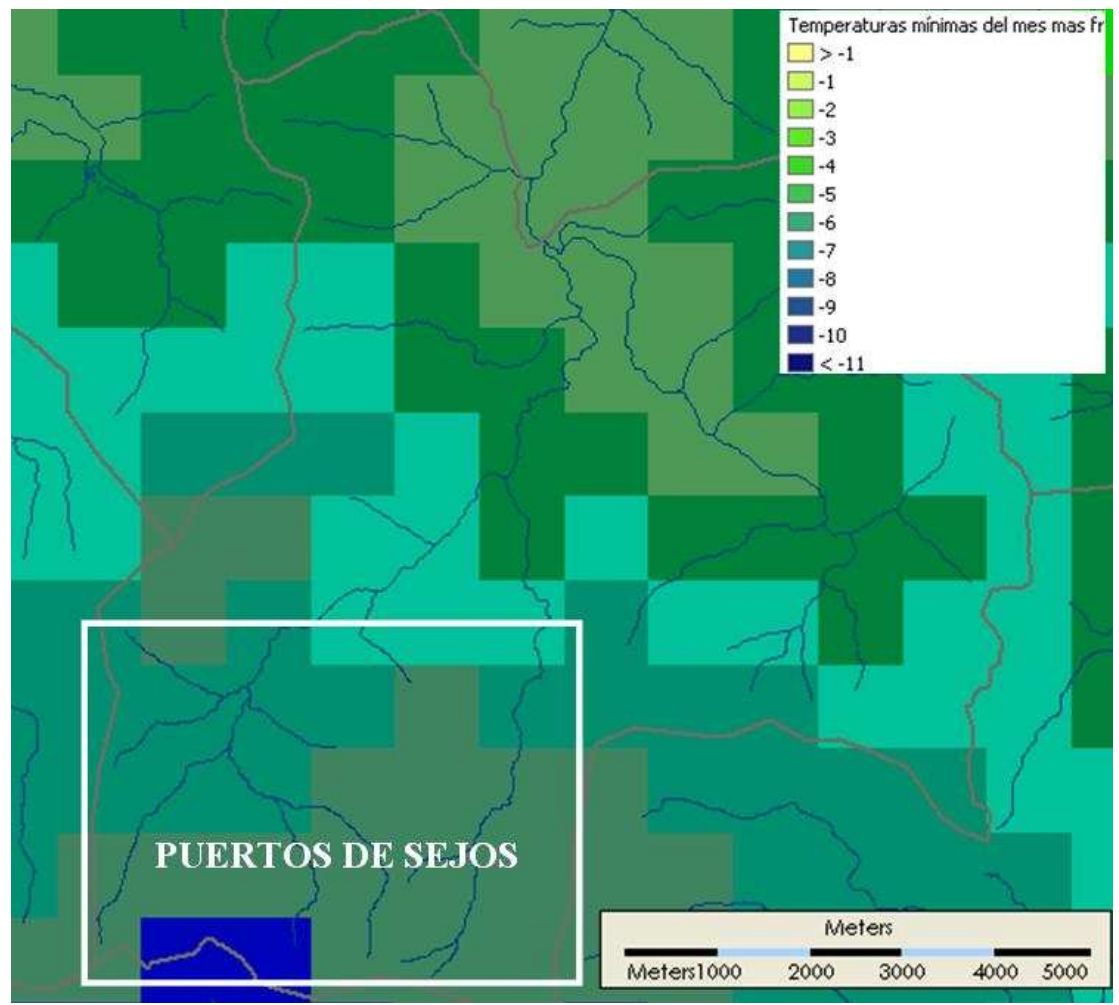

Figura 2.8. Mapa de temperaturas mínimas medias del mes más frío de los Puertos de Sejos y sus alrededores (adaptado de Gutiérrez et al., 2005).

\subsubsection{Geología, geomorfología y edafología.}

Desde el punto de vista geológico, Sejos está situado en una extensa cuenca sedimentaria marina que se formó durante la Era Paleozoica o primaria, la cual concluyó hace unos 230 millones de años (Cendrero et al., 1986). Los afloramientos de los materiales más antiguos se localizan en las zonas más elevadas de Sejos, componiéndose de pizarras y areniscas del periodo Carbonífero. A continuación aparece una pequeña porción del periodo Pérmico, perteneciente al final de la era Paleozoica, consistente en un mosaico de conglomerados, pizarras y areniscas rojas muy compactadas que ocupan el flanco sur de la zona conocida como La Concilla y una porción de la cuenca del Saja situada junto a esa zona. En el resto del área, los materiales paleozoicos han sido cubiertos por sucesivos sedimentos ya más modernos, pertenecientes a la era Mesozoica, también conocida como era Secundaria, de 225 a 65 millones de años. Estos materiales, formados principalmente por conglomerados de areniscas, limonitas y arcillas del periodo Triásico, ocupan la mayor parte de la superficie de Sejos y es sobre ellos donde se propicia un suelo rico que permite un buen desarrollo de la vegetación. 
La geomorfología de Sejos está representada por procesos de glaciarismo y sedimentación fluvial. La forma de valle glaciar con su perfil característico en "U" se aprecia en las zonas altas de los puertos. Las formas glaciares son perceptibles en los Picos Hiján y Cordel donde se encuentra un amplio circo con sus morrenas de sedimentación lateral y de fondo, testimonio y legado de la Era de los hielos. Los ríos Bijoz y Cureñas en su avance modifican el perfil de valle glaciar hacia un valle fluvial en "V" ocupados en su curso medio por hayedos.

La figura 2.9 describe los suelos de los puertos de Sejos según su agrupación funcional. Predominan los suelos muy someros (de menos de $10 \mathrm{~cm}$ de espesor), silíceos y con abundantes afloramientos, junto con suelos definidos como poco evolucionados y de carácter ácido. En la parte norte, coincidiendo con las zonas de menor altitud de Sejos, existen suelos evolucionados de carácter muy ácido. 


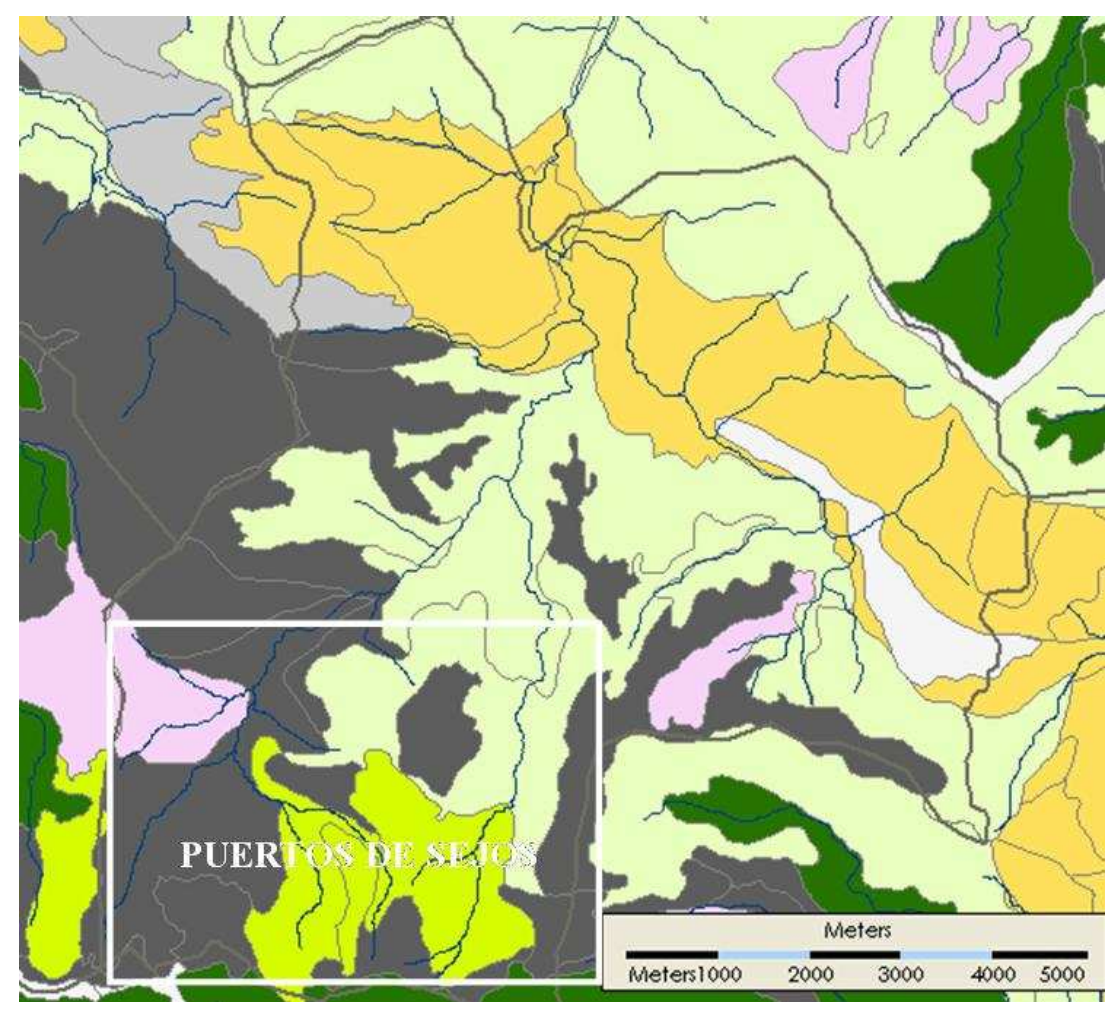

\section{AGRUPACIONES FUNCIONALES}

01- Suelos muy someros ( $<10 \mathrm{~cm}$ espesor) y abundantes afloramientos. Siliceos.

$\square 02$ - Suelos muy someros ( $<10 \mathrm{~cm}$ espesor) y abundantes afloramientos. Calizos.

03- Suelos asociados al grupo 01, de espesor irregular. Siliceos.

04- Suelos asociados al grupo 01, de espesor irregular. Calizos.

05- Suelos someros ( $<25 \mathrm{~cm}$ espesor) y suelos asociados. Sliceos

06- Suelos someros ( $<25 \mathrm{~cm}$ espesor) y suelos asociados. Calizos.

07- Suelos saturados de agua.

08-Suelos Salinos.

109-Suelos de Textura Gruesa: Arenosos.

10- Suelos poco desarrollados sobre depósitos fluviales.

11- Suelos poco evolucionados de carácter ácido.

12- Suelos poco evolucionados de carácter neutro o básico, a veces calcáreos.

13- Suelos evolucionados y muy evolucionados de carácter muy ácido y con acumulación de materia orgánica.

14- Suelos evolucionados de carácter muy ácido.

15- Suelos muy evolucionados de carácter muy ácido.

16- Suelos evolucionados de carácter neutro y básico. Cambisoles.

17- Suelos con desarrollo de horizonte árgico asociados al grupo 12.

18- Suelos con acumulación de arcilla muy acusada -hor rárgico- y carácter neutro o básico.

19-Suelos neutros o básicos de acumulación de materia orgánica en superficie.

20-5uelos antrópicos.

21- Áreas misceláneas (Urbano, vías construidas, embalses...)

Figura 2.9. Mapa de agrupaciones funcionales de suelos de los Puertos de Sejos y sus alrededores (adaptado de Ferrer i Marco et al., 2006). 


\subsection{La vegetación}

\subsubsection{Clasificación fitogeográfica}

La flora y vegetación se distribuye, en primer lugar, según patrones macroclimáticos y geográficos (Box, 1981). En este sentido, y siguiendo el trabajo sintético de RivasMartínez et al. (2002), Sejos se sitúa desde el punto de vista biogeográfico entre el extremo nororiental del Sector Campurriano-Carrionés de la Subprovincia Orocantábrica y el extremo suroccidental del Sector Cántabro-Euskaldún de la Subprovincia CántabroAtlántica. La presencia de la Subprovincia Cántabro-Atlántica se deja ver en las cotas inferiores de Sejos por la existencia de ejemplares aislados de cajiga (Quecus robur) y del brezo Erica ciliaris, especies ausentes en la Subprovincia Orocantábrica. Por otro lado, la abundancia de plantas como la escoba Genista florida subsp. polygaliphylla y la presencia de enebrales y brezales-arandaneras de alta montaña, sitúan la mayor parte de Sejos dentro de la Subprovincia Orocantábrica.

Desde el punto de vista bioclimático, Sejos se caracteriza por poseer un macrobioclima templado euoceánico, por disponer de termotipos supratemplado (montano) y orotemplado (subalpino) y por tener un ombroclima hiperhúmedo. Los tipos de pastos encontrados en Sejos responden en buena parte a esta adscripción biogeográfica y bioclimática.

\subsubsection{Tipificación de los pastos de Sejos}

La vegetación de la zona principal de Sejos (1232 hectáreas; figura 2.10) se ha cartografiado recientemente a escala 1:2.000 (Busqué et al., 2006), en base a una tipificación previa de los pastos existentes según su composición botánica. A continuación se describen los principales tipos de pastos presentes en Sejos: 


\section{Comunidades herbáceas.}

\section{Cervunal húmedo}

Pastos montanos de cobertura herbácea completa, característicos de suelos siempre húmedos y muy ácidos. Se caracterizan por el predominio de cervuno (Nardus stricta) y la presencia frecuente de plantas como Succisa pratensis, Carex panicea y Carum verticillatum. Asimilables a la alianza fitosociológica Nardion.

\section{Pastos de Festuca-Agrostis}

Pastos montanos de cobertura herbácea completa, de suelos ácidos y ligeramente arenosos. Se caracterizan por la presencia de cervuno, festuca (Festuca nigrescens) y agrostis (Agrostis capillaris), Carex caryophyllea, Hieracium pilosella, Jasione laevis, etc. Desde el punto de vista fitosociológico, se considerarían una transición entre las alianzas Nardion y Cynosurion.

\section{Pastos de Agrostis curtisii}

Son pastos montanos caracterizados por una cobertura vegetal muy alta, sobre suelos muy ácidos y degradados por incendios y normalmente en pendientes medias. Predomina el pelo de ratón (Agrostis curtisii) en su composición botánica, encontrándose normalmente en mosaico con brezales con presencia de árgoma (Ulex gallii). Asimilables a facies herbáceas de la subalianza fitosociológica Daboecienion cantabricae.

\section{Pastos sobre suelos someros}

Son pastos montanos con presencia apreciable de huecos desnudos, sobre suelos ralos y arenosos y, por tanto, con escasa capacidad de retención de agua e incidencia acusada de estrés hídrico. Se caracterizan por la presencia de Agrostis durieui, Rumex angiocarpus y Sedum anglicum. Asimilables a la alianza fitosociológica Sedion pyrenaici.

\section{Majadales}

Llamados "midiajos" en la zona por ser lugares de descanso del ganado durante las horas centrales en los días de buen tiempo. Se caracterizan por una cobertura herbácea total, suelos profundos, compactados y muy fértiles, fruto de la intensa acción de pisoteo y 
deyecciones del ganado. Su composición botánica está definida por la Poa supina, siendo esta especie exclusiva en las situaciones de majadeo más intensivas. A medida que la presión del ganado es menor, aparecen principalmente Agrostis capillaris y trébol blanco (Trifolium repens). Asimilables a la alianza fitosociológica Poion supinae.

\section{Pastos de Carex asturica y Deschampsia flexuosa}

Pastos alti-montanos con cobertura vegetal media, sobre suelos someros y en pendientes medias o fuertes. Botánicamente se caracteriza por las dos especies que le dan nombre, siendo común su presencia en mosaico con matorral de Erica arborea. Asimilables a facies herbáceas de la alianza Genistion polygaliphyllae.

\section{Pastos mesófilos o de mesobromion}

Pastos montanos de cobertura herbácea completa, asentados sobre suelos profundos y fértiles. Además de festuca y agrostis, se caracterizan por la presencia abundante de Bellis perennis, Lotus corniculatus, Plantago media, Poa pratensis, Prunella vulgaris, Trifolium repens, etc. Desde el punto de vista fitosociológico, se considerarían dentro de la alianza Cynosurion, con ciertas características de Festuca-Brometea.

\section{Juncales}

Pastos montanos de cobertura herbácea completa, sobre suelos con humedad elevada permanente y en pendientes bajas o nulas. Se caracterizan por la presencia constante de Juncus effusus y Senecio aquaticus y la abundancia de Agrostis capillaris. Asimilables a la alianza fitosociológica Juncion acutiflori.

\section{Turberas}

Bajo esta denominación, se agrupan todas aquellas situaciones con suelos permanentemente encharcados y con presencia de especies herbáceas y leñosas características de zonas higroturbosas ácidas. Son comunidades asimilables a las alianzas fitosociológicas Caricion fuscae y Calluno-Sphagnion papillosi. 


\section{Pastos de Festuca rivas-martinezii}

Pastos subalpinos de cobertura media, sobre suelos someros, dominados por esta gramínea, y normalmente en mosaico con brezales-enebrales. Asimilables a la alianza Teesdaliopsio-Luzulion caespitosae.

\section{Comunidades leñosas.}

\section{Brezales con predominio de Calluna vulgaris}

Incluyen todas las comunidades arbustivas de baja talla del piso subalpino, tanto las dominadas por Calluna vulgaris, sobre suelos profundos más largamente innivados (asimilables a la asociación fitosociológica Vaccinio microphylli-Callunetum vulgaris), como las que presentan coberturas altas del enebro rastrero, y con menor cobertura de nieve (asimilables a la asociación fitosociológica Junipero nanae-Vaccinietum microphylli).

\section{Brezales con predominio de Erica tetralix}

Comunidades altimontanas de brezo de baja altura, sin presencia de U. gallii o de E. vagans, y asentadas sobre suelos muy ácidos. Forma normalmente mosaicos con cervunales húmedos y secos. Asimilables a las asociación fitosociológica Erico tetralicisUlicetum gallii, en una facies sin U. gallii, y también a la Carici asturicae-Callunetum vulgaris, cuando la Calluna es muy dominante.

\section{Brezales con predominio de Erica vagans}

Comunidades montanas de brezo de altura baja y media, sobre suelos profundos y relativamente fértiles. Al brezo Erica vagans, pueden acompañarle otras leñosas como Ulex gallii, Daboecia cantabrica, Genista hispanica subsp. occidentalis, etc. Suele presentarse en mosaico con los pastos de Festuca-Agrostis ricos. Asimilable a la asociación fitosociológica Daboecio cantabricae-Ulicetum gallii.

\section{Brezales con Ulex gallii y sin E. vagans}

Comunidades montanas de brezo de baja o media altura, sobre suelos ácidos y normalmente sobre pendientes medias. Probablemente los suelos se encuentren más degradados que los correspondientes a la comunidad precedente. El escajo es 
frecuentemente acompañado por Calluna vulgaris y E. tetralix. En situaciones puntuales aparecen E. cinerea o E. australis. Suelen presentarse en mosaico con pastos de Agrostis curtisii. Asimilables a la asociación fitosociológica Daboecio cantabricae-Ulicetum gallii.

\section{Escobales}

Comunidades arbustivas altas del piso montano, asentadas sobre suelos ácidos, ligeramente arenosos, en pendientes suaves a medias, y dominadas en el estrato arbustivo por la escoba Genista florida subsp. polygaliphylla. Normalmente presenta un estrato herbáceo denso con abundancia de Agrostis capillaris. Fitosociológicamente se encuadra en la asociación Cytiso cantabrici- Genistetum polygaliphyllae.

\section{Brezales de Erica arborea}

Comunidades arbustivas del piso montano, de porte alto, dominadas por esta especie de brezo y, en muchos casos, sobre suelos con gran cantidad de rocas. Generalmente ocupan laderas frecuentemente cubiertas por nieblas, colonizadas también por el abedul (Betula alba). Fitosociológicamente se encuadra dentro de la alianza Genistion polygaliphyllae.

\section{Helechales}

Comunidades montanas de bajo- medio porte dominadas por el helecho común (Pteridium aquilinum), producto del descenso en la presión de pastoreo de zonas de pasto herbáceo. Ocupan pendientes medias, con suelos ácidos profundos. Su clasificación fitosociológica no está aun resuelta.

\section{Acebales}

Comunidad arbórea del piso montano superior, dominado por densas masas de Ilex aquifolium originadas a partir de bosques de hayas o robles. Inmersas en pastizales con mayor o menor grado de matorralización, se les atribuye un origen asociado al manejo del hombre que ha eliminado el resto de las especies del bosque y conservado las acebedas por su interés como lugar de refugio del ganado frente a las inclemencias del tiempo. Fitosociológicamente está clasificado dentro de la alianza Fagion sylvaticae. 


\section{Abedulares}

Comunidad arbórea situada por debajo del área subalpina. Asentado sobre sustratos oligótrofos y en exposiciones de umbría formando bosques ralos, dominados por Betula alba y Sorbus aucuparia, en combinación con brezo de Erica arborea. Se encuadra dentro de la asociación fitosociológica Luzulo henriquesii-Betuletum celtibericae.

\section{Hayedos}

Hayedos acidófilos, mesofíticos y de distribución orocantábrica, en los que son frecuentes además de Fagus sylvatica, Vaccinium myrtillus, Crepis lampsanoides y otros. Fitosociológicamente se encuadran dentro de la alianza Fagion sylvaticae.

\section{Matorral espinoso}

Asentado sobre todo tipo de suelos, se presenta cerca de los cursos de agua. Fitosociológicamente se encuadra dentro de la alianza Pruno-Rubion.

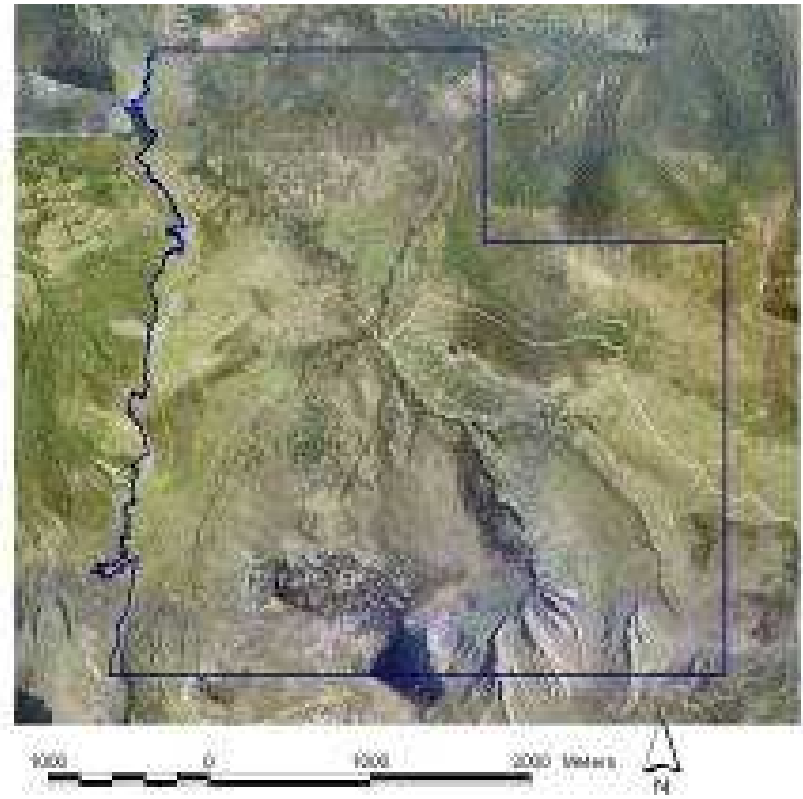

Figura 2.10. Ortofoto representando el área cartografiada de los puertos de Sejos.

La tabla 2.1 muestra la superficie ocupada por cada comunidad en el área de Sejos. Predominan los pastos herbáceos, y dentro de éstos los clasificados como de FestucaAgrostis (tabla 2.1). Los pastos arbustivos son también muy abundantes, predominando los brezales de bajo porte sobre los brezales de Erica arborea y los escobales.

Las figuras 2.11 y 2.12 muestran la distribución de todos los pastos herbáceos y arbustivos respectivamente, mientras que la figura 2.13 sintetiza la distribución de la 
vegetación, agrupada por la preponderancia en las manchas de tres grandes categorías de vegetación: herbácea, arbustiva y leñosa.

Tabla 2.1. Superficie y porcentaje de la superficie total ocupada por las distintas comunidades vegetales de Sejos.

\begin{tabular}{lcc} 
Comunidad vegetal & Superficie (ha) & Cobertura $(\%)$ \\
\hline PASTOS HERBÁCEOS & & \\
Pastos de Festuca-Agrostis & 433,4 & 35,2 \\
Cervunal húmedo & 76,0 & 6,2 \\
Pastos mesófilos & 41,0 & 3,3 \\
Pastos de Agrostis curtisii & 37,3 & 3,0 \\
Pastos sobre suelos someros & 14,4 & 1,2 \\
Pastos de C. asturica y D. flexuosa & 13,7 & 1,1 \\
Turberas & 12,1 & 1,0 \\
Helechales & 11,2 & 0,9 \\
Juncales & 8,3 & 0,7 \\
Majadales & 3,6 & 0,3 \\
Pastos de Festuca rivas-martinezii & 1,7 & 0,1 \\
& & \\
Subtotal & $\mathbf{6 5 2 , 7}$ & $\mathbf{5 3 , 0}$ \\
\hline PASTOS ARBUSTIVOS & & \\
Brezales de Calluna vulgaris & $\mathbf{1 3 0 , 8}$ & $\mathbf{1 0 , 6}$ \\
Brezales con E. vagans & 147,7 & 12,0 \\
Brezales de E. arborea & 87,7 & 7,1 \\
Escobales & 83,0 & 6,7 \\
Brezales-tojales con E. tetralix & $\mathbf{1 0 0 , 0}$ \\
Matorral espinoso & 77,3 & 6,3 \\
Subtotal & 14,4 & 1,2 \\
\hline FORMACIONES ARBÓREAS & 0,3 & 0,0 \\
Abedulares & & \\
Hayedos & $\mathbf{1 1 0 1 , 2}$ & $\mathbf{8 9 , 4}$ \\
Acebedas & $\mathbf{3 , 1}$ \\
\hline SUPERTICIE TOTAL & $\mathbf{3 3 , 3}$ \\
\hline
\end{tabular}



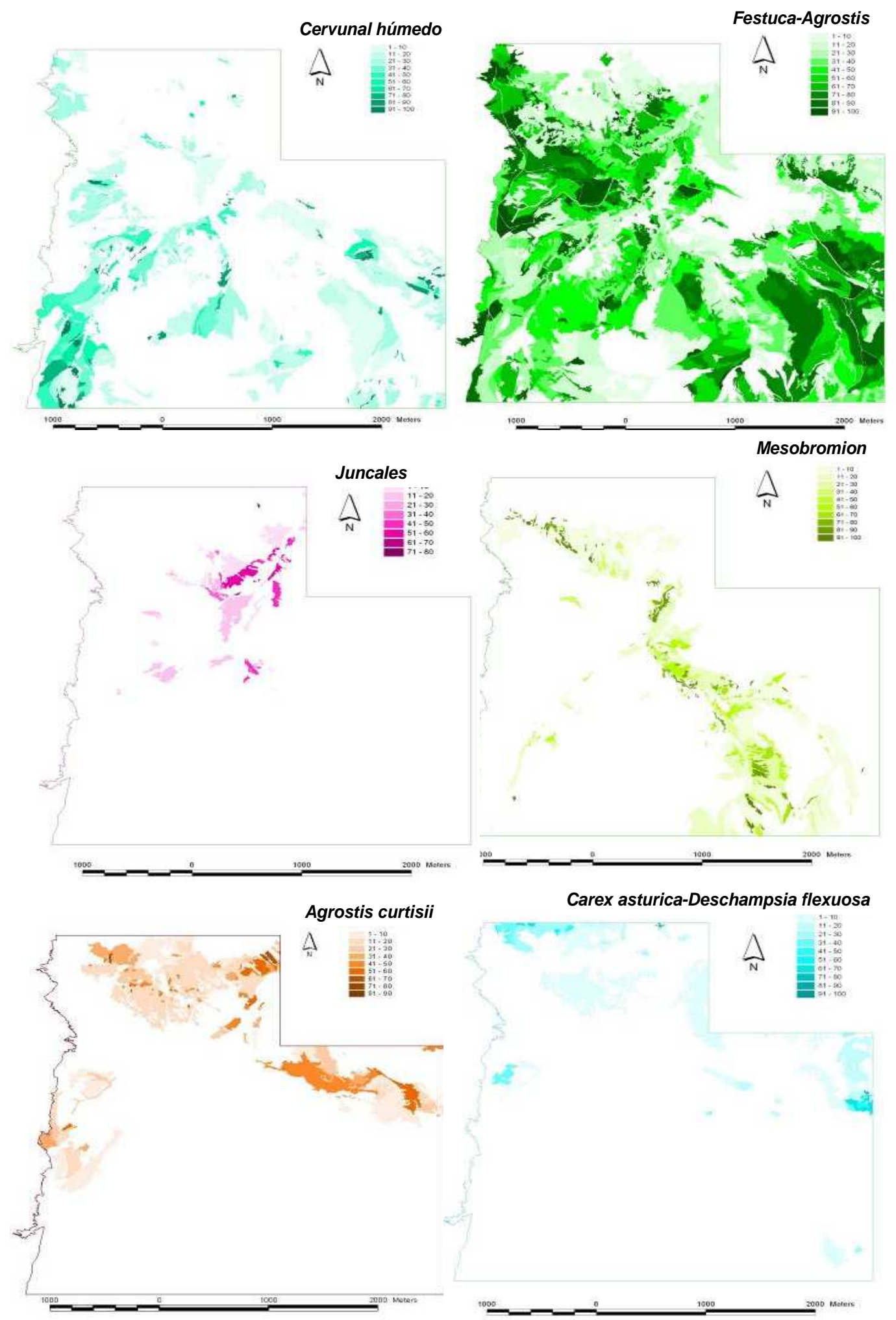

Carex asturica-Deschampsia flexuosa

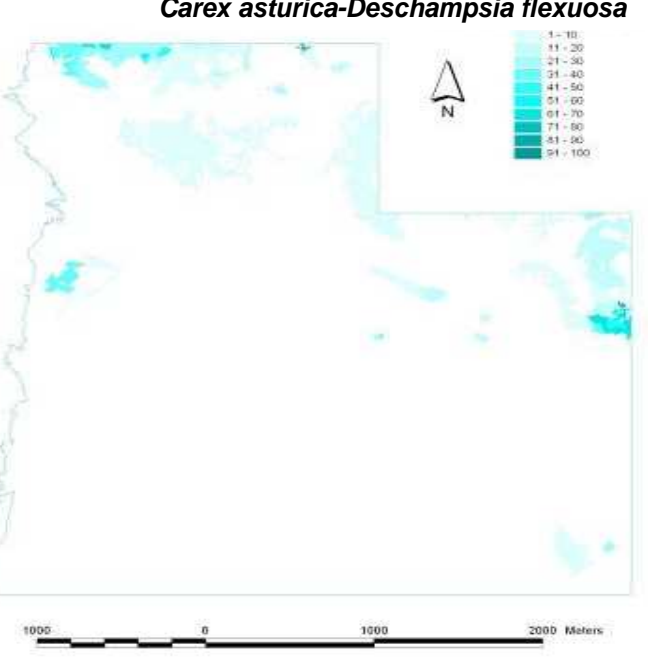

Figura 2.11. Mapas de las comunidades vegetales herbáceas más representativas de los puertos de Sejos. 

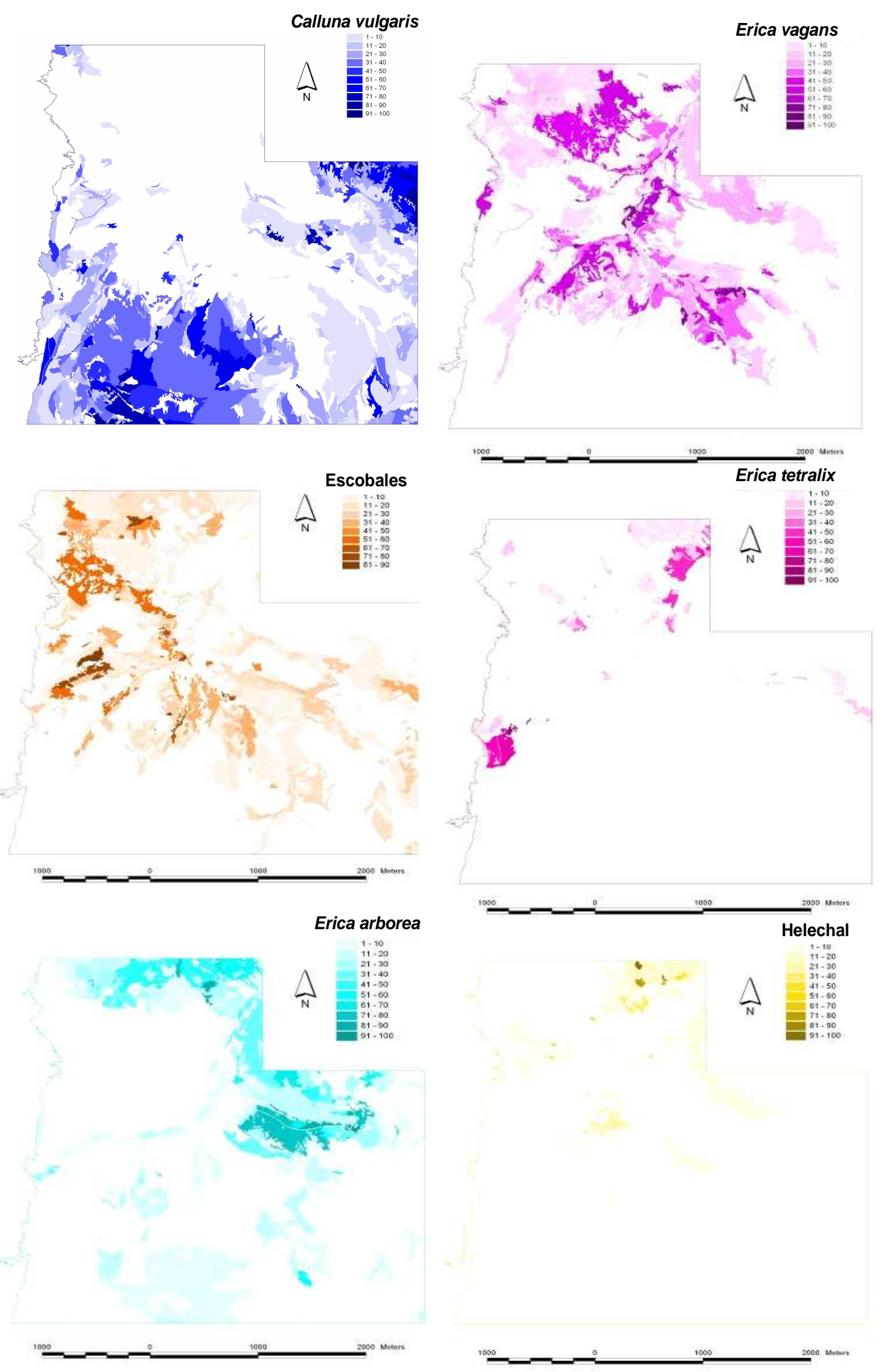

Figura 2.12. Mapas de las comunidades vegetales arbustivas más representativas de los puertos de Sejos. 


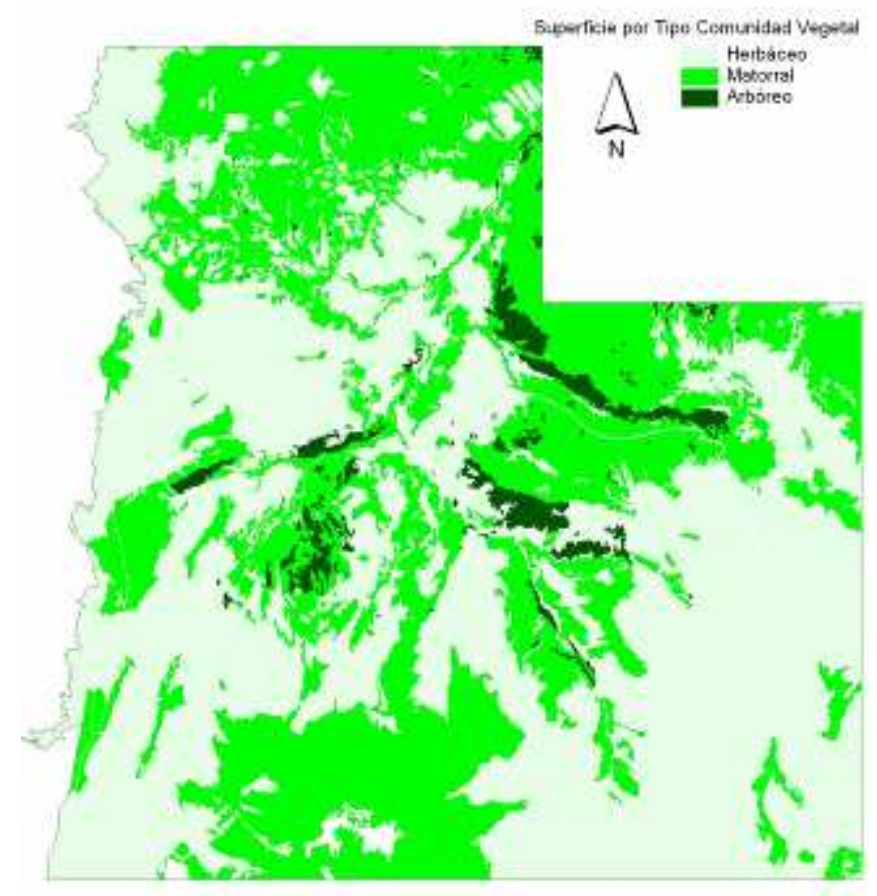

Figura 2.13. Distribución espacial de la vegetación de Sejos según el dominio superficial de uno de los tres grandes grupos de vegetación existente: herbáceo, arbustivo y arbóreo.

\subsubsection{La lecherina (Euphorbia polygalifolia)}

La lecherina (Euphorbia polygalifolia Boiss. \& Reut. ex Boiss.) es un caméfito endémico de la Cordillera Cantábrica, común en comunidades arbustivas acidófilas montanas dominadas por brezos (Calluna vulgaris, Erica spp.) o escobas (Genista florida subsp. polygaliphylla). Esta planta, apenas consumida por el ganado vacuno y caballar, está proliferando de forma alarmante en los pastos de puerto acidófilos de Cantabria en los últimos años, perjudicando su utilización pastoral y diversidad vegetal (Busqué et al., 2003). La lecherina posee características ecológicas similares a otra euforbia (Euphorbia esula), una de las plantas invasoras alóctonas de Norte América más estudiadas y de mayor problemática, con 2 millones de hectáreas de pastos de diente con alto grado de invasión (Anderson et al., 2003).

La distribución de la lecherina y la específica de los pastos de Festuca-Agrostis se muestran en la figura 2.14, siendo notable la correspondencia existente entre ambas distribuciones. En concreto, la lecherina coloniza en mayor medida los pastos de FestucaAgrostis sobre suelos de materiales ácidos poco consolidados, con escasa capacidad de 
retención de agua, y por tanto proclives a desencadenar estrés hídrico en el pasto herbáceo en épocas de crecimiento con escasas precipitaciones.
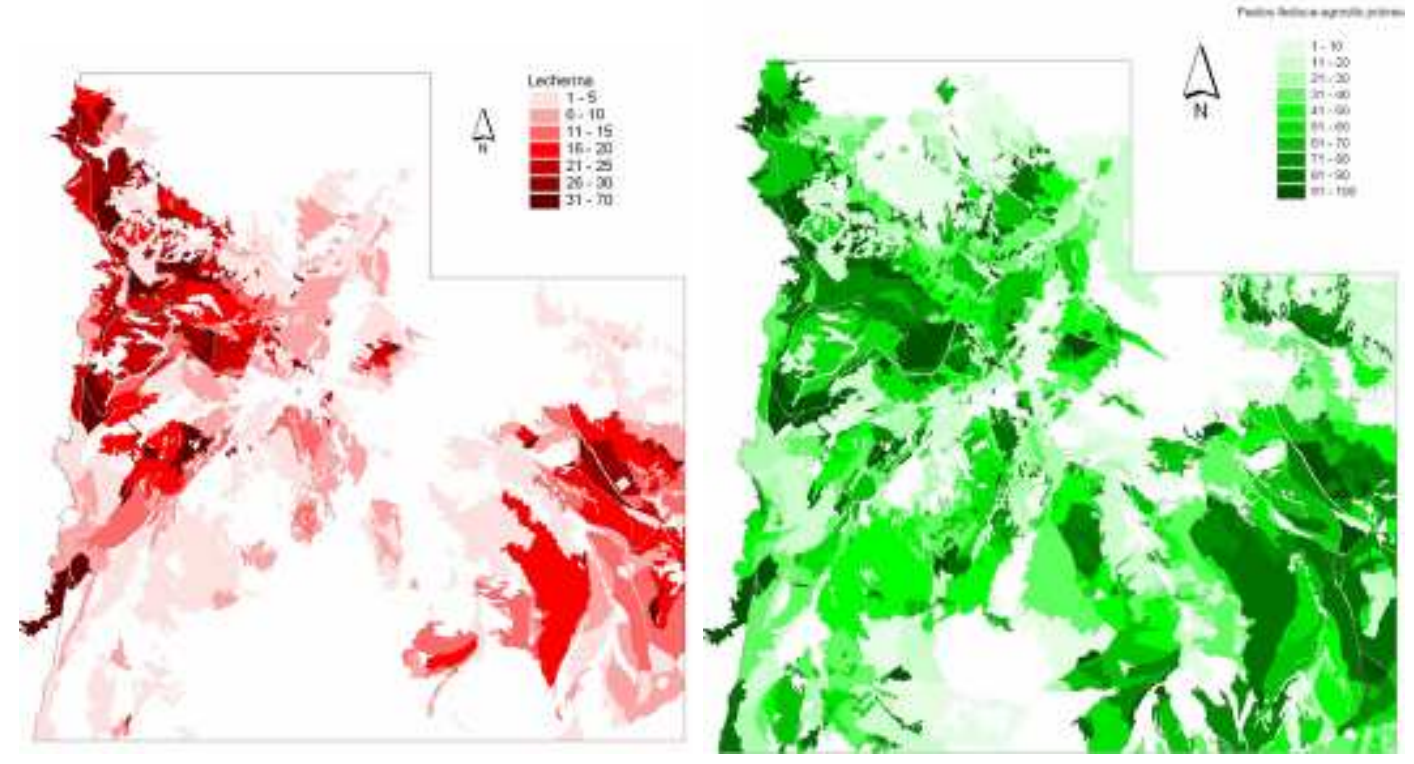

Figura 2.14. Superficie de Sejos ocupada por lecherina (izquierda) y por la comunidad vegetal de pastos herbáceos de Festuca-Agrostis (derecha), según sus porcentajes de cobertura.

El área de pasto herbáceo con coberturas de lecherina por encima del 15\% (zonas consideradas ya con serios problemas de degradación) es de 183 hectáreas: un 28,5\% del total de área con pasto herbáceo de Sejos y un 16,6\% del total de la superficie cartografiada.

\subsection{El pastoreo}

\subsubsection{Origen histórico y gestión tradicional}

La Mancomunidad Campoo Cabuérniga (MCC) es una propiedad mancomunada, única en la Cordillera Cantábrica por su extensión (7000 ha) y forma de propiedad (compartida por cuatro municipios).

Según Ríos y Ríos (1878), los orígenes de la MCC se remontan a una Concordia de 1497, por la cual los vecinos de Valle de Cabuérniga, Ruente, Los Tojos (municipios cabuérnigos) y los de otros pueblos más cercanos al litoral (denominados Gajucos), podían subir a apacentar sus ganados durante el verano a los montes de la Hermandad de Campoo 
de Suso (actual terreno de la MCC), a cambio de que los ganados de la Hermandad, en época de nieve, pudiesen pasar y pastar por los términos de Los Tojos, Valle de Cabuérniga y Ruente en su trashumancia habitual hacia las zonas costeras. A raíz de la Real sentencia del 23 de mayo de 1743, los cuatro municipios formaron una Mancomunidad para el disfrute y aprovechamiento de los montes públicos y el terreno deslindado por la misma. La sentencia delimitó lo que actualmente se conoce como Mancomunidad de Campoo Cabuérniga, perteneciente a los Ayuntamientos de Valle de Cabuérniga, Ruente, Los Tojos y Hermandad de Campoo de Suso. No obstante, no todos los pueblos pertenecientes a estos municipios tienen derechos de aprovechamiento ganadero dentro de la finca de la Mancomunidad (figura 2.15).

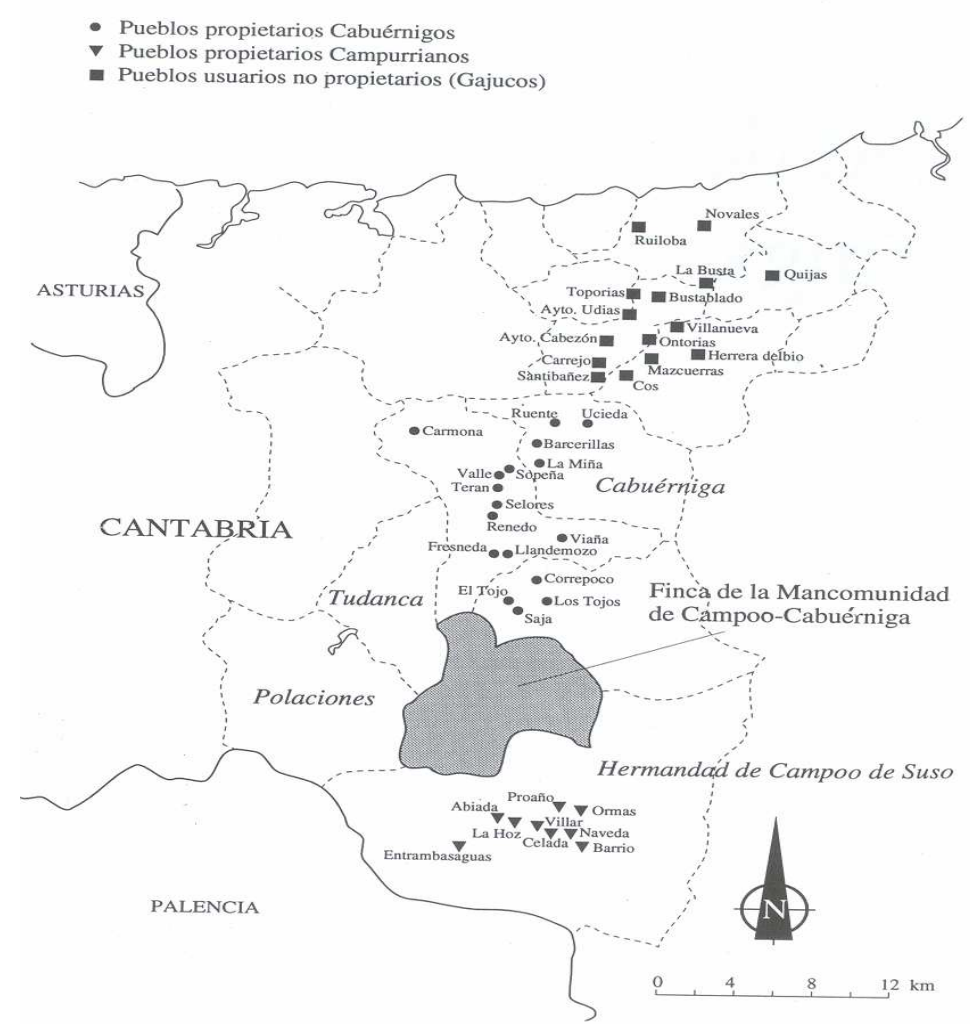

Figura 2.15. Localización de los pueblos con derechos históricos de aprovechamiento en la finca de la Mancomunidad Campoo Cabuérniga. (Gómez Sal et al., 1995).

Las últimas normas que han aparecido sobre el aprovechamiento de pastos en la Mancomunidad quedan recogidas en el Boletín Oficial de Cantabria $n^{\circ} 116$, de 12 de junio de 1989. Según estas normas la MCC queda dividida en dos zonas (figura 2.16): puertos altos y puertos bajos. Los puertos de Sejos serían considerados como puertos altos y en 
ellos tendrían derecho a pastar gratuitamente los ganados campurrianos (Hermandad de Campoo de Suso) desde el 16 de mayo al 15 de junio (en la actualidad el censo de ganado campurriano que pasta en la MCC es relativamente bajo en comparación con el censo de ganado cabuérnigo) y los ganados cabuérnigos desde el 16 de junio hasta el 15 de octubre. Los ganados de los pueblos gajucos podrían entrar a los puertos bajos acompañando a los cabuérnigos previo pago de un canon a la Junta de la MCC.

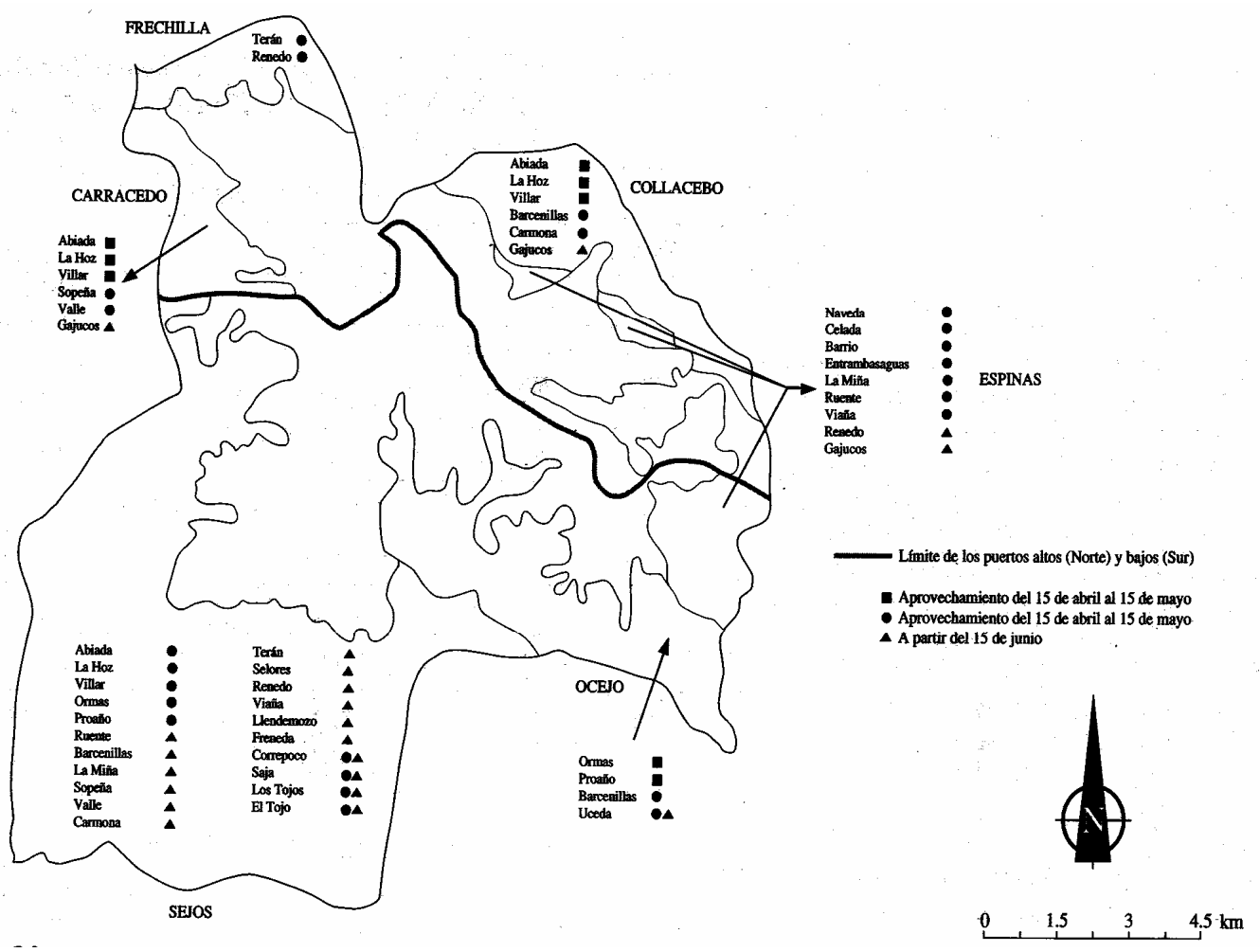

Figura 2.16. Distribución espacio-temporal actual de los pastos de la Mancomunidad Campoo Cabuérniga con indicación de los pueblos con derechos de pastoreo en cada época y zona (Gómez Sal et al., 1995).

En la práctica, el ganado de cada pueblo se manejaba históricamente en el puerto como una unidad o cabaña y disponía de un área de pastoreo concreta y conocida por los demás pueblos. De esta forma, más de una veintena de cabañas cubrían la superficie pastable de la MCC cada verano, contando todas ellas con lugares de pernocta (seles) estratégicamente ubicados (figura 2.17). Cada cabaña era manejada por personal especializado (vaqueros, becerreros y sarrujanes) que convivía con el ganado noche y día. El ganado tradicionalmente utilizado era el vacuno de raza tudanca. Se trata de una raza 
autóctona de la zona, empleada ancestralmente para trabajo y transporte y como productora de carne.

En la segunda mitad del siglo XX este sistema pastoral sufre un cambio radical. La apertura de las primeras pistas de acceso, junto a la llegada de los medios de transporte motorizados, permiten hacer visitas puntuales al ganado y no tener que residir en el puerto todo el verano. De esta forma, los oficios tradicionales (vaqueros, becerreros y sarrujanes) acabaron desapareciendo y con ellos el manejo de todo el ganado de un mismo pueblo como una única cabaña. Es decir, cada ganadero pasa a manejar su rebaño de forma independiente. En principio, se mantuvieron los alcances tradicionales de cada pueblo: los ganaderos del mismo pueblo siguieron llevando su ganado a la zona que históricamente les correspondía. Sin embargo, ese respeto se va diluyendo con el tiempo, bajo el amparo de la normativa actual que únicamente divide la $\mathrm{MCC}$ en puertos altos y bajos, sin regular por lo demás la distribución espacial del pastoreo que se venía haciendo tácitamente desde hacía siglos.

No hay que olvidar además, que en estas últimas décadas se han producido importantes cambios socioeconómicos en el medio rural: emigración de la mano de obra más capacitada, envejecimiento y abandono de los ganaderos, llegada de las ayudas de la Unión Europea o mejora de las condiciones de vida. Estos cambios han influido en los sistemas pastorales, provocando, en líneas generales, un manejo del ganado menos controlado y menos ligado al territorio (por una menor disponibilidad de mano de obra). En general existe también una escasa dirección del pastoreo por parte del ganadero y una bajada del puerto del vacuno, en muchos casos sin mediación del ganadero, en cuanto detectan escasez del pasto de buena calidad. Esto provoca una utilización del espacio cada vez más restringida a las zonas de mayor valor forrajero, con los consiguientes desequilibrios de sobrepastoreo de esas zonas e infrapastoreo del resto. Las frecuentes actuaciones en forma de desbroces de brezales en las zonas altas contribuyen poco a "expandir" las distribuciones del pastoreo, dado el bajo valor nutritivo del pasto resultante y la capacidad de rebrote del matorral desbrozado, al ser éste escasamente consumido.

Pero no sólo han cambiado los ganaderos: el ganado también ha cambiado. La base animal tradicional en la comarca, constituida por pequeñas cabañas de vacas tudancas (raza autóctona considerada en la actualidad como de especial protección), se absorbe en buena parte por la introducción de otras razas bovinas de aptitud cárnica (charolesa, limusina, parda de montaña o pirenaica entre otras); los cruzamientos de vacas tudancas con 
sementales de otras razas se generalizan; el ganado caballar va ganando progresivamente terreno, favorecido por su menor problemática sanitaria y por su manejo poco demandante de mano de obra.

Hay que destacar que la zona de estudio ha sufrido y sufre aún las consecuencias de un control infructuoso de las enfermedades objeto de campaña oficial de saneamiento en vacuno (principalmente brucelosis y tuberculosis). Esas campañas han supuesto el sacrificio de muchas vacas nacidas y criadas en la comarca, recurriéndose para la reposición a ganado foráneo en muchos casos. Lo cual ha conllevado una indudable pérdida de "cultura pastoral" del ganado, atesorada durante siglos (Montserrat y Fillat, 1977; Provenza, 2007).

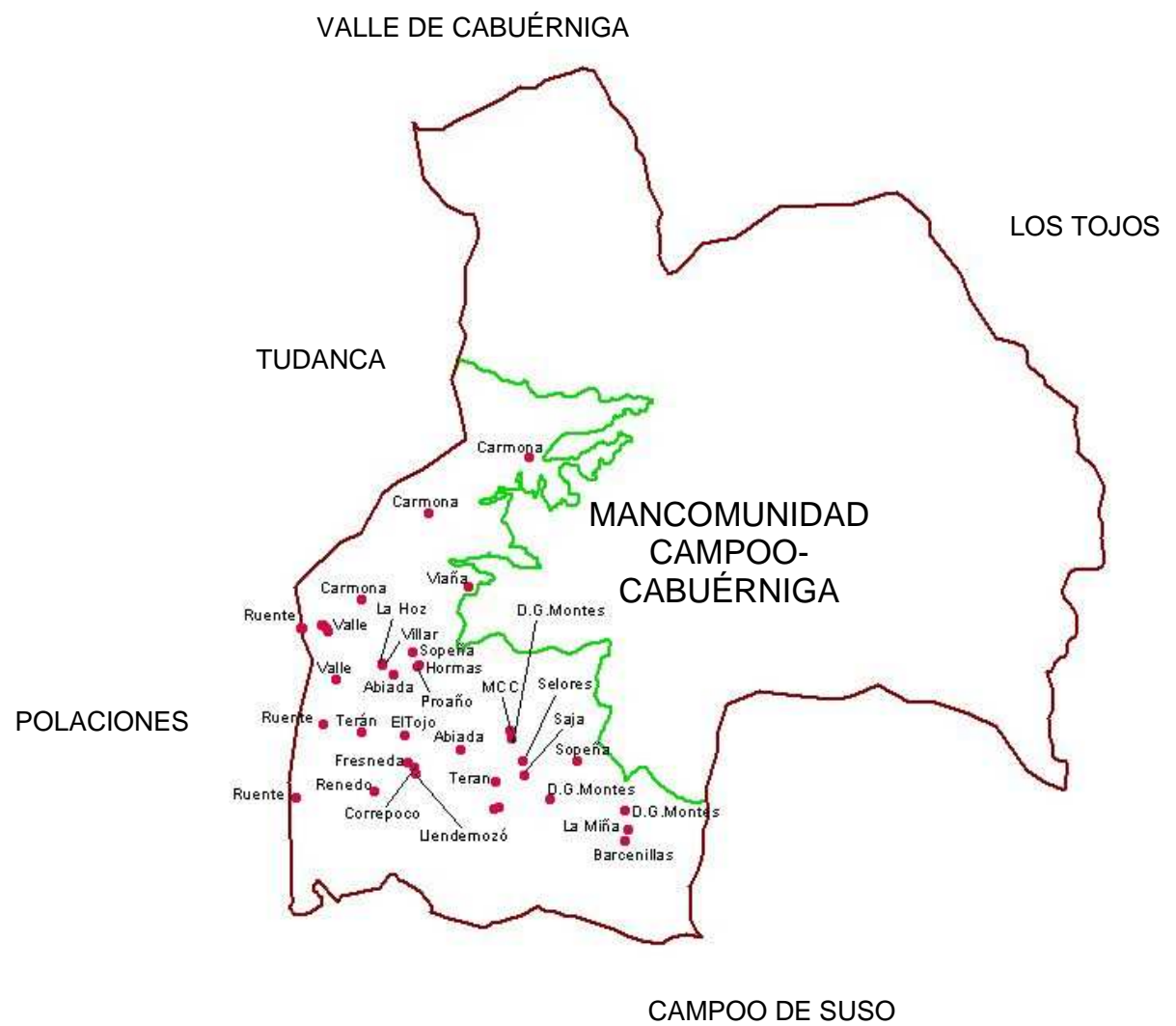

Figura 2.17. Localización de los seles en los puertos de Sejos dentro de la Mancomunidad Campoo Cabuérniga (Busqué et al., 2006).

\subsubsection{Estado actual}

Los principales herbívoros presentes en los puertos de Sejos son los ungulados domésticos: el ganado vacuno y caballar, estando ausentes el ganado ovino y caprino. Entre los ungulados salvajes destaca la presencia de ciervos (Cervus elaphus), aunque 
también existe un pequeño grupo de rebecos (Rupricabra rupricapra). El ganado vacuno y caballar pastorea desde finales de primavera hasta el otoño, cumpliendo unas fechas de entrada establecidas en el reglamento de la finca de la Mancomunidad Campoo Cabuérniga (Gómez-Sal et al., 1995). Los ciervos permanecen en Sejos mientras no exista cubierta de nieve, siendo común su observación pastoreando en muchos inviernos de escasa innivación.

La tabla 2.2 recoge la evolución histórica del censo del ganado en pastoreo dentro de la MCC (Busqué et al., 2006).

Tabla 2.2. Evolución en el número de vacas marcadas para subir a la Mancomunidad Campoo Cabuérniga por municipios (años 1982, 1991 y 2002) y censo de caballar en 2002. Entre paréntesis $\mathbf{n}^{\circ}$ de cabañas ganaderas.

\begin{tabular}{llllll} 
Municipio & $1982^{1}$ & $1991^{1}$ & $2002^{2}$ & $\begin{array}{l}\mathrm{N}^{\circ} \text { cabañas de } \\
\geq 30 \text { vacas }(2002)\end{array}$ & $\begin{array}{l}\text { Caballar } \\
2002^{2}\end{array}$ \\
\hline Los Tojos & $1566(64)$ & $1398(51)$ & $1785(38)$ & 25 & $249(13)$ \\
\hline Ruente & $520(27)$ & $400(34)$ & $472(19)$ & 7 & $196(16)$ \\
\hline Cabuérniga & $1335(60)$ & $1129(58)$ & $2646(70)$ & 37 & $377(32)$ \\
\hline Gajucos* & $146(9)$ & $277(21)$ & $125(8)$ & 1 & 0 \\
\hline TOTAL & $3567(160)$ & $3204(164)$ & $5028(135)$ & 70 & $822(61)$ \\
\hline
\end{tabular}

${ }^{1}$ Fuente: Gómez-Sal et al. (1995); ${ }^{2}$ Datos de la MCC.

* Ganado de ciertos municipios de la comarca litoral de Cantabria con derecho histórico al pastoreo

De los datos de la tabla 2.2 es interesante observar algunas tendencias. El número total de vacas subiendo a puerto aumentó considerablemente en los últimos 10 años (incremento del 61\% de 1991 a 2002), para un número inferior de propietarios. A nivel de municipios, este incremento se debió principalmente al aumento observado en Cabuérniga (incremento del 134\% de 1991 a 2002). El censo vacuno de este municipio (campaña de saneamiento; tabla 5.10 de Gómez Sal et al., 1995) muestra que en 1991 subió a puerto alrededor del $43 \%$ del total de vacuno de Valle de Cabuérniga, mientras que en 2002, se estima que este porcentaje fue de un $74 \%$.

El número de propietarios de vacuno subiendo a la MCC mostró un apreciable descenso a nivel comarcal (descenso del 18\% de 1991 a 2002), con caídas fuertes en el municipio alto (Los Tojos: -25\%) y bajo (Ruente: -44\%) y un incremento notable en el municipio medio (Cabuérniga: $+21 \%$ ). El resultado de combinar el aumento del número de vacas marcadas y la disminución del número de cabañas fue un claro aumento del tamaño 
medio de cabaña (de 20 a 37 vacas en los últimos 10 años). En términos absolutos este aumento de tamaño de cabaña fue mayor para los ganaderos de los municipios de Los Tojos (de 27 a 47 vacas por cabaña) y Valle de Cabuérniga (de 19 a 38 vacas por cabaña) y menor en el de Ruente (de 12 a 25 vacas por cabaña). En cualquier caso, la distribución de los tamaños de cabaña fue sesgada, con un número alto de cabañas de pocos animales (figura 2.18). Lo mismo ocurrió en el caso de cabañas de caballar (figura 2.19). Se estima que la mayor parte de los pequeños ganaderos fueron personas con otra actividad principal, familiares de otros ganaderos con mayor número de animales o jubilados. El ganado caballar supuso un $14 \%$ del total de cabezas de ganado marcadas para subir a puerto en 2002. En la mayor parte de los casos la duración de su estancia en la MCC fue muy superior a la del vacuno.

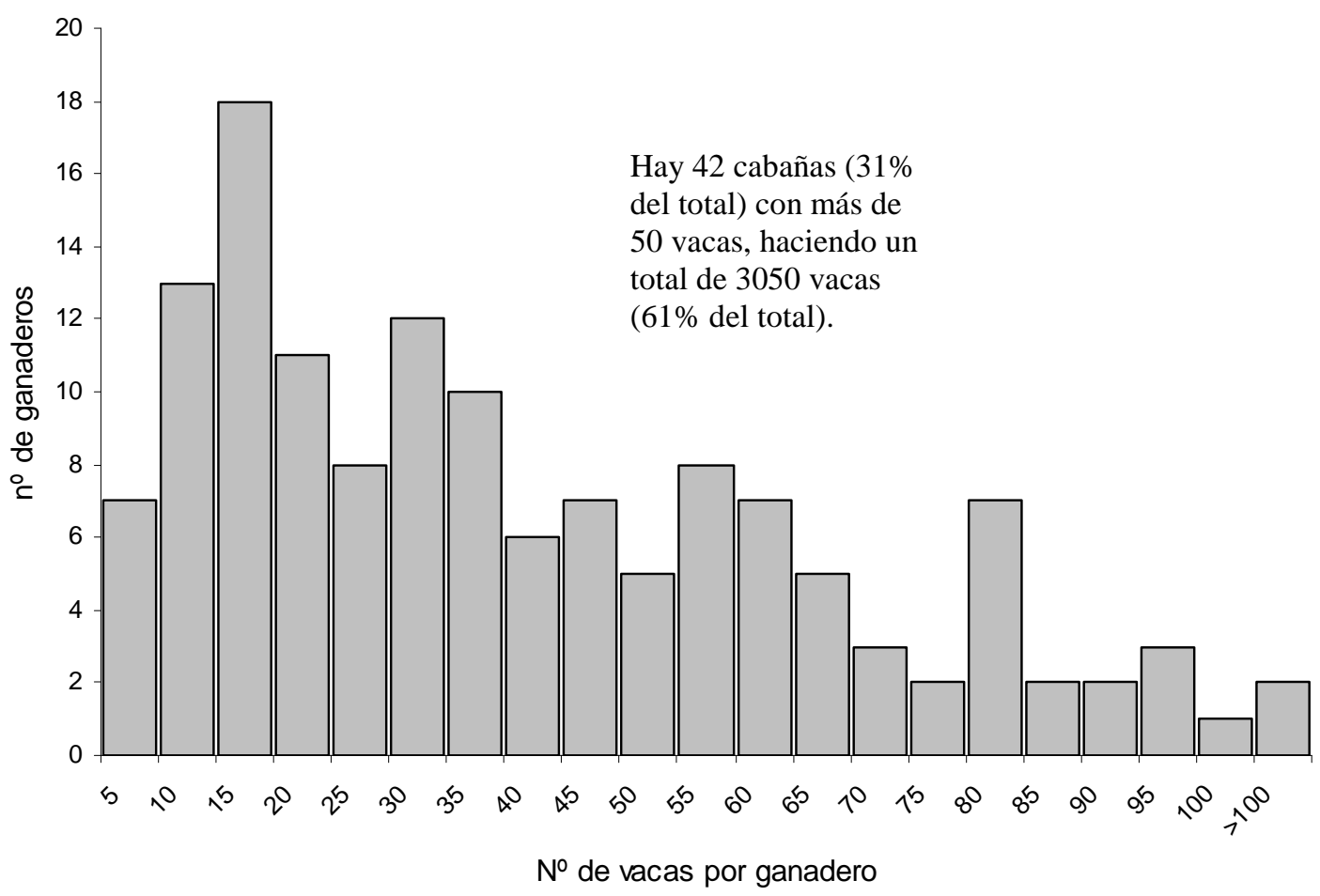

Figura 2.18. Distribución de los tamaños de las cabañas de vacuno que subieron a la Mancomunidad Campoo Cabuérniga en 2002. 


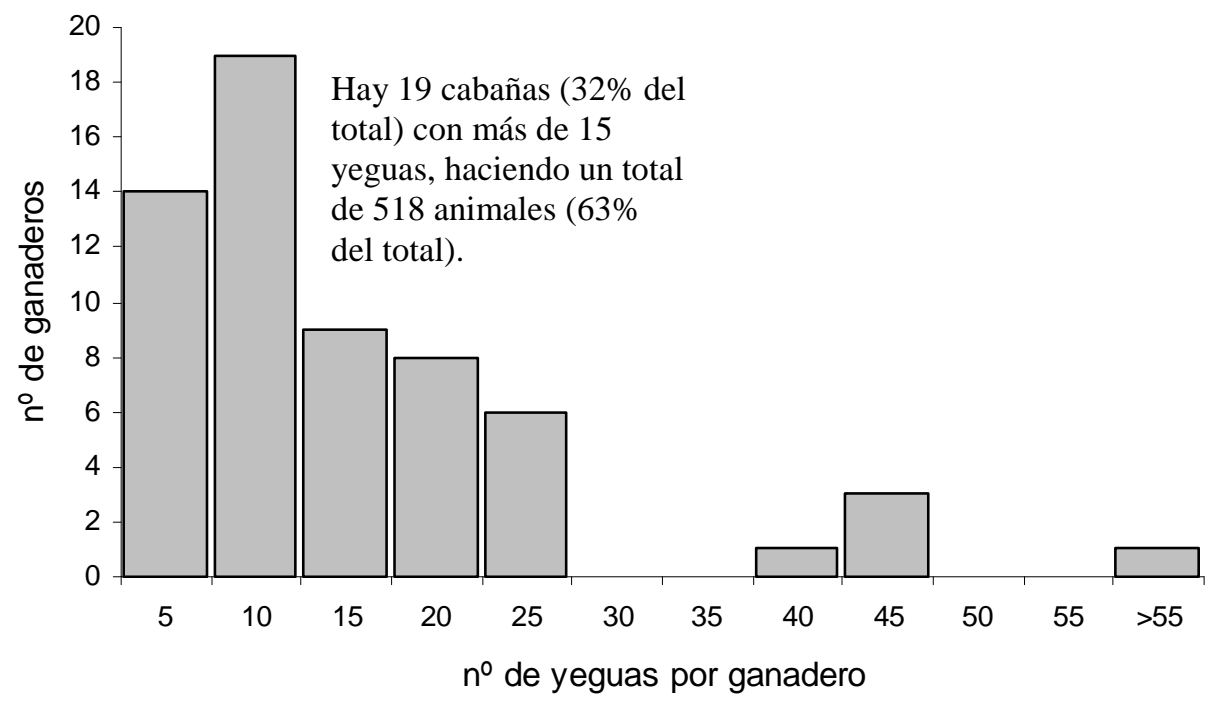

Figura 2.19. Distribución de los tamaños de las cabañas de caballar que subieron a la Mancomunidad Campoo Cabuérniga en 2002.

Centrándose en los puertos de Sejos, una zonificación de su área (figura 2.20) permite detallar más la distribución del ganado dentro de estos puertos (CIFA, 2004).

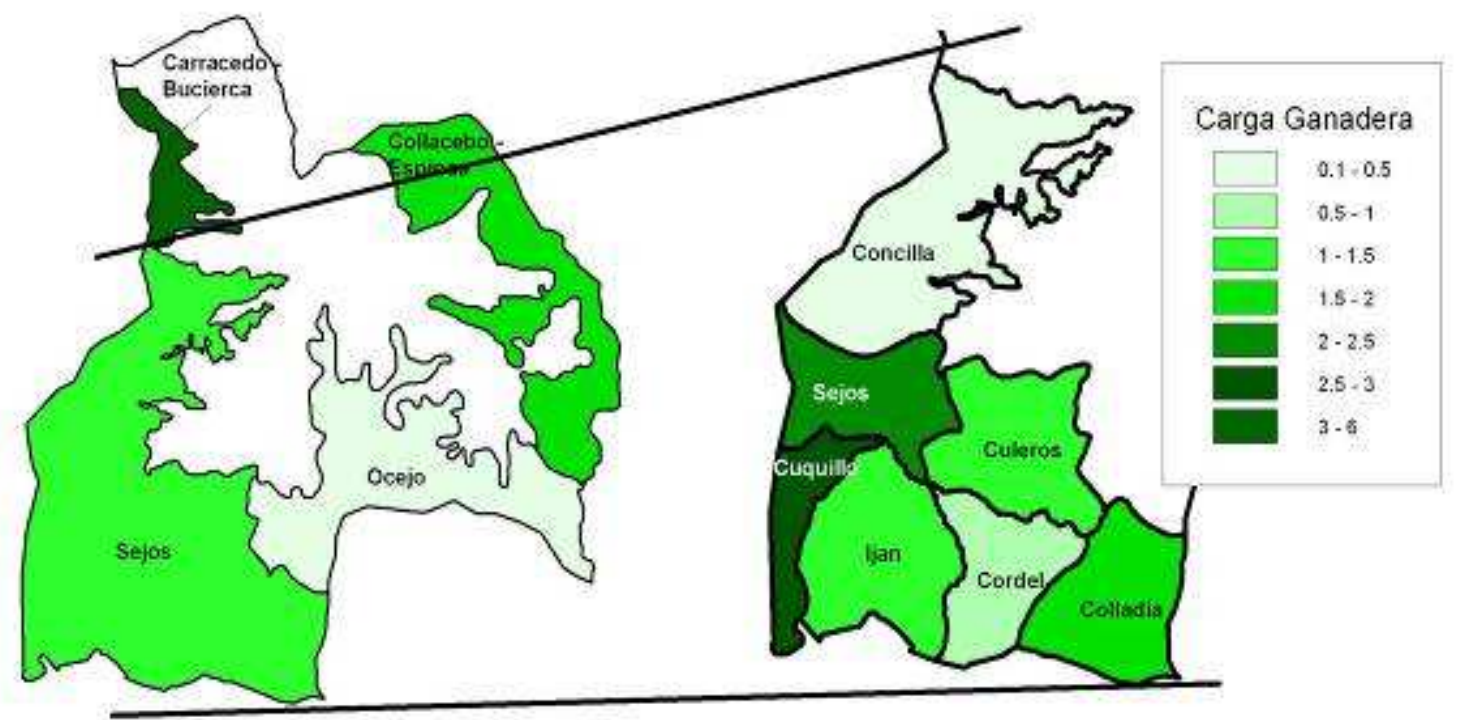

Figura 2.20. Zonificación de las zonas pastorales de la Mancomunidad Campoo Cabuérniga (izquierda) y del área de estudio de los puertos de Sejos (derecha).

La carga ganadera general de vacuno (i.e., sin considerar la proporción de superficie de pasto herbáceo en cada zona) fue alta en las zonas de Cuquillo, Sejos y Colladía, media 
en Hiján, Cordel y Culeros, y muy baja en Concilla. La alta carga de Cuquillo fue en su mayor parte debida al vacuno del pueblo de Ruente (municipio del mismo nombre), en Sejos al vacuno de Carmona (municipio de Valle de Cabuérniga), y en Colladía estuvo principalmente repartida entre vacuno de Saja (municipio de Los Tojos), Carmona y La Miña (municipio de Valle de Cabuérniga).

La carga de caballar en Cuquillo destacó por encima de todas las demás, mientras que Concilla volvió a mostrar los valores más bajos. El caballar de Ruente fue el principal responsable de la alta carga en Cuquillo.

La mayoría de las cabañas tuvieron sus alcances en zonas cercanas a sus seles tradicionales (figura 2.17). Por otro lado, las cabañas de los pueblos con el mayor número de animales en el área total de Sejos (Carmona, El Tojo [municipio de Los Tojos], y también Renedo [municipio de Valle de Cabuérniga]) estuvieron más dispersas en distintas zonas.

Con el fin de complementar la información sobre la distribución espacio-temporal del ganado en Sejos, Busqué et al. (2006) realizaron encuestas a los ganaderos, cotejando los datos que aportaron con los proporcionados por la guardería de la Mancomunidad Campoo Cabuérniga. Los datos más relevantes que caracterizaron las ganaderías pastando en Sejos en 2003 fueron:

- El tamaño medio de las cabañas de caballar fue de 14 animales $( \pm 12,3)$, y el de las cabañas de vacuno de $43( \pm 28,9)$.

- En caballar predominaron los animales de escaso formato (92\% del total), catalogados como "del país", frente a los de raza hispano-bretona.

- En vacuno la raza pura dominante fue la tudanca (36\%), seguido de limusina (6\%), casina $(2 \%)$, charolesa $(1 \%)$ y parda de montaña $(0,5 \%)$. La mayoría de las vacas fueron mixtas de las razas anteriores (54\%).

- La distribución del caballar según el tipo de animal fue de un 40\% de yeguas con cría, un $39 \%$ de yeguas sin cría, un $18 \%$ de quincenos y un $3 \%$ de sementales.

- La distribución del vacuno según el tipo de animal fue de un 21\% de vacas con cría, un $61 \%$ de vacas sin cría, un $17 \%$ de novillas y un $1 \%$ de toros. El número de toros disminuyó radicalmente en 2004 por las medidas de control sanitario adoptadas a partir de ese año. 
- El periodo medio de pastoreo de las cabañas de caballar en Sejos fue de 120 días $( \pm 30,3$ días $)$, mientras que las cabañas de vacuno permanecieron una media de 85 días ( $\pm 19,0$ días). La evolución estacional del censo de ganado en puerto se representa en la figura 2.21 .

- Un 45\% de las cabañas de vacuno y un $29 \%$ de las de caballar fueron periódicamente suplementadas en el puerto con sal por sus dueños.

- El promedio de visitas a las cabañas en puerto por parte de los ganaderos de vacuno fue de $14( \pm 13,2)$ y de $15( \pm 11,3)$ por los ganaderos de caballar en el total de la estación de pastoreo. Estos valores corresponden a medias de 1 visita cada 6 días y cada 8 días para el vacuno y caballar respectivamente.

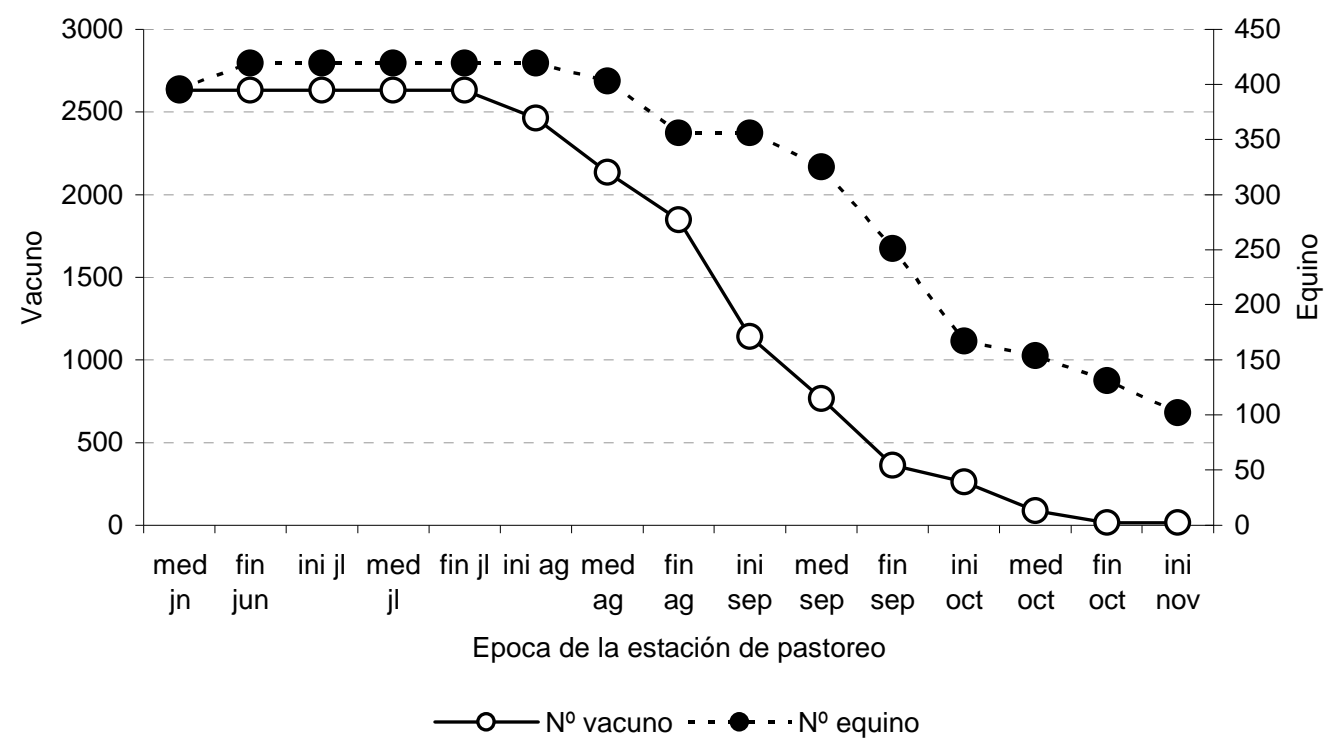

Figura 2.21. Evolución del número de ejemplares de vacuno (eje vertical izquierdo) y caballar (eje vertical derecho) pastando en los puertos de Sejos en el verano-otoño de 2003.

La información anteriormente expuesta sobre la distribución espacial y temporal del ganado en Sejos fue integrada en un modelo denominado PUERTO (Busqué et al., 2006), diseñado para simular el funcionamiento del pastoreo en los puertos de montaña cantábricos. Este modelo permitió estimar el grado de utilización forrajera del pasto, que representa la relación entre la biomasa aérea consumida por el ganado y la biomasa producida desde el comienzo de la estación de pastoreo. La comparación de sus valores con valores de utilización forrajera críticos (valores máximos de utilización sostenible; Rickert, 1996) permite detectar posibles desequilibrios en forma de sobrepastoreo. Los 
resultados obtenidos de la aplicación de dicho modelo ponen de manifiesto la existencia de amplias zonas sobrepastoreadas en Sejos (figura 2.22).

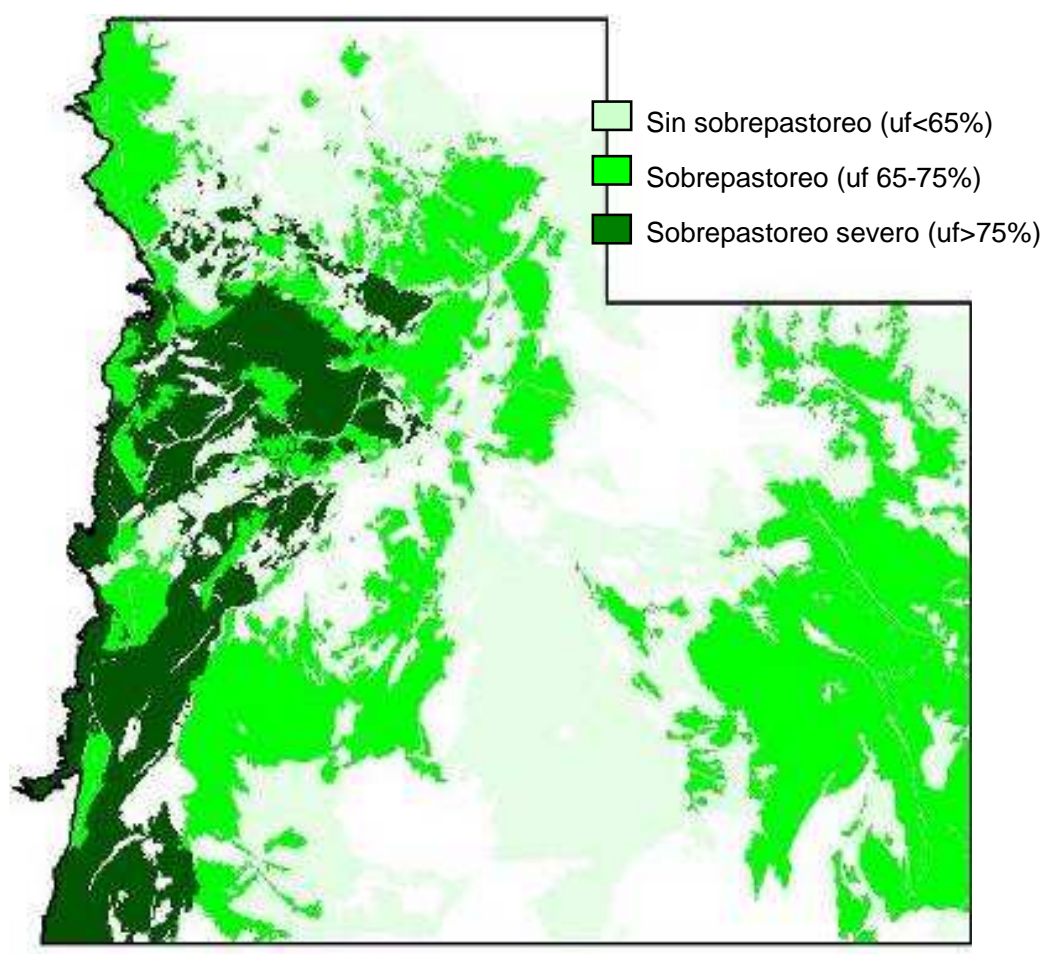

Figura 2.22. Estimación de la utilización forrajera total de los pastos del tipo Festuca-Agrostis por el pastoreo de vacuno y caballar en los puertos de Sejos (Mancomunidad-Campoo Cabuérniga) en la estación de pastoreo de 2003 (Busqué et al., 2006). 
3. REVISIÓN BIBLIOGRÁFICA. Relación pasto-herbívoro: pautas y desequilibrios 



\subsection{Introducción}

La crisis de los sistemas pastorales de montaña cantábricos en los últimos decenios (explicado en el capítulo 2) parece coincidir con el proceso de invasión de lecherina. Aunque no se descarta la intervención de otros factores, parece claro que la defoliación excesiva del pasto herbáceo con predominio de las gramíneas Agrostis capillaris y Festuca nigrescens y la escasa defoliación de la lecherina son factores determinantes a la hora de activar el proceso de invasión de lecherina (Busqué et al., 2003).

La búsqueda de razones que expliquen la relación entre los cambios acaecidos en la gestión pastoral y el sobrepastoreo y degradación de una importante superficie de pasto de alto valor productivo y ecológico, requiere de un estudio en detalle del comportamiento del ganado en pastoreo y de sus efectos sobre la dinámica de la vegetación a distintas escalas: desde una mancha de pasto homogéneo, hasta el sistema de pastoreo de una unidad de paisaje (Gómez, 2008), como es un puerto de montaña cantábrico. Como primer paso de este estudio, en este capítulo se revisa el estado actual del conocimiento científico sobre el comportamiento del ganado en pastoreo extensivo y la relación entre el pastoreo y la dinámica de la vegetación en estos ecosistemas pastorales. El objetivo de este capítulo es revisar la información existente sobre las pautas que gobiernan la relación pasto-herbívoro, en los trabajos de investigación desarrollados en condiciones similares a las del sistema de pastoreo que aquí se estudia.

Asimismo, se realiza una revisión de la naturaleza de los procesos de invasión por plantas no apetecibles para los herbívoros en otros sistemas pastorales, visto también desde la perspectiva de la interacción entre el pasto y los herbívoros. Dada su similitud con la invasión de lecherina, se hace especial referencia a la invasión de pastos de diente de Norte América por otra euforbia (Euphorbia esula), en este caso alóctona. Esta planta, considerada como una de las invasoras más agresivas en Estados Unidos (DiTomaso, 2000), está invadiendo pastos aprovechados en pastoreo por vacuno y, consecuentemente, está afectando negativamente a su utilización ganadera (Hein y Miller, 1992).

En los temas tratados en esta revisión se hace siempre hincapié en la visión de la relación pasto-herbívoro a distintas escalas espacio-temporales, ya que ésta es muy dependiente de la escala, existiendo un entramado de efectos directos e indirectos entre procesos que funcionan a distintas escalas (Senft et al., 1987; Bailey et al., 1996). 


\subsection{Dinámica de la vegetación y pastoreo.}

\subsubsection{Dinámica de la vegetación.}

Una comunidad vegetal se define como un conjunto de especies vegetales que suelen encontrarse juntas de modo reiterado en el territorio (Terradas, 2001). La composición botánica y productividad de las comunidades vegetales viene condicionada en primer lugar por una adaptación genética histórica a las condiciones climáticas, topográficas y edáficas locales (Archer, 1996). Esas condiciones determinan la disponibilidad de los principales recursos por los que compiten las plantas: luz, agua, espacio y nutrientes minerales. Así, la coexistencia de distintas especies vegetales dentro de una misma comunidad vegetal se puede producir por la diversidad de estrategias respecto al uso de los recursos existentes, dentro del gradiente definido por dos tipos extremos: la capacidad de aprovechar rápidamente los recursos limitantes y la de sobrevivir en situaciones de escasez de recursos (Bullock, 1996).

Además del nivel de recursos presentes, y especialmente en ecosistemas pastorales, es necesario considerar un segundo factor de gran importancia para la supervivencia y crecimiento de las plantas: la perturbación. Grime $(1979 ; 2001)$ considera dos tipos de factores externos que limitan la cantidad de materia vegetal presente en cualquier hábitat: el estrés, que engloba limitaciones del crecimiento vegetal a través de la escasez de recursos, y la perturbación, que considera aquellos eventos (exposición al consumo por herbívoros, patógenos, viento, frío, fuego, etc.) que producen pérdidas puntuales, parciales o totales, de tejidos vegetales. La intensidad del estrés y de la perturbación originan, según este autor, las tres estrategias básicas de las plantas (este autor apunta que la situación de niveles altos de estrés y perturbación no es apta para la vida vegetal). Un nivel de estrés alto combinado con un grado de perturbación bajo conlleva la dominancia de plantas tolerantes al estrés (S), caracterizadas por un ritmo de crecimiento bajo. Niveles bajos de estrés y elevados de perturbación conducen a la dominancia de plantas ruderales (R), con ciclos vitales muy cortos. En condiciones de estrés y perturbación bajas predominan las plantas competitivas (C), de alto crecimiento y tamaño. Siguiendo este esquema, cualquier especie vegetal puede situarse en un punto de coordenadas dentro de un triángulo cuyos vértices son las estrategias extremas $\mathrm{C}, \mathrm{S}$ y $\mathrm{R}$ (figura 3.1). 


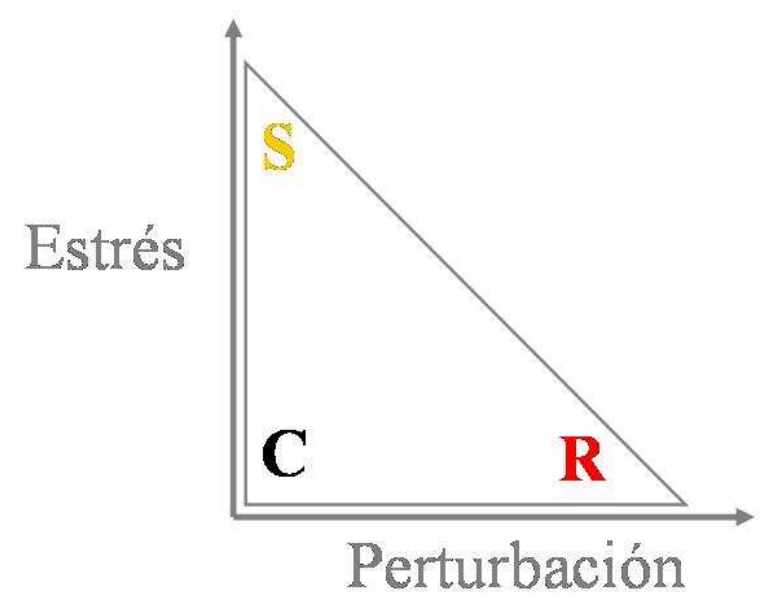

Figura 3.1. Triángulo de estrategias extremas de las plantas (C: competitivas; $S$ : tolerantes al estrés; R: ruderales) en función de las condiciones de perturbación y estrés (Hodgson et al., 1999).

Considerando también las estrategias regenerativas de las plantas, Hodgson (1990) resume el porvenir de una especie vegetal presente en un pasto determinado como dependiente de la velocidad con la que pueda colonizar espacios libres del suelo, de la agresividad con la que ocupa el espacio una vez establecida, de la tolerancia a las limitaciones medioambientales existentes y de los efectos de la defoliación u otras perturbaciones. Cualquier cambio en los niveles de recursos y perturbaciones característicos de una comunidad vegetal, o la aparición de nuevas especies vegetales, puede producir la sustitución de unas plantas por otras, denominándose este proceso dinámica de la vegetación.

En el caso concreto de los pastos de montaña susceptibles de ser invadidos por Euphorbia polygalifolia, la dinámica de la vegetación que conduce a dicha invasión se iniciaría con una sustitución del cervuno (Nardus stricta) por la festuca (Festuca nigrescens) en pastos sin dominio de lecherina, seguida de una posterior sustitución de la festuca por la lecherina hasta la dominancia de esta última en el pasto (Busque et al., 2003). Según estos autores, este proceso de invasión estaría siendo favorecido por la alta intensidad de una perturbación específica hacia las gramíneas, como es el pastoreo, y posiblemente por su interacción con la escasez temporal de un recurso como es el agua, también específico para las gramíneas, dada la distribución superficial de sus raíces (Dawson et al., 2000). 
Siguiendo el esquema de Grime $(1979,2001)$ y Hodgson et al. (1999), se puede interpretar esta dinámica vegetal considerando los tipos funcionales a los que corresponden las especies principales implicadas en la sucesión (valor extremo S para Nardus stricta, valor intermedio entre los tres extremos CSR en Festuca nigrescens y valor cercano a $\mathrm{C}$ en Euphorbia polygalifolia) y teniendo en cuenta la naturaleza específica de la perturbación del pastoreo. Esta dinámica quedaría reflejada en la figura 3.2. Así, la sustitución del cervuno por la festuca es debida a que ambas reciben el mismo tipo de perturbación (pastoreo de vacuno y caballar), estando el tipo funcional de la festuca más adaptado a esta por tener más carácter ruderal que el cervuno. La desaparición de la festuca se explicaría por la superación de un umbral de pastoreo soportable por su tipo funcional intermedio. En este caso, la lecherina podría sustituir a la festuca por ser más competitiva para aprovechar los recursos disponibles (i.e. por su capacidad para aprovechar agua de estratos del suelo más profundos) y fundamentalmente por ser capaz de evitar la perturbación que supone ser defoliada.

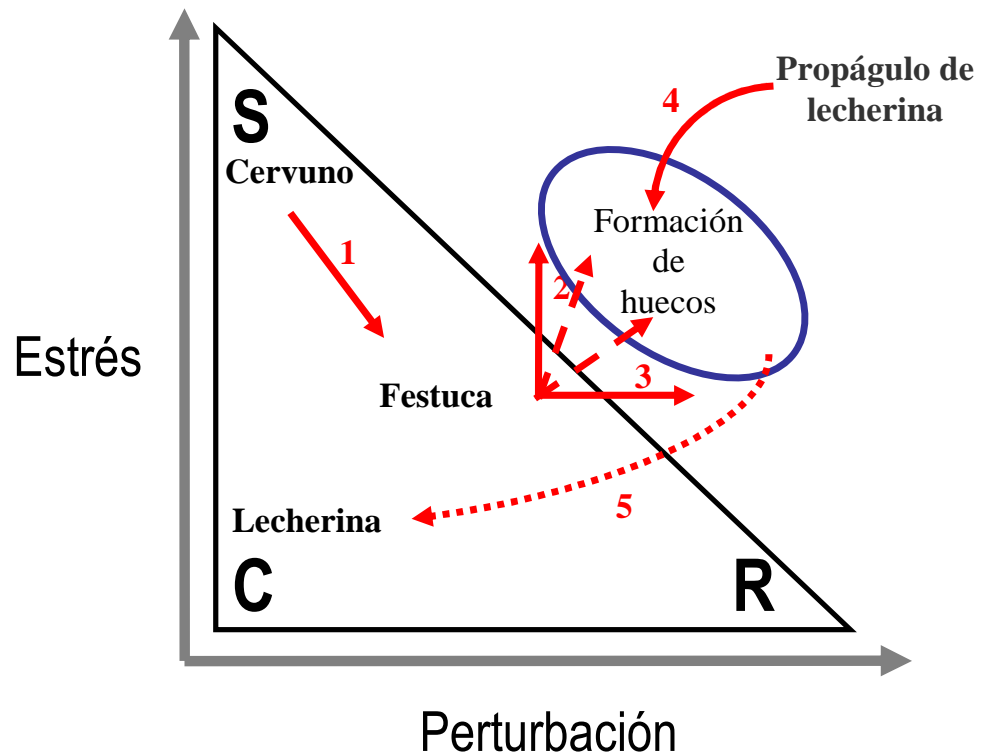

Figura 3.2. Modelo conceptual de la dinámica de invasión de Euphorbia polygalifolia (lecherina) en los pastos de diente de los puertos de Sejos según el esquema de estrategias CSR (Grime, 1979). Paso 1: la festuca (Festuca nigrescens) sustituye al cervuno (Nardus stricta) cuando aumenta la intensidad de pastoreo por vacuno y caballar (aumento de perturbación [defoliación] y disminución de estrés [fertilización]). La incidencia de descensos acusados en la disponibilidad de recursos (p.ej. sequías; paso 2) o de perturbaciones puntuales muy fuertes (p.ej. más defoliación o hozaduras o toperas; paso 3), o de combinaciones de ambas, desplaza la situación a condiciones inviables para la vida vegetal (formación de huecos). Paso 4: los huecos son colonizados posteriormente por propágulos de lecherina que, en su estado adulto (paso 5) cambian las características del hábitat (aseguran la disponibilidad de recursos por la mayor profundidad de las raíces y evitan la defoliación por vacuno y caballar mediante la producción de defensas químicas). 


\subsubsection{Efectos directos del pastoreo sobre las plantas}

El pastoreo es la principal fuente de perturbación que afecta a los ecosistemas pastorales, con importantes implicaciones tanto en la productividad animal como en la diversidad y estructura del ecosistema vegetal (Briske, 1996). El esquema de interacciones planta-animal de la figura 3.3 muestra las acciones directas del pastoreo (defoliación, aportación de excretas y pisoteo) y cómo estas pueden ocasionar cambios en la estructura y composición botánica de la vegetación.

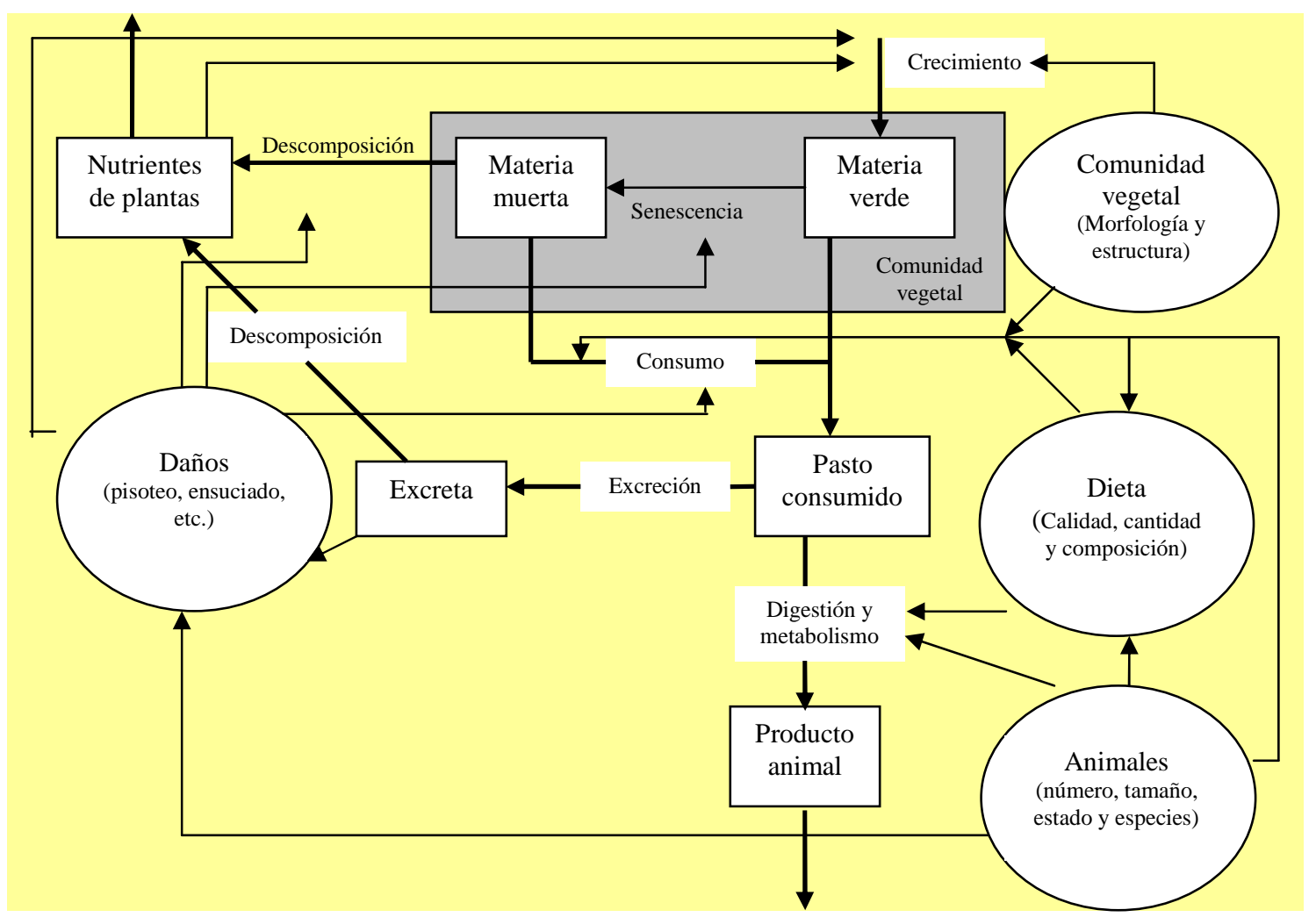

Figura 3.3. Interrelaciones entre planta y animal en los sistemas de pastoreo. Las líneas y flechas en negrita indican los flujos y la partición de la materia a través del sistema; los factores que son alterados por las decisiones del manejo del pastoreo y que influyen en el ritmo de los procesos (crecimiento, consumo, etc.) se inscriben en círculos; las líneas sencillas indican impactos y relaciones (adaptado de Grant y Maxwell, 1988).

En primer lugar, el consumo de material vegetal o defoliación por parte de los animales puede reducir el crecimiento de la planta defoliada y suponer un desvío de recursos para reestablecer los daños producidos. Además, la defoliación puede incrementar la mortalidad por la eliminación de tejidos y por la apertura de heridas susceptibles de ser atacadas por patógenos. Por último, la probabilidad de que se produzca la floración, el número de semillas, el tamaño de la semilla y el número y tamaño de brotes vegetativos 
podrían disminuir por una reducción del crecimiento o por la eliminación de flores y semillas durante el pastoreo (Grant y Maxwell, 1988).

Esta visión negativa de la defoliación sobre la persistencia de las plantas defoliadas no ocurre en muchas especies vegetales adaptadas al pastoreo. Incluso puede ser diferente según la naturaleza y reacción a la defoliación del recurso limitante en el entorno de la planta (Wise y Abrahamson, 2005). Algunas plantas disponen de mecanismos de tolerancia a un rango de intensidades de defoliación que evitan pérdidas en su rendimiento y muchas veces incluso favorecen un crecimiento posterior más elevado (Briske, 1986). Estos mecanismos pueden ser morfológicos, principalmente disponibilidad de meristemos residuales capaces de activarse con condiciones de luz adecuadas o tras la defoliación de los meristemos apicales dominantes, o fisiológicos, como el aumento compensatorio tras la defoliación de las tasas fotosintéticas y de absorción de nutrientes (McNaughton, 1983; Doescher et al., 1997; Meyer, 1998). Por encima de unos rangos de defoliación, específicos para cada planta, esta resistencia por tolerancia desaparece (tabla 3.1).

Tabla 3.1. Efectos negativos del sobrepastoreo versus posibles efectos positivos del pastoreo moderado en la fisiología de los pastos (adaptado de Holechek et al., 2004).

\begin{tabular}{l|l}
\multicolumn{1}{c|}{ Sobrepastoreo } & \multicolumn{1}{|c}{ Pastoreo moderado } \\
\hline $\begin{array}{l}\text { Descenso de la fotosíntesis } \\
\text { Reducción del almacenamiento de glúcidos } \\
\text { Reducción del desarrollo radicular }\end{array}$ & $\begin{array}{l}\text { Aumento de la fotosíntesis } \\
\text { Aumento del ahijado } \\
\text { Reducción de las pérdidas por transpiración } \\
\text { Inoculación con sustancias promotoras del } \\
\text { crecimiento } \\
\text { Reducción de la producción de semillas } \\
\text { muerta que podría física y químicamente inhibir el } \\
\text { crecimiento vegetativo }\end{array}$ \\
$\begin{array}{l}\text { Reducción de la capacidad para competir con } \\
\text { las plantas no pastadas }\end{array}$ & $\begin{array}{l}\text { Reducción de la acumulación de materia } \\
\text { muerta }\end{array}$
\end{tabular}

En este sentido, y a una escala temporal a medio plazo (más de una estación de pastoreo), el concepto de utilización forrajera crítica cuantifica la máxima utilización forrajera (porcentaje del crecimiento del pasto que es consumido por los animales a lo largo de la estación de pastoreo) que no causa degradación del pasto, considerando como tal cambios indeseados en las características del suelo y la vegetación, generalmente asociados con descensos importantes en la productividad del pasto (Rickert, 1996). Este 
concepto se debe aplicar a una escala temporal de varios años y es diferente para cada tipo de pasto, pudiendo existir un gradiente positivo según la disponibilidad de recursos (p.ej. agua) de este (tabla 3.2). Los efectos de un pastoreo intenso y prologando sobre aspectos como la producción y distribución de la biomasa radicular del pasto (Dawson et al., 2000), ayudan a explicar esta relación entre utilización forrajera crítica y disponibilidad de recursos.

Tabla 3.2. Ejemplos de utilización forrajera crítica en diferentes tipos de pastos (adaptado de Holechek et al. [2004] y Rickert [1996]).

\begin{tabular}{l|c}
\multicolumn{1}{c|}{ Tipo de pasto } & Utilización crítica (\%) \\
\hline Pastos semidesérticos (EE.UU.) & $30-40$ \\
Sotobosque de eucaliptal (Australia) & 30 \\
Pradera mixta del Norte (EE.UU.) & $40-50$ \\
Pastos de clima templado (Reino Unido) & $60-90$ \\
\hline
\end{tabular}

En el caso de los pastos de puerto susceptibles de invadirse de lecherina, Busqué et al. (2003) cuantificaron su utilización forrajera dentro del rango de las consideradas críticas en pastos de clima templado (73,4\%; ver tabla 3.2), mientras que la utilización de la lecherina fue prácticamente nula.

La estacionalidad del pastoreo es otro factor importante a considerar, debido a la distinta sensibilidad que pueden mostrar las plantas a la defoliación según su fenología (Kemp, 1999). En general, las plantas son más sensibles a la defoliación durante la germinación, en estado de plántula, cuando se regeneran desde yemas y durante la floración. En la germinación y la regeneración desde yemas, las plantas merman en gran medida sus reservas energéticas. Cuando florecen, su crecimiento vegetativo se paraliza y las reservas son utilizadas para la formación de tallos, flores y frutos. En este sentido, las tasas de rebrote de plantas de lecherina son significativamente menores cuando estas se defoliaron el año precedente al inicio del verano (en floración) que cuando se defoliaron al final del verano (con rebrotes vegetativos) (Busqué et al., 2007b).

Además del efecto de la defoliación, el pastoreo implica otros efectos directos sobre las plantas. La excreción de deyecciones sólidas y líquidas produce perturbaciones puntuales y una distribución heterogénea de nutrientes en el suelo (Steinauer y Collins, 1995), afectando a la distribución espacial de las plantas según su tipo funcional: promueve 
las más cercanas a los tipos ruderales y competidoras (Grime, 1979). Los animales juegan también un papel importante en la dinámica de la vegetación a través de su papel como dispersores exo y endozoócoros de semillas (Fischer et al., 1996; Ramos et al., 2005). Por último, el pisoteo intenso del ganado puede producir efectos negativos sobre el recubrimiento vegetal, derivados de la compactación del terreno y de la destrucción de plantas (Cole, 1995). La combinación de defoliación y pisoteo característica del pastoreo reduce la acumulación de materia muerta en el suelo (Severson y Debano, 1991) y en casos extremos puede llegar a producir un incremento de la cobertura de suelo desnudo y de la evaporación. El resultado es una degradación de la estructura del suelo, favoreciendo la dominancia de las plantas más resistentes a estas condiciones (Archer y Smeins, 1991).

\subsubsection{Estrategias de las plantas de evasión del pastoreo.}

En ciertas comunidades vegetales, el pastoreo no se produce sobre todas las plantas con la misma intensidad. Los casos más notorios de rechazo al pastoreo se producen en plantas con distintos mecanismos de evasión a la defoliación (Briske, 1996).

Dichos mecanismos reducen la probabilidad y severidad del pastoreo (tabla 3.3), incluyendo adaptaciones en su arquitectura para quedar físicamente fuera del alcance de pastoreo de los animales (Noy-Meir et al., 1989), defensas mecánicas (Coley, 1983) o síntesis de compuestos secundarios que pueden producir efectos tóxicos sobre los animales (tabla 3.3), siendo este el caso de la lecherina. 
Tabla 3.3. Mecanismos de evasión de las plantas para resistir el pastoreo (adaptado de Briske, 1996).

\begin{tabular}{|c|c|}
\hline $\begin{array}{c}\text { Grupo de } \\
\text { mecanismos }\end{array}$ & Denominación \\
\hline $\begin{array}{l}\text { Defensas } \\
\text { mecánicas }\end{array}$ & $\begin{array}{l}\text { Estructuras disuasorias (espinas) } \\
\text { Características de la epidermis (pubescencia, ceras, silificación) } \\
\text { Anatomía de la hoja (resistencia al desgarro, nervios vasculares) }\end{array}$ \\
\hline $\begin{array}{l}\text { Asociaciones } \\
\text { defensivas }\end{array}$ & $\begin{array}{l}\text { Simbiosis con microorganismos (productores de mecanismos de evasión) } \\
\text { Asociaciones interespecíficas (expresión diferencial de los mecanismos de evasión } \\
\text { entre especies vegetales) }\end{array}$ \\
\hline $\begin{array}{l}\text { Compuestos } \\
\text { secundarios }\end{array}$ & Compuestos fenólicos, toxinas nitrogenadas, terpenos, oxalatos... \\
\hline $\begin{array}{l}\text { Evasión } \\
\text { espacial }\end{array}$ & $\begin{array}{l}\text { Forma de crecimiento (reemplazamiento de herbáceas altas por herbáceas de porte } \\
\text { bajo para evitar ser pastadas) } \\
\text { Plasticidad arquitectónica (desarrollo de portes postrados o decumbentes en } \\
\text { respuesta al pastoreo intensivo) }\end{array}$ \\
\hline $\begin{array}{l}\text { Evasión en el } \\
\text { tiempo }\end{array}$ & $\begin{array}{l}\text { Crecimiento asíncrono (crecimiento durante las épocas en que la intensidad de } \\
\text { pastoreo es más reducida) } \\
\text { Resistencia asociada al desarrollo de la planta (aumento de la concentración de } \\
\text { glúcidos estructurales y descenso de la de nitrógeno en tejidos maduros) }\end{array}$ \\
\hline
\end{tabular}

Los compuestos denominados "compuestos secundarios" (en contraposición a los productos del metabolismo primario), engloban sustancias de una gran diversidad bioquímica, que en su mayoría protegen a las plantas de los herbívoros a través de un rechazo directo por olores o sabores desagradables, o a través de una aversión postingestiva causada por efectos nocivos en el animal (Provenza, 1995). Entre los grupos más representativos destacan los compuestos fenólicos (taninos, fitoestrógenos y cumarinas), las toxinas nitrogenadas (alcaloides, glicósidos cianogénicos, glucosinolatos, aminoácidos tóxicos, lecitinas e inhibidores de las proteasas), los terpenos (lactosas sesquiterpénicas, glicósidos cardiacos y saponinas) los hidrocarburos poliacetilénicos y los oxalatos (ver revisión de Ramos et al., 1998). En Euphorbia esula se ha descrito la presencia de taninos, diterpenoides como el ingenol, y algunos ésteres de ingenol o de forbol relacionados con el desarrollo de aversiones en el ganado vacuno al consumo de esta planta (Evans y Kinghorn, 1977; Kronberg et al., 1995).

\subsubsection{Dinámica de la vegetación asociada al pastoreo}

Briske (1996) combina los dos mecanismos de resistencia de las plantas al pastoreo (tolerancia y evasión) para proponer un modelo de dinámica de vegetación entre dos tipos funcionales de plantas según el grado de resistencia de dichos mecanismos frente a un 
gradiente en la intensidad de defoliación (figura 3.4). El tipo funcional $A$ tiene un nivel de evasión del pastoreo bajo, pero tolera la defoliación de forma muy eficiente (interfiere débilmente en el rendimiento productivo y reproductivo de la planta) a niveles de pastoreo bajos. El tipo funcional $B$ tiene, por contra, niveles de evasión de pastoreo altos, no es tan eficiente como el tipo $A$ en tolerar la defoliación a niveles bajos de pastoreo, pero mantiene una eficiencia media hasta niveles medios de pastoreo. Con estas características, si la presión de pastoreo aumenta en la comunidad vegetal formada por los tipos funcionales $A$ y $B$, se llegará a un punto (límite de resistencia), donde la resistencia al pastoreo del tipo funcional $A$ se iguala a la del tipo funcional $B$. A partir de este punto, el tipo funcional $B$ crecerá a una tasa mayor que el tipo $A$, por tener entonces una mayor resistencia al pastoreo. En estas condiciones, el tipo funcional $A$, antes dominante, perderá su ventaja competitiva y podrá llegar a extinguirse localmente (O’Connor, 1991). La intensidad de pastoreo a la cual la contribución de los mecanismos de tolerancia es eliminada representa el límite de tolerancia. En este punto, el rebrote de la planta es eliminado por completo debido a las limitaciones fotosintéticas o meristemáticas. La planta podría llegar a morir si la intensidad de pastoreo se mantiene.

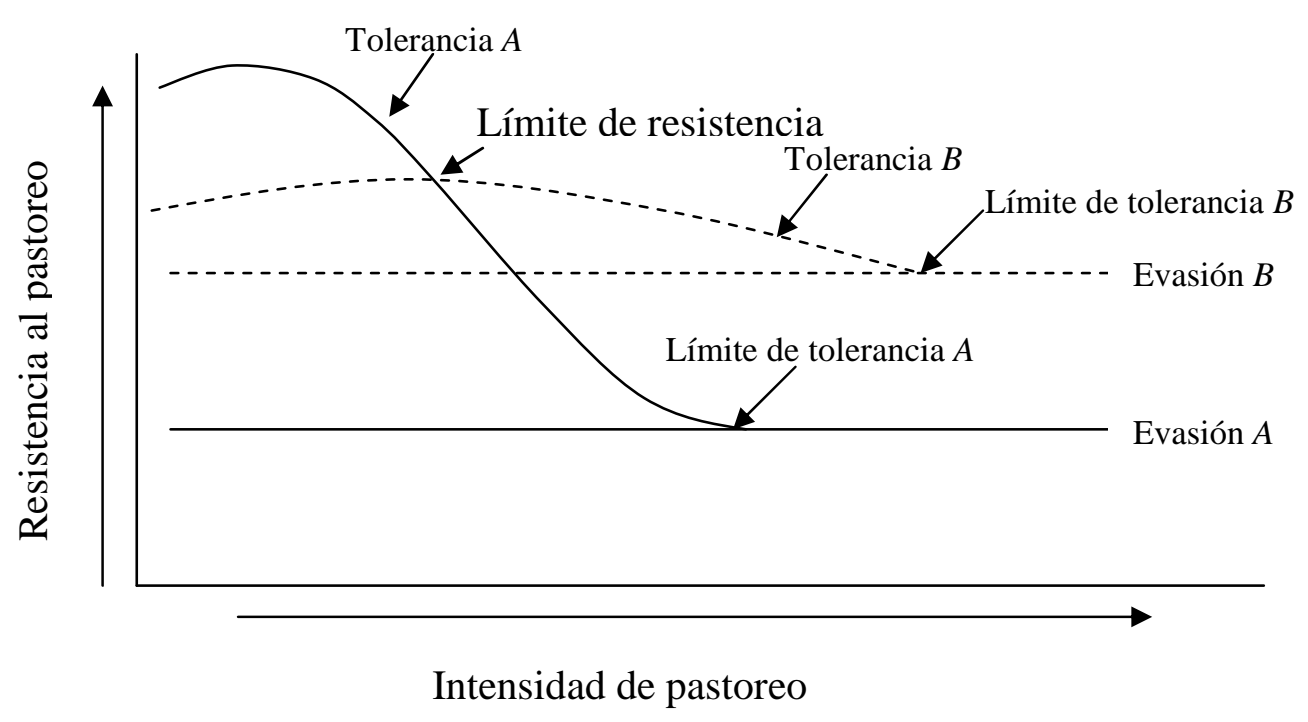

Figura. 3.4. Interpretación funcional de la dinámica de vegetación de pastos herbáceos mesotróficos representados por dos tipos funcionales de plantas: $A$ y $B$ (adaptado de Briske, 1996).

Según Briske (1996), el tipo funcional $A$ se correlaciona bien con los atributos que caracterizan a las plantas de estrategia competidora (C; Grime, 1979). Este autor arguye 
que la inversión en mecanismos de tolerancia al pastoreo es más rentable para el crecimiento que la inversión en mecanismos de evasión, mucho más costoso desde el punto de vista energético y, por tanto, más característica de las plantas con estrategia tolerante al estrés (tipo funcional $B$ de la figura 3.4). Siguiendo esta hipótesis, se concluye que la supresión de los mecanismos de tolerancia en poblaciones dominadas por especies competidoras puede ser uno de los principales procesos que contribuyen al reemplazo de estas especies vegetales en pastos herbáceos mesotróficos (Briske, 1996; Holechek et al., 2004).

Aunque este esquema parece funcionar adecuadamente con grupos de herbáceas presentes en pastos templados (Ansquer et al., 2004), existen otras especies (p.ej. Pteridium aquilinum, Urtica urens) que, estando clasificadas como puramente competidoras (Hodgson et al., 1999), parecen invertir más en mecanismos de evasión al pastoreo que en mecanismos de tolerancia. Euphorbia polygalifolia podría comportarse en parte de esta manera: produciendo compuestos secundarios que creen aversión a su consumo por parte del ganado vacuno y caballar y, a su vez, manteniendo unas tasa de crecimiento elevada (Busqué et al., 2003), característica de las plantas competidoras.

Dentro de la dinámica de la vegetación pastoral, Archer (1996) añade el concepto de dinámica no lineal, frente a los modelos clásicos de clímax y dinámica sucesional en equilibrio (Clements, 1916). Este autor propone un esquema (figura 3.5), donde los cambios en la composición de especies vegetales asociados al pastoreo selectivo conllevan un reemplazo de las plantas herbáceas más apetecibles por plantas leñosas poco apetecibles para el ganado, pasando por un límite de transición crítico, que produce cambios abruptos y no lineales en la vegetación.

Según este modelo, una intensificación del pastoreo alterará la composición herbácea, ya que los animales prefieren pastar ciertas especies (del tipo $A$ de la figura 3.4), que podrían ser relativamente intolerantes a la defoliación. Estas especies acaban siendo reemplazadas por otras menos apetecibles o más resistentes al pastoreo más intensivo (del tipo $B$ de la figura 3.4). Los huecos formados por la muerte de las plantas pastadas, o por un descenso de su recubrimiento, suponen una oportunidad para el establecimiento de otras especies. Si la presión de pastoreo disminuye antes de alcanzar un límite de transición crítico, se podría retornar a la situación de partida (se pasa del dominio del tipo $B$ al tipo A). El ritmo de recuperación dependerá de las condiciones climáticas y de los cambios producidos en la fertilidad y estructura del suelo. Si la intensidad de pastoreo se mantiene, 
la biomasa herbácea podría disminuir, así como la capacidad de las plantas pastadas para excluir competitivamente a otras plantas. El incremento del tamaño y la densidad de las plantas poco apetecibles, ya sean herbáceas o arbustivas, provocan una mayor intensificación de la presión de pastoreo sobre las plantas apetecibles supervivientes. A medida que el establecimiento de las plantas leñosas va siendo mayor, nuevos procesos de sucesión y retroalimentaciones positivas conducen al sistema a un nuevo estado. La reducción de las herbáceas apetecibles y el deterioro de su banco de semillas (se alcanza el límite de tolerancia del tipo funcional A), así como posibles cambios en la estructura y fertilidad del suelo, harán improbable el retorno al predominio de las herbáceas, incluso retirando al ganado. El límite de transición crítico de Archer (figura 3.5) correspondería a una presión de pastoreo equivalente a la utilización forrajera crítica definida por Rickert (1996, ver apartado 3.2.2).

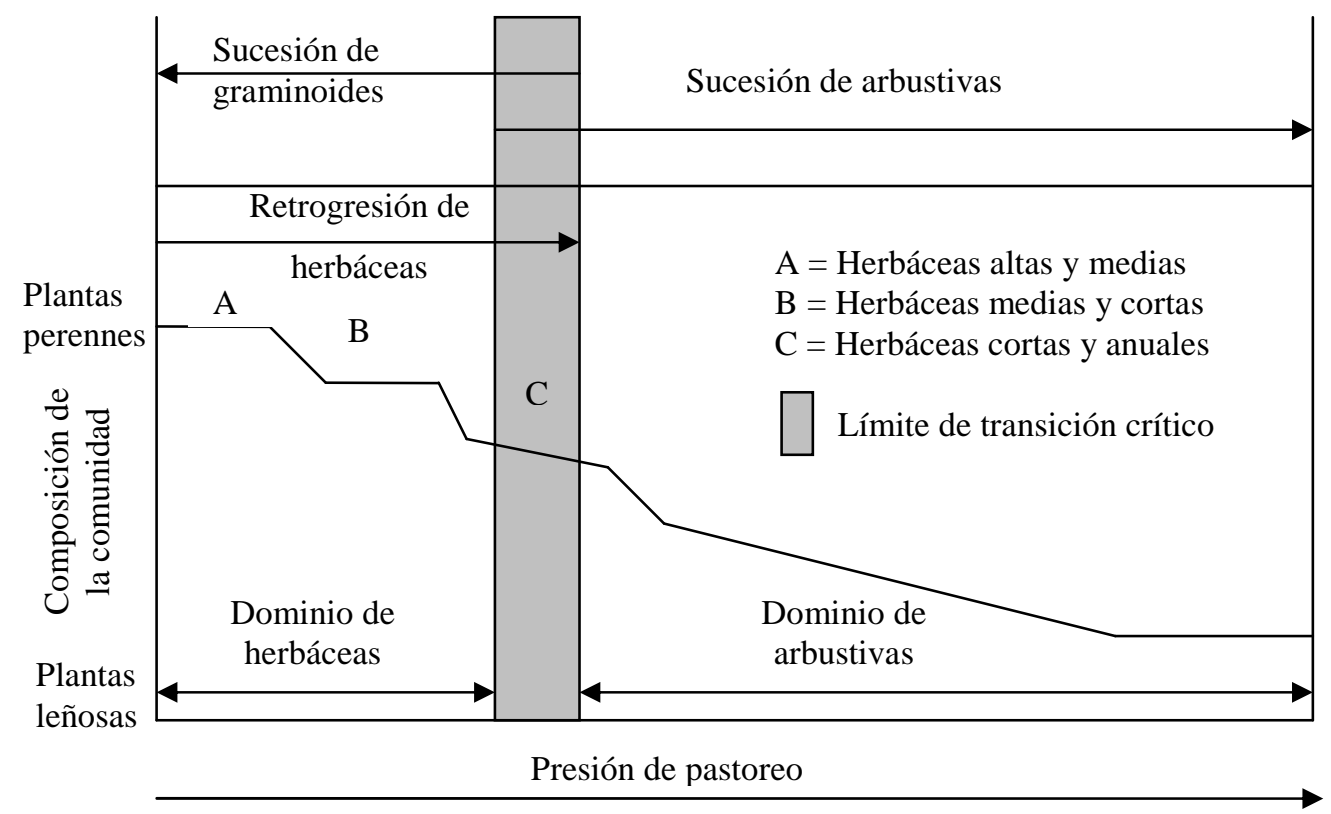

Figura 3.5. Modelo conceptual de la abundancia de plantas herbáceas y leñosas en ecosistemas pastorales (adaptado de Archer, 1996).

Apoyando las teorías anteriores, varios trabajos de invasiones de pasto por especies vegetales poco apetecibles para el ganado, apuntan al sobrepastoreo como principal factor desencadenante. Allen et al. (1991) estudiaron el proceso de invasión de un cactus (Opuntia imbricata) en los pastos del sur de EE.UU. Estos autores sugieren que el sobrepastoreo crea huecos y espacios abiertos en la vegetación aprovechados por las 
semillas y los tallos de Opuntia. En Nueva Zelanda, el sobrepastoreo de sus praderas ha desencadenado procesos invasores de malas hierbas exóticas como Hieracium spp. (Scott et al., 2001). En Australia, Orr et al. (1993), estudiando la dinámica del sotobosque de Acacia aneura en una zona semiárida sometida a un sobrepastoreo por ganado ovino, encontraron un descenso del recubrimiento vegetal asociado a una menor presencia de especies graminoides perennes. Paralelamente, registraron invasiones de malas hierbas como Eremophila gilesii. Otros ejemplos de invasiones asociadas al sobrepastoreo son la de Chuquiraga avellanedae en pastos de Argentina (Beeskow et al., 1995) o de Calotropis procera y Jatropha gossypiifolia en praderas de Cuba (Wezel y Bender, 2004).

Jauffret y Lavorel (2003) también atribuyen un papel prominente al sobrepastoreo en la degradación de pastos áridos de Túnez. Asumen que, como resultado del pastoreo selectivo y la baja aceptabilidad debido a la presencia de grandes espinas (Astragalus armatus) o sustancias tóxicas (Thymelaea hirsuta), estas especies poco palatables empiezan gradualmente a dominar. No obstante, reconocen la dificultad de discriminar entre la respuesta de la vegetación a las perturbaciones derivadas del pastoreo de la derivada del estrés abiótico de la falta de agua y concluyen que ambos factores afectan a la estructura de la vegetación y al funcionamiento del ecosistema en combinación. Otros autores atribuyen un papel más activo a la sequía que al pastoreo en los procesos de degradación de los pastos. En este sentido, Biondini et al. (1998) estudiaron durante 8 años el efecto de un gradiente en la intensidad de pastoreo (no pastoreo; pastoreo moderado: utilización forrajera del 10\%; y pastoreo intenso: utilización forrajera del 50\%) en praderas estadounidenses con precipitaciones medias anuales de unos $450 \mathrm{~mm}$. De cara a los cambios en la producción y composición botánica de los pastos, estos autores atribuyeron un papel principal a las variaciones climáticas, en especial a la sequía, y un papel secundario a la intensidad de pastoreo. A similares conclusiones llegaron Sternberg et al. (2000) en un estudio de cuatro años en pastos herbáceos mediterráneos (Israel), con precipitaciones medias anuales de $570 \mathrm{~mm}$. Teague et al., (2004) estudiaron durante 6 años los efectos de la sequía y la intensidad de pastoreo en Texas (EE.UU.) en praderas con precipitaciones medias anuales de $648 \mathrm{~mm}$. Estos autores encontraron que la climatología tuvo una influencia dominante, teniendo un efecto significativo sobre la cobertura vegetal, la biomasa de todos los grupos funcionales de vegetación considerados y la cantidad de suelo desnudo, e interactuando significativamente con los tratamientos de pastoreo. De este 
trabajo se desprende que los periodos de escasez de lluvias complementan los efectos de los herbívoros, pudiendo provocar periodos de degradación acelerada.

Finalmente, es interesante considerar que la invasión de pastos por una especie no palatable para los herbívoros puede ser un primer paso hacia la colonización de otras especies que necesiten de la protección de la especie no palatable frente a dichos herbívoros para establecerse (Milchunas y Noy-Meir, 2002). En este caso, la especie invasora funciona como facilitadora (Smit et al., 2006) a la colonizadora final. En el caso de los pastos invadidos por lecherina de Sejos, se plantea la hipótesis de que traspasando un umbral de invasión de lecherina, las manchas de pasto invadidas son menos visitadas por el ganado existente (ver escala de hábitat de la tabla 3.4 o de parche de la tabla 3.5), lo cual facilitará el establecimiento dentro de las matas de lecherina de especies leñosas muy sensibles al pastoreo en estado joven como Calluna vulgaris, Genista pilosa y G. florida. Se puede proponer así un proceso completo de dinámica vegetal, donde tras una invasión de los pastos herbáceos de festuca y agrostis por lecherina debida al sobrepastoreo (primera fase), se pasa en una segunda fase a una matorralización posterior por ericáceas y genistas por infrapastoreo (Busqué et al., 2007a). Este proceso de matorralización por sobrepastoreo inicial contrasta con los abundantemente descritos como resultado del abandono o infrapastoreo (García-Ruiz et al., 1996; Molinillo et al., 1997; Luick, 1998; Zervas, 1998; Osoro et al., 2000; Dullinger et al., 2003; Bartolomé et al., 2005; Jewell et al., 2005; Roura-Pascual et al., 2005; Peco et al., 2006; Riedel, 2007), también característicos de la zona estudiada, si bien localizados en las zonas más alejadas y de peor acceso. 


\subsection{Comportamiento del ganado en pastoreo}

\subsubsection{Introducción}

Como se ha mencionado previamente, la invasión de pastos de montaña por lecherina ha coincidido en el tiempo con cambios drásticos en el sistema de manejo del ganado (capítulo 2). La distribución histórica de las zonas de pastoreo entre distintos pastores responsables de las cabañas ganaderas de cada pueblo, permitía un aprovechamiento homogéneo y controlado de los pastos. Sin embargo, en las últimas décadas estos pastores han ido desapareciendo. Actualmente, el ganado pasta libremente a lo largo de la estación de pastoreo y se sabe que, en estas circunstancias, este no se distribuye homogéneamente en los pastos sino que muestra un comportamiento selectivo: rechaza unas zonas y aprovecha otras con distinta intensidad y frecuencia a la esperada por azar.

Otro factor que podría estar implicado como causante del proceso invasor de la lecherina es el cambio producido en las últimas décadas en las especies y razas de ganado que aprovechan los pastos de montaña: la vaca autóctona de raza tudanca ha sido sustituida en gran parte por razas foráneas de mejor aptitud cárnica pero peor adaptadas al medio y, por otra parte, el ganado caballar está experimentando un aumento considerable. Estos cambios podrían estar provocando alteraciones en el aprovechamiento de los pastos favoreciendo la proliferación de lecherina, ya que cada especie de ungulado utiliza las distintas comunidades vegetales disponibles de forma diferente (Gordon, 1989c; Menard et al, 2002), presentando distintos grados de solapamiento en su utilización (Gordon e Illius, 1989).

Los patrones de comportamiento de los grandes herbívoros en pastoreo son regulados por factores abióticos (topografía, existencia de agua, etc.), bióticos (especie animal, calidad del pasto, etc.) y culturales (prácticas aprendidas por las cabañas ganaderas intergeneracionalmente), afectando todos ellos al equilibrio del ecosistema pastoral (Coughenour, 1991; Bailey et al., 1996; Provenza, 2007). En este apartado se describen las distintas escalas utilizables a la hora de estudiar el comportamiento en pastoreo del ganado y se concreta la escala de estudio elegida para nuestro trabajo. A su vez, se revisan distintos factores que influyen en dicho comportamiento y se profundiza en las diferencias entre especies de ganado comparando tanto sus sistemas digestivos como sus patrones temporales y su selección de la dieta en pastoreo. 


\subsubsection{Escalas en el estudio del comportamiento en pastoreo.}

Los grandes herbívoros interactúan con los recursos pastables a varios niveles de resolución ecológica, que, de mayor a menor resolución, serían: la comunidad vegetal, el hábitat y la región (Senft et al., 1987). Para cada escala, estos autores definen sus unidades de selección, la frecuencia de toma de decisiones, los objetivos hipotéticos del pastoreo, así como los factores, tanto interactivos como no interactivos, que influyen en la toma de decisiones del ganado (tabla 3.4).

Tabla 3.4. Jerarquización ecológica del pastoreo de grandes herbívoros (adaptado de Senft et al., 1987).

\begin{tabular}{|c|c|c|c|}
\hline & \multicolumn{3}{|c|}{ Escala de la jerarquía ecológica } \\
\hline $\begin{array}{c}\text { Componente de la } \\
\text { vegetación }\end{array}$ & Comunidad vegetal & Hábitat & Región \\
\hline $\begin{array}{l}\text { Unidades de } \\
\text { selección }\end{array}$ & $\begin{array}{l}\text { Plantas, puntos de } \\
\text { alimentación o } \\
\text { microparches }\end{array}$ & $\begin{array}{l}\text { Comunidades o } \\
\text { grandes parches }\end{array}$ & Hábitat \\
\hline $\begin{array}{c}\text { Comportamiento } \\
\text { en pastoreo }\end{array}$ & Selección de la dieta & $\begin{array}{c}\text { Selección del área de } \\
\text { alimentación }\end{array}$ & $\begin{array}{c}\text { Migración, } \\
\text { nomadismo, } \\
\text { trashumancia, puerto }\end{array}$ \\
\hline $\begin{array}{c}\text { Frecuencia de } \\
\text { comportamiento } \\
\text { (decisiones/año) } \\
\end{array}$ & $10^{7}$ & $10^{4}$ & $1-10$ \\
\hline $\begin{array}{c}\text { Objetivos } \\
\text { hipotéticos del } \\
\text { pastoreo }\end{array}$ & $\begin{array}{c}\text { Maximización de } \\
\text { nutrientes } \\
\text { Minimización de } \\
\text { toxinas } \\
\text { Balance de nutrientes }\end{array}$ & $\begin{array}{c}\text { Optimización de la } \\
\text { eficiencia del pastoreo }\end{array}$ & $\begin{array}{c}\text { Mantenimiento de la } \\
\text { ingestión } \\
\text { Evitar los factores } \\
\text { físicos de estrés }\end{array}$ \\
\hline $\begin{array}{c}\text { Factores } \\
\text { interactivos }\end{array}$ & $\begin{array}{l}\text { Biomasa del pasto } \\
\text { Calidad nutritiva } \\
\text { Morfología vegetal }\end{array}$ & $\begin{array}{l}\text { Biomasa de pasto } \\
\text { Calidad nutritiva }\end{array}$ & Biomasa de pasto \\
\hline $\begin{array}{l}\text { Factores no } \\
\text { interactivos }\end{array}$ & $\begin{array}{c}\text { Variables } \\
\text { microespaciales }\end{array}$ & $\begin{array}{c}\text { Substrato } \\
\text { Topografía } \\
\text { Localización del agua } \\
\text { Microclima }\end{array}$ & $\begin{array}{c}\text { Geomorfología } \\
\text { Clima regional } \\
\text { Barreras físicas } \\
\text { Localización del agua }\end{array}$ \\
\hline
\end{tabular}

Bailey et al. (1996) profundizaron en la delimitación de estas escalas, proponiendo hasta seis niveles de selección en grandes herbívoros atendiendo a la escala espacial en que se manifiestan (tabla 3.5). Para cada nivel, definen unos criterios de selección implicados en la estrategia de pastoreo del ganado (disponibilidad y calidad del pasto, topografía, etc.) y unos mecanismos que podrían afectar a los patrones de distribución del pastoreo (tasa de ingestión, memoria espacial, etc.). Según estos autores, los herbívoros integrarían las 
consecuencias de los niveles de selección de menor escala espacial (bocados, puntos de pastoreo, parches) a la hora de evaluar las alternativas de selección a niveles de mayor escala (sesión de pastoreo, unidad pastoral, zona geográfica de pastoreo), tal y como puede observarse en la tabla.

En este capítulo se van a analizar los factores que afectan al comportamiento en pastoreo de los grandes herbívoros dentro de la escala de selección de hábitat según Senft et al., (1987; tabla 3.4) o de selección de parche o sesión de pastoreo según Bailey et al., (1996; tabla 3.5). La selección a esta escala de detalle intermedia implica diferencias en la intensidad de uso de las distintas comunidades vegetales a las que el ganado tiene acceso y, por ello, podría explicar en parte las causas del proceso de degradación de los pastos que ha conducido a la invasión de lecherina en ciertas comunidades vegetales. Además, podría sentar las bases para implementar medidas de corrección encaminadas a equilibrar la distribución del ganado en estos pastos. 
Tabla 3.5. Atributos de las escalas espaciotemporales que describen el pastoreo de los grandes herbívoros (adaptado de Bailey et al., 1996).

\begin{tabular}{|c|c|c|c|c|}
\hline $\begin{array}{c}\text { Nivel } \\
\text { espacial }\end{array}$ & $\begin{array}{c}\text { Nivel } \\
\text { temporal. } \\
\text { Intervalo } \\
\text { entre } \\
\text { decisiones }\end{array}$ & $\begin{array}{c}\text { Características o } \\
\text { comportamientos } \\
\text { definitorios }\end{array}$ & $\begin{array}{c}\text { Criterios de selección } \\
\text { potencial }\end{array}$ & $\begin{array}{c}\text { Mecanismos } \\
\text { potenciales que } \\
\text { podrían afectar a } \\
\text { los patrones de } \\
\text { distribución del } \\
\text { pastoreo }\end{array}$ \\
\hline Bocado & $\begin{array}{c}1-2 \\
\text { segundos }\end{array}$ & $\begin{array}{c}\text { Movimientos de } \\
\text { labios, lengua y cuello }\end{array}$ & $\begin{array}{c}\text { Concentración de } \\
\text { nutrientes, } \\
\text { concentración de } \\
\text { compuestos } \\
\text { secundarios, tamaño de } \\
\text { la planta }\end{array}$ & $\begin{array}{l}\text { Ritmo de ingestión, } \\
\text { selección de la dieta } \\
\text { y consecuencias } \\
\text { postingestivas }\end{array}$ \\
\hline $\begin{array}{l}\text { Punto de } \\
\text { pastoreo }\end{array}$ & $\begin{array}{c}5-100 \\
\text { segundos }\end{array}$ & $\begin{array}{c}\text { Emplazamiento de las } \\
\text { patas delanteras }\end{array}$ & $\begin{array}{l}\text { Abundancia de pasto, } \\
\text { calidad del pasto, } \\
\text { especies vegetales, } \\
\text { interacciones sociales }\end{array}$ & $\begin{array}{l}\text { Ritmo de tránsito } \\
\text { digestivo, ritmo de } \\
\text { ingestión }\end{array}$ \\
\hline Parche & $\begin{array}{l}1-30 \\
\text { minutos }\end{array}$ & $\begin{array}{l}\text { Reorientación del } \\
\text { animal a una nueva } \\
\text { orientación. Ruptura } \\
\text { en la secuencia de } \\
\text { pastoreo }\end{array}$ & $\begin{array}{l}\text { Abundancia de pasto, } \\
\text { calidad del pasto, } \\
\text { especies vegetales, } \\
\text { interacciones sociales, } \\
\text { topografía }\end{array}$ & $\begin{array}{l}\text { Ritmo de tránsito } \\
\text { digestivo, frecuencia } \\
\text { de retorno, ritmo de } \\
\text { ingestión, teoría de } \\
\text { optimización del } \\
\text { pastoreo, frecuencia } \\
\text { de selección } \\
\text { (memoria espacial) }\end{array}$ \\
\hline $\begin{array}{l}\text { Sesión de } \\
\text { pastoreo }\end{array}$ & 1-4 horas & Sesión de pastoreo & $\begin{array}{l}\text { Topografía, distancia al } \\
\text { agua, calidad del pasto, } \\
\text { abundancia del pasto, } \\
\text { fenología, predación }\end{array}$ & $\begin{array}{c}\text { Frecuencia de } \\
\text { selección (memoria } \\
\text { espacial) }\end{array}$ \\
\hline $\begin{array}{c}\text { Unidad } \\
\text { pastoral }\end{array}$ & 1-4 semanas & $\begin{array}{l}\text { Áreas centrales donde } \\
\text { los animales beben y } \\
\text { descansan entre } \\
\text { sesiones de pastoreo }\end{array}$ & $\begin{array}{l}\text { Disponibilidad de agua, } \\
\text { abundancia de pasto, } \\
\text { fenología, } \\
\text { termorregulación, } \\
\text { competición }\end{array}$ & $\begin{array}{c}\text { Trashumancia, } \\
\text { migración, frecuencia } \\
\text { de selección } \\
\text { (memoria espacial) }\end{array}$ \\
\hline $\begin{array}{l}\text { Zona de } \\
\text { pastoreo }\end{array}$ & $\begin{array}{l}1 \text { mes a } 2 \\
\text { años }\end{array}$ & $\begin{array}{l}\text { Dispersión o } \\
\text { migración }\end{array}$ & $\begin{array}{l}\text { Disponibilidad de agua, } \\
\text { abundancia de pasto, } \\
\text { fenología, competición, } \\
\text { termorregulación }\end{array}$ & $\begin{array}{l}\text { Migración, } \\
\text { dispersión, } \\
\text { trashumancia }\end{array}$ \\
\hline
\end{tabular}




\subsubsection{Factores que afectan al comportamiento en pastoreo.}

\subsubsection{Especie animal}

En este apartado se revisan las diferencias entre especies de herbívoros ungulados que afectan a su comportamiento en pastoreo. Se estudia el ganado vacuno y caballar, mayoritarios en la zona de estudio, tratando de encontrar pistas que contribuyan a explicar el papel de cada uno de estos tipos de ganado en la dinámica de la invasión de los pastos de Sejos por la lecherina. También se trata del ganado ovino, intentando dotar de fundamento científico una posible estrategia de control de la invasión basada en la utilización de esta especie. Inicialmente, se describen las características morfofisiológicas de sus sistemas digestivos, las cuales sirven de base para explicar los patrones temporales de pastoreo y la selección de su dieta revisados posteriormente.

\section{$\underline{\text { Sistemas digestivos }}$}

Entre las distintas especies de herbívoros ungulados, las diferencias morfofisiológicas de sus sistemas digestivos afectan de forma importante a su comportamiento en pastoreo. Hoffman (1988) realizó una clasificación funcional de los rumiantes relacionando estas características digestivas con su capacidad de selección de la dieta en pastoreo, en función de su grado de especialización en consumir herbáceas o forrajes con alto contenido de pared celular (conocidos como "pastoreadores") o consumir alimentos con escaso desarrollo de la pared celular (denominados "ramoneadores") (figura 3.6). Así las vacas, con una morfología bucal poco selectiva, están especializadas en el pastoreo de herbáceas, en tanto que las cabras, ovejas y ciervos, considerados consumidores intermedios entre los clasificados como "pastoreadores" y los "ramoneadores", pueden pastar selectivamente las partes más nutritivas de las especies leñosas (tabla 3.6). 


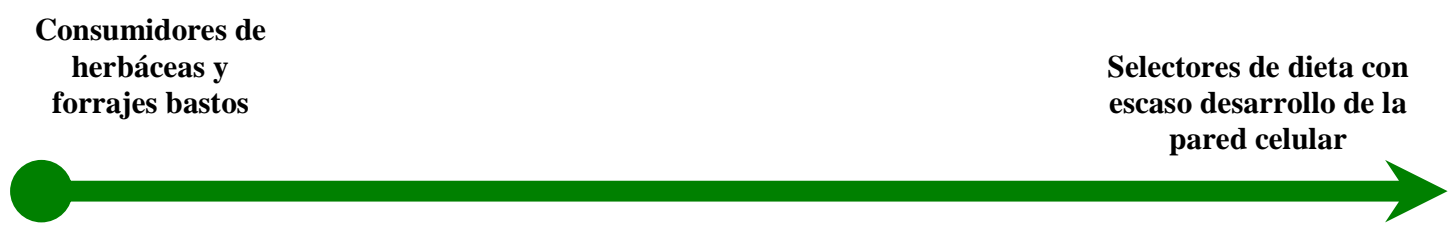

CAPACIDAD DE SELECCIÓN DE LA DIETA

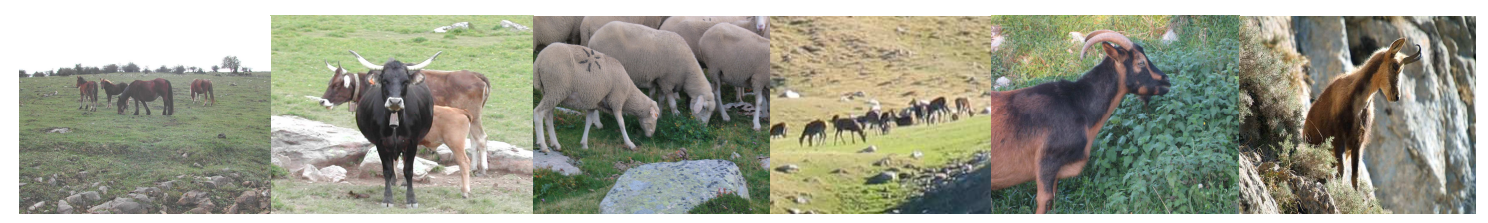

Figura 3.6. Gradiente de la capacidad selectiva de la dieta de distintos herbívoros (adaptado de Hoffman, 1988).

El ganado caballar, no incluido en la clasificación de Hoffman (1988) por no ser un rumiante, se podría clasificar junto con el vacuno como consumidor de herbáceas y forrajes bastos aunque sería aún menos selector. La ingesta del ganado vacuno y caballar (mayoritarios en los puertos de Sejos) en pastoreo se caracteriza por contener cantidades considerables de glúcidos estructurales, celulosas y hemicelulosas en su mayoría. La digestión de estos compuestos de la pared celular y de otros contenidos celulares asociados, depende de la actividad de enzimas microbianos dentro del tracto digestivo de los ungulados, que son capaces de romper los enlaces químicos de estos compuestos estructurales. El vacuno y el caballar han evolucionado, desde un origen común, hacia dos sistemas distintos para posibilitar la acción de sus microorganismos digestivos (Janis, 1976). 
Tabla 3.6. Comparación morfo-fisiológica de los sistemas digestivos de dos tipos extremos de rumiantes: selectores de dietas con escaso desarrollo de la pared celular y consumidores de herbáceas y forrajes bastos (adaptado de Hoffman, 1988).

\begin{tabular}{|c|c|c|c|}
\hline Característica & $\begin{array}{c}\text { Selectores de dietas } \\
\text { con escaso } \\
\text { desarrollo de la } \\
\text { pared celular }\end{array}$ & $\begin{array}{l}\text { Consumidores de } \\
\text { herbáceas y } \\
\text { forrajes bastos }\end{array}$ & Significado \\
\hline $\begin{array}{l}\text { Abertura de la } \\
\text { boca }\end{array}$ & $\begin{array}{l}\text { Estrecha y } \\
\text { puntiaguda }\end{array}$ & Ancha y plana & $\begin{array}{l}\text { Bocas más estrechas y puntiagudas permiten arrancar } \\
\text { pequeñas ramas y mordisquear flores y frutos. }\end{array}$ \\
\hline Labios & Móviles y flexibles & $\begin{array}{l}\text { Gruesos e } \\
\text { inmóviles }\end{array}$ & $\begin{array}{l}\text { Los labios flexibles permiten seleccionar partes de las } \\
\text { plantas en oferta. }\end{array}$ \\
\hline Lengua & Delgada & Gruesa & $\begin{array}{l}\text { La lengua fina ayuda a seleccionar diferentes partes de la } \\
\text { planta. }\end{array}$ \\
\hline $\begin{array}{l}\text { Papilas } \\
\text { gustativas }\end{array}$ & Pocas & Muchas & $\begin{array}{l}\text { El olor es probablemente más importante en la selección } \\
\text { de la dieta de los "selectores" mientras el sabor lo es en el } \\
\text { caso de los "consumidores de herbáceas". }\end{array}$ \\
\hline Dientes & Angulosos & Planos & $\begin{array}{l}\text { Los "selectores" pueden morder el material vegetal, } \\
\text { liberando los contenidos celulares fácilmente } \\
\text { fermentables. Los "consumidores de herbáceas" muelen } \\
\text { el alimento, favoreciendo la digestión de las paredes } \\
\text { celulares de cara a la digestión microbiana en rumen. }\end{array}$ \\
\hline $\begin{array}{l}\text { Músculos de la } \\
\text { mandíbula }\end{array}$ & Poco desarrollados & Muy desarrollados & $\begin{array}{l}\text { Un mayor desarrollo de estos músculos es necesario en el } \\
\text { caso de los "consumidores de herbáceas" para moler la } \\
\text { parte fibrosa de su dieta. }\end{array}$ \\
\hline $\begin{array}{l}\text { Glándulas } \\
\text { salivares }\end{array}$ & Grandes & Pequeñas & $\begin{array}{l}\text { Los "selectores" necesitan más saliva para evitar que se } \\
\text { acidifique el pH del rumen debido a la fermentación de } \\
\text { grandes cantidades de contenidos celulares rápidamente } \\
\text { fermentables relacionado también con el consumo de } \\
\text { compuestos secundarios. }\end{array}$ \\
\hline Rumen & $\begin{array}{l}\text { Sencillo y más } \\
\text { pequeño }\end{array}$ & $\begin{array}{l}\text { Subdividido y más } \\
\text { grande }\end{array}$ & $\begin{array}{l}\text { Un rumen más sencillo permite que el alimento abandone } \\
\text { rápidamente el rumen; esto es una desventaja a la hora de } \\
\text { digerir alimentos con mucha fibra, como la hierba, que } \\
\text { requieren mucho tiempo de fermentación. } \\
\text { Los "consumidores de herbáceas" pueden almacenar } \\
\text { grandes cantidades de alimento en su rumen, lo cual es } \\
\text { una ventaja para fermentar forrajes con mucha fibra. }\end{array}$ \\
\hline $\begin{array}{l}\text { Músculos del } \\
\text { rumen }\end{array}$ & Poco desarrollados & Muy desarrollados & $\begin{array}{l}\text { Músculos del rumen desarrollados permiten manejar } \\
\text { grandes cantidades de alimento en el rumen. }\end{array}$ \\
\hline $\begin{array}{l}\text { Papilas } \\
\text { ruminales }\end{array}$ & $\begin{array}{l}\text { Recubrimiento } \\
\text { completo del rumen }\end{array}$ & $\begin{array}{l}\text { Recubrimiento } \\
\text { incompleto }\end{array}$ & $\begin{array}{l}\text { Un incremento de estas estructuras en los "selectores" } \\
\text { permite que los ácidos producidos durante la } \\
\text { fermentación abandonen rápidamente el rumen ayudando } \\
\text { al control del pH ruminal. }\end{array}$ \\
\hline Omaso & Pequeño & Grande & $\begin{array}{l}\text { Tamaños grandes implican una mayor superficie de } \\
\text { absorción disponible. }\end{array}$ \\
\hline Hígado & Grande & Pequeño & $\begin{array}{l}\text { Un hígado grande permite la utilización más rápida de los } \\
\text { productos de la fermentación ruminal en los "selectores" } \\
\text { y detoxificar mejor las sustancias tóxicas de las plantas } \\
\text { consumidas (compuestos secundarios). }\end{array}$ \\
\hline $\begin{array}{l}\text { Volumen del } \\
\text { intestino grueso }\end{array}$ & Grande & Pequeño & $\begin{array}{l}\text { Mayores volúmenes indican que la fermentación } \\
\text { intestinal es más importante en los "selectores". La parte } \\
\text { menos digestible del material vegetal ingerido que } \\
\text { abandona rápidamente el rumen de los "selectores" sufre } \\
\text { una fermentación adicional en el intestino grueso, } \\
\text { proporcionándoles una fuente de energía suplementaria. }\end{array}$ \\
\hline
\end{tabular}

En el sistema digestivo de los rumiantes, el alimento es disgregado mediante la regurgitación y rumia del bolo alimenticio hasta lograr un tamaño de partícula que facilite la degradación microbiana del alimento en el rumen, antes de su entrada al abomaso. En 
cambio, la degradación microbiana en el caballar ocurre en el ciego, después de que el alimento haya abandonado el estómago y sin que se produzca el proceso de regurgitación. Estas diferencias se traducen en un mayor tiempo de permanencia del alimento en el tracto digestivo y, gracias a ello, en una digestión más completa de los compuestos de la pared celular en el aparato digestivo del vacuno (Janis, 1976; Demment y Van Soest, 1985; Rittenhouse, 1986), independientemente del grado de fibrosidad del forraje (Duncan et al., 1990). En situaciones en las que los recursos pastables son limitados, esta digestión de la fibra más eficiente en los rumiantes les situaría en ventaja competitiva respecto al caballar, ya que necesitan menos alimento para obtener la misma energía (Illius y Gordon, 1992). En cambio, la menor permanencia del alimento en el tracto digestivo del caballar permite una mayor ingestión diaria de alimento por kilogramo de peso metabólico (Cymbaluk, 1990; Menard et al., 2002) en comparación con el vacuno en situaciones de alta disponibilidad de pasto, especialmente cuando este es de baja calidad nutritiva (Menard et al., 2002).

En el caso concreto de la proteína, la formación de proteína microbiana en el rumen, antes de atravesar el abomaso y el intestino delgado, facilita que sea digerida y absorbida en dichos lugares. En cambio, en el caballar la proteína microbiana se forma en el intestino grueso y, por tanto, es más probable que se pierda en las heces, aunque, por el contrario, en esta especie una gran parte de la proteína del alimento es absorbida en el intestino delgado antes de sufrir la fermentación microbiana (Gibbs et al., 1988). Cuando se ha comparado la digestibilidad de la proteína en forrajes para ambas especies (utilizando desde henos de gramíneas con menos de un $10 \%$ de proteína bruta hasta alfalfa deshidratada con más de un $22 \%$ ) se han obtenido valores similares tanto en digestibilidad aparente como en digestibilidad real (Vander Noot y Gilbreath, 1970; Cymbaluk, 1990) o superiores en digestibilidad aparente para el caballar ingiriendo dietas en pastoreo con porcentajes de proteína del 8-10\% (Rittenhouse, 1986).

Las necesidades metabólicas de mantenimiento de los mamíferos aumentan exponencialmente con su peso corporal (PV), siguiendo la relación alométrica $\mathrm{PV}^{0,75}$ (Illius y Gordon, 1987). Por otro lado, el volumen digestivo, muy relacionado con la capacidad digestiva, es una función lineal del peso corporal (Demment y Van Soest, 1985). Un mayor tamaño corporal supone, por tanto, una disminución de la relación gasto metabólico/capacidad digestiva. Además, dado que el tiempo de retención del alimento en el aparato digestivo es proporcional a este ratio, cuanto mayor es el tamaño corporal del 
animal, mayor sería su capacidad para aprovechar eficientemente alimentos de bajo valor nutritivo. Por ello, cuando la calidad de forraje es limitante, mayores tamaños corporales resultarían ventajosos. En cambio, cuando el limitante es la cantidad, animales de pequeño formato (como las ovejas o las cabras) se verían favorecidos, ya que tienen mayor capacidad para cubrir sus necesidades metabólicas de mantenimiento con poco alimento de alta calidad nutritiva (Demment y Van Soest, 1985; Illius y Gordon, 1987).

Tanto el vacuno como el caballar, al contrario que el ovino, se caracterizan por poseer bocas de gran tamaño y con una gran anchura de la arcada incisiva, provocando una escasa selectividad en el consumo de plantas en pastoreo (Hanley, 1982; Gordon e Illius, 1988). El ganado caballar, a diferencia del vacuno, cuenta con incisivos en ambas mandíbulas, lo que le permite aprovechar pastos de escasa altura que el ganado vacuno es incapaz de pastar y que tiene que abandonar en busca de zonas con mayores alturas de pasto (Gordon e Illius, 1989; Menard et al., 2002). Edwards y Hollis (1982) compararon la distribución del pastoreo del ganado vacuno y caballar entre áreas con alta concentración de defecaciones de los equinos y áreas con escasas defecaciones. Estos autores atribuyeron la escasa utilización del vacuno de las áreas no defecadas (sólo el 2\% de las observaciones de ganado vacuno tuvieron lugar en zonas no defecadas) a su incapacidad para pastar en estas zonas donde la vegetación era usualmente inferior a $2 \mathrm{~cm}$. En cambio, el ganado caballar evitó las zonas defecadas y utilizó en gran medida las zonas no defecadas. En este sentido, en un estudio de utilización de la vegetación por ganado vacuno y caballar en una zona de dunas, Lamoot et al. (2005) encontraron que el caballar pastaba indistintamente en zonas con una altura de hierba de menos de $3 \mathrm{~cm}$ y en zonas con alturas entre 3 y $20 \mathrm{~cm}$, mientras que el vacuno utilizaba más las zonas con alturas entre 3 y $20 \mathrm{~cm}$.

\section{Patrones temporales de pastoreo}

En cuanto a los patrones de utilización temporal de la vegetación, varios autores han puesto de manifiesto, para distintos hábitats y razas, que el ganado caballar pasa mucho más tiempo pastando al día que el ganado vacuno (Arnold y Dudzinski, 1978; Pratt et al., 1986; Menard et al., 2002; Lamoot et al., 2005) (ver tabla 3.7). Estacionalmente, y para ambas especies, se ha descrito una relación directa entre el tiempo diario de pastoreo y la disponibilidad de pasto (Pratt et al., 1986; Menard et al., 2002; Lamoot et al., 2005).

Se ha observado que en el ganado vacuno la actividad de pastoreo se centra en dos periodos del día principalmente: un primer pico en las primeras horas de la mañana y un 
segundo, normalmente más intenso, en las horas finales de la tarde (Arnold y Dudzinski, 1978; Mandaluniz, 2003). En cambio, el ganado caballar muestra una menor variación en el tiempo dedicado al pastoreo a lo largo del día (Arnold y Dudzinski, 1978). Pratt et al. (1986) pusieron de manifiesto que el ganado caballar puede pasar una gran parte de las horas nocturnas pastando (entre un $60 \%$ de la noche en verano y un $70 \%$ en primavera), mientras que el ganado vacuno apenas pasta por la noche (valores medios de un $10 \%$ de tiempo nocturno pastando, con máximos en invierno y primavera del 20\%).

En cuanto al número de bocados por minuto, Lamoot et al. (2005) observaron valores similares en ambas especies (29,2 boc/min en vacuno y 31,5 en caballar) en una zona de vegetación dunar de la costa belga. Estos valores fueron significativamente superiores en primavera respecto al invierno en ambas especies (32,7 vs. 21,9 respectivamente en vacuno y 41,2 vs. 27,5 en caballar). Mandaluniz (2003) obtuvo tasas medias en ganado vacuno mayores en verano que en otoño ( 56,0 vs. 48,7 boc/min).

El tamaño del bocado, que junto al tiempo de pastoreo y el número de bocados por unidad de tiempo, determinan la ingestión del ganado (Hodgson, 1990), suele presentar una gran variación como fruto de su estrecha relación con las características del pasto (Mantecón et al., 1998). Esta variable se puede expresar como el producto del volumen del pasto aprehendido por su densidad. Por su parte, el volumen de pasto aprehendido en un bocado es el resultado del producto del área de aprehensión, dependiente principalmente de la especie animal y su estructura morfobucal (Hongo y Akimoto, 2003), por la profundidad (altura) de cada bocado, función fundamentalmente de la altura del pasto (Wade et al., 1989).

En determinados rangos de valores, el tamaño del bocado no es independiente de las otras variables que definen la ingestión forrajera diaria. Bocados más grandes implican una mayor necesidad de tiempo para la masticación y deglución, por lo que desciende el número de bocados por minuto (Hodgson, 1990). A otra escala temporal, mayores valores del tamaño medio del bocado incidirán en menores tiempos de pastoreo diario, al producirse antes el llenado del tracto digestivo o la satisfacción de las necesidades nutritivas del animal. 
Tabla 3.7. Comparación del tiempo dedicado a la actividad de pastoreo por el ganado vacuno y caballar.

(*) No se aportan valores relativos de cada especie y se marca la superioridad del tiempo en pastoreo del caballar en términos absolutos.

\begin{tabular}{|c|c|c|c|c|c|c|c|}
\hline Autores & Hábitat & Época & Tipo de animal & $\begin{array}{c}\text { Tipo de } \\
\text { seguimiento }\end{array}$ & $\begin{array}{c}\text { Tiempo en } \\
\text { pastoreo del } \\
\text { vacuno }(\%)\end{array}$ & $\begin{array}{c}\text { Tiempo en } \\
\text { pastoreo del } \\
\text { caballar }(\%)\end{array}$ & $\begin{array}{c}\text { Diferencia } \\
(\%)\end{array}$ \\
\hline Rittenhouse, 1986 & $\begin{array}{c}\text { Pastos semiáridos en } \\
\text { Colorado }\end{array}$ & $\begin{array}{c}\text { Finales de } \\
\text { primavera a otoño }\end{array}$ & $\begin{array}{c}\text { Vacas y yeguas no } \\
\text { lactantes }\end{array}$ & 24 horas & 43 & 68 & 57 \\
\hline Rittenhouse, 1986 & $\begin{array}{c}\text { Pastos semiáridos en } \\
\text { Colorado } \\
\end{array}$ & $\begin{array}{c}\text { Finales de } \\
\text { primavera a otoño }\end{array}$ & Vacas y yeguas lactantes & 24 horas & 46 & 75 & 63 \\
\hline Pratt et al., 1986 & $\begin{array}{c}\text { Inglaterra, varias } \\
\text { comunidades herbáceas y } \\
\text { leñosas }\end{array}$ & Todo el año & Vacas y ponies & 24 horas & 57 & 75 & 32 \\
\hline Menard et al., 2002 & $\begin{array}{c}\text { Francia, zona de marisma, } \\
\text { clima mediterráneo }\end{array}$ & Verano & $\begin{array}{c}\text { Vacas charolesas, yeguas } \\
\text { locales }\end{array}$ & 24 horas & 36 & 54 & 50 \\
\hline Menard et al., 2002 & $\begin{array}{c}\text { Francia, zona de marisma, } \\
\text { clima mediterráneo }\end{array}$ & Otoño & $\begin{array}{c}\text { Vacas charolesas, yeguas } \\
\text { locales }\end{array}$ & 24 horas & 45 & 68 & 51 \\
\hline Lamoot et al., 2005 & Bélgica, zona de dunas & Todo el año & Vacas y ponies & Horas de luz & 38 & 71 & 87 \\
\hline Lamoot et al., 2005 & Bélgica, zona de dunas & Verano & Vacas y ponies & Horas de luz & 30 & 66 & 120 \\
\hline Duncan, 1983 & $\begin{array}{c}\text { Marismas francesas, clima } \\
\text { mediterráneo }\end{array}$ & Todo el año & Yeguas & 24 horas & & 65 & \\
\hline $\begin{array}{c}\text { Arnold y Dudzinski, } \\
1978 \\
\end{array}$ & - & Invierno & Vacas y yeguas & 24 horas & & +2 horas* & \\
\hline $\begin{array}{c}\text { Arnold y Dudzinski, } \\
1978\end{array}$ & - & Invierno & Vacas y yeguas & 24 horas & & $+6,5$ horas* & \\
\hline Mandaluniz, 2003 & $\begin{array}{c}\text { Puertos de Cordillera } \\
\text { Cantábrica } \\
\end{array}$ & Primavera-otoño & Vacas & Horas de luz & 34 & & \\
\hline
\end{tabular}




\section{$\underline{\text { Selección de la dieta en pastoreo }}$}

Diversos trabajos han puesto de manifiesto que tanto el ganado vacuno como el caballar pastan selectivamente dentro de los hábitats y comunidades vegetales a los que tienen acceso (Hansen et al., 1977; Pratt et al., 1986; Putman et al., 1987; Menard et al., 2002; Loucougaray et al., 2004; Lamoot et al., 2005) y muestran una selección positiva por las comunidades vegetales donde domina el componente herbáceo sobre el arbustivo o leñoso. En este sentido, Hansen et al. (1977) encontraron en Colorado (EE.UU.) que las dietas de caballos y vacas en pastoreo estaban compuestas en más de un $90 \%$ por herbáceas. Pratt et al. (1986) estimaron, dentro de un mosaico de comunidades herbáceas y arbustivas de Inglaterra, un índice de preferencia (modificación del índice de Hunter [1962]; valores entre 0 y +1 indican selección positiva y entre -1 y 0 selección negativa) para las herbáceas que variaba, para el ganado vacuno, entre 0,524 en febrero y 0,843 en agosto. En el caso del caballar, este índice oscilaba entre 0,410 en febrero y 0,755 en marzo. Putman et al. (1987) encontraron que entre un 70 y un $80 \%$ de las observaciones de pastoreo en vacuno y caballar, dependiendo del momento del año, eran realizadas sobre herbáceas. Estos autores señalaron que, en el caso del ganado caballar, esta tendencia se mantuvo en los meses de verano con valores incluso superiores a los del vacuno (80 90\%), pero se debilitó en los meses invernales donde el porcentaje de observaciones sobre herbáceas descendió hasta el 50\%. En un trabajo en Wyoming (EE.UU.) con dos cargas ganaderas distintas de ganado vacuno y caballar, moderada y alta, Krysl et al. (1984) observaron que los caballos pastaban mayoritariamente herbáceas en verano, tanto con cargas altas $(79 \%$ de herbáceas en la dieta) como con cargas moderadas (70\%). Estos valores fueron inferiores en el caso del vacuno, con un 63 y $48 \%$ para cargas altas y moderadas respectivamente. En el invierno tendieron a descender los valores en caballar hasta un $66 \%$ con cargas altas y $60 \%$ con cargas moderadas y a igualarse en el caso del vacuno con un 65 y $66 \%$ respectivamente. Menard et al. (2002) encontraron que un $46 \%$ y un $49 \%$ del tiempo anual de pastoreo en caballar y vacuno, respectivamente, se llevaba a cabo sobre comunidades herbáceas de marisma que representaban menos de un $10 \%$ de la superficie estudiada. Lamoot et al. (2005) cuantificaron una mayor proporción del tiempo de pastoreo en el hábitat herbáceo por el caballar (79\%) que por el vacuno (55\%), si bien ambas especies mostraron una selección positiva hacia estas comunidades a lo largo de todo el año. 
Gordon (1989b) estudió la selección de comunidades vegetales por distintos ungulados en la isla de Rhum (Reino Unido), observando que el ganado vacuno y el caballar se alimentaban principalmente de comunidades mesótrofas de graminoides de alta calidad nutritiva (dominadas por Festuca rubra y Agrostis capillaris). Sin embargo, encontró que el vacuno, a diferencia del caballar, abandonaba estos pastos en invierno para aprovechar comunidades oligótrofas de menor calidad dominadas por Molinia caerulea. El autor sugiere que este patrón de pastoreo podría deberse a que el ganado vacuno es incapaz de utilizar la escasa altura que el pasto mesótrofo posee en esa época del año por no poseer incisivos superiores como el ganado caballar. Este último cubriría en invierno sus altas necesidades de ingestión aumentando el rango de su dieta, es decir, consumiendo otras especies como graminoides mesótrofas y latifoliadas vivas y muertas menos ingeridas en otras épocas del año (Gordon, 1989c). Esta tendencia a la exclusión del vacuno por parte del caballar en comunidades vegetales con pasto de escasa altura también ha sido referida por Pratt et al. (1986).

Por otro lado, Menard et al. (2002) observaron en vacuno y caballar una selección positiva hacia las comunidades herbáceas. No obstante, las vacas ingirieron más trébol y otras dicotiledóneas mientras que el ganado caballar ingirió herbáceas más bastas. Estos autores relacionaron este mayor consumo de latifoliadas en vacuno con su contenido en compuestos secundarios, que podrían tener distintos efectos sobre rumiantes y digestores cecales.

En cuanto a las diferencias en la selección de la dieta en pastoreo entre el ganado vacuno y ovino, Grant et al. (1985) encontraron, en pastos herbáceos de composición florística similar a la de los pastos objeto de nuestro estudio, una mayor selección por parte del ovino tanto de componentes vegetales vivos como de especies latifoliadas. Estos autores atribuyeron estos resultados a las diferencias en la altura a la que los animales pastaban en relación a la localización vertical de cada especie vegetal en el dosel del pasto en función de su porte (mayor profundidad de pastoreo del ovino), así como a la mayor capacidad del ovino para seleccionar las plantas y partes de plantas integrantes de cada bocado. Así mismo, otros autores han detectado diferencias importantes a favor del ovino en la selección de especies latifoliadas que contienen distintos tipos de compuestos secundarios para defenderse del pastoreo (Cheeke, 1988; Ralphs et al., 1991), relacionando estos resultados con diferencias en los sistemas hepáticos y ruminales de destoxificación. Los animales considerados como "pastoreadores" (consumidores básicamente de 
herbáceas), como sería el vacuno, apenas habrían tenido necesidad de desarrollar sus sistemas de destoxificación, debido a la escasa presencia de defensas químicas en las plantas que generalmente han constituido sus dietas. Por el contrario, los "ramoneadores" o los consumidores de dietas mixtas, como el ovino, se habrían visto obligados a invertir más recursos en el perfeccionamiento de sus sistemas de destoxificación a lo largo de su evolución (Cheeke y Palo, 1995).

Otra diferencia entre vacuno y ovino, que merece la pena señalar, radicaría en el patrón de selección de cervuno (Nardus stricta), gramínea ampliamente extendida en nuestra zona de estudio. Osoro et al. (2000), estudiando también pastos de FestucaAgrostis de la Cordillera Cantábrica, observaron que a medida que disminuía la disponibilidad de herbáceas apetecibles, el ganado vacuno incrementaba considerablemente la ingestión de Nardus, mientras que el ganado ovino apenas incorporaba dicho componente en su ingesta.

En cuanto a la utilización de comunidades arbustivas y arbóreas, los datos bibliográficos muestran en muchos casos la existencia de interacciones entre la especie animal y la estación del año. Putman et al. (1987) encontraron porcentajes de componentes arbustivos y leñosos de hasta un 50\% en la dieta invernal del ganado caballar, destacando la presencia de Ulex spp., Pteridium aquilinum, Calluna vulgaris y, sobre todo, hojas de árboles. En el ganado vacuno, que recibió suplementación forrajera durante el invierno, no se encontraron porcentajes superiores al $30 \%$ en ningún mes del año, siendo Calluna vulgaris el principal componente arbustivo de su dieta. En los meses de verano estos valores descendieron para ambas especies, pero más acusadamente en caballar, tendiendo a igualarse en un 15\% para ambas especies. En cambio, Menard et al. (2002) encontraron mayor presencia de arbustivas en la dieta del vacuno (principalmente Phillyrea angustifolia). Estos autores llegaron a contabilizar un $21 \%$ de los bocados en pastoreo del ganado vacuno sobre especies arbustivas en los meses de otoño, mientras este porcentaje fue prácticamente nulo en el caballar. Esta misma tendencia fue observada por Lamoot et al. (2005), con unas proporciones del tiempo en pastoreo del ganado caballar en comunidades arbustivas y leñosas del $21 \%$, frente al $45 \%$ en el caso del vacuno. En ambientes de alta montaña en los Pirineos, similares a los de nuestro trabajo, Aldezabal (2001) apenas encontró componentes leñosos en la dieta de yeguas y vacas (proporción en la dieta inferior al $1 \%$ y rechazo casi total). 
El solapamiento de dietas en vacas y yeguas que comparten ecosistemas pastorales es, en general, alto. Menard et al. (2002) estiman solapamientos que varían desde el 58\% en invierno hasta el $77 \%$ en primavera. Krysl et al. (1984) estimaron en verano un alto solapamiento en las dietas tanto con cargas moderadas (promedio del 71\%) como con cargas altas (promedio del 73\%). En el invierno, los solapamientos fueron aún mayores, con un promedio del $78 \%$ con cargas altas y $86 \%$ con cargas moderadas. Salter y Hudson (1980) compararon las dietas de vacas y caballos en una zona cercana a las Montañas Rocosas y encontraron solapamientos cercanos al 70\% para el periodo estival estudiado. En el caso de solapamiento de hábitats utilizados, Lamoot et al. (2005) encontraron valores de alrededor del $80 \%$ a lo largo del año.

Gordon e Illius (1989) sugieren que durante el verano, que es cuando los recursos pastables en la isla de Rhum son elevados en calidad y cantidad, el solapamiento se incrementa entre las especies que pastan en la zona (ciervos, vacas y ponis), ya que todas ellas aprovechan las comunidades vegetales con elevada disponibilidad de material vegetal vivo de alta digestibilidad. En invierno, cuando los recursos pastables son menos abundantes y digestibles, se reduce el solapamiento entre especies, ya que estas seleccionan diferentes comunidades vegetales. Sólo la especie dominante, en este caso el ciervo, sigue teniendo acceso a los recursos preferidos por todas las especies en verano (comunidades de graminoides mesótrofas vivas), mientras que las otras especies se ven obligadas a aprovechar otros recursos. Los ponis utilizan mayoritariamente graminoides mesotrófas tanto vivas como muertas y el ganado vacuno aprovecha las comunidades más pobres y menos digestibles de graminoides oligótrofas.

Duncan (1983) estudió los factores que podían estar implicados en la distribución del ganado caballar en una zona marismeña de Francia y sugiere que el único buen estimador de la preferencia de hábitat para el pastoreo es la abundancia de alimento. Los caballos preferían pastar en áreas de pasto de alta calidad (material vegetal vivo) siempre que hubiera una disponibilidad razonable $\left(>90 \mathrm{~g} / \mathrm{m}^{2}\right)$. Al igual que Gordon e Illius (1989) en la isla de Rhum, encontró que cuando la materia verde empezaba a escasear, al final del invierno, la táctica del caballar era buscar áreas con presencia abundante de plantas perennes herbáceas, verdes o muertas.

\subsubsection{Raza}

Los limitantes ambientales con los que se ha enfrentado cada raza de ganado pueden haber condicionado la evolución de sus características morfofisiológicas, 
determinando, a su vez, su comportamiento en pastoreo. Revesado (1994) encontró diferencias significativas en la selección de la dieta entre dos razas de ganado ovino, churra y merina, que fueron relacionadas con el distinto manejo a que cada raza se ha visto sometida a lo largo de la historia. Osoro et al. (1999), en un estudio sobre las características de la ingestión de dos razas ovinas, gallega y lacha, asocian el menor tamaño corporal de la raza gallega con una mayor capacidad para aprovechar los recursos de las zonas pobres donde la disponibilidad de especies apetecibles es baja. Otro trabajo, en este caso con ganado caprino, permitió encontrar diferencias significativas en el consumo de enebro (Juniperus pinchotii) entre dos razas, angora y española (Pritz et al., 1997).

En el ganado vacuno, Herbel y Nelson (1966) encontraron diferencias entre razas (hereford y Santa Gertrudis) en el tiempo de desplazamiento y las distancias viajadas durante la jornada de pastoreo. La Santa Gertrudis pasó cerca del doble de tiempo andando que la hereford, lo cual se justificaría por la mayor tolerancia al calor de esta raza en comparación con las de origen europeo como la hereford. Siguiendo esta línea, Bailey et al. (2001) compararon el comportamiento en pastoreo entre las razas tarentaise y hereford. Las vacas de raza tarentaise fueron observadas a mayor distancia vertical de los puntos de agua y pastaron en zonas con pendientes más fuertes que las vacas hereford. En este estudio, los animales de raza tarentaise podrían haber estado más adaptados al pastoreo en pendiente ya que son originarias de los Alpes franceses, mientras que las hereford se desarrollaron en zonas menos abruptas de Inglaterra.

En cambio, otros trabajos no han encontrado grandes diferencias entre razas respecto al tiempo diario en pastoreo (Arnold y Dudzinski, 1978) o la selección de la dieta (Walker et al., 1981; García-González et al., 1992). No obstante, hay que tener en cuenta que en estos últimos trabajos se compararon razas que provenían de ecosistemas con mayor parecido entre sí.

\subsubsection{Variabilidad individual.}

Howery et al. (1996) observaron una alta variabilidad al estudiar la utilización por distintas vacas de un mismo rebaño sobre ciertos hábitats (principalmente zonas riparias y zonas elevadas), con lo cual sugieren que una selección de los animales que menos utilizan las áreas riparias podría servir para mejorar la distribución del ganado y evitar el 
sobrepastoreo de estas zonas más frágiles. Asimismo, Bailey et al. (2004) distinguieron dentro de un mismo rebaño en pastoreo dos tipos de vacas según su utilización del territorio: vacas "escaladoras", que aprovechaban en mayor medida las zonas más altas y pendientes, y vacas de fondo de valle, con una proporción de su tiempo significativamente superior en las zonas más bajas y de menor pendiente.

Factores como la edad del animal, su estado fisiológico y condición corporal pueden influir en la variabilidad individual del comportamiento en pastoreo (Arnold y Dudzinski, 1978). En concreto, estos autores refieren datos del tiempo diario en pastoreo de ovejas que son menores en animales jóvenes respecto a los adultos, en ovejas secas que en aquellas que se encuentran en lactación y en ovejas gordas frente a individuos delgados.

\subsubsection{Aprendizaje postingestivo.}

Respecto al comportamiento de las distintas especies de ungulados en la selección en pastoreo de la lecherina, se ha observado un rechazo total en el caballar y casi total en el vacuno. Por contra, las ovejas consumen lecherina de forma notable, sobre todo cuando la altura del pasto herbáceo disponible entre matas de lecherina es baja (Mora et al., 2007a). Asimismo, se ha observado que los ciervos (principal ungulado salvaje presente en los puertos afectados por la invasión de E. polygalifolia) también consumen lecherina de forma apreciable (datos sin publicar). En la selección de la dieta en pastoreo en un ecosistema heterogéneo, además de la disponibilidad de nutrientes (Hunter, 1962; Senft et al., 1985), los herbívoros se guían por otros factores relacionados con procesos de aprendizaje, forjados sobre la base de las consecuencias experimentadas tras la ingestión del alimento. Este aprendizaje permite a los animales seleccionar la vegetación de acuerdo con sus necesidades y limitaciones específicas cuando tienen a su disposición pastos no sólo con distintas concentraciones de nutrientes sino también con distintas concentraciones de toxinas (Provenza, 1995). La importancia del aprendizaje a partir de las consecuencias postingestivas en la selección de la dieta ha sido demostrada en numerosas especies animales (Provenza et al., 1992). Los animales muestrean el alimento y son capaces de asociar su sabor con las consecuencias postingestivas experimentadas: si dichas consecuencias son positivas se incrementará su ingestión mientras que si son negativas, puede crearse una aversión hacia el alimento y reducirse la ingestión (Provenza, 1996; Frutos et al., 1998). Los animales utilizan su experiencia para mostrar un comportamiento selectivo también en pastoreo, eligiendo unas especies vegetales sobre otras (Provenza y 
Balph, 1987; Duncan et al., 2000). No obstante, es importante tener en cuenta que la preferencia es relativa y depende de las elecciones disponibles, no existiendo límites concretos entre preferencias y aversiones (Frutos et al., 2001). En el caso de la lecherina, una vez que la disponibilidad de pasto no invadido en la zona desciende a valores muy bajos, las vacas y yeguas prefieren abandonar los puertos donde se encuentra la invasión en busca de otros puertos más bajos, antes que pastar las zonas de pasto invadidas (aunque las yeguas abandonan más tarde que las vacas) (Busqué et al., 2006).

El rechazo del ganado vacuno hacia la Euphorbia esula, pese a su elevada disponibilidad y aparente valor nutritivo (Roberts y Olson, 1999), ha sido relacionado con la presencia de compuestos secundarios potencialmente tóxicos, principalmente diterpenoides, que provocarían el desarrollo de una aversión condicionada hacia el consumo de esta especie (Kronberg et al., 1993; Kronberg et al., 1995; Halaweish et al., 2002). Por contra, las ovejas (Landgraf et al., 1984) y cabras (Kirby et al., 1997) consumen E. esula sin sufrir sus consecuencias tóxicas. En el caso de E. polygalifolia, las consecuencias negativas derivadas de su posible contenido de compuestos secundarios podrían ser las responsables de la aversión que experimentan ambas especies a su consumo. En cambio, el hecho de que las ovejas no desarrollen una aversión condicionada hacia la Euphorbia esula (Landgraf et al., 1984), permite especular que este tipo de ganado podría ser también menos susceptible a los compuestos secundarios de la lecherina.

Se sabe que los compuestos secundarios pueden jugar un papel muy importante en la selección de la dieta de las diferentes especies de rumiantes (Frutos et al., 2001). Así, las diferencias en la susceptibilidad a la presencia de compuestos secundarios en estas especies animales podrían ser consideradas como un reflejo de la estrategia de alimentación y la naturaleza de la dieta con la que ha evolucionado cada especie, traduciéndose en un mayor o menor desarrollo de sus sistemas de destoxificación (Cheeke y Palo, 1995). El rumen posee una considerable capacidad destoxificadora (Carlson y Breeze, 1984; Smith, 1992; Domínguez-Bello, 1996) de modo que la microbiota ruminal de especies diferentes puede presentar distinta capacidad para degradar los compuestos secundarios de las plantas que ingieren en sus dietas (Wachenheim et al., 1992; Duncan et al., 1997). En este sentido, Kronberg y Walker (1993) indicaron que las diferencias observadas en el comportamiento ingestivo de cabras y ovejas ante un pasto invadido por Euphorbia esula podrían ser causadas por diferencias interespecíficas en la actividad ruminal. Además, las comunidades microbianas pueden cambiar dependiendo de los sustratos disponibles (Van Soest, 1994) y 
con la exposición prolongada y creciente a compuestos potencialmente negativos, permitiendo a los rumiantes incrementar su tolerancia a algunas plantas inicialmente tóxicas (Freeland y Janzen, 1974; Smith, 1992).

\subsubsection{Factores sociales: actuaciones humanas, aprendizaje social y competencia del ganado.}

El ganadero tiene la posibilidad de modificar la distribución espacial de su rebaño en el pasto ya sea directamente, conduciendo al ganado a una zona determinada o vallando la zona de pastos que se desea aprovechar, o indirectamente mediante la disposición en puntos estratégicos de suplementos de sal o melazas que actúan como focos de atracción para el ganado (Montserrat, 1978). La disposición de suplementos a base de melazas junto a bloques de sal incrementa significativamente la utilización del pasto cercano por el ganado vacuno durante los meses de otoño e invierno (Bailey y Welling, 1999). A su vez, Bailey et al. (2001) comprobaron que el uso de suplementos de melazas como atrayente del ganado vacuno también es efectivo en los meses de verano, cifrando en unos 600 metros la distancia influida en cuanto a la utilización del pasto. Además, comprobaron que la utilización del forraje era menor $(\mathrm{P}<0,01)$ conforme aumentaba la distancia al suplemento. El uso de suplementos se está empleando también en un intento de enseñar al ganado vacuno a ingerir especies invasoras como E. esula (Voth, 2007). En nuestra zona de estudio, la utilización de suplementos de sal o melazas con estos objetivos es bastante excepcional y la modificación directa de la distribución del ganado de produce sólo puntualmente y se limita a evitar que el ganado sobrepase los límites del puerto.

Aparte del control del ganadero, dentro del propio rebaño existe un aprendizaje social que engloba los conocimientos adquiridos por un animal joven imitando el comportamiento de su propia madre, de otras madres o de otros animales coetáneos del mismo rebaño. Esta organización social del rebaño, muy similar a la de los herbívoros ungulados silvestres, mantiene y transmite una cultura necesaria para sobrevivir en ese ambiente (Provenza, 2007). Distintos autores han sugerido que la transmisión de información sobre aspectos como la localización del alimento, los puntos de abrevada, los refugios naturales, etc., condiciona de forma importante el posterior comportamiento en pastoreo de la recría (Provenza y Balph, 1987; Lawrence, 1990; Ralphs et al., 1994; Busqué et al., 2008). Este aprendizaje, si se facilita, es en general más eficiente para el animal que el adquirido por el proceso de prueba y error a través de la evaluación de las 
consecuencias post-ingestivas (Provenza, 2007). Howery et al. (1998), en un área grande de pastoreo, encontraron una dependencia significativa entre el lugar donde se criaron los animales y la zona en la que permanecieron posteriormente a lo largo de su vida. En concreto, la recría concentró sus actividades dentro de un radio de $1 \mathrm{~km}$ del centro de localización de sus madres. La persistencia en el tiempo de esta dependencia inicial en el comportamiento de la recría se vio afectada significativamente por otras influencias sociales (como el comportamiento de otros animales coetáneos) y por factores ambientales como la ocurrencia de sequías.

Otro factor social que puede afectar al comportamiento del ganado en pastoreo es la interacción entre rebaños que pastan en una misma zona, principalmente a nivel de especie y de raza. Arnold y Dudzinski (1978) describen la existencia de una clara dominancia del ganado caballar sobre el vacuno que se manifiesta con comportamientos agresivos de las yeguas hacia las vacas que se cruzan en su camino. No obstante, este comportamiento excluyente entre ambos tipos de ganado no siempre se produce, de forma que ambas especies de ganado pueden compartir habitualmente zonas de pastoreo y de descanso. En otro estudio, Wagnon et al. (1966; citado por Arnold y Dudzinski, 1978) señalaron la existencia de diferencias raciales en la dominancia social en rebaños compuestos por ganado vacuno de razas angus, shorthorn y hereford. Las vacas angus resultaron ser las más dominantes y las hereford las que menos. En este estudio se halló, dentro de cada raza, una relación positiva entre dominancia social y tamaño corporal.

\subsubsection{Vegetación: disponibilidad, valor nutritivo y estructura.}

Diversos trabajos han puesto de manifiesto que las características propias del pasto, como la biomasa disponible, el valor nutritivo o su estructura, influyen de forma importante sobre la distribución del ganado en pastoreo (Gillen et al., 1984; Gillen et al., 1985; Smith et al., 1992; Parsons et al., 2003). Se sabe que el ganado puede memorizar la localización de lugares con distinta disponibilidad de alimento (Bailey et al., 1989) y que puede asociar la calidad del alimento con su localización espacial (Bailey y Sims, 1998) utilizando esa información posteriormente en el proceso de toma de decisiones en pastoreo.

Pinchak et al. (1991) sugirieron que la distribución del ganado vacuno en pastoreo estaría en primer lugar limitada por la localización de los puntos de agua y por la complejidad de la topografía. Posteriormente, en un segundo proceso de selección, el 
ganado vacuno aprovecharía las distintas comunidades vegetales disponibles en cada zona en función de las características intrínsecas del pasto. En este sentido, Van Rees y Hutson (1983) vieron que, en los casos en los que la distancia a los puntos de agua y las condiciones topográficas no son limitantes, la selección de las áreas de pastoreo depende principalmente de la disponibilidad de plantas apetecibles para el ganado.

En un trabajo con ganado caballar, Duncan (1983) observó que la abundancia de alimento fue la mejor variable indicadora de sus preferencias de hábitat para las actividades de pastoreo. Los caballos prefirieron las áreas con mayores concentraciones de alimento de alta calidad (materia verde), siempre que, como ya se señaló anteriormente, cuenten con una disponibilidad de pasto considerable (mayor de $90 \mathrm{~g} / \mathrm{m}^{2}$ ).

En el caso del ganado vacuno, Senft et al. (1985) encontraron cuatro variables indicadoras de la selección de las comunidades vegetales y relacionadas con la disponibilidad y el valor nutritivo del pasto. La cantidad de nitrógeno por metro cuadrado de las especies vegetales preferidas por el ganado fue la variable más correlacionada $(r=$ 0,745; $\mathrm{P}<0,001)$. La segunda variable con mayor índice de correlación fue la biomasa de las especies preferidas, seguida de la cantidad de nitrógeno en la materia verde total por metro cuadrado y de la biomasa de la materia verde total. De estos resultados se desprende que tanto la cantidad como la calidad del pasto son importantes en la selección de las comunidades vegetales que realiza el ganado vacuno en pastoreo, existiendo adicionalmente una selección más fina orientada a las mismas características (calidadcantidad) pero de las especies más apetecibles existentes en el pasto.

Por el contrario, Owens et al. (1991) encontraron una relación negativa entre disponibilidad de materia verde y utilización del pasto por el ganado vacuno, debida a la alta densidad presente de la dicotiledónea anual Xanthocephalum texanum, poco apetecible para el ganado. En este mismo trabajo, se observó también un descenso en la utilización de graminoides asociado a un aumento de la presencia de arbustivas (Prosopis glandulosa, Acacia tortuosa, Acacia greggii y Celtis pallida) que actuaron como barrera física al consumo de las primeras.

En el caso de los pastos de Sejos invadidos por E. polygalifolia se produce un proceso similar. La lecherina, rechazada por el ganado, protege de su consumo por el ganado a otras especies de alto valor nutritivo presentes entre sus matas. Así, se observa 
una acumulación de biomasa forrajera de plantas apetecibles dentro de las matas de lecherina muy superior a la existente entre matas de lecherina (Busqué et al., 2003).

\subsubsection{Distancia a puntos de agua.}

La distribución de puntos de abrevada también condiciona la utilización por el ganado de los pastos adyacentes. Diversos trabajos han demostrado la existencia de una relación negativa entre la utilización del pasto y la distancia a los puntos de agua, concentrándose el ganado en las zonas próximas a los lugares de abrevada (Cook, 1966; Arnold y Dudzinski, 1978; Roath y Krueger, 1982; Gillen et al., 1984; Irving et al., 1995). La importancia del agua como factor limitante de la distribución del ganado en pastoreo es mayor en climas semiáridos o áridos (Arnold y Dudzinski, 1978), o en años secos (Roath y Krueger, 1982). Para estos últimos autores, la localización del agua, junto con las características de la vegetación, fueron los parámetros más importantes en la determinación del grado de utilización de los pastos. Gillen et al. (1984) encontraron, en pastos de montaña en Estados Unidos, que el ganado vacuno prefería áreas localizadas a menos de $200 \mathrm{~m}$ del agua y evitaba las zonas alejadas a más de $600 \mathrm{~m}$. Irving et al. (1995) evaluaron la utilización de los pastos por el ganado vacuno en un gradiente de distancias desde un punto de agua hasta una distancia de $3 \mathrm{~km}$. La utilización final no descendió significativamente hasta aproximarse a la máxima distancia. No obstante, existieron patrones de utilización temporal que podrían ser descritos como una ola, con la defoliación empezando cercana a las fuentes de agua en el día 1 de pastoreo y alejándose hasta el final de los pastos en el quinto y último día de de prueba. Por otro lado, cuando Cook (1966) estudió la interacción entre la distancia al agua y la pendiente del terreno encontró que, conforme el porcentaje de pendiente disminuía, la distancia al agua se mostraba como un factor más significativo en la utilización de los pastos.

\subsubsection{Pendiente del terreno}

La pendiente del terreno puede llegar a dificultar los desplazamientos del ganado en pastoreo, en especial para especies de gran tamaño corporal como el vacuno y el caballar. En el caso del vacuno, Mueggler (1965) encontró que, con una pendiente del 10\%, la utilización del pasto tuvo lugar dentro de una distancia de 890 metros desde el inicio de la pendiente, mientras que con una pendiente del $60 \%$, el $75 \%$ de la utilización se concentró 
en tan solo 38 metros. Estos resultados ponen de manifiesto cómo pendientes severas pueden provocar que el ganado se mueva menos, disminuyendo su área de pastoreo. Gillen et al. (1984) mostró la existencia de una relación inversa entre pendiente y preferencia para el pastoreo por el ganado vacuno siendo este el factor abiótico más determinante para explicar su utilización del pasto. Cook (1966) también estudió el efecto de otras variables relacionadas con la pendiente del terreno, como la pendiente media general, la pendiente de la zona adyacente al punto de agua o el porcentaje máximo de pendiente entre la posición del ganado y el agua. Este autor incide en que una medida sencilla no es adecuada para evaluar la influencia de la pendiente sobre la utilización del pasto. En todo caso, a la hora de interpretar la utilización de pastos con distintas pendientes, habría que tener en cuenta, además de lo mencionado anteriormente, el mayor gasto energético del ganado al moverse en terrenos en pendiente (Lachica et al., 1997; 1999), así como las relaciones entre pendiente y productividad del pasto.

\subsubsection{Variables meteorológicas}

Otras variables que influyen en el comportamiento en pastoreo del ganado son las meteorológicas. Así por ejemplo, el ganado tiende a utilizar, en especial en días de altas temperaturas, las zonas de pasto más altas y más expuestas al viento, donde es más fácil lograr una adecuada termorregulación y escapar de los insectos picadores (Arnold y Dudzinski, 1978; Aldezabal et al., 1999). En este sentido, Duncan (1983) describe cómo el ganado caballar responde de forma diferente al viento dominante en el invierno respecto al verano: en invierno los animales se orientan en el sentido del viento para proteger la parte de su cuerpo más sensible al frío, la cabeza. En verano, en cambio, se orientan contra el viento para proteger sus cabezas de las picaduras de los insectos.

Variables como el tiempo diario dedicado a pastar pueden verse afectadas por las condiciones de temperatura (Arnold y Dudzinski, 1978). En concreto, en pruebas con un rango de temperaturas de -24 a $5^{\circ} \mathrm{C}$ el tiempo diario de pastoreo del vacuno aumentó con la temperatura (Malechek y Smith, 1976) mientras en otra prueba con altas temperaturas y humedades relativas, el tiempo dedicado a pastar descendió por encima de $\operatorname{los} 26^{\circ} \mathrm{C}$ (Seath y Miller, 1946).

En cuanto a la selección de las zonas de pastoreo a pequeña escala en función de su régimen térmico, Duncan et al. (2001) encontraron que los movimientos en pastoreo de 
ganado ovino apenas se vieron afectados por este factor. No obstante, hay que considerar que estos autores trabajaron con un rango de temperaturas comprendido en la zona termoneutra del ovino. 
4. PRUEBA 1. Composición botánica y química y utilización digestiva de pastos invadidos por lecherina (Euphorbia polygalifolia) 



\subsection{Introducción}

Los pastos de Festuca-Agrostis en los puertos de Sejos presentan en la actualidad una estructura heterogénea: manchas de pasto invadido por E. polygalifolia, con gran acumulación de biomasa y escaso aprovechamiento pastoral, se disponen en mosaico junto a manchas de pasto aún no invadido, con plantas de menor porte y fuertemente pastoreadas (Busqué et al, 2003).

Se sabe que los animales interactúan con los recursos pastables a varios niveles de resolución ecológica (Senft et al., 1987; Bailey et al., 1996). En nuestro caso, parece evidente que el ganado mayoritario en la zona (vacuno y caballar) realiza una selección a nivel de bocado dentro de las manchas de Festuca-Agrostis rechazando aquellas zonas colonizadas por E. polygalifolia y provocando, por tanto, la mencionada estructura heterogénea de este tipo de pastos.

La selección de cada bocado por parte del animal está condicionada, en gran medida, por la densidad de nutrientes en el pasto y la disponibilidad de material vegetal (Hunter, 1962; Senft et al., 1985). Sin embargo, no siempre estos factores son suficientes para explicar el comportamiento ingestivo de los animales en pastoreo libre. Por ejemplo, la Euphorbia esula es rechazada por el ganado vacuno en los pastos de Norte América, pese a su elevada disponibilidad y densidad de nutrientes (Roberts y Olson, 1999). En el caso de Sejos, la disponibilidad de pasto de Festuca-Agrostis en las zonas invadidas por lecherina también es elevada, pero esto no impide que dichas zonas sean claramente rechazadas por el ganado (Busqué et al., 2003). En este sentido, se sabe que el aprendizaje permite a los animales seleccionar la vegetación de acuerdo con sus necesidades y limitaciones específicas, cuando tienen a su disposición pastos no sólo con distintas concentraciones de nutrientes sino también con distintas concentraciones de toxinas (Provenza, 1995). De esta forma, el rechazo a la Euphorbia esula en Norte América se ha relacionado con la presencia de compuestos secundarios, principalmente diterpenoides aunque también se han encontrado taninos, y pueden producir efectos tóxicos sobre los animales que provocarían el desarrollo de una aversión condicionada hacia el consumo de esta especie (Kronberg et al., 1993; Kronberg et al., 1995; Halaweish et al., 2002). Por el contrario, en el caso de la E. polygalifolia no se conocen datos de sus contenidos ni de nutrientes ni de compuestos secundarios.

Por otro lado, se sabe que el grupo botánico de las especies que componen los pastos y su fenología son dos de los principales factores que influyen en su valor nutritivo (López 
et al., 1991; Marinas et al., 2003). La digestibilidad de las especies arbustivas y graminoides suele ser menor que la de leguminosas y otras especies latifoliadas. A su vez, la calidad en los estados fenológicos inmaduros es generalmente mayor que en los estados maduros (Van Soest, 1994) ya que el avance de la fenología se traduce en una menor relación hojas/tallos así como en un incremento de las paredes celulares y de la lignificación de las plantas (Ugherughe, 1986).

Por todo ello, este experimento se realizó para probar la siguiente hipótesis: los pastos invadidos por lecherina presentan, a lo largo de la estación de pastoreo, un menor valor nutritivo que los pastos libres de la invasión. Esta diferencia podría deberse a la presencia o ausencia de lecherina en el pasto, o a los cambios en la composición botánica de los pastos invadidos respecto a los pastos sin invadir (como consecuencia de la propia invasión por lecherina).

Con el fin de contrastar la hipótesis planteada, se estudió la evolución temporal de algunos parámetros indicativos del valor nutritivo (composición botánica y química y utilización digestiva) de los siguientes sustratos: pasto invadido por lecherina; pasto invadido por lecherina al que se le sustrae la lecherina; pasto libre de la invasión por lecherina y plantas de lecherina.

\subsection{Material y métodos.}

\subsubsection{Recogida de pastos.}

La recogida de muestras se llevó a cabo en los pastos de puerto de Sejos (ver descripción de la zona de estudio en el capítulo 2) durante la estación de pastoreo de 2004 (5 muestreos mensuales entre mayo y septiembre). Se recogió una muestra de pasto invadido por lecherina y otra de pasto libre de la invasión (pero susceptible de ser invadido) en cada una de las tres zonas de Sejos consideradas en el estudio: Los Puentes (coordenadas UTM: 391180-4769980), Llanocastrillo (coordenadas UTM: 3929604769480) y El Cuadro (coordenadas UTM: 392660-4768800). Cada muestra, recogida mediante siega con cuchilla eléctrica de mano, correspondía a un área total de $1,0 \mathrm{~m}^{2}$, ya que se segaron cuatro cuadrados de $0,25 \mathrm{~m}$ de lado.

Las muestras de pasto invadido se dividieron, a su vez, en dos submuestras: una de ellas constituyó el sustrato denominado "pasto invadido por lecherina”; en la otra se separó la lecherina del resto de la submuestra constituyendo los sustratos "pasto invadido al que se le sustrae la lecherina" y "lecherina". 
Por otro lado, se recogieron mensualmente, desde junio a septiembre, 2 muestras de plantas de lecherina que fueron inmediatamente congeladas y posteriormente liofilizadas de cara a la realización de los análisis de taninos, terpenoides y otros compuestos lipofílicos extraíbles.

Todas las muestras se molieron con una criba de $1 \mathrm{~mm}$ de diámetro y se conservaron en bolsas de plástico de cierre hermético hasta su análisis.

\subsubsection{Composición botánica.}

Las muestras de pastos descritas anteriormente se pesaron y, en una submuestra representativa, se separaron las siguientes fracciones: graminoides, leguminosas, lecherina y otras especies latifoliadas. A su vez, estas fracciones fueron pesadas en fresco, secadas a $50^{\circ} \mathrm{C}$ hasta alcanzar un peso constante y pesadas de nuevo en seco para conocer la disponibilidad total de cada pasto por unidad de superficie y la contribución de cada uno de los grupos botánicos separados, expresada como porcentaje de la materia seca total.

\subsubsection{Composición química.}

El contenido de materia seca (MS) se determinó por desecación en una estufa de ventilación forzada (Heraeus RTV-220, Alemania) a $50^{\circ} \mathrm{C}$, hasta alcanzar un peso constante, y el de cenizas mediante la incineración de las muestras, anteriormente secadas, en un horno mufla (Hobersal 12- PR/400, España) a 500-550 ${ }^{\circ} \mathrm{C}$, durante 6 horas (AOAC, 2000). El contenido de materia orgánica (MO) se estimó como la diferencia entre el contenido de MS y el de cenizas.

Para el análisis del contenido de nitrógeno $(\mathrm{N})$ de las muestras, según el método Kjeldalh (AOAC, 2000), se utilizó un autoanalizador Kjeltec System 1035 (Tecator, Suecia). La proteína bruta (PB) se estimó multiplicando el contenido de $\mathrm{N}$ por el factor 6,25 .

Los contenidos de fibra neutro detergente (FND) y fibra ácido detergente (FAD) se determinaron en un analizador de fibra $\mathrm{ANKOM}^{220}$ (Estados Unidos), de acuerdo con los métodos de Van Soest et al. (1991) y Goering y Van Soest (1970).

El contenido de taninos totales se analizó siguiendo el método colorimétrico basado en el empleo del reactivo Folin-Ciocalteu y la polivivilpolipirrolidona (PVPP), descrito por Makkar et al. (1993). Una vez eliminados los pigmentos y la grasa mediante lavados con 
una solución de éter dietílico y ácido acético, los fenoles totales (FT) se extrajeron con acetona al 70\%. Este extracto de FT se trató a continuación con PVPP, formándose un precipitado con los taninos y quedando en el sobrenadante únicamente los fenoles de bajo peso molecular (fenoles simples, FS). El contenido de FT en el primer extracto (antes del tratamiento con PVPP), así como el de FS en el segundo extracto (tras el tratamiento con PVPP) se determinaron con el reactivo Folin-Ciocalteu, utilizando ácido tánico (AT, Merck, Alemania) como estándar de referencia. La diferencia entre los valores de FT y FS representa el contenido de taninos totales (TT), expresado en equivalentes de AT.

Los análisis de los compuestos lipofílicos extraíbles de la lecherina fueron realizados por el Departamento de Biotecnología Vegetal del Instituto de Recursos Naturales y Agrobiología de Sevilla (CSIC). Para ello, se realizó una extracción de los lípidos de la lecherina en un equipo Soxhlet para su posterior análisis por cromatografía de gases y cromatografía de gases/espectrometría de masas (GC/MS).

\subsubsection{Cultivos discontinuos de microorganismos ruminales: producción de gas y degradación ruminal in vitro.}

En este apartado se estudiaron in vitro una serie de parámetros indicativos de la fermentación ruminal (producción de gas y de ácidos grasos volátiles, concentración de amoniaco, etc.) de los cuatro sustratos descritos anteriormente (ver apartado 4.2.1), recogidos en una de las tres zonas estudiadas (Los Puentes) durante los meses de mayo, junio, julio, agosto y septiembre de 2004. Para ello, se utilizaron cultivos discontinuos de microorganismos ruminales y la técnica in vitro de producción de gas descrita por Theodorou et al. (1994) y modificada por Mauricio et al. (1999).

Tres muestras de cada sustrato, de aproximadamente $500 \mathrm{mg}$, se pesaron en botellas de suero de $125 \mathrm{~mL}$. En cada botella se dosificaron $10 \mathrm{~mL}$ de inóculo ruminal y $40 \mathrm{~mL}$ de un medio de incubación (1:4; McDougall, 1948) que contenía una solución de macrominerales, una solución tampón, una solución reductora, una solución de microminerales y una solución de resazurina como indicador del potencial redox. Se utilizaron dos inóculos ruminales (réplicas) que se obtuvieron de 5 ovejas adultas de raza merina fistuladas en el rumen y alimentadas previamente con heno de alfalfa ad libitum. Dichos inóculos se recogieron antes de que los animales recibieran la primera comida de la mañana y, una vez filtrados a través de dos capas de gasa, se transportaron al laboratorio en un termo precalentado y gaseado con $\mathrm{CO}_{2}$. 
Todas las incubaciones se llevaron a cabo en un incubador (Memmert BE 500, Alemania) a $39^{\circ} \mathrm{C}$.

Se realizaron 2 series:

Serie I: incubaciones de 24 horas. Se estudió la desaparición de materia seca (DMS), la producción de ácidos grasos volátiles $(\mathrm{AGV})$ y la concentración de amoniaco $\left(\mathrm{NH}_{3}\right)$.

Serie II: los sustratos se incubaron durante 144 horas, para conocer la cinética completa de producción de gas así como la DMS.

En total, en cada serie se utilizaron 132 botellas: 4 sustratos $\times 5$ meses de corte $\times 3$ botellas (repeticiones) $\times 2$ inóculos (réplicas) +12 botellas control (blancos con medio de incubación e inóculo ruminal pero sin sustrato; 6 para cada uno de los dos inóculos).

Para realizar las lecturas de presión se utilizó un transductor de presión T443A (Bailey \& Mackey, Reino Unido) conectado a una salida visual (Data Track Process Instruments 223, Reino Unido). Las lecturas se realizaron a las 2, 4, 6, 9, 12, 15, 19, 24, 30, 35,5, 48, 59, 72, 96, 120 y 144 horas post-incubación. La presión (psi) se midió pinchando cada botella con una aguja de $0,6 \mathrm{~mm}$ de diámetro conectada al transductor. Una vez desconectado el transductor de la aguja, ésta se dejaba unos segundos pinchada en la botella para permitir la salida de todo el gas acumulado. Las botellas se agitaron individualmente después de cada lectura. A partir de los valores de presión obtenidos, corregidos tanto para la cantidad de materia orgánica incubada como para la producción de gas de las botellas control, se estimó el volumen de gas producido mediante una ecuación de regresión lineal entre el volumen y la presión, obtenida a partir de 17.790 medidas simultáneas de ambos parámetros (Hervás et al., 2005).

Transcurrido el tiempo previsto de incubación ( 24 horas para la serie I y 144 horas para la serie II) se detuvo la fermentación mediante la introducción de las botellas en agua con hielo. Posteriormente, el residuo se filtró utilizando crisoles provistos de una placa porosa (100-160 $\mu \mathrm{m}$; Pyrex, Stone, Reino Unido), con la ayuda de una bomba de vacío (KNF Neuberger VDE0530, Alemania) y un baño de ultrasonidos (P Selecta 3512, España) cuando éste fue necesario. El contenido de los crisoles se secó en una estufa (Heraeus RTV-220, Alemania) durante 24 horas a $103^{\circ} \mathrm{C}$ para estimar la desaparición de MS (DMS).

En el caso de las botellas de la serie I, una muestra del fluido de aproximadamente 10 mL se centrifugó a 600 x $g$ y $4{ }^{\circ} \mathrm{C}$ durante 15 minutos para eliminar partículas del sustrato. 
Seguidamente, una alicuota de $4 \mathrm{~mL}$ de cada sobrenadante fue acidificada con $4 \mathrm{~mL}$ de $\mathrm{HCl}\left(0,2 \mathrm{~mol} \mathrm{~L}^{-1}\right)$ para la determinación de amoniaco. Para la determinación de los ácidos grasos volátiles (AGV) se empleó otra alicuota de $0,8 \mathrm{~mL}$ de cada sobrenadante a la que se añadió una solución desproteinizante $\left(20 \mathrm{~g} \mathrm{~L}^{-1}\right.$ de ácido metafosfórico y $4 \mathrm{~g} \mathrm{~L}^{-1}$ de ácido crotónico [utilizado como estándar interno] en $\left.\mathrm{HCl}\left[0,5 \mathrm{~mol} \mathrm{~L}^{-1}\right]\right)$. Todas las muestras fueron almacenadas a $-30{ }^{\circ} \mathrm{C}$ hasta su análisis.

\section{$\underline{\text { Producción de gas en ausencia y presencia de PEG }}$}

Como método alternativo al análisis químico (cuantitativo) de taninos de la lecherina recogida en los meses de junio, julio, agosto y septiembre, se llevó a cabo un análisis cualitativo, basado en la estimación de la actividad biológica de los taninos como inhibidores de la fermentación ruminal (Álvarez del Pino et al., 2005). Para ello, se utilizó la técnica in vitro de producción de gas en ausencia y presencia de polietilenglicol (PEG), un detergente con una elevada afinidad por estos compuestos fenólicos, que inhibe su actividad. De esta forma, la diferencia en la producción de gas entre las incubaciones "sin" y "con" este agente, es una medida indirecta de la inhibición de la fermentación ruminal causada por los taninos.

La incubación se realizó a 24 horas siguiendo exactamente el procedimiento descrito anteriormente, con la única diferencia de que, además de los $500 \mathrm{mg}$ de sustrato, en las botellas "con PEG", se pesaron también 1000 mg de PEG (Fluka Biochemica, Buchs, Suiza). Para esta prueba se incubaron 54 botellas en total: 2 sustratos de lecherina (réplicas) $\times 4$ meses de corte $\times 2$ tratamientos ("con" y "sin" PEG) $\times 3$ botellas (repeticiones) +6 blancos.

\section{$\underline{\text { Análisis de amoniaco y ácidos grasos volátiles }}$}

Las concentraciones de amoniaco se determinaron por un método colorimétrico (Weatherburn, 1967). Las muestras se descongelaron a $4^{\circ} \mathrm{C}$, se centrifugaron (Kubota 6900, Japón) y se filtraron (Whatman \#40) para eliminar cualquier sólido en suspensión. Para la determinación del contenido de amoniaco, las muestras se trataron con fenol, sodio pentacianoferroso III 2-hidrato, hidróxido de sodio e hipoclorito sódico (todos ellos de Panreac) y sus absorbancias se leyeron en un espectrofotómetro (Shimadzu Sipper A 160, Japón). Para la preparación del estándar y la realización de las curvas patrón, se utilizó una solución de cloruro de amonio (Probus). 
Las concentraciones de $\mathrm{AGV}$ se determinaron mediante cromatografía de gases (Carro et al., 1999). Estos análisis se realizaron en colaboración con el grupo de Nutrición Animal del Departamento de Producción Animal de la Universidad de León.

Las muestras se descongelaron en cámara frigorífica a $4^{\circ} \mathrm{C}$, se centrifugaron (Beckman GS-ISR, Estados Unidos) y el sobrenadante se almacenó a $4^{\circ} \mathrm{C}$ hasta su posterior análisis. Para la determinación de los AGV se utilizó un cromatógrafo de gases Shimadzu GC 14B (Shimadzu Corporation, Kyoto, Japón). Como patrón interno se usó ácido crotónico (Merck-Schuchart, Hohenbrunn, Alemania).

\subsubsection{Cálculos y análisis estadístico}

Los datos de producción de gas se ajustaron al modelo exponencial descrito por France et al. (2000):

$$
G=A \times\left(1-\mathrm{e}^{(-c \times(t-L a g))}\right),
$$

siendo $G(\mathrm{~mL} / \mathrm{g} \mathrm{MO})$ la tasa de producción de gas en el tiempo $t(\mathrm{~h}), A(\mathrm{~mL} / \mathrm{g} \mathrm{MO})$ la producción asintótica de gas, $c\left(\mathrm{~h}^{-1}\right)$ el ritmo fraccional de producción de gas y Lag (h) el tiempo de retraso entre el inicio de la incubación y el inicio de la producción de gas. Tras comprobar que el parámetro Lag era nulo en todos los ajustes realizados, se suprimió del modelo exponencial utilizado. Para la realización de los ajustes matemáticos se utilizó el procedimiento NLIN (Nonlinear Regresion) del programa estadístico SAS (SAS, 1999).

La extensión de la degradación en el rumen $(\mathrm{ED}, \mathrm{g} / \mathrm{kg})$ y el ritmo medio de fermentación $(\mathrm{RMF}, \mathrm{mL} / \mathrm{h})$ fueron calculados asumiendo un ritmo de paso $\left(\mathrm{K}_{\mathrm{p}}\right)$ de $0,028 \mathrm{~h}^{-1}$, de acuerdo con las ecuaciones propuestas por France et al. (2000):

$$
\begin{aligned}
& \mathrm{ED}=\left(c \times \mathrm{DMS} /\left(c+\mathrm{K}_{\mathrm{p}}\right)\right) \times \mathrm{e}^{-(\mathrm{Kp} \times \text { Lag })} \\
& \mathrm{RMF}=A \times c /(2 \times \ln 2+c \times \text { Lag })
\end{aligned}
$$

La producción de metano $\left(\mathrm{CH}_{4} ; \mu \mathrm{mol}\right)$ se calculó en función de las cantidades de acético (A), propiónico $(\mathrm{P})$ y butírico $(\mathrm{B})$ producidas, siguiendo la ecuación propuesta por Blümmel et al. (1997):

$$
\mathrm{CH}_{4}=0,5 \mathrm{~A}-0,25 \mathrm{P}+0,5 \mathrm{~B}
$$


Todos los datos se analizaron mediante un análisis de medidas repetidas en el tiempo, utilizando el procedimiento MIXED del paquete estadístico SAS (SAS, 1999) y de acuerdo con el siguiente modelo general:

$$
\mathbf{Y}_{\mathrm{ij}}=\mu+\mathbf{P}_{\mathrm{i}}+\mathbf{M}_{\mathrm{j}}+\mathbf{P} \mathbf{M}_{\mathrm{ij}}+\varepsilon_{\mathrm{ij}}
$$

siendo:

$\mathrm{Y}_{\mathrm{ij}}$, la variable dependiente,

$\mu$, la media,

$\mathrm{P}_{\mathrm{i}}$, el efecto debido al tipo de pasto,

$\mathbf{M}_{\mathrm{j}}$, el efecto debido al mes de recogida de las muestras de pasto (considerado como medida repetida en el tiempo),

$\mathrm{PM}_{\mathrm{ij}}$, el efecto debido a la interacción entre el tipo de pasto y el mes,

$\varepsilon_{\mathrm{ij}}$, el error residual.

Se utilizó una estructura de covarianza simple por ser la que mejor se ajustaba a los datos observados en base al criterio Bayesiano de Schwarz (SBC). Se consideraron diferencias estadísticamente significativas aquellas con un valor de $\mathrm{P}<0,05$ y tendencias aquellas con $\mathrm{P}>0,05$ pero $<0,10$. Cuando el nivel de significación de la interacción "pasto $\mathrm{x}$ mes" fue $\mathrm{P}<0,05$, las medias se compararon utilizando una $t$ de Student (mediante la sentencia LSMEANS del SAS, 1999).

\subsection{Resultados}

\subsubsection{Composición botánica}

La composición botánica de los pastos estudiados se recoge en la tabla 4.1. En general, todos ellos estuvieron formados mayoritariamente por especies graminoides $\mathrm{y}$, en menor medida, por plantas clasificadas dentro del grupo "otras latifoliadas". Por contra, la presencia de leguminosas estuvo por debajo del $2 \%$ en todos los pastos.

Cabe destacar el valor medio de la proporción de lecherina en los pastos invadidos (44,5\%), como indicador de la elevada intensidad de la invasión en los pastos afectados. Consecuentemente, al comparar el pasto invadido con el pasto no invadido por lecherina se 
observó una menor proporción $(\mathrm{P}<0,05)$ de leguminosas $(0,2$ vs. $1,3 \%)$, graminoides $(49,9$ vs. $80,6 \%)$ y otras latifoliadas (5,3 vs. $16,8 \%)$.

De la comparación entre el pasto no invadido y el pasto invadido al que se le sustrae la lecherina (denominado "invasinlech" en todas las tablas y figuras), se pudo inferir una mayor presencia en el primero de leguminosas $(1,3$ vs. $0,3 \%$; $\mathrm{P}<0,05)$ y otras latifoliadas $(16,8$ vs. 10,2; $\mathrm{P}<0,05)$. Por el contrario, las graminoides abundaron más en el “invasinlech" (89,5 vs. $80,0 \%$; $\mathrm{P}<0,05)$.

Por otro lado, las proporciones de lecherina en el pasto invadido alcanzadas en los meses de junio y agosto fueron significativamente más altas que en el resto de meses de la estación de pastoreo, coincidiendo con unos niveles de graminoides menores en esos meses (figura 4.1). En cambio, las proporciones de leguminosas y otras latifoliadas no variaron de forma significativa a lo largo de la estación de pastoreo. Así mismo, la composición botánica de los demás pastos estudiados también permaneció estable a lo largo de la estación de pastoreo, a excepción de la proporción de "otras latifoliadas" del pasto "invasinlech" que se disparó en el mes de agosto. Con un valor medio del 18,8\%, sobrepasa en más de un $100 \%$ los valores de los meses contiguos $(7,3$ y 7,9 en julio y septiembre respectivamente). 
Tabla 4.1. Composición botánica (\%MS) de pastos invadidos por lecherina, pastos no invadidos y pastos invadidos por lecherina a los que se les ha sustraído la lecherina (invasinlech), a lo largo de la estación de pastoreo.

\section{Leguminosas Graminoides Lecherina Otras}

\begin{tabular}{|c|c|c|c|c|c|}
\hline & $\begin{array}{l}\text { Invadido por } \\
\text { lecherina }\end{array}$ & $0,2^{\mathrm{b}}$ & $49,9^{c}$ & $44,5^{\mathrm{a}}$ & $5,3^{\mathrm{c}}$ \\
\hline & Invasinlech & $0,3^{\mathrm{b}}$ & $89,5^{\mathrm{a}}$ & - & $10,2^{\mathrm{b}}$ \\
\hline \multirow[t]{6}{*}{ Pasto } & $\begin{array}{l}\text { No invadido } \\
\text { por lecherina }\end{array}$ & $1,3^{\mathrm{a}}$ & $80,6^{\mathrm{b}}$ & $1,3^{\mathrm{b}}$ & $16,8^{\mathrm{a}}$ \\
\hline & e.e.d. & 0,44 & 2,64 & 1,50 & 2,38 \\
\hline & Sig. & $*$ & $* * *$ & $* * *$ & $* * *$ \\
\hline & Mayo & 0,2 & $77,5^{\mathrm{a}}$ & $20,7^{b}$ & 8,6 \\
\hline & Junio & 0,7 & $71,3^{\mathrm{ab}}$ & $26,5^{\mathrm{a}}$ & 10,2 \\
\hline & Julio & 0,4 & $77,1^{\mathrm{a}}$ & $20,7^{b}$ & 8,7 \\
\hline \multirow[t]{4}{*}{ Mes } & Agosto & 0,8 & $65,0^{\mathrm{b}}$ & $28,1^{\mathrm{a}}$ & 15,4 \\
\hline & Septiembre & 0,8 & $75,8^{\mathrm{a}}$ & $18,5^{b}$ & 11,0 \\
\hline & e.e.d. & 0,56 & 3,41 & 2,38 & 3,08 \\
\hline & Sig. & ns & $* *$ & $* *$ & ns \\
\hline \multirow{2}{*}{ Pasto $\mathrm{x}$ mes } & e.e.d. & 0,97 & 5,91 & 3,36 & 5,34 \\
\hline & Sig. & ns & ns & $* * *$ & ns \\
\hline
\end{tabular}

e.e.d.: error estándar de la diferencia. Sig.: nivel de significación estadística (P). ns: no significativo; t: $0,10>\mathrm{P}>0,05 ; *: \mathrm{P}<0,05 ; * *: \mathrm{P}<0,01 ; * * *: \mathrm{P}<0,001$. Valores con diferentes letras en la misma columna difieren significativamente $(\mathrm{P}<0,05)$. 

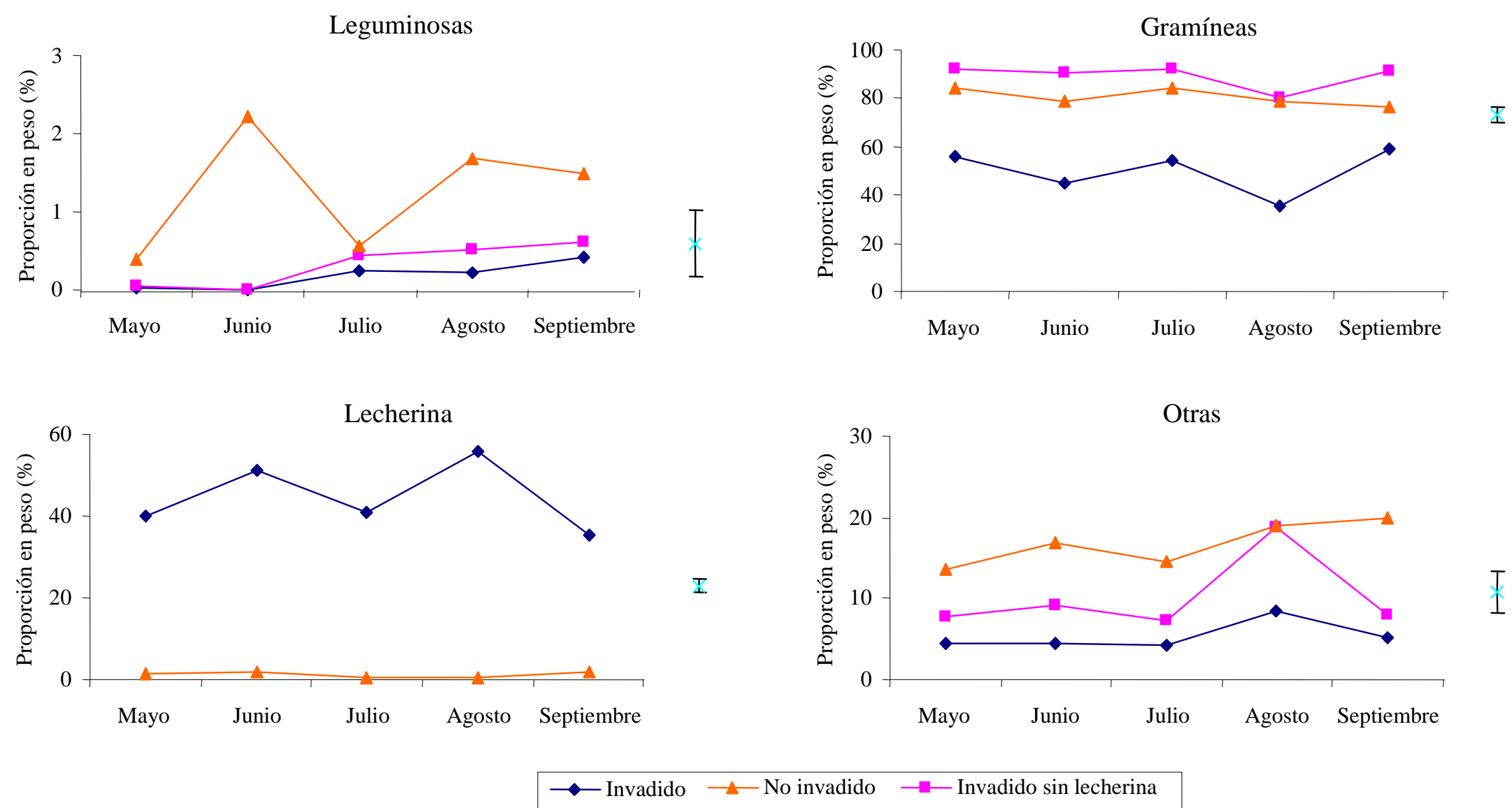

Figura 4.1. Evolución de la composición botánica de los pastos invadidos por lecherina, los pastos no invadidos y los pastos invadidos por lecherina a lo que se les ha sustraído la lecherina, a lo largo de la estación de pastoreo. 


\subsubsection{Composición química}

La composición química de los sustratos estudiados se muestra en la tabla 4.2. La lecherina se caracterizó por superar los contenidos de MO del resto de sustratos estudiados, con un valor medio del 94,9\%. Por el contrario, mostró unos porcentajes de FND y FAD claramente inferiores a los obtenidos en los demás pastos (valores medios de 34,9 y 21,2\%, respectivamente). Por otro lado, sus niveles de PB (valor medio del 11,7\%) no difirieron significativamente de los encontrados en el pasto invadido y en el pasto invadido sin lecherina, siendo todos ellos menores a los detectados en el pasto no invadido.

El pasto invadido registró contenidos de MO superiores al pasto no invadido por lecherina. En cambio, los niveles de PB y FND fueron significativamente más bajos $(11,0$ vs. $14,7 \%$ y 50,6 vs. 56,0\%, respectivamente). Como cabía esperar, el pasto invadido mostró unos valores intermedios respecto a sus dos componentes principales (lecherina y pasto invadido sin lecherina) en los parámetros estudiados.

Cuando se comparó el pasto "invasinlech" con el pasto no invadido, se encontraron valores de MO más elevados en el primero de ellos $(93,5$ vs. 92,0) al igual que en la FND y FAD (62,2 vs. $56,0 \%$ y 30,4 vs. $26,0 \%$, respectivamente). Por contra, la PB fue menor $(10,6$ vs. $14,7 \%)$.

Respecto a la evolución de la composición química de los pastos a lo largo de la estación de pastoreo, los valores de MO se mantuvieron estables en líneas generales, especialmente en las muestras de lecherina (figura 4.2). En cambio, la PB descendió significativamente en todos los pastos a medida que avanzaron los meses. Los valores medios fueron superiores al $12 \%$ en los meses de mayo y junio y en torno al $9 \%$ en septiembre, a excepción del pasto no invadido que mostró contenidos más elevados que el resto de sustratos, oscilando entre un 18,1\% en mayo y un 12,0\% en septiembre. Destacó el brusco descenso generalizado de la PB de junio a julio (con un valor medio del 14,4 al 11,0\%; ver tabla 4.2 y figura 4.2). Así mismo, se observaron dos picos de FND y FAD en los meses de julio y septiembre, con valores significativamente superiores al resto de los meses. 
Tabla 4.2. Composición química (\%MS; materia orgánica, proteína bruta, fibra neutro detergente y fibra ácido detergente) de la lecherina, pastos invadidos por lecherina, pastos no invadidos y pastos invadidos por lecherina a los que se les ha sustraído la lecherina (invasinlech), a lo largo de la estación de pastoreo.

\begin{tabular}{|c|c|c|c|c|c|}
\hline & & MO & PB & FND & FAD \\
\hline \multirow{6}{*}{ Pasto } & Lecherina & $94,9^{\mathrm{a}}$ & $11,7^{\mathrm{b}}$ & $34,9^{\mathrm{d}}$ & $21,2^{\mathrm{c}}$ \\
\hline & $\begin{array}{l}\text { Invadido por } \\
\text { lecherina }\end{array}$ & $93,8^{\mathrm{b}}$ & $11,0^{\mathrm{b}}$ & $50,6^{\mathrm{c}}$ & $26,7^{\mathrm{b}}$ \\
\hline & Invasinlech & $93,5^{\mathrm{b}}$ & $10,6^{\mathrm{b}}$ & $62,2^{\mathrm{a}}$ & $30,4^{\mathrm{a}}$ \\
\hline & $\begin{array}{l}\text { No invadido } \\
\text { por lecherina }\end{array}$ & $92,0^{\mathrm{c}}$ & $14,7^{\mathrm{a}}$ & $56,0^{\mathrm{b}}$ & $26,0^{\mathrm{b}}$ \\
\hline & e.e.d. & 0,30 & 0,63 & 1,10 & 0,52 \\
\hline & Sig. & $* * *$ & $* * *$ & $* * *$ & $* * *$ \\
\hline \multirow{7}{*}{ Mes } & Mayo & $94,1^{\mathrm{a}}$ & $14,4^{\mathrm{a}}$ & $48,5^{\mathrm{b}}$ & $24,6^{\mathrm{b}}$ \\
\hline & Junio & $93,5^{\mathrm{ab}}$ & $14,4^{\mathrm{a}}$ & $48,3^{\mathrm{b}}$ & $25,0^{\mathrm{b}}$ \\
\hline & Julio & $93,3^{b}$ & $10,9^{b}$ & $53,2^{\mathrm{a}}$ & $27,3^{\mathrm{a}}$ \\
\hline & Agosto & $93,5^{\mathrm{ab}}$ & $10,7^{\mathrm{b}}$ & $49,4^{\mathrm{b}}$ & $25,1^{\mathrm{b}}$ \\
\hline & Septiembre & $93,3^{b}$ & $9,6^{\mathrm{b}}$ & $55,3^{\mathrm{a}}$ & $28,3^{\mathrm{a}}$ \\
\hline & e.e.d. & 0,33 & 0,70 & 1,23 & 0,58 \\
\hline & Sig. & ns & $* * *$ & $* * *$ & $* * *$ \\
\hline \multirow{2}{*}{ Pasto $\mathrm{x}$ mes } & e.e.d & 0,66 & 1,40 & 2,46 & 1,15 \\
\hline & Sig. & ns & ns & ns & $\mathrm{ns}$ \\
\hline
\end{tabular}

e.e.d.: error estándar de la diferencia. Sig.: nivel de significación estadística (P). ns: no significativo; t: $0,10>\mathrm{P}>0,05 ; *: \mathrm{P}<0,05 ; * *: \mathrm{P}<0,01 ; * * *: \mathrm{P}<0,001$. Valores con diferentes letras en la misma columna difieren significativamente $(\mathrm{P}<0,05)$. 

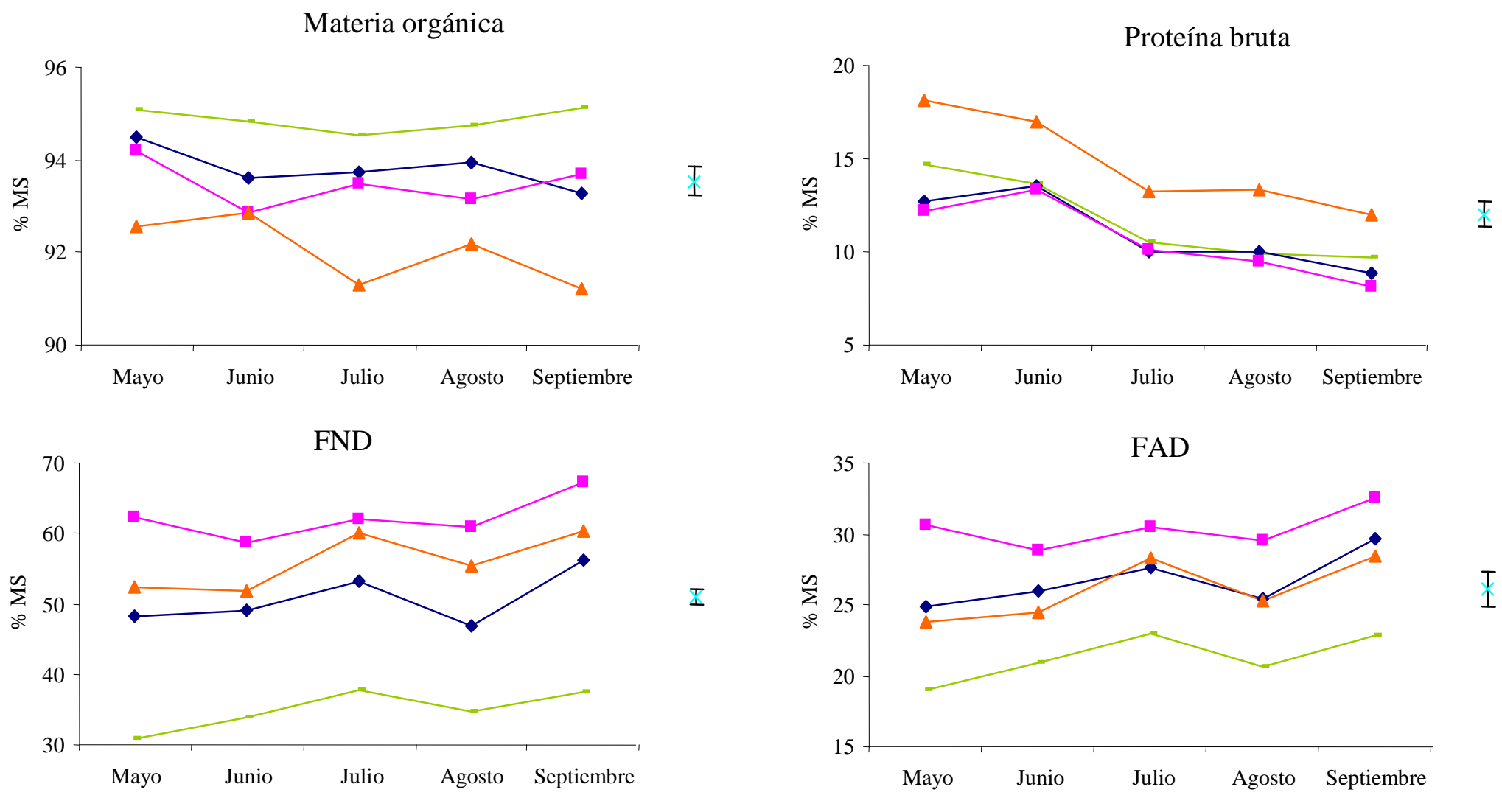

Lecherina
$\rightarrow$ Invadido sin lecherina
- Invadido
No invadido

Figura 4.2. Evolución de la composición química (MO, PB, FND y FAD) de la lecherina, los pastos invadidos por lecherina, los pastos no invadidos y los pastos invadidos por lecherina a los que se les ha sustraído la lecherina, a lo largo de la estación de pastoreo. 
Además de las variables de composición química convencionales en los estudios de nutrición animal descritas anteriormente, la tabla 4.3 recoge también los contenidos de taninos totales encontrados en la lecherina a lo largo de la estación de pastoreo, así como el porcentaje de incremento en la producción de gas cuando se incuba in vitro con PEG. Al igual que en el resto de parámetros químicos estudiados, destaca la estabilidad de estos contenidos en el periodo analizado (valores en torno a $150 \mathrm{~g}$ de equivalentes de ácido tánico/kgMS). Por su parte, las producciones de gas en presencia de PEG aumentaron en torno a un $10 \%$, con valores mínimos para el mes de julio con un $9,1 \%$ y máximos para el mes de septiembre con un $14,4 \%$.

Tabla 4.3. Contenido de taninos totales en la lecherina (g de equivalentes de ácido tánico/kgMS) e incremento en la producción de gas a las 24 horas cuando se incuba in vitro con PEG (dPEG; \%), a lo largo de la estación de pastoreo.

\begin{tabular}{lcccc}
\cline { 2 - 4 } & Junio & Julio & Agosto & Septiembre \\
\hline Taninos totales (g/kgMS) & 148 & 166 & 158 & 145 \\
\hline dPEG $(\%)$ & 10,1 & 9,1 & 12,0 & 14,4 \\
\hline
\end{tabular}

El análisis del extracto lipofílico de la lecherina reveló la existencia de una diversidad de compuestos de masa molecular alta, principalmente compuestos triterpenoidales y esteroidales. El cromatograma del extracto lipofílico total se muestra en la figura 4.3 y la identificación y cuantificación de los compuestos en la tabla 4.4. Entre los compuestos triterpenoidales, destacan la ß-amirina, el lupeol y el ciclolaudenol, así como los ácidos triterpénicos oleanólico y ursólico. También se identificaron triterpenoles esterificados con ácidos grasos de cadena larga, así como otros en los que aparecen como benzoatos (aunque en estos últimos no se pudo determinar la estructura exacta). 


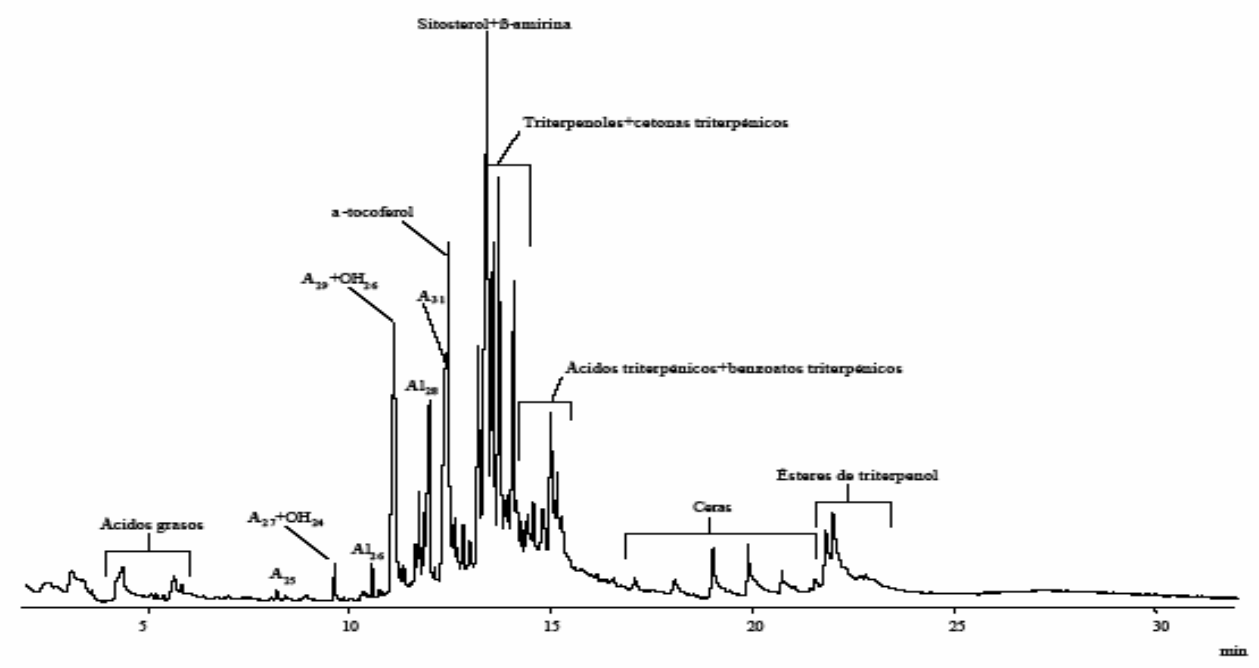

Figura 4.3. Cromatograma del extracto lipofílico total de la lecherina. An: alcanos, Aln: aldehidos, OHn: alcoholes (n corresponde al número de átomos de carbono).

Tabla 4.4. Lípidos identificados en la lecherina (mg/kg MS).

\begin{tabular}{|c|c|c|c|}
\hline Compuesto & Contenido & Compuesto & Contenido \\
\hline n-alcanos & 1629,2 & Esteroles/triterpenoles & 5657,4 \\
\hline n-pentacosano & 21,3 & Sitosterol & 1306,2 \\
\hline n-heptacosano & 49,7 & Beta-amirina & 460,4 \\
\hline n-nonacosano & 460,8 & Lupeol & 1064,9 \\
\hline n-hentriacosano & 663,9 & Ciclolaudenol & 795,4 \\
\hline n-tritriacontano & 433,5 & Ursa-9(11),12-dien-3-ol & 141,9 \\
\hline Hidrocarburos esteroidales & 251,0 & a-tocoferol (vitamina E) & 1888,6 \\
\hline Estigmastadieno & 50,2 & Cetonas triterpénicas & 720,3 \\
\hline Estigmasta-3,5,22-trieno & 124,5 & Ursa-9(11),12-dien-3-ona & 66,4 \\
\hline Estigmasta-3,5-dieno & 76,3 & Beta-amirenona & 467,5 \\
\hline Aldehidos & 1411,9 & 13,27-cicloursan-3-ona & 186,4 \\
\hline n-hexacosanal & 215,4 & Ceras & 1862,3 \\
\hline n-octacosanal & 1196,5 & $\mathrm{C}_{38}$ & 79,3 \\
\hline Ácidos grasos & 1738,7 & $\mathrm{C}_{40}$ & 157,9 \\
\hline Ácido n-hexadecanoico & 1331,6 & $\mathrm{C}_{42}$ & 649,5 \\
\hline Ácido 9-octadecanoico & 340,8 & $\mathrm{C}_{44}$ & 708,1 \\
\hline Ácido n-octadecanoico & 66,3 & $\mathrm{C} 48$ & 62,7 \\
\hline Alcoholes & 609,6 & Ésteres de triterpenol & 2329,4 \\
\hline n-tetracosanol* & 19,9 & Ácidos triterpénicos & 32410,2 \\
\hline \multirow[t]{3}{*}{ n-hexacosanol } & 589,7 & Ácido oleanólico & 3572,8 \\
\hline & & Ácido ursólico & 28837,4 \\
\hline & & Benzoatos triterpénicos & 1804,0 \\
\hline
\end{tabular}




\subsubsection{Cultivos discontinuos de microorganismos ruminales: producción de gas y degradación ruminal in vitro}

Como se puede observar en la tabla 4.5, la incubación in vitro de los sustratos estudiados dio lugar a una interacción significativa entre el tipo de pasto y el mes de recogida de la muestra para todas las variables estudiadas, a excepción del ritmo fraccional de producción de gas. Destaca en primer lugar la estabilidad de los valores obtenidos en la incubación de la lecherina a lo largo de la estación de pastoreo para todas la variables estudiadas (ver figura 4.4); con excepción de un menor valor de la extensión de la degradación en el rumen en el mes de septiembre respecto a los meses de mayo y junio. En oposición, el pasto no invadido muestra las mayores variaciones temporales, con valores mínimos en el mes de julio para la totalidad de los parámetros mostrados en la figura 4.4.

Ninguno de los sustratos estudiados alcanzó valores significativamente superiores a los obtenidos por la lecherina para los parámetros indicativos de la fermentación ruminal in vitro, a excepción de la producción asintótica de gas, donde esta euforbiácea mostró valores inferiores a los encontrados en los pastos "invasinlech" y "no invadido". Destaca en particular la superioridad del ritmo fraccional de producción de gas de la lecherina en comparación con los demás sustratos. Esta gran diferencia en el ritmo de fermentación explica por qué la lecherina obtuvo unos valores más elevados en comparación con el resto de sustratos para la extensión de la degradación en el rumen (ED) pese a sus valores discretos de producción asintótica de gas (figura 4.4). 
Tabla 4.5. Producción de gas asintótica $\left(A, \mathrm{~mL} \mathrm{~g}^{-1} \mathrm{MO}\right)$, ritmo fraccional de producción de gas $\left(c, \mathrm{~h}^{-1}\right)$, desaparición de materia seca (DMS, $\mathrm{g} \mathrm{kg}^{-1}$ ), ritmo medio de fermentación (RMF, $\mathrm{mL} \mathrm{h}^{-1}$ ) y extensión de la degradación en el rumen (ED, $\mathrm{g} \mathrm{kg}^{-1}$ ) de los sustratos lecherina, pastos invadidos por lecherina, pastos no invadidos y pastos invadidos por lecherina a los que se les ha sustraído la lecherina (invasinlech), a lo largo de la estación de pastoreo.

\begin{tabular}{|c|c|c|c|c|c|c|}
\hline & & $\mathbf{A}$ & c & RMF & DMS & ED \\
\hline \multirow{6}{*}{$\begin{array}{l}\text { Tipo de } \\
\text { pasto }\end{array}$} & Lecherina & $261^{\mathrm{c}}$ & $0,042^{\mathrm{a}}$ & $7,98^{\mathrm{a}}$ & $740^{\mathrm{a}}$ & $444^{\mathrm{a}}$ \\
\hline & $\begin{array}{l}\text { Invadido por } \\
\text { lecherina }\end{array}$ & $244^{\mathrm{d}}$ & $0,027^{\mathrm{c}}$ & $4,87^{\mathrm{c}}$ & $640^{c}$ & $316^{\mathrm{c}}$ \\
\hline & Invasinlech & $297^{\mathrm{a}}$ & $0,022^{\mathrm{d}}$ & $4,78^{\mathrm{c}}$ & $659^{c}$ & $292^{d}$ \\
\hline & $\begin{array}{l}\text { No invadido } \\
\text { por lecherina }\end{array}$ & $285^{\mathrm{b}}$ & $0,032^{b}$ & $6,72^{\mathrm{b}}$ & $702^{\mathrm{b}}$ & $376^{\mathrm{b}}$ \\
\hline & e.e.d. & 4,9 & 0,0017 & 0,428 & 15,2 & 11,4 \\
\hline & Sig. & $* * *$ & $* * *$ & $* * *$ & $* * *$ & $* * *$ \\
\hline \multirow{7}{*}{ Mes } & Mayo & $269^{\mathrm{b}}$ & $0,035^{\mathrm{a}}$ & $6,76^{\mathrm{a}}$ & $699 b$ & $385^{\mathrm{a}}$ \\
\hline & Junio & $286^{\mathrm{a}}$ & $0,031^{\mathrm{abc}}$ & $6,38^{\mathrm{ab}}$ & $740^{\mathrm{a}}$ & $385^{\mathrm{a}}$ \\
\hline & Julio & $262^{b c}$ & $0,029^{b c}$ & $5,50^{\mathrm{bc}}$ & $636^{\mathrm{c}}$ & $321^{\mathrm{b}}$ \\
\hline & Agosto & $285^{\mathrm{a}}$ & $0,032^{\mathrm{ab}}$ & $6,62^{\mathrm{a}}$ & $719^{\mathrm{ab}}$ & $383^{\mathrm{a}}$ \\
\hline & Septiembre & $257^{\mathrm{c}}$ & $0,028^{c}$ & $5,18^{\mathrm{c}}$ & $633^{\mathrm{c}}$ & $312^{\mathrm{b}}$ \\
\hline & e.e.d. & 5,5 & 0,0019 & 0,428 & 16,9 & 12,7 \\
\hline & Sig. & $* * *$ & $*$ & $*$ & $* * *$ & $* * *$ \\
\hline \multirow{2}{*}{$\begin{array}{l}\text { Pasto } \mathrm{x} \\
\text { mes }\end{array}$} & e.e.d. & 10,9 & 0,0038 & 0,957 & 33,9 & 25,5 \\
\hline & Sig. & $* * *$ & $\mathrm{~ns}$ & $\mathrm{t}$ & $* * *$ & $* * *$ \\
\hline
\end{tabular}

e.e.d.: error estándar de la diferencia. Sig.: nivel de significación estadística (P). ns: no significativo; t: $0,10>\mathrm{P}>0,05 ; *: \mathrm{P}<0,05 ; * *: \mathrm{P}<0,01 ; * * *: \mathrm{P}<0,001$. Valores con diferentes letras en la misma columna difieren significativamente $(\mathrm{P}<0,05)$. 

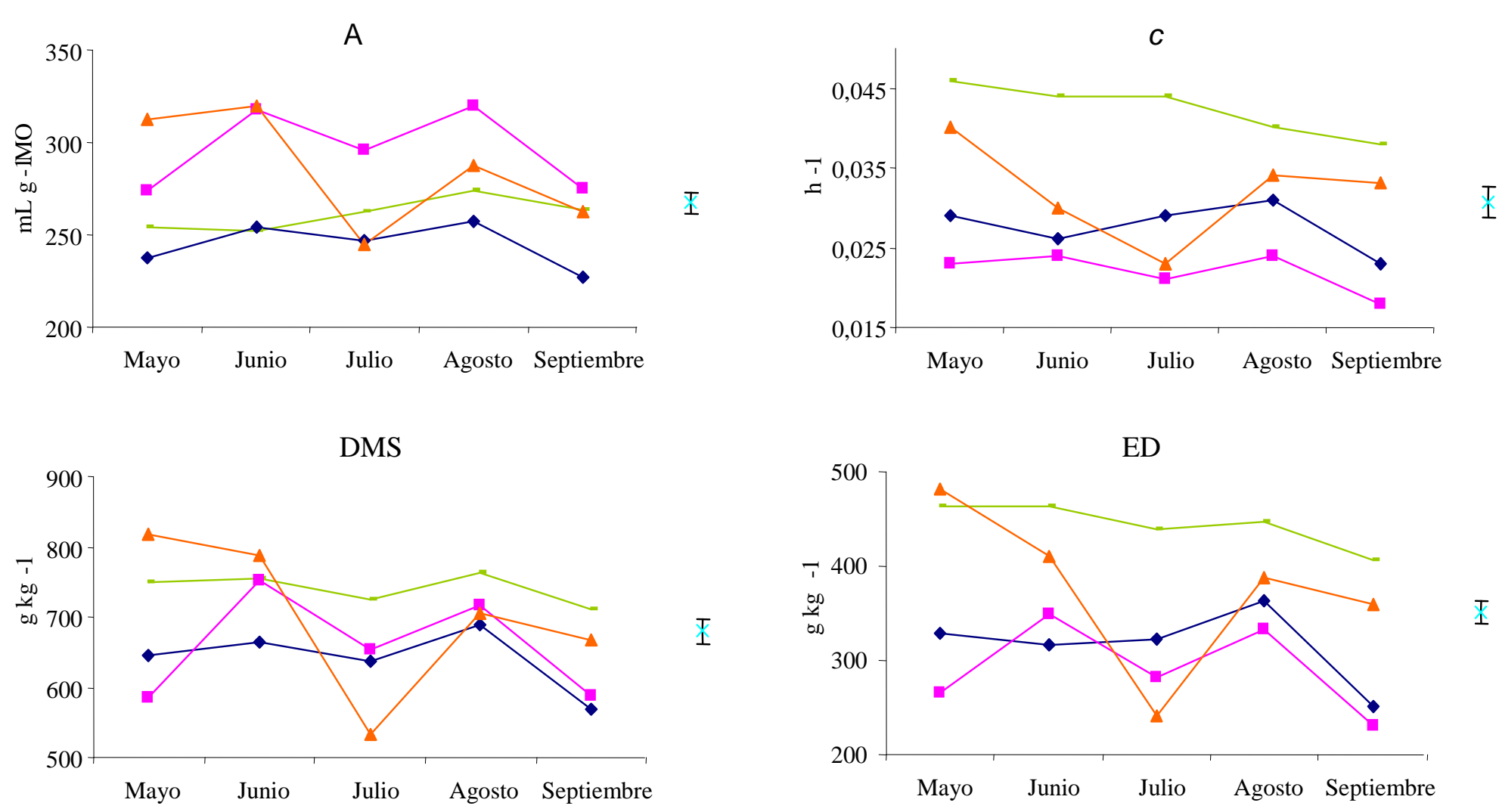

- Lecherina Invadido sin lecherina $\quad \because$ - Invadido

Figura 4.4. Evolución de la producción de gas asintótica $\left(A, \mathrm{~mL} \mathrm{~g}^{-1} \mathrm{MO}\right)$, ritmo fraccional de producción de gas $\left(c, \mathrm{~h}^{-1}\right)$, desaparición de materia seca $\left(\mathrm{DMS}, \mathrm{g} \mathrm{kg}^{-1}\right)$ y extensión de la degradación en el rumen $\left(\mathrm{ED}, \mathrm{g} \mathrm{k}^{-1}\right)$ de los sustratos lecherina, pastos invadidos por lecherina, pastos no invadidos y pastos invadidos por lecherina a los que se ha sustraído la lecherina, a lo largo de la estación de pastoreo. 


\section{$\underline{\text { Amoniaco y ácidos grasos volátiles }}$}

La tabla 4.6 muestra los resultados de concentración de amoniaco y de producción de ácidos grasos volátiles y metano. Nuevamente se repite la interacción observada en la tabla 4.5: la incubación in vitro de los sustratos estudiados dio lugar a una interacción significativa entre el tipo de pasto y el mes de recogida de la muestra de pasto para la concentración de amoniaco y para la producción de los distintos AGV estudiados y de metano estimado. El pasto no invadido volvió a mostrar las mayores variaciones temporales con descensos severos en los valores obtenidos en el mes de julio mientras que la lecherina se volvió a comportar, a su vez, como el sustrato más estable (ver figura 4.5).

En general, las concentraciones de amoniaco fueron máximas para las incubaciones de pasto no invadido y mínimas para las de lecherina (valores medios de 399 y $267 \mathrm{mg} \mathrm{L}^{-1}$, respectivamente). A su vez, las incubaciones de pasto no invadido produjeron más AGV totales que las incubaciones con los otros sustratos, excepto en las muestras recogidas en el mes de julio donde se invirtió totalmente el resultado. En este caso, el pasto no invadido mostró valores inferiores al resto de sustratos. La superioridad del pasto no invadido en la producción de AGV totales, en todos los meses excepto julio, se puede atribuir principalmente a unos valores significativamente más elevados de propiónico y butírico y de los denominados "otros" AGV (que incluyen isobutírico, valérico, isovalérico y caproico).

Si comparamos el pasto invadido y el pasto invadido sin lecherina, a pesar de la menor concentración de amoniaco en el sustrato lecherina, no se puede decir que la presencia de esta euforbia influyera significativamente en las concentraciones de amoniaco. En cuanto a los AGV, solamente en el caso de la producción de propiónico se encontró una fuerte superioridad del "invasinlech" respecto al pasto invadido. La lecherina mostró producciones de AGV totales superiores a las encontradas en los dos sustratos anteriores, principalmente atribuibles a una mayor producción de acético. En cambio, en el caso del propiónico, la lecherina obtuvo valores similares a los encontrados en el pasto invadido y menores que el "invasinlech". Por otro lado, la lecherina mostró, junto al pasto invadido, las relaciones acético/propiónico (A/P) más elevadas independientemente del mes de muestreo, explicándose así las diferencias observadas entre el pasto invadido y el “invasinlech" (3,78 vs. 2,90; $\mathrm{P}<0,05)$. A su vez, la producción estimada de metano y la relación $\mathrm{CH}_{4} / \mathrm{AGV}$ totales fueron también mayores en las incubaciones realizadas con 
lecherina, respecto al pasto invadido y al "invasinlech" en el caso del metano y respecto al "invasinlech" y al pasto no invadido en la relación $\mathrm{CH}_{4} / \mathrm{AGV}$ totales.

Tabla 4.6 Concentración de amoniaco $\left(\mathrm{NH}_{4} \mathrm{mg} \mathrm{L}^{-1}\right)$, producción de ácidos grasos volátiles (AGV totales $[\mathrm{AGVt}]$, acético $[\mathrm{A}]$, propiónico $[\mathrm{P}]$, butírico $[\mathrm{B}] \mathrm{y}$ "otros" $\left.\mathrm{AGV} ; \mathbf{m m o l} \mathbf{L}^{-1}\right)$, relación acético:propiónico (A:P, mol:mol), producción estimada de metano $\left(\mathrm{CH}_{4}, \mu \mathrm{mol}\right)$ y relación $\mathrm{CH}_{4}: \mathrm{AGV}$ totales $(\mu \mathrm{mol}: \mu \mathrm{mol})$ en incubaciones in vitro de 24 horas de los sustratos lecherina, pastos invadidos por lecherina, pastos no invadidos y pastos invadidos por lecherina a los que se les ha sustraído la lecherina (invasinlech), a lo largo de la estación de pastoreo.

\begin{tabular}{|c|c|c|c|c|c|c|c|c|c|c|}
\hline & & $\mathrm{NH}_{4}$ & AGVt & $\mathbf{A}$ & $\mathbf{P}$ & B & $\operatorname{Otros}^{\mathrm{Y}}$ & $\mathbf{A} / \mathbf{P}$ & $\mathbf{C H}_{4}$ & $\begin{array}{c}\mathrm{CH}_{4} / \\
\mathrm{AGVt}\end{array}$ \\
\hline \multirow{6}{*}{ Pasto } & Lecherina & $267^{\mathrm{c}}$ & $36,63^{\mathrm{b}}$ & $26,87^{\mathrm{a}}$ & $6,71^{\mathrm{c}}$ & $2,23^{\mathrm{b}}$ & $0,81^{\mathrm{c}}$ & $4,02^{\mathrm{a}}$ & $641^{\mathrm{a}}$ & $0,352^{\mathrm{a}}$ \\
\hline & $\begin{array}{l}\text { Invadido por } \\
\text { lecherina }\end{array}$ & $321^{\mathrm{b}}$ & $32,91^{\mathrm{c}}$ & $23,48^{\mathrm{b}}$ & $6,26^{\mathrm{c}}$ & $2,10^{\mathrm{b}}$ & $1,07^{\mathrm{bc}}$ & $3,78^{\mathrm{a}}$ & $561^{\mathrm{bc}}$ & $0,341^{\mathrm{a}}$ \\
\hline & Invasinlech & $342^{\mathrm{b}}$ & $33,68^{\mathrm{c}}$ & $22,57^{\mathrm{b}}$ & $7,77^{\mathrm{b}}$ & $2,12^{\mathrm{b}}$ & $1,22^{\mathrm{b}}$ & $2,90^{\mathrm{b}}$ & $520^{\mathrm{c}}$ & $0,308^{\mathrm{b}}$ \\
\hline & $\begin{array}{l}\text { No invadido } \\
\text { por lecherina }\end{array}$ & $399^{\mathrm{a}}$ & $39,81^{\mathrm{a}}$ & $25,80^{\mathrm{a}}$ & $9,25^{\mathrm{a}}$ & $2,78^{\mathrm{a}}$ & $1,97^{\mathrm{a}}$ & $2,81^{\mathrm{b}}$ & $597^{\mathrm{ab}}$ & $0,302^{\mathrm{b}}$ \\
\hline & e.e.d. & 11,0 & 1,341 & 1,020 & 0,298 & 0,165 & 0,157 & 0,158 & 27,2 & 0,0057 \\
\hline & Sig. & $* * *$ & $* * *$ & $* * *$ & $* * *$ & $* *$ & $* * *$ & $* * *$ & $* *$ & $* * *$ \\
\hline \multirow{7}{*}{ Mes } & Mayo & $308^{\mathrm{b}}$ & $36,81^{\mathrm{ab}}$ & $25,63^{\mathrm{a}}$ & $7,67^{\mathrm{a}}$ & $2,49^{\mathrm{a}}$ & $1,02^{\mathrm{b}}$ & 3,41 & $604^{\mathrm{a}}$ & 0,330 \\
\hline & Junio & $383^{\mathrm{a}}$ & $38,76^{\mathrm{a}}$ & $26,42^{\mathrm{a}}$ & $7,96^{\mathrm{a}}$ & $2,53^{\mathrm{a}}$ & $1,85^{\mathrm{a}}$ & 3,44 & $622^{\mathrm{a}}$ & 0,325 \\
\hline & Julio & $327^{\mathrm{b}}$ & $34,91^{\mathrm{b}}$ & $24,19^{\mathrm{a}}$ & $7,51^{\mathrm{a}}$ & $2,09^{\mathrm{bc}}$ & $1,12^{\mathrm{b}}$ & 3,26 & $563^{\mathrm{ab}}$ & 0,321 \\
\hline & Agosto & $315^{\mathrm{b}}$ & $37,34^{\mathrm{ab}}$ & $25,79^{\mathrm{a}}$ & $7,85^{\mathrm{a}}$ & $2,45^{\mathrm{ab}}$ & $1,24^{\mathrm{b}}$ & 3,42 & $608^{\mathrm{a}}$ & 0,327 \\
\hline & Septiembre & $329^{\mathrm{b}}$ & $30,95^{\mathrm{c}}$ & $21,37^{\mathrm{b}}$ & $6,52^{\mathrm{b}}$ & $1,97^{\mathrm{c}}$ & $1,09^{\mathrm{b}}$ & 3,36 & $502^{\mathrm{b}}$ & 0,324 \\
\hline & e.e.d. & 12,2 & 1,499 & 1,140 & 0,334 & 0,185 & 0,175 & 0,176 & 30,4 & 0,0064 \\
\hline & Sig. & $* * *$ & $* * *$ & $* *$ & $* *$ & $*$ & $* * *$ & $\mathrm{~ns}$ & $* *$ & $\mathrm{~ns}$ \\
\hline \multirow{2}{*}{$\begin{array}{l}\text { Pasto } \\
\text { x mes }\end{array}$} & e.e.d. & 24,5 & 2,999 & 2,280 & 0,667 & 0,369 & 0,350 & 0,352 & 60,7 & 0,0129 \\
\hline & Sig. & $\mathrm{t}$ & $* *$ & $*$ & * & $*$ & $\mathrm{t}$ & $\mathrm{ns}$ & $*$ & $\mathrm{~ns}$ \\
\hline
\end{tabular}

e.e.d.: error estándar de la diferencia. Sig.: nivel de significación estadística (P). ns: no significativo; t: $0,10>\mathrm{P}>0,05 ; *: \mathrm{P}<0,05 ; * *: \mathrm{P}<0,01 ; * * *: \mathrm{P}<0,001$. Valores con diferentes letras en la misma columna difieren significativamente $(\mathrm{P}<0,05)$. ${ }^{\ddagger}$ Dentro del grupo de "otros" AGV se incluyen: isobutírico; valérico, isovalérico y caproico. 

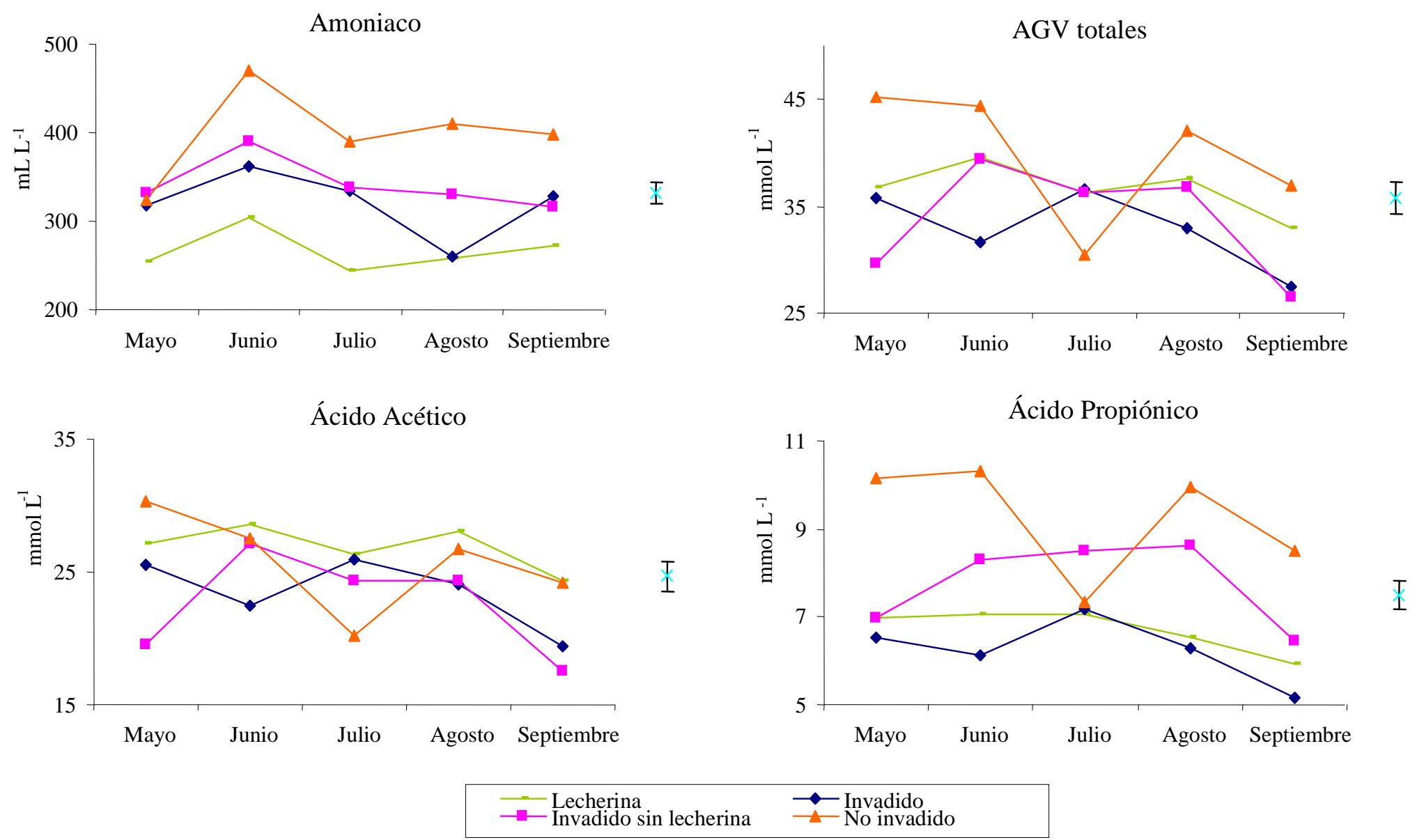

Figura 4.5. Evolución de la concentración de amoniaco $\left(\mathrm{NH}_{4}, \mathrm{mg} \mathrm{L}^{-1}\right)$, producción de ácidos grasos volátiles (mmol $\mathrm{L}^{-1}$; $\mathrm{AGV}$ totales, acético y propiónico) en incubaciones a 24 horas in vitro de los sustratos lecherina, pastos invadidos por lecherina, pastos no invadidos y pastos invadidos por lecherina a los que se les ha sustraído la lecherina, a lo largo de la estación de pastoreo. 


\subsection{Discusión}

\subsubsection{Composición botánica}

El dominio observado de las especies graminoides en los pastos estudiados (tabla 4.1 y figura 4.1), es característico de la mayoría de los pastos herbáceos en áreas de montaña (Aldezabal, 2001; Mandaluniz, 2003). Sin embargo, Mandaluniz (2003) en pastos de montaña a 1000-1300 msnm de altitud en el País Vasco, encuentra una composición porcentual menos dominada por las graminoides (valores medios en pastos dominados por Festuca-Agrostis del 65,5\% en comparación con el 80,6\% de nuestro pasto de FestucaAgrostis no invadido, situación más comparable). No obstante, hay que tener en cuenta que, además de las diferentes ubicaciones geográficas, su estimación de la composición botánica fue a nivel de cobertura de cada componente en el pasto y no como proporción en peso.

Los niveles de presencia de la E. polygalifolia encontrados en los pastos invadidos, cercanos al 45\%, son elevados. Sin embargo, en pastos invadidos por Euphorbia esula en EE.UU., se han llegado a registrar porcentajes superiores, con valores entre el 50 y el $65 \%$ en pastos no tratados (Kirby et al., 1997).

La composición botánica de los pastos estudiados se vio afectada significativamente por la invasión de E. polygalifolia. Lógicamente, la proliferación de lecherina en los pastos invadidos se tradujo en que las proporciones de todos los demás componentes botánicos fueron significativamente menores respecto a las encontradas en los denominados "pastos no invadidos". Estos resultados coinciden con lo apuntado por Belcher y Wilson (1989) en un estudio de la composición botánica de pastos invadidos por Euphorbia esula en Canadá. En cualquier caso, las diferencias encontradas entre el pasto no invadido y el pasto invadido al que se le sustrae la lecherina (invasinlech), sugieren que las proporciones en peso de los distintos componentes botánicos en los pastos de Festuca-Agrostis de Sejos, no se vieron afectadas únicamente por el efecto directo de la progresión de un componente, la lecherina, que llega a copar casi la mitad de su biomasa. Varios autores (Coughenour, 1991; Alonso, 1994; Aldezabal, 2001) han puesto de manifiesto que la ausencia prolongada de pastoreo puede influir en la composición botánica de los pastos. En nuestro caso, el rechazo al consumo de lecherina por parte del ganado presente en la zona (vacuno y caballar), estaría protegiendo de la defoliación al resto de las especies cercanas a los brotes de lecherina. En este sentido, el aumento constatado de las especies graminoides y el 
descenso de las dicotiledóneas en los pastos "invasinlech" (apenas pastoreados) respecto a los pastos no invadidos (intensamente defoliados por el ganado), coincide con lo encontrado por Aldezabal (2001) tras comparar zonas excluidas y no excluidas al pastoreo en comunidades vegetales de alta montaña utilizadas notablemente por el ganado. Las rosetas y, en general, las formas de crecimiento de porte bajo típicas de las dicotiledóneas pratenses, están mejor adaptadas a las condiciones de pastoreo que a las condiciones de exclusión (Treskonova, 1991). El pastoreo del ganado elimina las graminoides de mayor porte, reduciendo la competencia por la luz, mientras que su porte bajo permite a las dicotiledóneas eludir los efectos de la defoliación por el ganado (Briske, 1996).

En cuanto a la evolución temporal de la composición botánica de los pastos estudiados, destaca lo ocurrido en el pasto invadido en el mes de agosto: se maximiza la presencia de lecherina y de otras latifoliadas y se minimiza la proporción de graminoides. Esta situación contrasta con la estabilidad temporal encontrada en el pasto no invadido. Es posible que la escasa disponibilidad de pasto herbáceo registrada en la parte final de la estación de pastoreo en Sejos, obligase a vacas y yeguas a tratar de aprovechar parcialmente las graminoides de mayor porte dentro de los parches de pasto colonizados por lecherina. Es decir, los animales habrían seleccionado las partes del pasto invadido más accesibles, minimizando el riesgo de ingerir lecherina en el mismo bocado. Esta interpretación concuerda con los resultados de Busqué et al. (2003), quienes encontraron un aumento del aprovechamiento por el ganado de los pastos invadidos por lecherina en esa parte final de la estación de pastoreo, coincidiendo también con la dinámica de la selección de estos pastos por el ganado descrita en el capítulo 5. A su vez, la escasa capacidad de selección del ganado vacuno y caballar, atribuible a su morfología bucal (Edwards y Hollis, 1982; Hoffman, 1988), sobre pastos herbáceos de altura muy baja, como es el caso de los pastos no invadidos, explicaría la estabilidad de la composición botánica de estos a lo largo de la estación de pastoreo.

\subsubsection{Composición química}

En otra euforbia invasora, la ya mencionada en diversas ocasiones Euphorbia esula, Fox et al. (1991) registraron mayores niveles de proteína bruta (15,6-27,3\%) y menores contenidos de fibra neutro detergente (17,9-33,8\%) según su estado fenológico, que los anteriormente descritos para E. polygalifolia $(9,65-14,71$ y 30,92-37,56\%, para PB y FND, 
respectivamente; tabla 4.2 y figura 4.2). No obstante, la lecherina mostró unos contenidos de materia orgánica y proteína bruta similares a los valores habituales en pastos herbáceos de puerto comúnmente aprovechados por el ganado (Revesado, 1994; Mandaluniz, 2003; García-González et al., 2005). Además, los valores de pared celular (FND y FAD) de la $E$. polygalifolia fueron muy inferiores a los señalados por dichos autores.

En función de estos resultados, no se puede interpretar que el rechazo del ganado vacuno y caballar hacia la lecherina y la consecuente proliferación de la misma, sea achacable a los parámetros químicos anteriormente citados. Sin embargo, existe una superioridad en los valores de proteína bruta de los pastos no invadidos respecto a los demás, incluyendo a la lecherina, que podría justificar una selección por el ganado a favor de dichos pastos no invadidos, ya que se sabe que el contenido en proteína es uno de los factores que pueden influir en la selección de la dieta en pastoreo (Senft et al., 1985). Ahora bien, la escasa disponibilidad por unidad de superficie de estos pastos (biomasa disponible media inferior a $40 \mathrm{~g} / \mathrm{m}^{2}$ incluso al inicio de la estación de pastoreo; Mora et al., 2007b) nos lleva a pensar que esta selección no pudo justificar, por sí sola, el claro rechazo mostrado por el vacuno hacia los pastos invadidos por lecherina. En este último trabajo citado, se intentó comprobar otra hipótesis relacionada con los patrones de selección del ganado en pastoreo, según la cual la mayor incidencia de invasión de E. polygalifolia sobre los pastos dominados por Festuca-Agrostis respecto a otros pastos herbáceos de Sejos sería consecuencia de su mayor utilización forrajera por el ganado, derivada posiblemente de su mayor valor nutritivo. Para ello, se comparó la disponibilidad vegetal, como estimador indirecto de la utilización forrajera, y algunos parámetros indicativos del valor nutritivo de los pastos de Festuca-Agrostis y cervunales (segunda comunidad herbácea en importancia en Sejos; ver tabla 2.1) a lo largo de la estación de pastoreo. Los resultados de ese estudio no mostraron diferencias significativas ni en la disponibilidad vegetal ni en la composición química y utilización digestiva de los dos tipos de pasto comparados, con la única excepción de algunos contenidos de minerales. Por lo tanto, no se pudo verificar la hipótesis de partida, si bien habría que profundizar en el conocimiento de las relaciones entre los contenidos de minerales en el pasto y el comportamiento del ganado en pastoreo. A su vez, convendría tener en cuenta que la diferente susceptibilidad de estas dos comunidades a la invasión por lecherina, también podría ser debida a diferencias en sus valores de utilización forrajera crítica (Rickert, 1996), fruto de diferentes características ecológicas, (por ejemplo, capacidad de retención hídrica o textura del suelo), capaces de 
potenciar o atenuar la competitividad de la lecherina en el proceso de invasión (Archer, 1996).

En el caso de la Euphorbia esula, que tampoco es consumida por el ganado vacuno (Lym y Kirby, 1987; Hein y Miller, 1992; Heemstra et al., 1999), este rechazo se ha relacionado con el desarrollo de aversiones condicionadas (Kronberg et al., 1993) frente a determinados compuestos secundarios presentes en la planta como taninos (Roberts y Olson, 1999) y terpenoides (Kronberg et al., 1995; Halaweish et al., 2002). En concreto, Roberts y Olson (1999) encontraron taninos en hojas, flores y tallos de E. esula (hasta 35 $\mathrm{mg} / \mathrm{g}$ de taninos condensados, según el método del vainíllico en medio ácido), registrando una correlación negativa entre el contenido de taninos y la degradación ruminal de la materia seca y entre la FND y la producción de gas in vitro. Respecto a los contenidos de taninos totales detectados en nuestro estudio (tabla 4.3), se puede decir que los niveles encontrados en la lecherina son elevados, por encima de los observados en especies arbustivas también presentes en el área de estudio como la Erica vagans (Hervás et al., 2003) perteneciente a la familia de las ericáceas, conocida por sus notables contenidos en taninos (Frutos et al., 2002), por lo que cabe esperar que fueran uno de los grupos de compuestos secundarios implicados en el rechazo del ganado vacuno al consumo de euforbiáceas. No obstante, a tenor de los resultados de las incubaciones in vitro de lecherina en presencia y en ausencia de PEG, no se puede decir que los contenidos de taninos totales tuvieran un efecto tan negativo como era esperable, en función de su contenido, sobre la producción de gas, ya que esta aumentó en valores comprendidos entre el 9,1 y el 14,4\%, cuando en otras especies vegetales con contenidos similares de taninos totales se han registrado aumentos hasta 30 veces superiores (Mlambo y Makkar, 2005). En todo caso, hay que tener en consideración que tanto las posibles diferencias en las estructuras de los taninos estudiados como el empleo de diferentes metodologías analíticas dificultan la comparación de los valores numéricos obtenidos en estos trabajos (ver revisión Frutos et al., 2004a).

Por su parte, Kronberg et al. (1995) y Halaweish et al. (2002) han puesto de manifiesto que terpenoides del tipo ingenano presentes en E. esula son capaces de crear aversiones y, por lo tanto, ser al menos responsables parciales del rechazo del ganado vacuno hacia la euforbiácea, ya que diversos trabajos han relacionado negativamente las concentraciones de terpenoides con el consumo por los animales de las especies vegetales donde se encuentran (Duncan et al., 1994; Pritz el al., 1997) y con la actividad microbiana 
en el rumen (Oh et al., 1967). Sin embargo, hay que tener en cuenta la enorme cantidad de compuestos englobados tanto dentro del grupo de los terpenoides como del de los taninos y la complejidad de sus interacciones (Langenheim, 1994). En este sentido, los compuestos apuntados por Halaweish et al. (2002), del tipo ingenano, como posibles implicados en el desarrollo de aversiones frente al consumo de Euphorbia esula, no fueron encontrados en la lecherina, en las condiciones analíticas utilizadas (figura 4.3 y tabla 4.4). No obstante, sí que se encontraron otros compuestos terpenoidales que bien directamente o a través de interacciones entre sí o con otros compuestos, podrían estar implicados en la generación de aversiones y en el consiguiente rechazo del ganado vacuno hacia el consumo de lecherina.

Dejando ya el tema de los compuestos secundarios, la invasión de lecherina en los pastos de Festuca-Agrostis modificó otros aspectos de su composición química. En concreto, el pasto invadido alcanzó un contenido de FND significativamente inferior al encontrado en el pasto no invadido. En principio hubiera sido esperable un resultado opuesto ya que un elevado aprovechamiento del pasto por el ganado minimizaría la acumulación de tejidos fibrosos en los pastos no invadidos. De hecho, el pasto "invasinlech", es decir, la fracción del pasto invadido que no es lecherina, mostró unos valores de FND superiores al resto de los pastos, indicando que la proliferación de lecherina causó posiblemente un embastecimiento de las especies acompañantes, resultado a su vez, de su escaso aprovechamiento por el ganado (Busqué et al., 2003). Además, la menor proporción de dicotiledóneas registrada en el pasto "invasinlech", también pudo favorecer este resultado, dados los menores contenidos, en líneas generales, de pared celular en las especies dicotiledóneas en comparación con las graminoides (Gordon, 1989a; Van Soest, 1994). En cualquier caso, los bajos valores de FND de la lecherina junto a su elevada presencia en el pasto invadido, habrían sido capaces de contrarrestar tanto el embastecimiento como el cambio en la composición botánica del pasto invadido.

Por otra parte, la invasión de lecherina también pudo ser responsable indirectamente del menor contenido proteico del pasto "invasinlech" respecto al pasto no invadido. En este sentido, las diferencias en la composición botánica de estos dos pastos podrían justificar en parte esos distintos contenidos proteicos. En concreto, la mayor presencia de dicotiledóneas y menor de graminoides en el pasto no invadido justificarían, según distintos autores (Gordon, 1989a; Marinas et al., 2003; Bovolenta et al., 2008), sus mayores niveles de proteína bruta. Sin embargo, otro parámetro que podría explicar las mencionadas diferencias en los contenidos proteicos pudo ser el estado fenológico de los 
pastos. En este sentido, el mayor aprovechamiento por el ganado del pasto no invadido favorecería el mantenimiento de estados fenológicos vegetativos, normalmente de mayor contenido proteico (Mattson, 1980).

En cuanto a la evolución de los parámetros de composición química con el tiempo, los contenidos de proteína bruta fueron máximos al inicio de la estación de pastoreo, coincidiendo con los estadios iniciales de crecimiento del pasto. Posteriormente, estos contenidos descendieron en todos los pastos estudiados conforme avanzó la estación de acuerdo con el patrón característico descrito por otros autores (Alonso, 1994; Ammar et al., 1999; Marinas et al., 2003; García-González et al., 2005). En este sentido, se sabe que las mayores concentraciones de nitrógeno se dan en los tejidos vegetales jóvenes y en crecimiento, ya que resultan necesarias para soportar los elevados ritmos de síntesis proteica que se mantienen en esos estados fenológicos. Estas concentraciones suelen descender con el avance de la estación de crecimiento hasta la senescencia del tejido vegetal, minimizándose la síntesis proteica y activándose procesos de hidrólisis y translocación de la proteína hacia las partes perennes de la planta (Mattson, 1980).

Por su parte, los contenidos de FND y FAD siguieron, en general, la evolución contraria a la descrita para la proteína; es decir, sus valores aumentaron con el avance de la estación de pastoreo, tal como es característico en el desarrollo fisiológico de las especies forrajeras, ya que el contenido de carbono estructural tiende a aumentar a lo largo del ciclo vegetativo de las plantas (Kilcher, 1981). Sin embargo, esa tendencia se vio truncada, para todos los pastos, en las muestras recogidas en el mes de agosto. En el caso de los pastos invadidos e "invasinlech" pudo influir el aumento registrado en ese mes de la proporción de especies dicotiledóneas, ya que estas plantas suelen presentar unos menores contenidos de pared celular en comparación con las graminoides (Bovolenta et al., 2008). Sin embargo, cabe pensar que ese no es el único factor que influyó en el descenso de los contenidos en pared celular en agosto, dado que en los pastos no invadidos (donde no se apreciaron esos cambios en la composición botánica) e incluso en la propia lecherina, también se constató dicho descenso. En este sentido, pudo producirse en esas fechas un rebrote del pasto, generándose nuevos tejidos vegetales con menores contenidos en carbono estructural (Kilcher, 1981). Aunque no se registraron datos pluviométricos durante el estudio, no es inusual el rebrote del pasto al final del verano, coincidiendo con periodos de lluvias tras periodos de escasez de precipitaciones (Busqué et al., 2003). 


\subsubsection{Cultivos discontinuos de microorganismos ruminales: producción de gas y degradación ruminal in vitro}

La lecherina mostró una superioridad muy clara en sus ritmos de fermentación ruminal respecto al resto de sustratos estudiados (tabla 4.5 y figura 4.4), coherentemente con sus contenidos significativamente inferiores de pared celular (Doane et al., 1997). Los valores de desaparición de materia seca (DMS) tras 144 horas de incubación también fueron máximos en la lecherina salvo en los meses de mayo y junio en los que el pasto no invadido alcanzó niveles superiores. Consecuentemente, la extensión de la degradación en el rumen también resultó más elevada en el caso de la euforbiácea. En general, los menores valores de producción de gas asintótica $(A)$ fueron registrados en el pasto invadido mientras que los máximos se obtuvieron en el "invasinlech". Estas diferencias se podrían justificar en parte por los menores valores de $A$ encontrados en la lecherina respecto al invasinlech. Sin embargo, dado que el pasto invadido mostró unos resultados significativamente por debajo de los encontrados en la lecherina, es factible pensar que la lecherina pudo influir en que la fracción del pasto invadido que no es lecherina fuera potencialmente menos degradable. Los contenidos en compuestos secundarios de la lecherina podrían estar detrás de estos efectos ya que, por ejemplo, se han encontrado correlaciones negativas entre los valores de $A$ y los contenidos de taninos atribuidas al efecto supresor de los taninos sobre la degradación ruminal (Frutos et al., 2002).

La lecherina presentó una producción de gas asintótica, un ritmo fraccional de producción de gas y un ritmo medio de fermentación similares a los obtenidos incubando heno de alfalfa también con inóculo ruminal de oveja y ajustando estos parámetros a un mismo modelo matemático (Hervás et al., 2005). Además la extensión de la degradación en el rumen es, dentro de esta misma comparación, del orden de un $30 \%$ superior en la euforbiácea. Por otra parte, habría que tener en cuenta que las ovejas que donaron los inóculos ruminales para nuestro estudio no habían ingerido previamente E. polygalifolia y, por tanto, las poblaciones microbianas del rumen no habrían tenido la posibilidad de adaptarse a esta planta (Yokoyama y Johnson, 1988; Duncan et al., 1997). Estos resultados podrían en principio abrir una puerta a la utilización de la lecherina como alimento para el ganado ovino dado que, tanto su composición química convencional como su utilización digestiva por estos animales podrían equipararse a las de un forraje apreciado como es el heno de alfalfa. A su vez, el aprovechamiento en pastoreo de la lecherina como alimento para las ovejas, ofrecería la posibilidad de emplear este tipo de ganado como herramienta 
de control biológico frente a la proliferación de esta planta, al igual que se ha propuesto en el caso de la invasión de E. esula en Norte América, donde se ha observado que las ovejas son capaces de consumir esta euforbiácea sin sufrir aparentemente sus posibles consecuencias tóxicas (Landgraf et al., 1984; Bangsund et al., 2001). En un experimento llevado a cabo con ganado ovino en una zona de Sejos muy invadida por la $E$. polygalifolia, se comprobó no sólo una significativa defoliación de los brotes de lecherina sino también que las ovejas no mostraban ni signos aparentes de intoxicación, ni efectos negativos sobre su rendimiento productivo. De hecho, los cambios de peso vivo mostraron una correlación significativa con la altura del pasto, pero no con el porcentaje de defoliación de la E. polygalifolia, que sería indicativo de la cantidad consumida (Mora et al., 2007a).

Evidentemente, los resultados de utilización digestiva de la lecherina aquí presentados tampoco justificarían el rechazo tan acusado de esta euforbiácea por parte del ganado vacuno por lo que, como ya se ha comentado en el apartado anterior de composición química y al igual que en el caso de la Euphorbia esula, habría que buscar en otros factores como los contenidos de compuestos secundarios, una justificación a dicho rechazo (Kronberg et al., 1995; Halaweish et al., 2002). En este sentido, y en relación también con el párrafo anterior, se sabe que existen diferencias entre rumiantes (por ejemplo vacas y ovejas) en la susceptibilidad al consumo de compuestos secundarios, reflejo posiblemente de la estrategia de alimentación con la que ha evolucionado cada especie (Cheeke y Palo, 1995). Esta evolución, plasmada en diferencias en sus sistemas de destoxificación permitiría que algunas especies puedan, tras un periodo de adaptación, consumir plantas potencialmente tóxicas sin sufrir sus consecuencias negativas (Duncan et al., 1997; Duncan et al., 2000). No obstante, este tema se tratará con mayor profundidad en el capítulo 6.

Por otro lado, la fracción de pared celular tiene generalmente una influencia negativa en la digestibilidad de los pastos (Kaitho et al., 1998), de modo que la superioridad del pasto no invadido respecto al pasto invadido y al "invasinlech" en los ritmos de fermentación podrían ser consecuencia de su mayor contenido en leguminosas y otras latifoliadas con una mayor proporción de contenidos celulares y de pectinas en sus paredes celulares, compuestos todos ellos rápidamente fermentables por los microorganismos ruminales (Hatfield y Weimer, 1995). 
Aunque el progresivo descenso de los parámetros indicativos de la fermentación ruminal in vitro con el avance de la estación de pastoreo, tal y como se observa en nuestros resultados, es habitual (Ammar et al., 2004), destaca en el pasto no invadido por lecherina un descenso brusco y generalizado de dichos parámetros en el mes de julio respecto a los dos controles anteriores. Este descenso coincide con una presión de pastoreo elevada sobre este tipo de pasto en esa época, unida al posible déficit hídrico ya comentado. En principio, parece lógico que sean los pastos no invadidos los que más padezcan el déficit hídrico de julio debido a que, al sufrir una mayor defoliación vía pastoreo, tendrían que compensar esa pérdida de tejidos aéreos a costa del crecimiento radicular, con la consiguiente pérdida de resistencia a la sequía (Dawson et al., 2000). En este sentido, el efecto del avance de la estación de pastoreo sobre la fermentación ruminal podría ser explicado por la evolución de los contenidos de los principales componentes de las paredes celulares (celulosa, hemicelulosa y lignina). Por un lado, Chaves et al. (2006) relacionaron la madurez de las especies pascícolas con un descenso de la proporción de hoja/tallo para justificar el declive de los parámetros indicativos de la utilización digestiva de diversas gramíneas por los rumiantes. Por otro lado, Marinas et al. (2003) sugieren que determinadas estructuras físicas podrían formar una barrera que dificultara la acción microbiana sobre los tejidos potencialmente fermentables en las muestras recogidas al final de la estación de pastoreo, en comparación con las de los primeros meses de la misma. Por ello, la lignificación de las plantas conforme estas maduran (que pesaría más en el caso de las leguminosas) no sería, en términos cuantitativos, el único factor responsable de parte de los cambios en la fermentación microbiana de los distintos tejidos, sino que también influiría su localización específica dentro de estos (Van Soest, 1994).

En cuanto a las concentraciones de amoniaco y producciones de ácidos grasos volátiles y de metano, como indicativos de la fermentación ruminal, las concentraciones de amoniaco encontradas en las incubaciones de todos los sustratos estudiados superaron tanto los $100 \mathrm{mg} \mathrm{L}^{-1}$ indicados por Van Soest (1994) como óptimos para la síntesis de aminoácidos y el crecimiento microbiano, como los $235 \mathrm{mg} / \mathrm{L}$ necesarios según Mehrez et al. (1977) para maximizar la degradación de la materia orgánica (tabla 4.6 y figura 4.5). Las concentraciones de amoniaco en las incubaciones de lecherina fueron significativamente menores a las del resto de los sustratos estudiados. Si bien esta inferioridad era esperable respecto al pasto no invadido por sus mayores contenidos de proteína bruta, no lo era tanto respecto al pasto invadido y al "invasinlech", ya que no 
existían diferencias significativas en los niveles de proteína bruta de los tres sustratos. La justificación de estos resultados podría estar relacionada con la presencia de taninos en la lecherina, ya que estos compuestos son capaces de disminuir la degradación de la proteína en el rumen mediante la formación de complejos tanino-proteína (Driedger y Hartfield, 1972; Hagerman et al., 1992). Sin embargo, contrariamente a lo esperado, la presencia de lecherina en el pasto invadido no llegó a plasmarse en diferencias significativas entre este y el "invasinlech".

Dado que los valores de propiónico registrados para la lecherina fueron similares a los encontrados en el pasto invadido y menores que en el "invasinlech", se podría sugerir que la lecherina tuvo un efecto depresor de la producción de propiónico en el caso del pasto invadido. En este sentido, Núñez-Hernández et al. (1991) detectaron una mayor producción de propiónico en ovejas y cabras que ingerían taninos inactivados por la presencia de PEG en relación a los animales que consumían taninos (sin PEG), al igual que Hill et al. (1986) en terneros con dietas que incluían un alimento rico en taninos en comparación con dietas sin ese alimento.

La lecherina mostró las producciones más elevadas de acético junto con el pasto no invadido, y las mayores relaciones acético/propiónico, resultados que podrían ser interpretados en principio como la ocurrencia de una mayor degradación de la fibra en el caso de las incubaciones con lecherina, dado que el acético es uno de los principales metabolitos de la flora celulolítica (Dijkstra, 1994). Así mismo, la lecherina favoreció la producción de los AGV englobados dentro del grupo "otros AGV" ya que tanto el propio sustrato lecherina como el pasto invadido mostraron unas mayores producciones que los otros dos sustratos. La producción de estos AGV está relacionada con la degradación de determinados aminoácidos, por lo que su mayor presencia se relaciona generalmente con una mayor liberación de nitrógeno degradable en el rumen (López et al., 2005).

Ahora bien, tanto estos últimos resultados como los descritos previamente en referencia al acético estarían contradiciendo la tendencia esperable si atendemos a la presencia de taninos en la lecherina. Sin embargo, podrían haberse producido interacciones entre los taninos y otros compuestos secundarios de la lecherina como los terpenoides, distorsionando los resultados en principio esperables de alguno de los parámetros estudiados (Duncan et al., 2000; Makkar, 2003; Mbugua et al., 2008). En concreto, la ocurrencia de interacciones entre taninos y terpenoides ha sido puesta de manifiesto por ejemplo en pruebas de preferencia con corderos, encontrándose diferencias en la ingestión 
de estos compuestos secundarios en función de las combinaciones de sus concentraciones en las dietas ofertadas (Mote et al., 2007). En este sentido, la presencia de determinadas combinaciones de distintos compuestos secundarios podría llevar a minimizar alguno de sus efectos característicos como sería el caso de la reducción de la proteolisis (Lyman et al., 2008; Rogosic et al., 2008).

Por último, la producción estimada de metano y la relación $\mathrm{CH}_{4} / \mathrm{AGV}$ totales, la cual puede ser un indicador de la cantidad de energía obtenida en el rumen por unidad de sustrato fermentado, presentaron los valores más elevados para la lecherina, lo que sugiere un descenso de la eficiencia energética en las incubaciones de esta euforbiácea.

\subsection{Conclusión e implicaciones}

La composición botánica de los pastos de Festuca-Agrostis se vio afectada significativamente por la invasión de lecherina, tanto directamente por la elevada presencia de esta euforbiácea en los pastos invadidos $(44,5 \%)$, como indirectamente por su efecto sobre los demás componentes (leguminosas, graminoides y otras latifoliadas). Estas diferencias se tradujeron en variaciones significativas en la composición química (contenido de MO, PB, FND y FAD) y utilización digestiva de los pastos invadidos respecto a los no invadidos. Sin embargo, dichas diferencias no justificarían por sí mismas el acusado rechazo del ganado vacuno hacia los pastos invadidos. En cambio, la presencia en la lecherina de taninos y terpenoides sí podría explicar dicho rechazo, mediante el desarrollo por el ganado de aversiones condicionadas hacia los alimentos que contienen estos compuestos secundarios.

Por lo tanto, aunque en esta prueba no fue posible realizar una valoración nutritiva sensu stricto (energética y proteica), nuestros resultados de composición y utilización digestiva sugieren que los pastos invadidos por lecherina presentarían, a lo largo de la estación de pastoreo, un menor valor nutritivo que los pastos libres de la invasión, lo cual apunta hacia la verificación de la hipótesis de partida. 

5. PRUEBA 2. Características del pastoreo estival del ganado vacuno y caballar en un puerto de la Cordillera Cantábrica invadido de lecherina (Euphorbia polygalifolia) 



\subsection{Introducción.}

La proliferación de especies vegetales potencialmente tóxicas para el ganado en pastos naturales puede ocasionar diversos impactos negativos sobre estos ecosistemas: pérdida de biodiversidad (Parmenter y MacMahon, 1983; Belcher y Wilson, 1989), incremento de la erosión del suelo (Lacey et al., 1989), deterioro de los hábitats de vida salvaje (Trammell y Butler, 1995; Sheley et al., 1998) y descenso del potencial productivo del ganado (Di Tomaso, 2000; Panter et al., 2002).

En el caso concreto de la lecherina (Euphorbia polygalifolia), las causas determinantes de su propagación desde las comunidades arbustivas donde comúnmente se encuentra (Díaz y Fernández-Prieto, 1994), hacia los pastos herbáceos de puerto aledaños pueden ser diversas. En todo caso, el análisis de este proceso de invasión vegetal debería enfocarse como un estudio ecológico comparativo del efecto de distintos factores sobre el crecimiento y la dinámica poblacional de la lecherina y de las especies más representativas del pasto herbáceo. De esta forma, la invasión de lecherina se produciría cuando la acción de estos factores fuese más favorable para ella que para las plantas características del pasto.

Uno de los principales factores que afectan a la dinámica y estructura de la vegetación en estos ecosistemas es, sin lugar a dudas, el pastoreo (McNaughton, 1983; Belsky, 1986). En este sentido, se plantea la hipótesis de que el proceso de invasión de lecherina en el pasto herbáceo se ha visto activamente favorecido por los cambios recientes en los sistemas de pastoreo utilizados en el puerto objeto del estudio (Sejos, Mancomunidad Campoo-Cabuérniga). Esta hipótesis se apoya en la percepción por los ganaderos usuarios del puerto de que el comienzo de la expansión de la lecherina coincidió en el tiempo con cambios drásticos en los sistemas de manejo del ganado en puerto. Hasta los años setenta del siglo pasado, el ganado, mayoritariamente vacuno autóctono de raza tudanca, era manejado en pastoreo por vaqueros, con límites en el puerto bien definidos para cada pueblo. Esto permitía un aprovechamiento espacial más homogéneo y controlado de los pastos. La desaparición de este sistema condujo a una mayor libertad en el pastoreo del ganado (ver capítulo 2), lo que unido a la amplia sustitución del ganado tudanco por vacuno de razas foráneas y por ganado caballar pudo dar lugar a un aprovechamiento más heterogéneo del territorio con altas concentraciones de animales en las zonas más favorables (Gómez-Sal et al., 1995). 
La escasa utilización por el ganado de las zonas menos accesibles deriva habitualmente en procesos de matorralización (Dullinger et al., 2003; Bartolomé et al., 2005; Riedel, 2007). Por otro lado, las áreas sobreutilizadas experimentan, en muchos casos, la invasión por especies poco apetecibles para el ganado (Allen et al., 1991; Biondini et al., 1998; Jauffret y Lavorel, 2003).

En sistemas de pastoreo con escasa influencia humana, los patrones de distribución de los grandes herbívoros están regulados por factores abióticos (topografía, localización de puntos de agua, climatología, etc.) y bióticos (especie y raza de ganado, calidad y cantidad de pasto, etc.), afectando todos ellos al equilibrio del ecosistema pastoral (Rittenhouse, 1986; Coughenour, 1991; Bailey et al., 1996). Además, el pastoreo es una actividad compleja que comporta múltiples procesos a distintas escalas espacio-temporales. La importancia de esta percepción escalar radica en que el efecto de los factores tanto de tipo abiótico como biótico sobre el pastoreo es diferente según la escala a la que se estudie. Así, el animal que pastorea valora las consecuencias obtenidas en los niveles de selección de escala espacial más detallada (bocados, puntos de pastoreo, manchas de pasto) a la hora de evaluar las alternativas de selección a niveles de menor detalle (sesión de pastoreo, unidad pastoral, zona geográfica de pastoreo) (Bartholomew 1964; Senft et al., 1987; Bailey et al., 1996).

En este capítulo se presenta un estudio de los patrones de pastoreo estival del ganado en el puerto de Sejos. En concreto, se plantean dos hipótesis sobre el comportamiento del ganado en pastoreo y su relación con la invasión de lecherina en los pastos herbáceos dominados por Festuca nigrescens y Agrostis capillaris, basadas en las observaciones de años previos:

1. Los distintos tipos de ganado presentes en el puerto (caballar y vacuno) utilizan el territorio de forma diferente. En este sentido, el ganado caballar concentra más su actividad en los pastos herbáceos y, dentro de estos, en los pastos de FestucaAgrostis.

2. A lo largo del verano se producen cambios en los patrones de pastoreo. Aunque inicialmente el ganado tiende a concentrarse en los pastos de Festuca-Agrostis, la elevada carga ganadera obliga a una utilización cada vez más equilibrada de todos los recursos forrajeros disponibles. Al final de la estación de pastoreo, la 
disminución de la carga ganadera favorece la selección de los pastos de FestucaAgrostis.

La verificación de estas hipótesis permitiría entender mejor las causas que producen el sobrepastoreo de los pastos de Festuca-Agrostis y que están conduciendo a su degradación a través de la invasión de la lecherina.

\subsection{Material y Métodos}

\subsubsection{Seguimientos}

Se realizaron un total de 33 seguimientos completos de vacas y yeguas, distribuidos en 3 épocas (inicio: desde el 22 de junio hasta el 21 de julio; medio: desde el 28 de julio hasta el 19 de agosto; final: desde el 2 hasta el 16 de septiembre) a lo largo de la estación de pastoreo de 2004. Las épocas se caracterizaron por unas cargas ganaderas y una disponibilidad de recursos forrajeros diferentes (ver tabla 5.1). La disponibilidad de pasto herbáceo se estimó mediante un muestreo de las manchas de este tipo de vegetación utilizadas por los animales en cada seguimiento. Cada muestreo consistió en la recogida de $1 \mathrm{~m}^{2}$ de forraje mediante siega a ras de suelo y en cuatro puntos diferentes de la mancha de vegetación aprovechada.

Cada seguimiento diario se realizó desde la salida a la puesta de sol y se focalizó sobre un animal elegido aleatoriamente entre todos los individuos adultos y sin cría de un rebaño. En ningún caso se muestreó un mismo individuo más de un día.

Se procuró alternar la especie ganadera (vacuno-caballar) en cada seguimiento diario consecutivo para equilibrar, en la medida de lo posible, el diseño experimental. Los seguimientos de ganado vacuno incluyeron vacas de raza tudanca, limusina y charolesa seleccionadas en función de su representatividad en el puerto (ver capítulo 2). Las yeguas eran todas "del país" poco mejoradas.

En cada sesión, tras realizar la identificación y descripción del animal (con el fin de facilitar su seguimiento a lo largo del día), se registraron con una periodicidad de 20 minutos las coordenadas geográficas de su posición mediante un sistema GPS (Sistema de Posicionamiento Global), verificando las mismas sobre el terreno con una ortofoto aérea 
(E: 1/2.000; fecha de vuelo: 2001; figuras 5.1 y 5.2), así como su actividad (pastoreo, descanso o desplazamiento).

Tabla 5.1. Seguimientos diurnos realizados en el estudio y características del pastoreo en el puerto de Sejos.

$$
\text { Inicio Medio Final }
$$

22 Junio-21 Julio 28 Julio-19 Agosto 2-16 Septiembre

\begin{tabular}{cccc}
$\mathrm{N}^{\mathrm{o}}$ yeguas seguidas & 6 & $5 *$ & $4^{*}$ \\
$\mathrm{~N}^{\mathrm{o}}$ vacas seguidas & 6 & 6 & 6 \\
\hline Carga ganadera media & 1,13 & 1,05 & 0,48
\end{tabular}

Biomasa en pie de pasto

Festuca-Agrostis-Nardus $\left(\mathrm{gm}^{-2}\right)$

$44 \quad 39 \quad 29$

1 Datos correspondientes a 2003 (tabla 2.21), considerando a un individuo adulto de vacuno o caballar como una UGM (Unidad de Ganado Mayor). * Por causas no previstas inicialmente no se pudieron completar los 3 seguimientos de yeguas que hubieran permitido tener un diseño experimental equilibrado. 


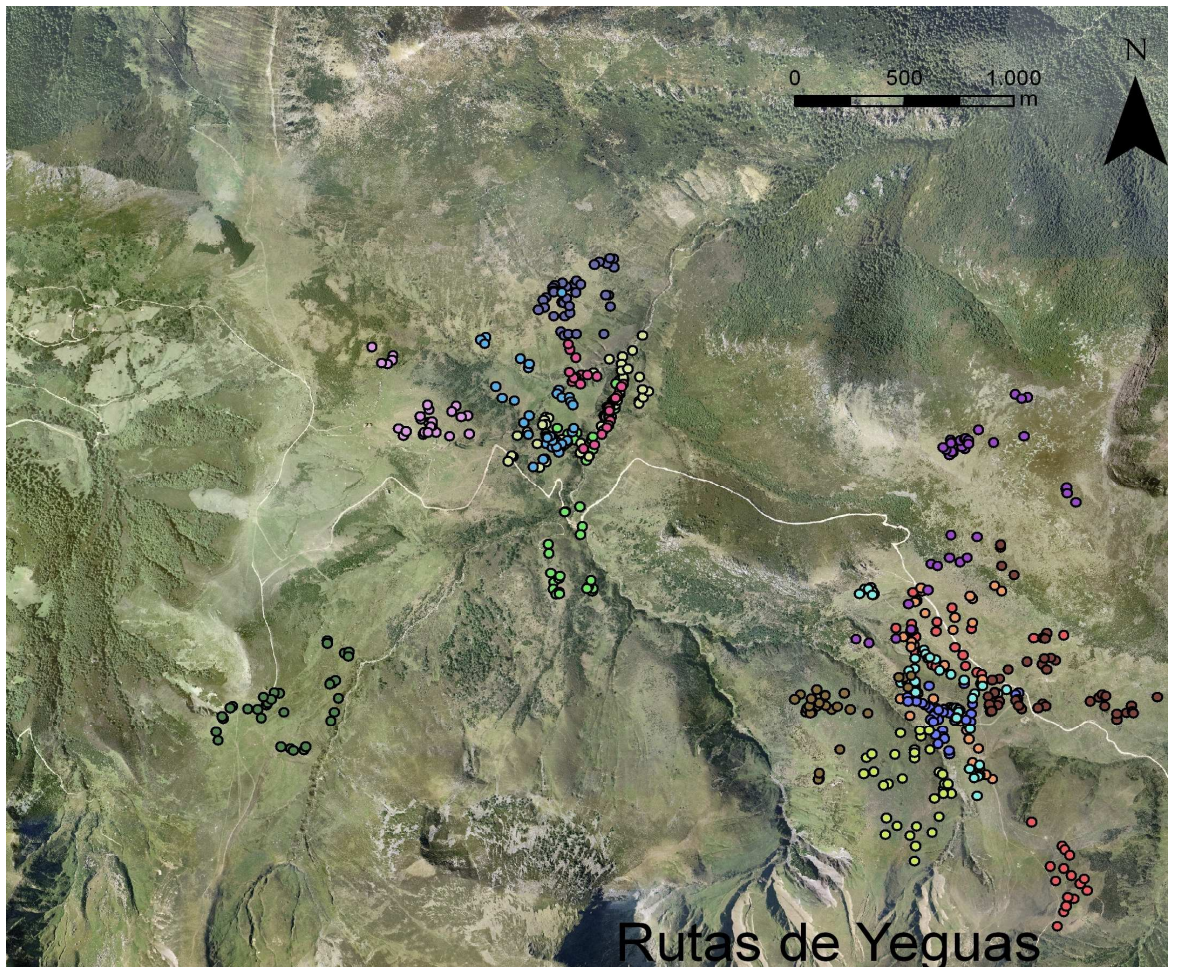

Figura 5.1. Localización de las posiciones de las 15 yeguas objeto de seguimiento diurno en los puertos de Sejos. Los puntos de igual color corresponden a un mismo seguimiento.

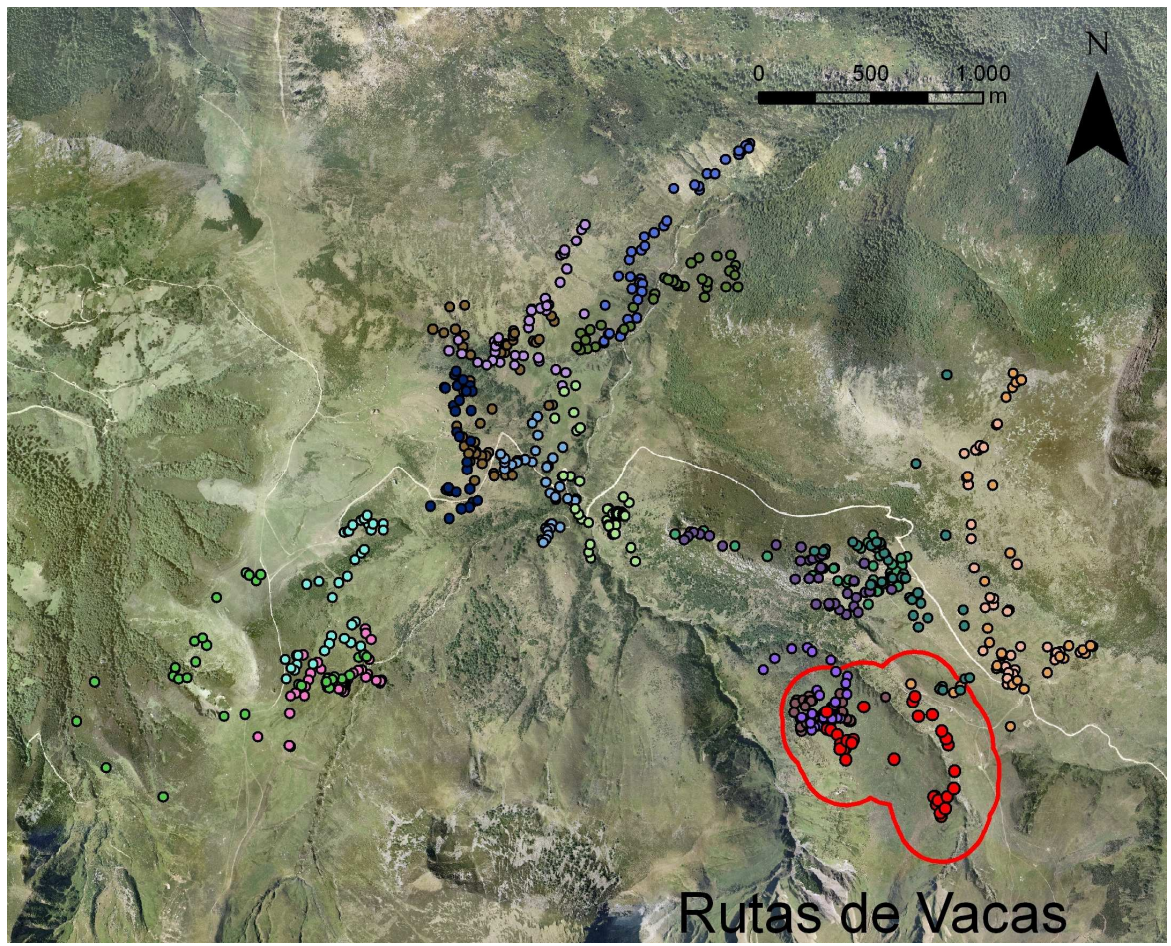

Figura 5.2. Localización de las posiciones de las 18 vacas objeto de seguimiento diurno en los puertos de Sejos. Los puntos de igual color corresponden a un mismo seguimiento. La línea roja delimita el área disponible definida para el seguimiento marcado con puntos rojos (ver figura 5.3 y apartado 5.2.2). 

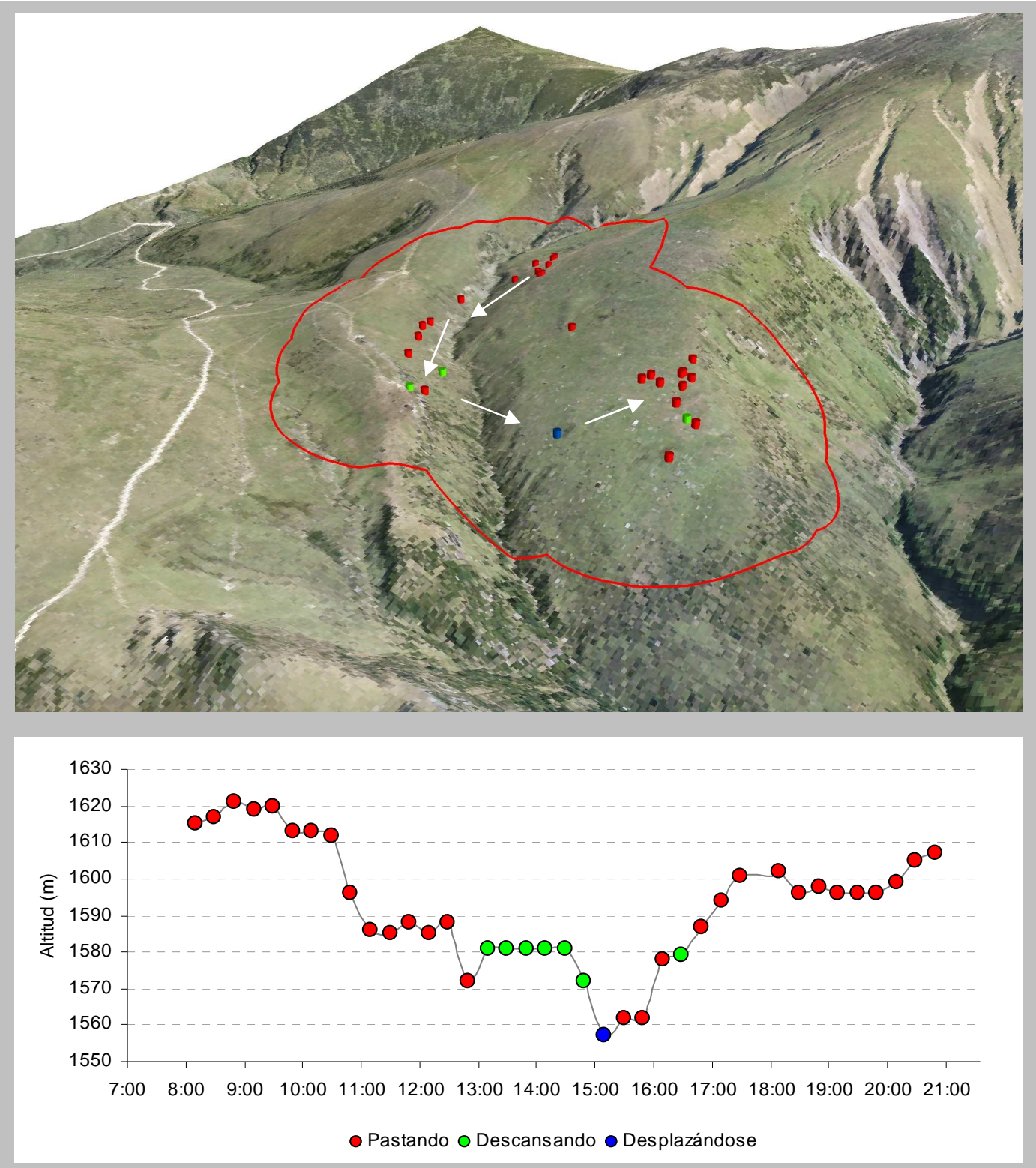

Figura 5.3. Ejemplo de un seguimiento diurno de ganado vacuno: en la imagen superior los puntos de igual color representan una actividad concreta del animal objeto de seguimiento (rojo: pastoreo; verde: descanso; azul: desplazamiento). La línea roja delimita el área disponible estimada para el pastoreo en ese seguimiento (ver apartado 5.2.2); la figura inferior recoge el transecto altitudinal del mismo seguimiento a lo largo del día. 
Tabla 5.2. Datos descriptivos correspondientes al ejemplo de seguimiento de la figura 5.3 (ver descripción de parámetros indicados en el apartado 5.2.2).

\begin{tabular}{|c|c|c|c|c|c|}
\hline \multirow{2}{*}{$\begin{array}{l}\text { Especie: vacuno } \\
\text { Fecha }\end{array}$} & \multicolumn{2}{|l|}{ Raza: charolesa } & \multirow{2}{*}{$\begin{array}{l}\text { Tiempo diurno } \\
\text { empleado }\end{array}$} & \multirow{2}{*}{$\begin{array}{l}\text { Pastoreo } \\
\text { Descanso }\end{array}$} & \multirow{2}{*}{$\begin{array}{l}79 \% \\
18 \% \\
\end{array}$} \\
\hline & \multicolumn{2}{|l|}{$09 / 09 / 2004$} & & & \\
\hline \multicolumn{2}{|l|}{ Duración de la ruta } & $12,7 \mathrm{~h}$ & \multirow{3}{*}{$\begin{array}{l}\text { Proporción de pasto } \\
\text { herbáceo }\end{array}$} & En AD & $81 \%$ \\
\hline \multicolumn{2}{|c|}{ Distancia total entre puntos } & $1983 \mathrm{~m}$ & & En ruta & $93 \%$ \\
\hline \multicolumn{2}{|c|}{ Superficie del área disponible (AD) } & 62 ha & & Selección (IJ) & $+0,54$ \\
\hline \multirow{3}{*}{ Altitud del AD } & Media & $1586 \mathrm{~m}$ & \multirow{3}{*}{$\begin{array}{l}\text { Proporción de pasto } \\
\text { arbustivo }\end{array}$} & En AD & $12 \%$ \\
\hline & Desv. estándar & $38,3 \mathrm{~m}$ & & En ruta & $7 \%$ \\
\hline & Asimetría & $-0,28$ & & Selección (IJ) & $-0,31$ \\
\hline \multirow{3}{*}{ Pendiente del AD } & Media & $18 \%$ & \multirow{3}{*}{$\begin{array}{l}\text { Proporción de Festuca- } \\
\text { Agrostis en el pasto } \\
\text { herbáceo }\end{array}$} & En AD & $67 \%$ \\
\hline & Desv. estándar & $8,5 \%$ & & En ruta & $96 \%$ \\
\hline & Asimetría & $-0,08$ & & Selección (IJ) & $+0,86$ \\
\hline \multirow{2}{*}{ Altitud de la ruta } & Media & $1593 \mathrm{~m}$ & \multirow{3}{*}{$\begin{array}{l}\text { Proporción de cervunal } \\
\text { en el pasto herbáceo }\end{array}$} & En AD & $9 \%$ \\
\hline & Desv. estándar & $16,8 \mathrm{~m}$ & & En ruta & $4 \%$ \\
\hline \multirow{2}{*}{$\begin{array}{l}\text { Pendiente de la } \\
\text { ruta }\end{array}$} & Media & $32,4 \%$ & & Selección (IJ) & $-0,47$ \\
\hline & Desv. estándar & $12,3 \%$ & \multirow{2}{*}{$\begin{array}{l}\text { Cobertura de lecherina } \\
\text { en el pasto herbáceo }\end{array}$} & En AD & $12 \%$ \\
\hline \multirow{3}{*}{$\begin{array}{l}\text { Selección de } \\
\text { altitudes (Índice } \\
\text { de Jacobs [IJ]) }\end{array}$} & Percentil 0-33\% & $-0,70$ & & En ruta & $12 \%$ \\
\hline & Percentil 33-67\% & $+0,63$ & \multirow{2}{*}{$\begin{array}{l}\text { Índice de diversidad de } \\
\text { la vegetación (Shannon) }\end{array}$} & En AD & 1,5 \\
\hline & Percentil 67-100\% & $-0,23$ & & En ruta & 1,7 \\
\hline \multirow{3}{*}{$\begin{array}{l}\text { Selección de } \\
\text { pendientes (IJ) }\end{array}$} & Percentil 0-33\% & $-0,90$ & \multirow{3}{*}{$\begin{array}{l}\text { Selección de pastos } \\
\text { invadidos de lecherina }\end{array}$} & Percentil 0-33\% & $-0,45$ \\
\hline & Percentil 33-67 \% & $-0,23$ & & Percentil 33-67\% & $+0,27$ \\
\hline & Percentil 67-100 \% & $+0,67$ & & Percentil 67-100\% & $+0,09$ \\
\hline
\end{tabular}

\subsubsection{Definición de las variables}

La información recogida en cada ruta de pastoreo, junto con la disponibilidad de una base cartográfica digital de la vegetación y de la topografía del puerto de Sejos ya existentes, permitieron analizar en detalle distintos aspectos de las pautas de comportamiento del ganado en el pastoreo estival.

Para cada seguimiento se definieron la disponibilidad y la utilización por el ganado de las distintas variables objeto del estudio.

La disponibilidad (área disponible; AD) se estimó calculando el área delimitada por la unión de las circunferencias con centro en los puntos de localización de los animales en cada observación y con un radio de $200 \mathrm{~m}$. La existencia de diferencias en las características topográficas y vegetales de las áreas disponibles así definidas, bien sea entre tipos de ganado o a lo largo de la estación de pastoreo, sirve como indicador de la existencia de variaciones en los patrones de pastoreo de los animales a una escala espacial de "grano grueso" (Laca, 2008). 
La utilización se estimó, a escala temporal, como el tiempo de permanencia de los animales objeto de seguimiento en cada nivel de las variables estudiadas respecto al tiempo total empleado en realizar la ruta.

A partir de la disponibilidad y utilización así definidas, se estimó la selección de distintos aspectos del territorio por el ganado (pendiente, altitud, tipos de vegetación) mediante el cálculo del Índice de Jacobs (IJ; Jacobs, 1974):

$$
\mathbf{I} \mathbf{J}_{i j}=\left(\mathbf{U}_{i j}-\mathbf{A}_{i j}\right) /\left\{\left(\mathbf{U}_{i j}+\mathbf{A}_{i j}\right)-\left[2 *\left(\mathbf{U}_{i j} * \mathbf{A}_{i j}\right)\right]\right\}
$$

Siendo $\mathrm{IJ}_{i j}$ la selección de la variable $i$ (p.ej. un tipo de pasto concreto) con respecto a su representación en el área total disponible para el animal $j$. Uij representa la proporción de tiempo que el animal $j$ utiliza la variable $i$ en su ruta diaria. A $i j$ es la proporción del área total disponible para el animal $j$ ocupado por la variable $i$. IJ oscila entre $(-1)$ y $(+1)$. Los valores entre (-1) y (0) indican que la variable está siendo rechazada por el animal en pastoreo (utilizada en menor proporción a lo disponible). Los valores entre (0) y $(+1)$ significan una selección positiva (utilizada en mayor proporción a lo disponible). El valor (0) representa una selección nula.

La disponibilidad, utilización y selección se estudiaron a los siguientes niveles de detalle:

- $\quad$ Características generales de las rutas diurnas.

- $\quad$ Características de las actividades del ganado: pastoreo y descanso.

- $\quad$ Características del pastoreo en relación con el tipo de pasto.

\subsubsection{Características generales de las rutas diurnas}

En este bloque se analizaron las siguientes variables de cada una de las rutas seguidas por los animales muestreados:

- Distancia recorrida. Estimada como la suma de las distancias entre puntos sucesivos dentro de cada ruta.

- Duración. Tiempo desde el inicio hasta el final de cada ruta.

- Altitud media. Valor medio de la altitud de todas las observaciones de cada ruta. 
- Variación de la altitud. Desviación estándar de la altitud de todas las observaciones de cada ruta (variación intra-ruta).

- Pendiente media. Valor medio de la pendiente de todas las observaciones de cada ruta.

- Variación de la pendiente. Desviación estándar de la pendiente de todas las observaciones de cada ruta (variación intra-ruta).

- Topografía de las áreas disponibles. Superficie, altitud y pendiente (medias, desviaciones estándar y asimetría) de las áreas disponibles de cada ruta.

- Grado de selección de la topografía. Tanto para la pendiente como para la altitud, y para cada área disponible, se delimitaron tres rangos de valores coincidentes con los tres percentiles de igual superficie (33,3\% del total; rango inferior, medio y superior). Seguidamente, considerando la utilización de cada rango delimitado, se calcularon sus índices de Jacobs.

\subsubsection{Características de las actividades del ganado: pastoreo y descanso}

Teniendo en cuenta que el desplazamiento sin pastoreo fue una actividad siempre minoritaria (valor medio de $4,8 \%$ de la duración total de las rutas diurnas), se estudiaron las siguientes variables para las dos actividades principales del ganado (pastoreo y descanso):

- Proporción del tiempo diurno empleado. Número de observaciones de cada actividad respecto al número total de observaciones de cada ruta.

- Altitud relativa media. Valor medio de la altitud relativa de todas las observaciones de cada ruta. La altitud relativa de cada observación se calculó como la diferencia entre su valor de altitud y el valor más bajo registrado a lo largo de la ruta.

La variación de la altitud relativa, la pendiente media, la variación de la pendiente y el grado de selección de la topografía se estimaron de acuerdo con lo descrito en el apartado anterior. 


\subsubsection{Características del pastoreo en relación con el tipo de pasto}

A partir de la información de la cartografía de la vegetación de la zona de estudio (Busqué et al., 2006) se calculó la superficie ocupada por los distintos tipos de pasto en las áreas disponibles. A su vez, con la información recopilada en los seguimientos, se estimó la utilización de estos tipos de pasto (proporción del número de observaciones de pastoreo sobre un pasto concreto respecto al total de observaciones en pastoreo). De esta forma se pudo estudiar la disponibilidad, utilización y selección del pasto por el ganado a los siguientes niveles de detalle:

- Pastos con dominio de especies herbáceas (pastos herbáceos) y pastos con dominio de especies arbustivas (pastos arbustivos).

- Pastos dominados por Festuca nigrescens y Agrostis capillaris (Festuca-Agrostis) y pastos dominados por Nardus stricta (cervunales). El cálculo de su disponibilidad y utilización se hizo con respecto al total de los pastos herbáceos. El resto de tipos de pastos herbáceos, mucho menos representados en Sejos (ver capítulo 2), fueron en general muy poco utilizados y por ello no se consideraron en el análisis.

- Cobertura de lecherina en el pasto de Festuca-Agrostis; expresada como la proporción de lecherina presente en dicho tipo de pasto.

- Diversidad vegetal. Se estimó a través del índice de Shannon $\left(\mathrm{H}^{\prime}=-\Sigma \mathrm{p}_{i} \times \ln \mathrm{p}_{i}\right.$ donde $\mathrm{p}_{i}$ es la proporción disponible o utilizada por el tipo de pasto $i$ en el área disponible o en la ruta de pastoreo), considerando las comunidades vegetales definidas en la tabla 2.1.

Para la estimación de la selección de los pastos de Festuca-Agrostis según su grado de invasión de lecherina, se establecieron tres percentiles idénticos en cuanto a superficie de pasto de Festuca-Agrostis en las áreas disponibles según un gradiente de cobertura de lecherina. La tabla 5.3 muestra los valores mínimos, medios y máximos de cobertura de lecherina en los rangos así definidos. 
Tabla 5.3. Valores mínimos, medios y máximos de cobertura de lecherina (\%) en pastos de FestucaAgrostis agrupados según su grado de invasión.

\begin{tabular}{lccc} 
& \multicolumn{3}{c}{ Grado de invasión de lecherina } \\
\cline { 2 - 4 } & Bajo & Medio & Alto \\
\hline Percentil & $0-33 \%$ & $33-67 \%$ & $67-100 \%$ \\
\hline Valor mínimo (\%) & 0,0 & 9,0 & 20,0 \\
Media (\%) & 5,8 & 14,0 & 32,1 \\
Valor máximo (\%) & 9,0 & 20,0 & 70,0 \\
\hline
\end{tabular}

\subsubsection{Análisis estadísticos}

El análisis estadístico consistió fundamentalmente en la confección de modelos lineales considerando las variables descritas en los apartados anteriores como variables respuesta y utilizando como herramienta estadística general el análisis de varianza. En los modelos se incluyeron los efectos fijos especie animal (esp $i$; $i$ vacuno y caballar), época de la estación de pastoreo ( $e p_{j} ; j$ : inicio, medio y final) así como su interacción [(esp $\times$ $e p)_{i j}$. El modelo principal que se probó fue:

$$
Y_{i j}=\mu+e s p_{i}+e p_{j}+(e s p \times e p)_{i j}+\varepsilon_{i j}
$$

Para ciertas variables, la existencia de relaciones lineales con otras variables continuas justificó la inclusión de estas últimas como covariables en el modelo general. Este fue el caso de la selección de la topografía (variables respuesta) y la asimetría del área disponible (covariables), de la utilización de los distintos tipos de pasto (variables respuesta) y sus proporciones en las áreas disponibles (covariables), así como de la selección de los pastos de Festuca-Agrostis según su grado de cobertura de lecherina (variables respuesta) y la proporción de pasto de Festuca-Agrostis sobre el total de pasto herbáceo en el área disponible (covariables). En todos estos análisis de covarianza se trabajó con los valores de las medias ajustadas, siendo estos los que se presentan siempre en el apartado de resultados.

Dado que ciertos análisis de varianza correspondientes al modelo general mostraron variabilidades elevadas para el ganado vacuno, se optó por realizar un análisis específico para éste, considerando por un lado los de la raza autóctona tudanca y por otro los de otras razas foráneas (limusina y charolesa), menos adaptadas en principio al pastoreo en la zona de estudio (raza $i$; $i$ tudanca y otras razas). Ante la escasez de animales de raza tudanca en 
la parte final de la estación de pastoreo, el efecto fijo época no se pudo incluir en el

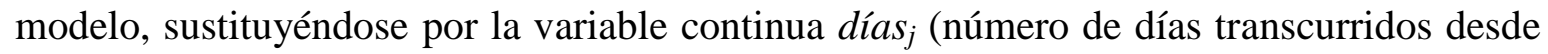
el primer seguimiento realizado -22 de junio-) como covariable en un modelo del tipo:

$$
Y_{i j}=\mu+\operatorname{raza}_{i}+\operatorname{dias}_{j}+\left(\operatorname{raza} \times \operatorname{di}^{\prime} a\right)_{i j}+\varepsilon_{i j}
$$

Partiendo de estos patrones de modelos generales, los modelos finales elegidos fueron variaciones de los mismos (p.ej., incluyendo o no las interacciones de los efectos fijos con las covariables), usando como regla general la confección del modelo más sencillo, manteniendo valores máximos en el coeficiente de determinación $\mathrm{R}^{2}$.

En los análisis de la selección de altitudes y pendientes, tanto generales como por actividades, además de los análisis de varianza dentro de cada percentil, se realizaron también análisis de varianza para comparar estadísticamente los valores de los distintos percentiles. En este caso, los percentiles se consideraron como efecto fijo. Estos análisis se realizaron separadamente por especies animales o por épocas si estos efectos habían resultado significativos en los análisis generales previos.

En el caso de los análisis por actividades o por tipos de pasto herbáceo, tras los análisis de varianza generales, se realizaron también pruebas de comparación de medias $(t$ de Student de muestras relacionadas) para poder comparar estadísticamente las variables analizadas entre actividades y entre tipos de pasto herbáceo. Estas pruebas también se realizaron separadamente por especies animales o por épocas si estas habían sido significativas en los análisis generales previos.

En determinadas ocasiones fue necesario transformar los valores de las variables respuesta para asegurar la homogeneidad de la varianza y la normalidad de las distribuciones muestreadas. En concreto, la transformación al arcoseno de su raíz cuadrada se utilizó en las variables proporción de tiempo diurno dedicado al pastoreo y al descanso así como en las proporciones de utilización de los distintos tipos de pasto por el ganado. La variación intra-ruta de la altitud relativa se transformó a su logaritmo neperiano. En estos casos, si bien los valores medios presentados en las tablas de resultados están retransformados para facilitar la comprensión, los valores de la desviación estándar (d.e.) corresponden a los valores originales para la variable transformada. 
Por otro lado, se realizó un análisis de correlaciones entre las disponibilidades, utilizaciones y selecciones de los distintos tipos de pastos estudiados con el fin de evaluar sus relaciones lineales.

Se consideraron diferencias estadísticamente significativas aquellas con un valor de $\mathrm{P}<0,05$ y tendencias aquellas con $\mathrm{P}>0,05$ pero $<0,10$.

Todos los análisis estadísticos se realizaron con el programa estadístico SPSS (SPSS, 1999).

\subsection{Resultados}

\subsubsection{Características generales de las rutas diurnas}

En el modelo general que incluyó los efectos fijos especie animal, época de la estación de pastoreo y su interacción no se detectaron diferencias significativas en la mayor parte de las características generales de las rutas diurnas (tabla 5.4).

Las únicas variables significativamente diferentes entre especies fueron las pendientes medias, tanto de las rutas seguidas por el ganado $(\mathrm{P}=0,004)$ como de sus áreas disponibles $(\mathrm{P}=0,011)$. La mayor pendiente media observada en las rutas de vacuno respecto a las de caballar $(28 \%$ vs. $21 \%$; e.e.d. $=2,2)$ fue fundamentalmente resultado de la diferencia existente en las pendientes medias de sus áreas disponibles (18\% vs. 16\%; e.e.d.=0,9), tal como se vio al incluir la pendiente media del área disponible como covariable en el modelo de la pendiente media de la ruta (con este modelo la especie y la interacción especie x pendiente del área disponible no fueron significativas).

En cuanto a la época, la única variable que mostró diferencias significativas fue la duración de la ruta diurna $(\mathrm{P}<0,001)$, debido a la disminución de las horas de luz en el transcurso del estudio, que osciló entre las 16 horas al inicio y las 12 horas al final. 
Tabla 5.4. Características generales de las rutas diurnas recorridas por el ganado. Nivel de significación estadística (P) de los efectos fijos especie (Esp: vacuno y caballar) y época (Ep: inicio, medio y final) y de su interacción.

\begin{tabular}{|c|c|c|c|c|c|c|c|}
\hline & & Media & d.e. & $\mathrm{R}^{2}$ & Especie & Época & $\begin{array}{l}\text { Esp x } \\
\text { Época } \\
\end{array}$ \\
\hline \multicolumn{2}{|c|}{ Distancia de la ruta $(\mathrm{m})$} & 2824 & 996 & -- & ns & ns & ns \\
\hline \multicolumn{2}{|c|}{ Duración de la ruta (h) } & 14,3 & 1,4 & 0,63 & $\mathrm{~ns}$ & $* * *$ & ns \\
\hline \multicolumn{2}{|c|}{ Superficie del área disponible (ha) } & 67,9 & 22,4 & -- & ns & ns & ns \\
\hline \multirow{2}{*}{ Altitud ruta } & Media (m) & 1482 & 126 & -- & ns & ns & ns \\
\hline & Variación intra-ruta (d.e.; m) & 26,8 & 13,8 & -- & ns & ns & ns \\
\hline \multirow{2}{*}{ Pendiente ruta } & Media (\%) & 25 & 7,01 & 0,20 & $* *$ & ns & ns \\
\hline & Variación intra-ruta (d.e.; \%) & 11,6 & 2,99 & -- & ns & ns & ns \\
\hline \multirow{3}{*}{$\begin{array}{l}\text { Altitud } \\
\text { disponible }\end{array}$} & Media (m) & 1481 & 122 & -- & ns & ns & ns \\
\hline & Variación intra-ruta (d.e.; m) & 42,5 & 12,1 & -- & ns & ns & ns \\
\hline & Asimetría intra-ruta $\left(g_{1}\right)$ & 0,16 & 0,55 & -- & ns & ns & ns \\
\hline \multirow{3}{*}{$\begin{array}{l}\text { Pendiente } \\
\text { disponible }\end{array}$} & Media (\%) & 17 & 2,73 & 0,19 & $*$ & ns & ns \\
\hline & Variación intra-ruta (d.e.; \%) & 8,5 & 1,06 & -- & ns & ns & ns \\
\hline & Asimetría intra-ruta $\left(g_{1}\right)$ & $-0,06$ & 0,19 & -- & ns & ns & ns \\
\hline
\end{tabular}

ns: no significativo; t: $0,10>\mathrm{P}>0,05 ; *$ : $\mathrm{P}<0,05 ; * *: \mathrm{P}<0,01 ; * * *: \mathrm{P}<0,001$. $\mathrm{R}^{2}$ : coeficiente de determinación del modelo; d.e.: desviación estándar.

La selección de altitudes experimentó cambios notables a lo largo de la estación de pastoreo en los percentiles de altitudes medio y superior (tabla 5.5 y figura 5.4), sin que se observaran diferencias entre especies, pero con una influencia de la asimetría de las altitudes en el área disponible (i.e, con un efecto significativo de la covariable y sus interacciones en los percentiles inferior y superior). En las épocas inicial e intermedia de la estación de pastoreo, el ganado se repartió de forma bastante homogénea entre los tres percentiles de altitudes, sin existir selecciones significativamente diferentes de cero en ninguno de ellos. Por el contrario, en la última época el ganado mostró una preferencia por el percentil de altitudes intermedio y rechazó en mayor medida los rangos extremos. La comparación entre percentiles para cada época mostró valores únicamente diferentes para la época final $(\mathrm{P}<0,05)$, siendo el valor del percentil intermedio significativamente diferente de los otros dos, que resultaron semejantes.

Entre especies se detectaron diferencias en la selección de los percentiles de pendientes medio y superior (tabla 5.5 y figura 5.5), con valores siempre más extremos para el vacuno que para el caballar. La comparación entre percentiles presentó valores diferentes para las dos especies $(\mathrm{P}<0,001)$, con el percentil de pendientes más altas diferente respecto a los otros dos. 
Tabla 5.5. Selección en los percentiles 0-33\%, 33-67\% y $67-100 \%$ de altitud y de pendiente en las rutas diurnas del ganado. Nivel de significación estadística (P) de los efectos fijos especie animal (Esp: vacuno y caballar) y época (Ep: inicio, medio y final), de la covariable coeficiente de asimetría de las altitudes o pendientes de las áreas disponibles (cov) y de sus interacciones.

\begin{tabular}{|c|c|c|c|c|c|c|c|c|c|c|c|}
\hline & & Media & d.e. & $\mathrm{R}^{2}$ & Esp & Ep & $\begin{array}{c}\text { Esp x } \\
\text { Ep }\end{array}$ & Cov & $\begin{array}{c}\text { Esp x } \\
\text { Cov }\end{array}$ & $\begin{array}{l}\text { Ep x } \\
\text { Cov } \\
\end{array}$ & $\begin{array}{c}\text { Esp x Ep } \\
\text { x Cov }\end{array}$ \\
\hline \multirow{3}{*}{ Altitud } & $\begin{array}{l}\text { Percentil } \\
0-33 \%\end{array}$ & $-0,20$ & 0,49 & 0,33 & ns & $\mathrm{ns}$ & ns & $* * *$ & No & No & No \\
\hline & $\begin{array}{l}\text { Percentil } \\
33-67 \%\end{array}$ & $+0,12$ & 0,44 & 0,11 & ns & $\mathrm{t}$ & ns & ns & ns & ns & No \\
\hline & $\begin{array}{l}\text { Percentil 67- } \\
100 \%\end{array}$ & $-0,10$ & 0,44 & 0,34 & ns & $*$ & ns & ns & No & No & $\mathrm{t}$ \\
\hline \multirow{3}{*}{ Pendiente } & $\begin{array}{l}\text { Percentil } \\
0-33 \%\end{array}$ & $-0,38$ & 0,47 & --- & ns & ns & $\mathrm{ns}$ & No & No & No & No \\
\hline & $\begin{array}{l}\text { Percentil } \\
33-67 \%\end{array}$ & $-0,53$ & 0,32 & 0,07 & $*$ & ns & ns & ns & No & No & No \\
\hline & $\begin{array}{l}\text { Percentil 67- } \\
100 \%\end{array}$ & 0,46 & 0,36 & --- & $*$ & ns & $\mathrm{ns}$ & ns & No & No & No \\
\hline
\end{tabular}

ns: no significativo; t: 0,10>P >0,05; *: $\mathrm{P}<0,05 ; * *: \mathrm{P}<0,01 ; * * *: \mathrm{P}<0,001 . \mathrm{R}^{2}$ : coeficiente de determinación del modelo; d.e.: desviación estándar. No: no se incluyó ese término en el modelo, al resultar no significativo y disminuir el coeficiente de determinación del mismo.

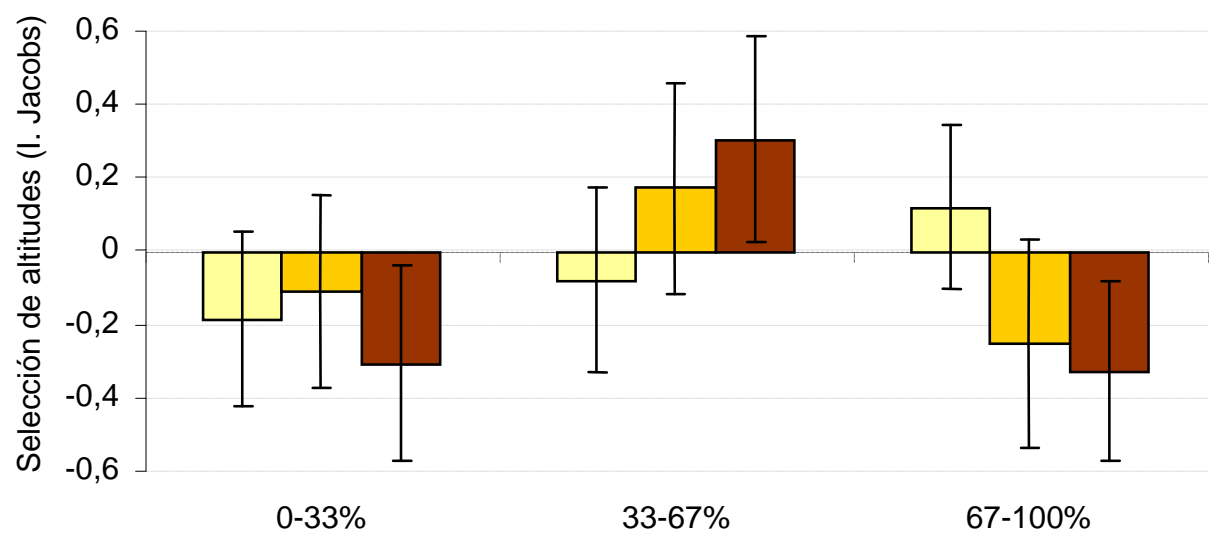

Percentiles de altitudes en las áreas disponibles

$\square$ Inicio $\square$ Medio $\square$ Final

Figura 5.4. Selección en los percentiles 0-33\%, 33-67\% y 67-100\% de las altitudes de las áreas disponibles según la época (inicio, medio y final). Las barras verticales señalan los intervalos de confianza con $\mathbf{P}=95 \%$. 


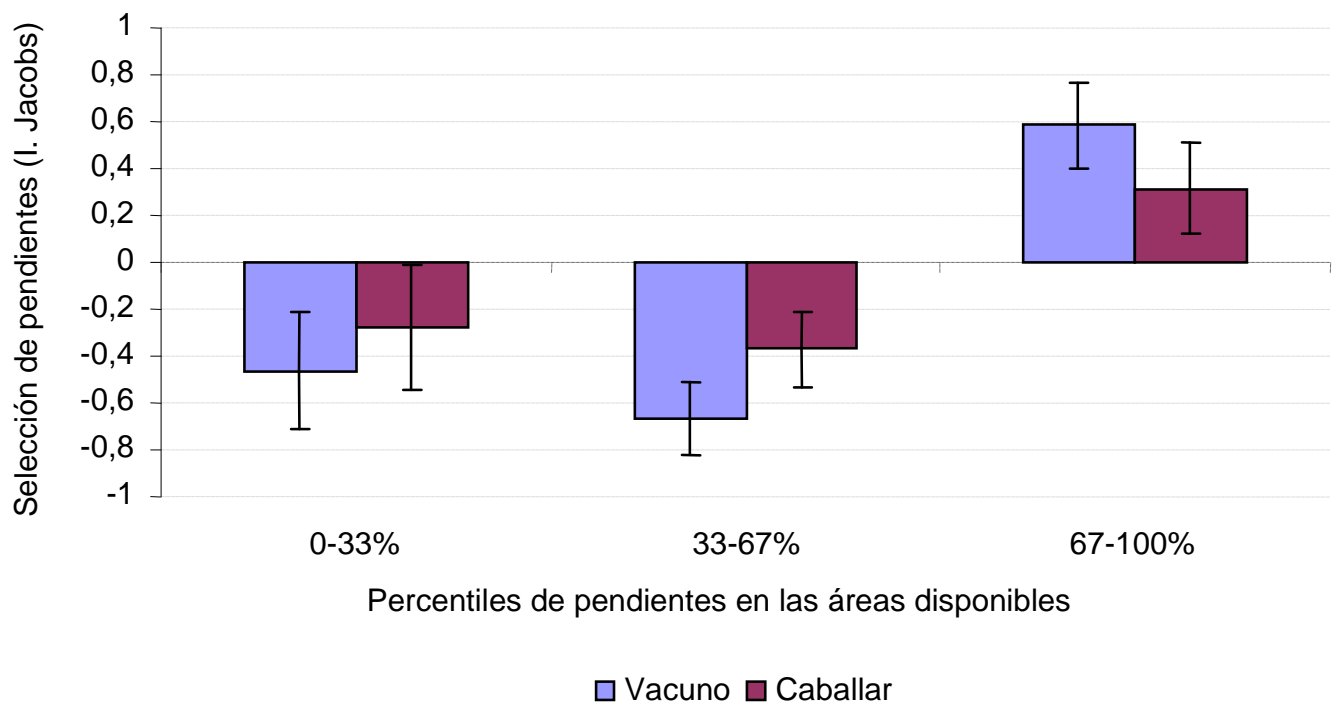

Figura 5.5. Selección en los percentiles 0-33\%, 33-67\% y 67-100\% de las pendientes de las áreas disponibles según la especie (vacuno y caballar). Las barras verticales señalan los intervalos de confianza con $\mathrm{P}=\mathbf{9 5 \%}$.

Dentro del vacuno no se observaron diferencias significativas $(\mathrm{P}>0,10)$ entre razas en ninguna de las variables estudiadas en este apartado.

\subsubsection{Características de las actividades del ganado: pastoreo y descanso}

El modelo general considerando los efectos fijos especie, época y su interacción, y realizado separadamente para cada una de las dos actividades principales del ganado, mostró diferencias significativas entre las especias animales estudiadas (tabla 5.6). Concretamente, estas diferencias se encontraron, al menos para alguna de las dos actividades, en la proporción de tiempo empleado, la pendiente media y la variación de esta dentro de la ruta (figura 5.6). La proporción de tiempo empleada fue diferente entre especies para las dos actividades, siendo las magnitudes de las diferencias similares en ambos casos. La elevada relación lineal existente entre el pastoreo y el descanso $(r=-0,97)$, debida al reducido tiempo empleado otras actividades (i.e. desplazamientos), explica esta similitud. La ausencia de un efecto de la época sobre la proporción de tiempo dedicada al pastoreo indica que el tiempo diurno dedicado a esta actividad fue disminuyendo a lo largo del verano, dado el acortamiento progresivo en las horas de luz (tabla 5.4). Una comparación de medias (prueba $t$ de Student para muestras relacionadas) mostró que el tiempo de pastoreo fue significativamente superior al tiempo de descanso $(\mathrm{P}<0,001)$ en las dos especies. 
La pendiente media utilizada en pastoreo fue significativamente inferior en el ganado caballar que en el vacuno. Sin embargo, para el descanso las dos especies mostraron pendientes medias muy semejantes, existiendo también una tendencia $(\mathrm{P}=0,072)$ a mostrar un incremento al final de la estación (valores de 19, 21 y $28 \%$ para el inicio, medio y final de la estación respectivamente; e.e.d.=4,0). Solamente en el ganado vacuno se encontraron diferencias significativas en la pendiente utilizada según la actividad $(\mathrm{P}<0,001)$, siendo estas mayores en el pastoreo que en el descanso.

La variación de las pendientes dentro de cada ruta fue mayor para las vacas que para las yeguas cuando estuvieron descansando y muy similar cuando estuvieron pastando. Para cada especie animal, una comparación de medias entre actividades mostró diferencias significativas en esta variable tanto en vacas $(\mathrm{P}=0,05)$ como en yeguas $(\mathrm{P}<0,001)$.

Las altitudes relativas medias no se vieron afectadas por los factores estudiados en las dos actividades y tampoco mostraron valores diferentes entre ellas. En cuanto a la variación de la altitud relativa dentro de la ruta, en el descanso se observó un descenso muy acusado en sus valores a partir de la época intermedia de la estación (figura 5.7) y sus valores fueron significativamente diferentes a los de pastoreo $(\mathrm{P}<0,05)$ en las épocas intermedia y final.

Tabla 5.6. Características de las rutas diurnas según la actividad desarrollada (pastoreo y descanso). Nivel de significación estadística (P) de los efectos fijos especie (Esp: vacuno y caballar) y época (Ep: inicio, medio y final) y de su interacción.

\begin{tabular}{llcccccc}
\hline & & Media & d.e. & $\mathrm{R}^{2}$ & Esp & Ep & $\begin{array}{c}\text { Esp } \\
\text { x Ep }\end{array}$ \\
\hline \multirow{2}{*}{ Proporción del tiempo diurno } & Pastoreo & 0,72 & $0,16^{1}$ & 0,45 & $* * *$ & $\mathrm{~ns}$ & $\mathrm{~ns}$ \\
& Descanso & 0,22 & $0,15^{1}$ & 0,46 & $* * *$ & $\mathrm{~ns}$ & $\mathrm{~ns}$ \\
\hline \multirow{2}{*}{ Altitud relativa (m) } & Pastoreo & 44 & 21,0 & --- & $\mathrm{ns}$ & $\mathrm{ns}$ & $\mathrm{ns}$ \\
& Descanso & 41 & 23,9 & --- & $\mathrm{ns}$ & $\mathrm{ns}$ & $\mathrm{ns}$ \\
\hline Variación intra-ruta de la & Pastoreo & 24,3 & $0,50^{2}$ & --- & $\mathrm{ns}$ & $\mathrm{ns}$ & $\mathrm{ns}$ \\
altitud relativa (m) & Descanso & 13,3 & $1,01^{2}$ & 0,27 & $\mathrm{~ns}$ & $* *$ & $\mathrm{~ns}$ \\
\hline \multirow{3}{*}{ Pendiente (\%) } & Pastoreo & 26 & 7,4 & 0,39 & $* * *$ & $\mathrm{~ns}$ & $\mathrm{~ns}$ \\
\hline \multirow{2}{*}{$\begin{array}{l}\text { Variación intra-ruta de la } \\
\text { pendiente }(\%)\end{array}$} & Descanso & 22 & 9,4 & 0,08 & $\mathrm{~ns}$ & $\mathrm{t}$ & $\mathrm{ns}$ \\
\hline
\end{tabular}

ns: no significativo; t: 0,10>P >0,05; *: $\mathrm{P}<0,05 ; * *: \mathrm{P}<0,01 ; * * *: \mathrm{P}<0,001 . \mathrm{R}^{2}$ : Coeficiente de determinación del modelo; d.e.: desviación estándar. ${ }^{1}$ Valor original para la variable transformada al arcoseno de su raíz cuadrada. ${ }^{2}$ Valor original para la variable transformada a su logaritmo neperiano. 

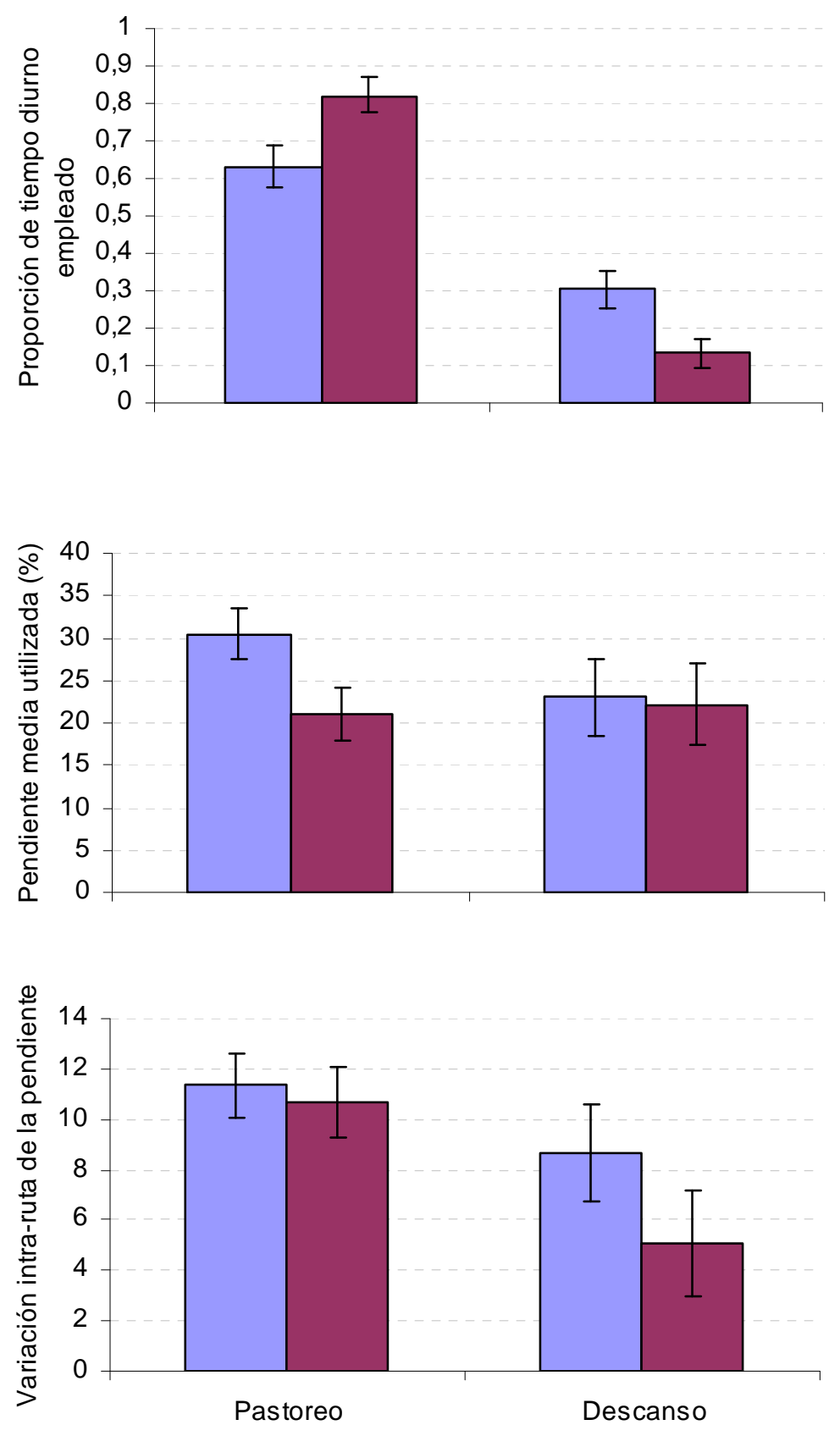

$\square$ Vacuno $\square$ Caballar

Figura 5.6. Características de las actividades de pastoreo y descanso en las rutas diurnas (proporción de tiempo empleado, pendiente media utilizada y variación de la pendiente utilizada en la ruta) según la especie (vacuno y caballar). Las barras verticales señalan los intervalos de confianza con $P=95 \%$ correspondientes a los análisis de cada actividad por separado. 


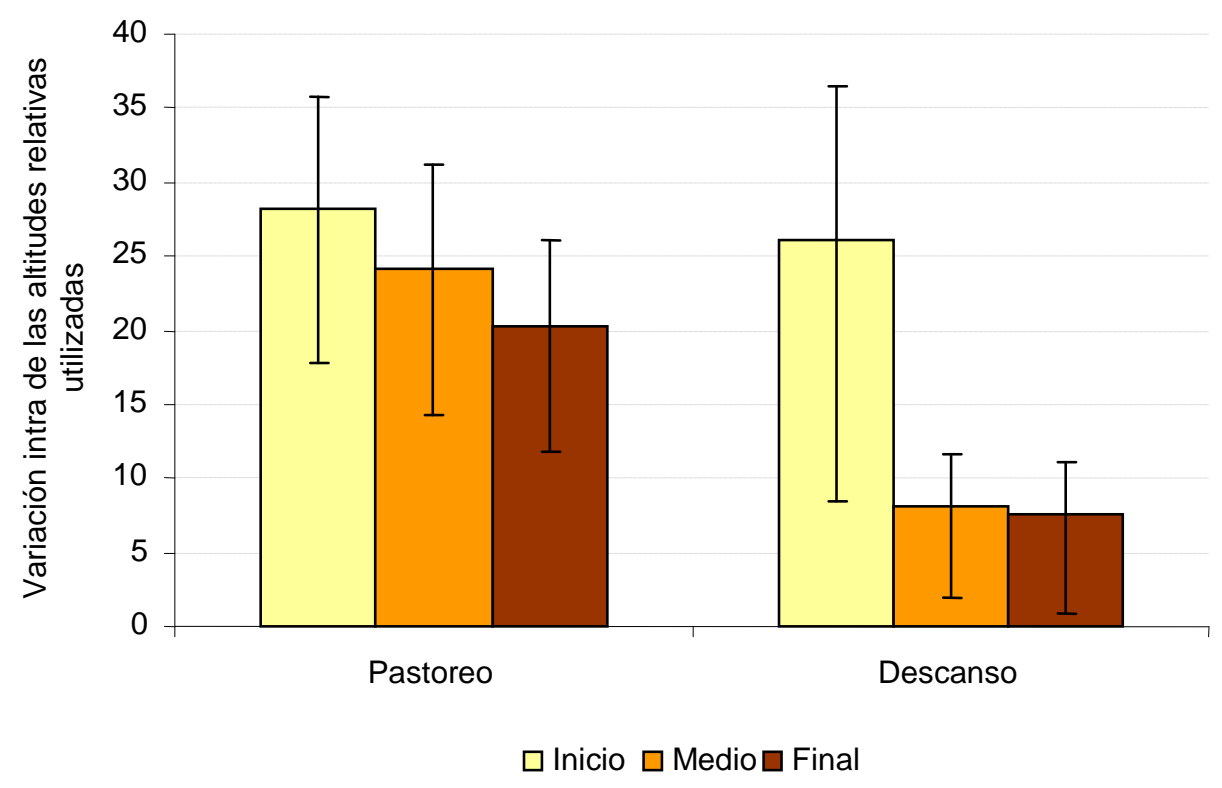

Figura 5.7. Variación intra-ruta de la altitud utilizada $(\mathrm{m})$ en la ruta diurna para las actividades de pastoreo y descanso según la época de la estación de pastoreo (inicio, medio y final). Las barras verticales señalan los intervalos de confianza con $P=95 \%$ correspondientes a los análisis de cada actividad por separado.

Dentro del ganado vacuno la única variable que mostró diferencias significativas según la raza fue la proporción de tiempo empleada en la actividad (tabla 5.7), con valores en pastoreo mayores para las vacas de razas foráneas que para las tudancas y al contrario en descanso (figura 5.8). A su vez, el tiempo de pastoreo fue mayor que el dedicado al descanso en ambas razas $(\mathrm{P}<0,05)$.

La comparación entre actividades mostró medias significativamente diferentes a favor del pastoreo en la pendiente utilizada $(\mathrm{P}<0,001)$ y en la variación de la pendiente en la ruta $(\mathrm{P}<0,05)$ tanto en tudanca como en las otras razas. 
Tabla 5.7. Características de las rutas diurnas del ganado vacuno según la actividad desarrollada (pastoreo y descanso). Nivel de significación estadística (P) del efecto fijo raza (tudanca y otras razas), de la covariable días desde el inicio del estudio (días) y de su interacción.

\begin{tabular}{llcccccc}
\hline & & Media & d.e. & $\mathrm{R}^{2}$ & Raza & Días & $\begin{array}{c}\text { Raza } \\
\text { x Días }\end{array}$ \\
\hline \multirow{2}{*}{ Proporción del tiempo diurno } & Pastoreo & 0,62 & $0,14^{1}$ & 0,39 & $* *$ & No & No \\
& Descanso & 0,31 & $0,12^{1}$ & 0,49 & $* *$ & No & No \\
\hline \multirow{2}{*}{ Altitud relativa (m) } & Pastoreo & 43 & 19,6 & --- & $\mathrm{ns}$ & No & No \\
& Descanso & 37 & 25,4 & --- & $\mathrm{ns}$ & No & No \\
\hline Variación intra-ruta de la & Pastoreo & 24,6 & 12,4 & --- & $\mathrm{ns}$ & No & No \\
Altitud relativa (m) & Descanso & 18,6 & 13,8 & --- & $\mathrm{ns}$ & No & No \\
\hline \multirow{2}{*}{ Pendiente (\%) } & Pastoreo & 30 & 5,6 & 0,08 & $\mathrm{~ns}$ & $\mathrm{t}$ & No \\
\hline \multirow{2}{*}{ Variación intra-ruta de la } & Descanso & 23 & 9,2 & --- & $\mathrm{ns}$ & No & No \\
Pendiente $(\%)$ & Pastoreo & 11,3 & 2,2 & 0,02 & $\mathrm{~ns}$ & $\mathrm{~ns}$ & $\mathrm{t}$ \\
\hline
\end{tabular}

ns: no significativo; t: $0,10>\mathrm{P}>0,05 ; *: \mathrm{P}<0,05 ; * *: \mathrm{P}<0,01 ; * * *: \mathrm{P}<0,001 . \mathrm{R}^{2}$ : Coeficiente de determinación del modelo; d.e.: desviación estándar. ${ }^{1}$ Valor original de la variable transformada al arcoseno de su raíz cuadrada. No: no se incluyó ese término en el modelo, al resultar no significativo y disminuir el coeficiente de determinación del mismo.

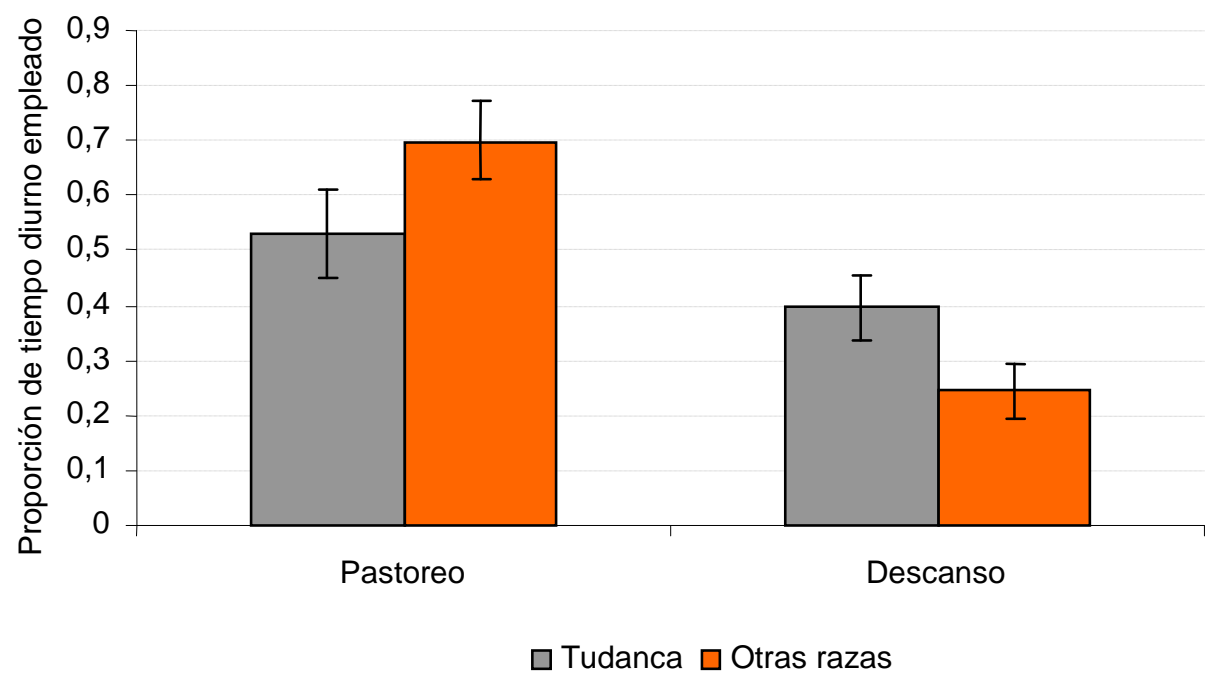

Figura 5.8. Proporción de tiempo diurno empleado en las actividades de pastoreo y descanso según la raza de ganado vacuno (tudanca y otras razas). Las barras verticales señalan los intervalos de confianza con $\mathbf{P}=\mathbf{9 5 \%}$ correspondientes a los análisis de cada actividad por separado.

Las selecciones de altitudes y pendientes en el modelo general de vacas y yeguas y para la actividad pastoreo fueron similares a las observadas previamente sin considerar la actividad, aunque con valores de selección positiva o negativa generalmente más marcados (comparar la tabla 5.8 y las figuras 5.9 y 5.10 con la tabla 5.5 y las figuras 5.4 y 5.5). Por su parte, las selecciones de altitudes y pendientes para la actividad descanso fueron siempre muy variables, no detectándose diferencias debidas ni a la especie animal ni a la 
época (tabla 5.8). La selección de pendientes para el descanso fue diferente $(\mathrm{P}<0,001)$ en el percentil de pendientes superior ( $+0,26$, seleccionada positivamente) y los rangos inferior y medios (-0,34 y -0,51, rechazados activamente), como se deduce de un análisis de varianza considerando el percentil como efecto fijo.

Por último, e igual que ocurría cuando no se distinguieron las actividades, en los análisis específicos para el vacuno no se apreció diferencia alguna entre razas.

Tabla 5.8. Selección en los percentiles 0-33\%, 33-67\% y 67-100\% de altitud y de pendiente en las rutas diurnas del ganado según la actividad desarrollada (pastoreo y descanso). Nivel de significación estadística (P) de los efectos fijos especie (Esp: vacuno y caballar) y época (Ep: inicio, medio y final), de la covariable coeficiente de asimetría de las altitudes o pendientes de las áreas disponibles (cov) y de sus interacciones.

\begin{tabular}{|c|c|c|c|c|c|c|c|c|c|c|c|}
\hline PASTOREO & & Media & d.e. & $\mathrm{R}^{2}$ & Esp & Ep & $\begin{array}{c}\text { Esp x } \\
\text { Ep }\end{array}$ & Cov & $\begin{array}{c}\text { Esp x } \\
\text { Cov }\end{array}$ & $\begin{array}{l}\text { Ep x } \\
\text { Cov }\end{array}$ & $\begin{array}{c}\text { Esp x Ep } \\
\text { x Cov }\end{array}$ \\
\hline \multirow{3}{*}{ IJ Altitud } & $\begin{array}{l}\text { Percentil } \\
0-33 \%\end{array}$ & $-0,27$ & 0,48 & 0,23 & ns & ns & ns & $*$ & No & No & No \\
\hline & $\begin{array}{l}\text { Percentil } \\
33-67 \%\end{array}$ & $+0,15$ & 0,46 & 0,09 & ns & $\mathrm{t}$ & ns & ns & ns & ns & No \\
\hline & $\begin{array}{l}\text { Percentil 67- } \\
100 \%\end{array}$ & -0.09 & 0,46 & 0,11 & ns & $*$ & ns & ns & No & No & No \\
\hline \multirow{3}{*}{ IJ Pendiente } & $\begin{array}{l}\text { Percentil } \\
0-33 \%\end{array}$ & $-0,48$ & 0,47 & 0,15 & $* *$ & $\mathrm{~ns}$ & ns & ns & ns & No & No \\
\hline & $\begin{array}{l}\text { Percentil } \\
33-67 \%\end{array}$ & $-0,44$ & 0,36 & 0,13 & $*$ & ns & ns & ns & No & No & No \\
\hline & $\begin{array}{l}\text { Percentil 67- } \\
100 \%\end{array}$ & 0,52 & 0,36 & 0,20 & $* *$ & $\mathrm{~ns}$ & ns & ns & No & No & No \\
\hline \multicolumn{12}{|l|}{ DESCANSO } \\
\hline \multirow{3}{*}{ IJ Altitud } & $\begin{array}{l}\text { Percentil } \\
0-33 \%\end{array}$ & $-0,31$ & 0,76 & 0,24 & ns & $\mathrm{ns}$ & ns & $* *$ & ns & ns & ns \\
\hline & $\begin{array}{l}\text { Percentil } \\
33-67 \%\end{array}$ & 0,00 & 0,74 & 0,06 & ns & ns & ns & ns & No & No & No \\
\hline & $\begin{array}{l}\text { Percentil 67- } \\
100 \%\end{array}$ & $-0,26$ & 0,74 & 0,35 & ns & $\mathrm{t}$ & ns & ns & ns & ns & $\mathrm{t}$ \\
\hline \multirow{3}{*}{ IJ Pendiente } & $\begin{array}{l}\text { Percentil } \\
0-33 \%\end{array}$ & $-0,34$ & 0,69 & 0,18 & ns & ns & ns & ns & ns & ns & No \\
\hline & $\begin{array}{l}\text { Percentil } \\
33-67 \%\end{array}$ & $-0,51$ & 0,68 & --- & ns & ns & ns & ns & ns & ns & ns \\
\hline & $\begin{array}{l}\text { Percentil 67- } \\
100 \%\end{array}$ & 0,26 & 0,70 & --- & ns & ns & ns & ns & ns & ns & $\mathrm{ns}$ \\
\hline
\end{tabular}

ns: no significativo; t: 0,10>P>0,05; *: $\mathrm{P}<0,05 ; * *: \mathrm{P}<0,01$; ***: $\mathrm{P}<0,001 . \mathrm{R}^{2}$ : Coeficiente de determinación del modelo; d.e.: desviación estándar. No: no se incluyó ese término en el modelo, al resultar no significativo y disminuir el coeficiente de determinación del mismo. 


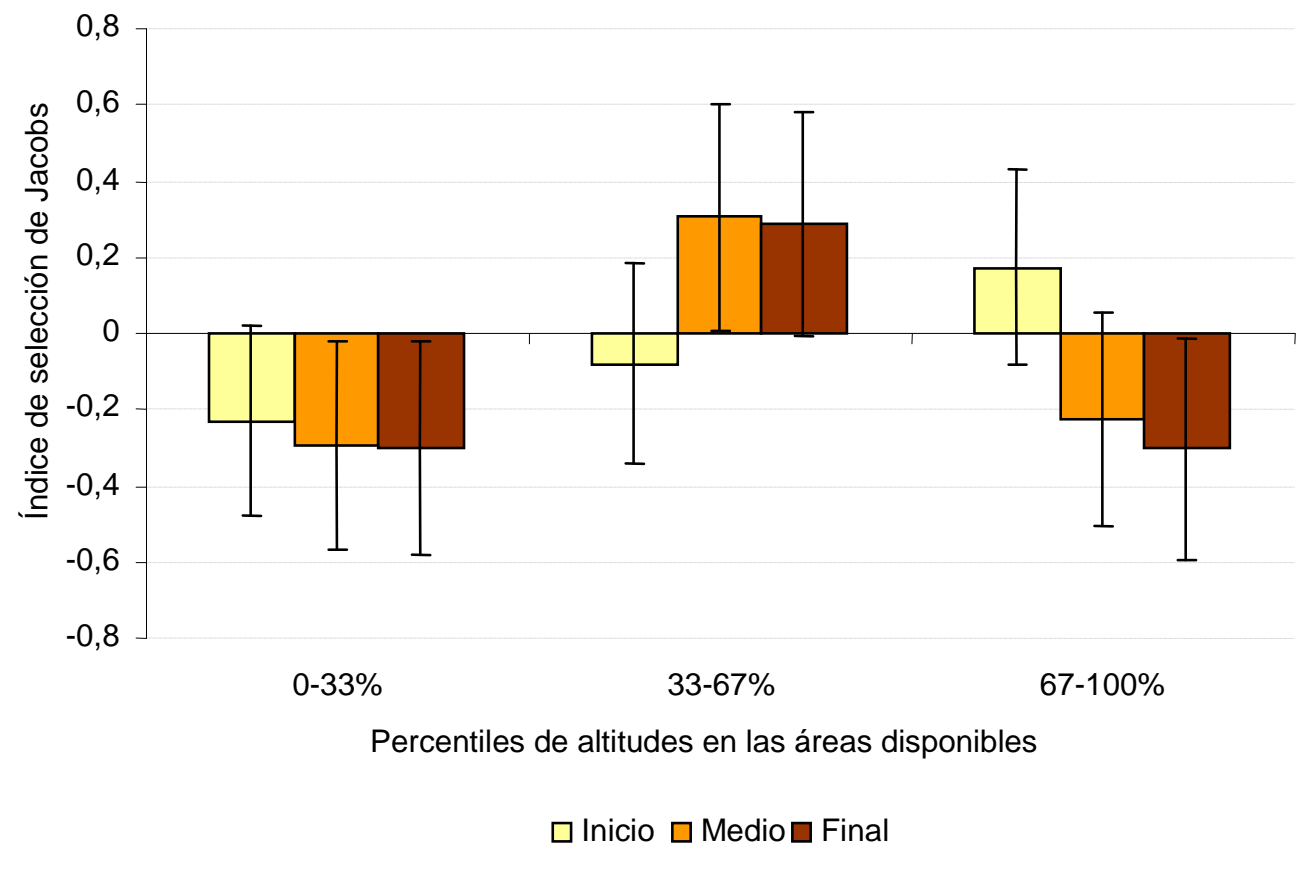

Figura 5.9. Selección en los percentiles 0-33\%, 33-67\% y 67-100\% de las altitudes de las áreas disponibles según la época (inicio, medio y final) para la actividad pastoreo. Las barras verticales señalan los intervalos de confianza con $\mathbf{P}=\mathbf{9 5 \%}$ correspondientes a los análisis de cada percentil por separado.

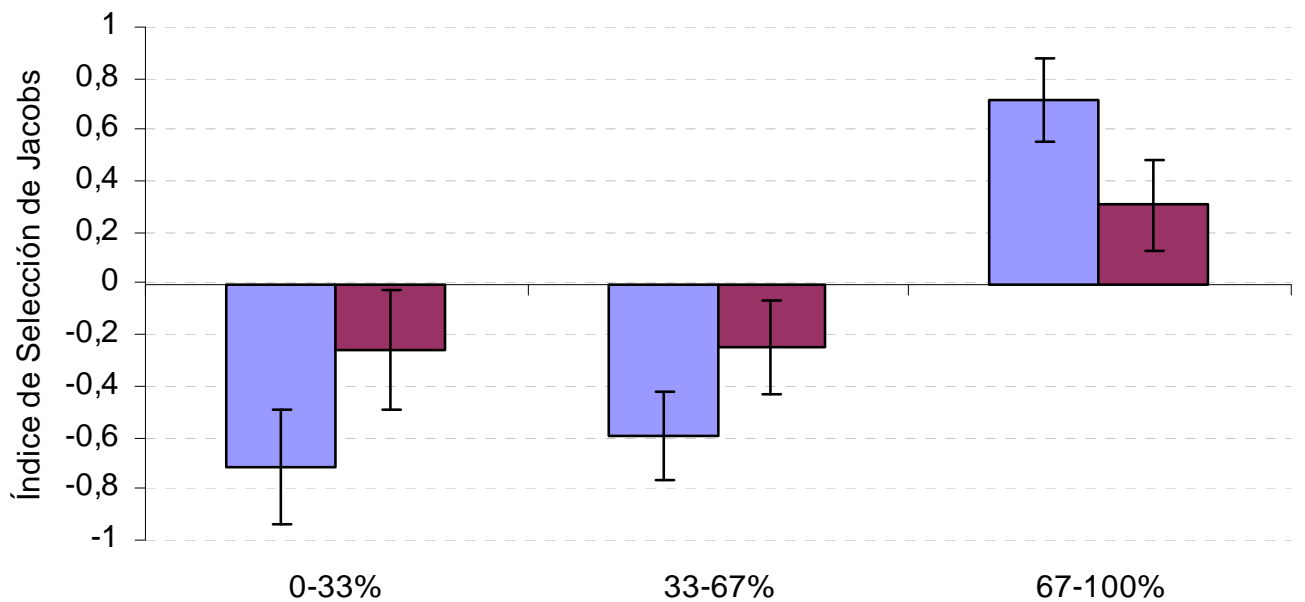

Percentiles de pendientes en las áreas disponibles

$\square$ Vacuno $\square$ Caballar

Figura 5.10. Selección en los percentiles 0-33\%, 33-67\% y 67-100\% de las pendientes de las áreas disponibles según la especie (vacuno y caballar) para la actividad de pastoreo. Las barras verticales señalan los intervalos de confianza con $\mathbf{P}=\mathbf{9 5 \%}$ correspondientes a los análisis de cada percentil por separado. 


\subsubsection{Características del pastoreo en relación con el tipo de pasto}

\section{Correlaciones entre disponibilidad, utilización y selección de los pastos}

Como se puede observar en la tabla 5.9, la selección del pasto (IJ) por el ganado estuvo siempre (para todos los tipos de pasto) correlacionada significativamente con la proporción de tiempo de utilización (PU) de dicho pasto en la ruta de los animales (coeficientes de correlación entre 0,56 y 0,95). Sólo para el pasto herbáceo existió también una correlación significativa, aunque baja, entre selección (IJ) y disponibilidad (PD). Entre las dos variables que definen la selección (proporción de pasto utilizado y proporción de pasto disponible) existieron siempre correlaciones medias-bajas para todos los tipos de pasto (coeficientes entre 0,44 y 0,76). Por último, se observaron elevadas correlaciones entre las disponibilidades de los tipos de pasto estudiados, excepto el cervunal, y la diversidad vegetal de las áreas disponibles.

Tabla 5.9. Correlaciones significativas $(\mathbf{P}<\mathbf{0 , 0 5})$ existentes entre disponibilidades, utilizaciones $\mathbf{y}$ selecciones de los distintos tipos de pastos estudiados y la diversidad vegetal (PD: proporción de pasto disponible; PU: proporción de pasto utilizado, estimado por tiempo de pastoreo; IJ: índice de selección de Jacobs del tipo de pasto; SPD: Índice de Shannon para las comunidades vegetales en el área disponible; SPU: Índice de Shannon para las comunidades pastadas en la ruta).

\begin{tabular}{|c|c|c|c|c|c|c|c|c|c|c|c|c|c|c|c|}
\hline & \multicolumn{2}{|c|}{ Herbáceo } & \multicolumn{3}{|c|}{ Arbustivo } & \multicolumn{3}{|c|}{ Festuca-Agrostis } & \multicolumn{2}{|c|}{ Cervunal } & \multicolumn{2}{|c|}{ Lecherina } & \multicolumn{2}{|c|}{ Diversidad } \\
\hline & & $\mathrm{PU}$ & IJ & PD & $\overline{\mathrm{PU}}$ & $\mathrm{IJ}$ & PD & $P U$ & $\mathrm{IJ}$ & $\overline{\mathrm{PU}}$ & $\overline{\mathrm{IJ}}$ & $\overline{\mathrm{PD}}$ & $\mathrm{PU}$ & SPD & SPU \\
\hline \multirow{3}{*}{ 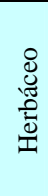 } & PD & $\begin{array}{c}0,54 \\
* *\end{array}$ & $\begin{array}{c}0,40 \\
*\end{array}$ & $\begin{array}{c}-0,96 \\
* * *\end{array}$ & $\begin{array}{c}-0,54 \\
* *\end{array}$ & $\begin{array}{c}-0,41 \\
*\end{array}$ & \multirow{3}{*}{\multicolumn{3}{|c|}{$\begin{array}{l}0,69 \\
* * *\end{array}$}} & & & \multirow[t]{3}{*}{$\begin{array}{c}0,44 \\
*\end{array}$} & \multirow[t]{3}{*}{$\begin{array}{c}0,41 \\
*\end{array}$} & $\begin{array}{r}-0,76 \\
* * *\end{array}$ & $\begin{array}{c}-0,40 \\
*\end{array}$ \\
\hline & PU & & $\begin{array}{r}\mathbf{0 , 9 5} \\
* * * *\end{array}$ & $\begin{array}{c}-0,44 \\
*\end{array}$ & $\begin{array}{l}-1 \\
* * *\end{array}$ & $\begin{array}{c}-0,94 \\
* * *\end{array}$ & & & & & & & & $\begin{array}{c}-0,48 \\
* * *\end{array}$ & $\begin{array}{c}-0,43 \\
*\end{array}$ \\
\hline & IJ & & & & $\begin{array}{c}-0,94 \\
* * *\end{array}$ & $\begin{array}{l}-1 \\
* * *\end{array}$ & & & & & & & & $\begin{array}{c}-0,36 \\
*\end{array}$ & $\begin{array}{c}-0,45 \\
* *\end{array}$ \\
\hline \multirow{3}{*}{ 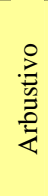 } & PD & & & & $\begin{array}{c}0,44 \\
*\end{array}$ & & \multirow{3}{*}{\multicolumn{3}{|c|}{$\begin{array}{c}-0,67 \\
* * *\end{array}$}} & & & \multirow[t]{3}{*}{$\begin{array}{c}-0,41 \\
*\end{array}$} & \multirow[t]{3}{*}{$\begin{array}{c}-0,41 \\
*\end{array}$} & $\begin{array}{l}0,79 \\
* * *\end{array}$ & $\begin{array}{c}0,42 \\
*\end{array}$ \\
\hline & $\mathrm{PU}$ & & & & & $\begin{array}{c}\mathbf{0 , 9 4} \\
* * *\end{array}$ & & & & & & & & $\begin{array}{c}0,48 \\
* *\end{array}$ & $\begin{array}{c}0,43 \\
*\end{array}$ \\
\hline & $\mathrm{IJ}$ & & & & & & & & & & & & & $\begin{array}{c}0,36 \\
*\end{array}$ & $\begin{array}{c}0,45 \\
* *\end{array}$ \\
\hline \multirow{3}{*}{ 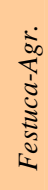 } & PD & & & & & & & $\begin{array}{l}0,58 \\
* * *\end{array}$ & & \multirow{3}{*}{\multicolumn{2}{|c|}{$\begin{array}{c}-0,47 \\
* *\end{array}$}} & $\begin{array}{l}0,68 \\
* * * *\end{array}$ & $\begin{array}{l}0,67 \\
\text { *** }\end{array}$ & $\begin{array}{c}-0,91 \\
* * *\end{array}$ & $\begin{array}{c}-0,4 \\
*\end{array}$ \\
\hline & PU & & & & & & & & $\begin{array}{l}\mathbf{0 , 7 3} \\
* * *\end{array}$ & & & $\begin{array}{c}0,49 \\
* *\end{array}$ & 0,42 & $\begin{array}{c}-0,4 \\
*\end{array}$ & \\
\hline & IJ & & & & & & & & & & & & & & \\
\hline \multirow{2}{*}{$\sum_{\overline{0}}^{\bar{J}}$} & PD & & & & & & & & & $\begin{array}{r}0,55 \\
* * *\end{array}$ & & $\begin{array}{c}0,36 \\
*\end{array}$ & & & \\
\hline & $\mathrm{PU}$ & & & & & & & & & & $\begin{array}{l}\mathbf{0 , 5 6} \\
* * *\end{array}$ & & $\begin{array}{c}0,36 \\
*\end{array}$ & & \\
\hline \multirow{2}{*}{ 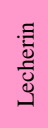 } & PD & & & & & & & & & & & & $\begin{array}{l}0,76 \\
* * *\end{array}$ & \multirow{2}{*}{\multicolumn{2}{|c|}{$\begin{array}{c}-0,74 \\
* * * \\
-0,59 \\
* * *\end{array}$}} \\
\hline & PU & & & & & & & & & & & & & & \\
\hline $\begin{array}{l}\dot{\vec{D}} \\
\dot{\vec{D}} \\
\dot{\vec{\theta}}\end{array}$ & SPD & & & & & & & & & & & & & & $\begin{array}{c}0,46 \\
* *\end{array}$ \\
\hline
\end{tabular}

Los valores en negrita corresponden a las correlaciones significativas entre selección y utilización para cada tipo de pasto. Los valores en cursivas corresponden a las correlaciones significativas entre disponibilidad y utilización para cada tipo de pasto. *: $\mathrm{P}<0,05 ; * *: \mathrm{P}<0,01 ; * * *: \mathrm{P}<0,001$. 


\section{$\underline{\text { Disponibilidad de los distintos tipos de pastos }}$}

Al considerar el modelo inicial que incluía como efectos fijos la especie animal, la época y su interacción, únicamente se registraron diferencias significativas entre especies para los componentes más genéricos de la vegetación disponible (pasto herbáceo y pasto arbustivo; tabla 5.10 y figura 5.11). En este sentido, las rutas de las vacas se situaron en áreas con mayor proporción de pastos arbustivos respecto a las de las yeguas y, dada su alta correlación (ver tabla 5.9), también estuvieron emplazadas en zonas de mayor diversidad vegetal (figura 5.11).

Tabla 5.10. Disponibilidad de los distintos tipos de pastos en las rutas diurnas de pastoreo. Nivel de significación estadística (P) de los efectos fijos especie (Esp: vacuno y caballar) y época (Ep: inicio, medio y final) y de su interacción.

\begin{tabular}{|c|c|c|c|c|c|c|}
\hline & Media & d.e. & $\mathrm{R}^{2}$ & Esp & Ep & Esp x Ep \\
\hline Proporción de pasto herbáceo sobre el pasto total & 0,65 & 0,12 & 0,20 & $* *$ & ns & $\mathrm{ns}$ \\
\hline Proporción de pasto arbustivo sobre el pasto total & 0,22 & 0,10 & 0,18 & $*$ & ns & $\mathrm{ns}$ \\
\hline Proporción de Festuca-Agrostis sobre el pasto herbáceo & 0,59 & 0,13 & 0,02 & $\mathrm{t}$ & ns & ns \\
\hline Proporción de cervunal sobre el pasto herbáceo & 0,10 & 0,07 & 0,03 & ns & ns & ns \\
\hline Lecherina en el pasto de Festuca-Agrostis & 0,14 & 0,05 & --- & ns & ns & ns \\
\hline Diversidad de comunidades (Índice de Shannon) & 1,86 & 0,24 & 0,02 & $*$ & ns & $\mathrm{ns}$ \\
\hline
\end{tabular}
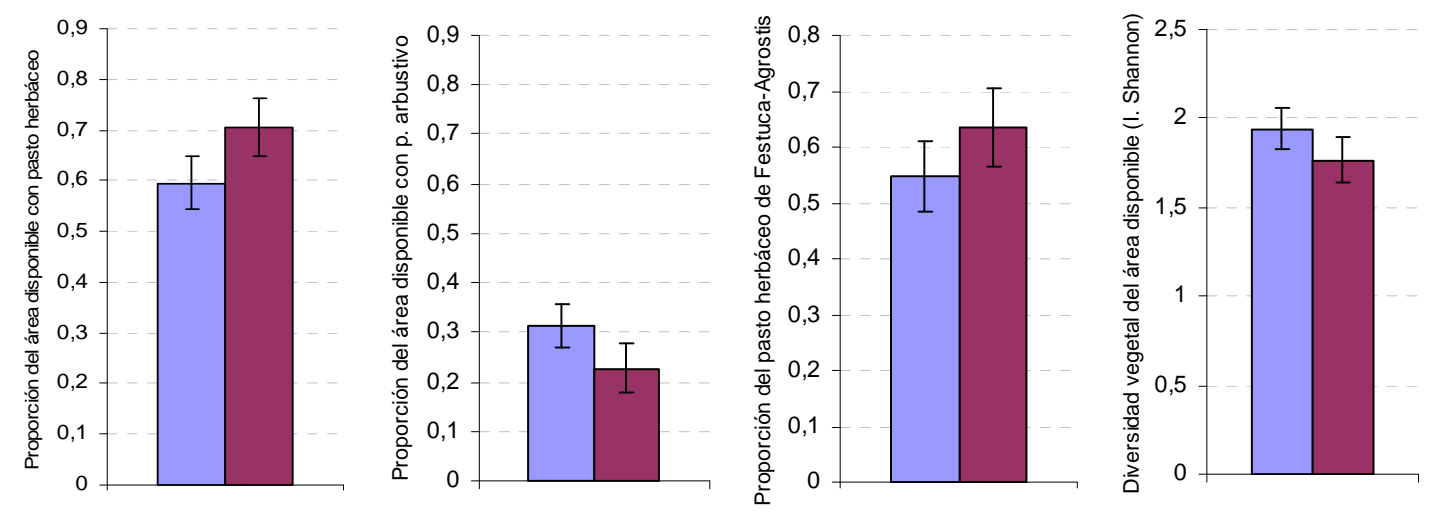

$\square$ Vacuno $\square$ Caballar

Figura 5.11. Disponibilidad de los distintos tipos de pastos en las rutas diurnas de pastoreo. Valores significativamente diferentes $(\mathbf{P}<0,05)$ según la especie (vacuno y caballar). Las barras verticales representan el intervalo de confianza al $95 \%$.

El modelo que contempló solamente las vacas mostró a su vez diferencias en los tipos de pasto presentes en las áreas disponibles para cada raza (tabla 5.11 y figura 5.12). 
La comparación entre los valores reflejados en las figuras 5.11 y 5.12 pone en evidencia la similitud en los valores de estas variables para el caballar y para el vacuno de razas foráneas. En la proporción de cervunal sobre pasto herbáceo y cobertura de lecherina en el pasto de Festuca-Agrostis, se detectaron también efectos significativos de la interacción raza $\times$ la covariable días desde el inicio del estudio (tabla 5.11). En concreto, se encontró una evolución descendente en estas proporciones en las vacas de raza tudanca, mientras que en el resto de las razas se observaron valores similares durante toda la estación de pastoreo.

Tabla 5.11. Disponibilidad de los distintos tipos de pasto en las rutas diurnas de pastoreo del ganado vacuno. Nivel de significación estadística (P) del efecto fijo raza de vacuno (tudanca y otras razas), de la covariable días desde el comienzo del estudio (días) y de su interacción.

\begin{tabular}{lccccccc}
\hline & Media & d.e. & $\mathrm{R}^{2}$ & Raza & $\begin{array}{c}\text { Días } \\
\text { Raza x } \\
\text { Días }\end{array}$ \\
\hline Proporción de pasto herbáceo sobre el pasto total & 0,60 & 0,12 & 0,40 & $* *$ & No & No \\
Proporción de pasto arbustivo sobre el pasto total & 0,31 & 0,10 & 0,38 & $* *$ & No & No \\
Proporción de Festuca-Agrostis sobre el pasto herbáceo & 0,55 & 0,13 & 0,46 & $* *$ & ns & No \\
Proporción de cervunal sobre el pasto herbáceo & 0,11 & 0,08 & 0,43 & $*$ & t & $*$ & $*$ \\
Cobertura de lecherina en el pasto de Festuca-Agrostis & 0,14 & 0,04 & 0,23 & $\mathrm{t}$ & $\mathrm{ns}$ & $*$ \\
Diversidad de las comunidades (Indice de Shannon) & 1,94 & 0,20 & 0,17 & $*$ & $\mathrm{~ns}$ & No \\
\hline
\end{tabular}
ns: no significativo; t: 0,10>P>0,05; *: $\mathrm{P}<0,05$; **: $\mathrm{P}<0,01 ; * * *: \mathrm{P}<0,001 . \mathrm{R}^{2}$ : Coeficiente de determinación del modelo; d.e.: desviación estándar. No: no se incluyó ese término en el modelo, al resultar no significativo y disminuir el coeficiente de determinación del mismo.
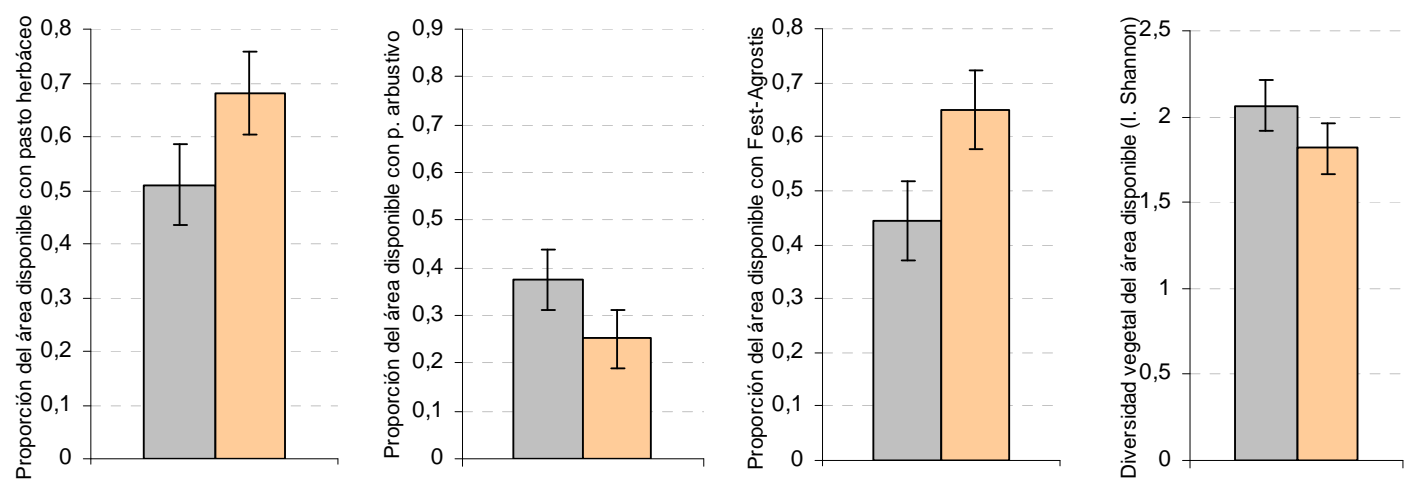

$\square$ Tudanca $\square$ Otras razas

Figura 5.12. Disponibilidad de los distintos tipos de pasto en las rutas diurnas de pastoreo del ganado vacuno. Las barras verticales representan el intervalo de confianza con $P=95 \%$. 


\section{$\underline{\text { Utilización de los distintos tipos de pasto por el ganado en sus rutas de pastoreo diurnas }}$}

La inclusión de una covariable representando la disponibilidad del tipo de pasto a estudiar dentro del área disponible, permitió cuantificar la parte de la varianza debida a la vegetación disponible en el área elegida por el animal y la parte atribuible a los efectos fijos considerados (tabla 5.12).

Tabla 5.12. Utilización de los distintos tipos de pasto por el ganado en sus rutas de pastoreo diurnas. Nivel de significación estadística (P) de los efectos fijos especie (Esp: vacuno y caballar), época (Ep: inicio, medio y final) y su interacción, así como de la covariable disponibilidad de cada componente vegetal analizado en las áreas disponibles en cada ruta (cov).

\begin{tabular}{|c|c|c|c|c|c|c|c|}
\hline & Media & d.e. ${ }^{1}$ & $\mathrm{R}^{2}$ & Esp & Ep & $\begin{array}{c}\text { Esp x } \\
\text { Ep }\end{array}$ & $\mathrm{Cov}$ \\
\hline $\begin{array}{l}\text { Proporción del pastoreo sobre } \\
\text { pasto herbáceo }\end{array}$ & 0,96 & 0,23 & 0,43 & $* *$ & $\mathrm{~ns}$ & ns & $*$ \\
\hline $\begin{array}{l}\text { Proporción del pastoreo sobre } \\
\text { pasto arbustivo }\end{array}$ & 0,04 & 0,23 & 0,41 & $* *$ & $\mathrm{~ns}$ & ns & $\mathrm{t}$ \\
\hline $\begin{array}{l}\text { Proporción de pastoreo } \\
\text { herbáceo sobre Festuca- } \\
\text { Agrostis }\end{array}$ & 0,74 & 0,34 & 0,34 & $* *$ & $\mathrm{~ns}$ & ns & $* * *$ \\
\hline $\begin{array}{l}\text { Proporción de pastoreo } \\
\text { herbáceo sobre cervunal }\end{array}$ & 0,07 & 0,25 & 0,46 & $\mathrm{t}$ & $*$ & ns & $*$ \\
\hline $\begin{array}{l}\text { Cobertura de lecherina en el } \\
\text { pasto de Festuca-Agrostis }\end{array}$ & 0,15 & 0,13 & 0,50 & ns & $\mathrm{t}$ & ns & $* * *$ \\
\hline $\begin{array}{l}\text { Diversidad de comunidades } \\
\text { pastadas (Índice de Shannon) }\end{array}$ & 1,00 & 0,28 & 0,30 & ns & $\mathrm{ns}$ & ns & $*$ \\
\hline
\end{tabular}

En todos los modelos la covariable mostró un efecto significativo, señalando la relación existente, siempre positiva, entre la proporción de cada tipo de pasto presente en el área disponible y su utilización por el ganado, tal como quedó ya patente en el análisis de correlaciones (tabla 5.9). Esta variable fue la única significativa en el análisis de la cobertura de lecherina en el pasto de Festuca-Agrostis utilizado y en la diversidad de comunidades vegetales pastadas en la ruta diurna. Para el resto de variables respuesta, es decir, para las proporciones de pastoreo sobre herbáceo, arbustivo, Festuca-Agrostis y cervunal) la especie animal se mostró significativa en todos los casos (figura 5.13), indicando que, además de una selección a nivel de áreas disponibles, dentro de ellas también existió una diferenciación entre vacas y yeguas respecto al tipo de pastos utilizados. En este caso, las yeguas pastaron casi exclusivamente sobre vegetación 
herbácea, y dentro de ella repartieron más el tiempo de pastoreo entre distintas comunidades, mientras que las vacas utilizaron mayoritariamente los pastos de FestucaAgrostis. En ningún caso se encontraron interacciones significativas entre la covariable (disponibilidad del tipo de pasto a estudiar dentro del área disponible) y los efectos fijos estudiados (especie y época), por lo que esta interacción no se muestra en la tabla.
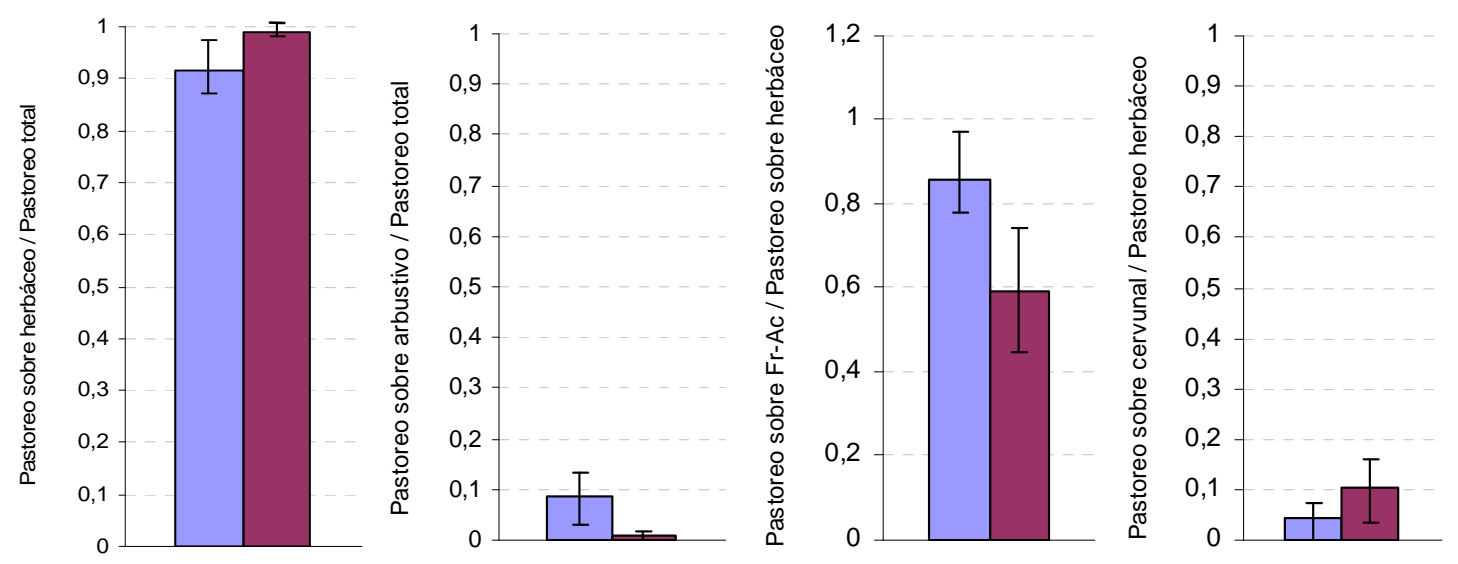

$\square$ Vacuno $\square$ Caballar

Figura 5.13. Utilización de los distintos tipos de pasto por el ganado en sus rutas de pastoreo diurnas. Las barras verticales representan el intervalo de confianza con $P=95 \%$.

La proporción de cervunal pastado respecto al total de pasto herbáceo utilizado fue significativamente diferente según la época considerada $(\mathrm{P}<0,05)$. En concreto, se observó una parada prácticamente total de su pastoreo en el último tercio de la estación de pastoreo (figura 5.14). Asimismo, también se encontró una tendencia $(\mathrm{P}=0,1)$ hacia una mayor utilización del cervunal por el ganado caballar. 


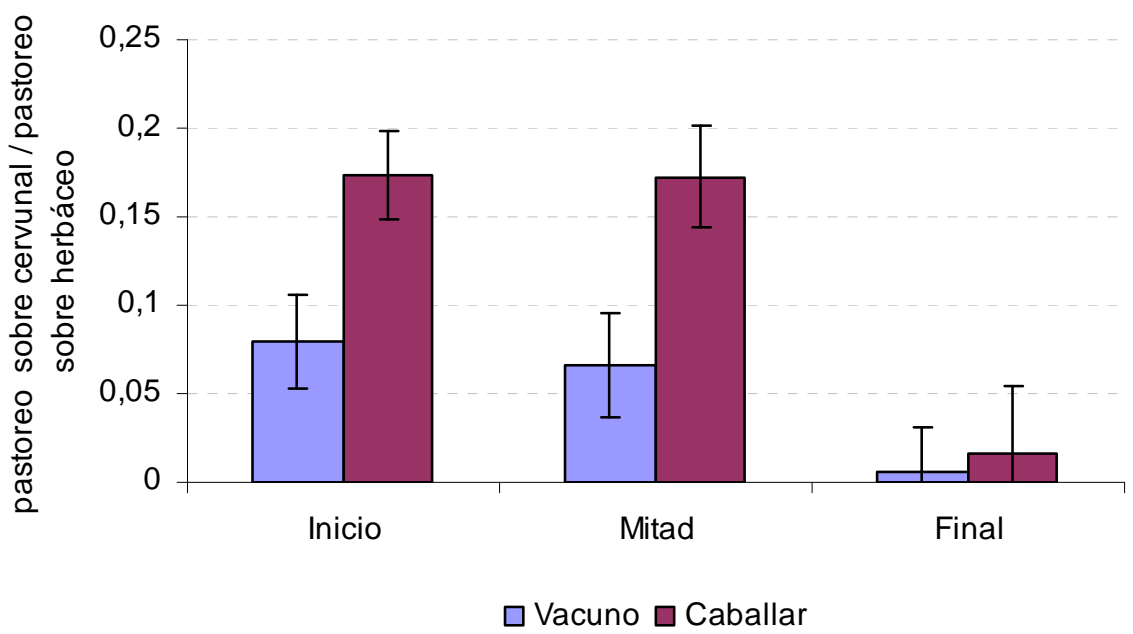

Figura 5.14. Evolución de la utilización de cervunal sobre pasto herbáceo en vacas y yeguas a lo largo

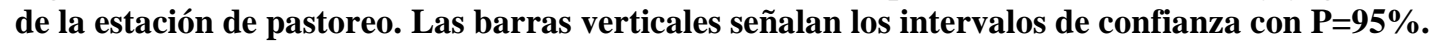

En el estudio específico del ganado vacuno, la interacción entre la raza y la covariable días desde el inicio del muestreo fue significativa en el análisis del aprovechamiento de algunos de los tipos de pasto (tabla 5.13 y figura 5.15). En el caso de la utilización de pastos herbáceos y arbustivos, se observó una acusada evolución lineal de las vacas tudancas hacia una menor utilización del herbáceo y una mayor utilización del arbustivo con el tiempo (figura 5.15), tanto al considerar todas las observaciones $\left(\mathrm{R}^{2}=0,87\right.$ ) como al eliminar la observación más alejada en el tiempo (día $73 ; \mathrm{R}^{2 *}=0,80$ ). En las otras razas de vacas no se encontró esta relación $(\mathrm{P}>0,1)$. Por otro lado, la utilización de los cervunales con respecto al total de pastos herbáceos también experimentó un descenso significativo con el tiempo en la tudanca $\left(\mathrm{R}^{2}=0,66\right.$; figura 5.15), incluso no considerando la observación mencionada anteriormente $\left(\mathrm{R}^{2^{*}}=0,62\right)$. Esta relación tampoco pudo observarse en las vacas de otras razas porque estas siempre lo consumieron de forma minoritaria $(\mathrm{P}>0,1)$.

La influencia significativa de la covariable proporción de la vegetación analizada en el área disponible sobre las variables respuesta pastos de Festuca-Agrostis, cobertura de lecherina en el pasto de Festuca-Agrostis y diversidad vegetal (tabla 5.13), junto con las diferencias detectadas entre razas a nivel de las áreas disponibles (tabla 5.11, figura 5.12), ponen de manifiesto la distinta escala espacial a la que dichas razas seleccionaron su dieta en pastoreo. 
Tabla 5.13. Utilización de los distintos tipos de pasto por el ganado vacuno en sus rutas de pastoreo diurnas. Nivel de significación estadística (P) del efecto fijo raza (tudanca y otras razas) y de las covariables: días desde inicio del estudio (días) y tipos de pastos en las áreas disponibles en cada ruta (cov2).

\begin{tabular}{|c|c|c|c|c|c|c|c|c|}
\hline & Media & d.e. ${ }^{1}$ & $\mathrm{R}^{2}$ & Raza & Días & Cov2 & $\begin{array}{c}\text { Raza } \\
x \\
\text { Días } \\
\end{array}$ & $\begin{array}{c}\text { Raza } \\
\text { x } \\
\text { Cov2 } \\
\end{array}$ \\
\hline $\begin{array}{l}\text { Proporción del pastoreo sobre pasto } \\
\text { herbáceo }\end{array}$ & 0,90 & 0,24 & 0,54 & ns & $*$ & No & $*$ & No \\
\hline $\begin{array}{l}\text { Proporción del pastoreo sobre pasto } \\
\text { arbustivo }\end{array}$ & 0,10 & 0,24 & 0,54 & ns & $*$ & No & $*$ & No \\
\hline $\begin{array}{l}\text { Proporción de pastoreo herbáceo } \\
\text { sobre Festuca-Agrostis }\end{array}$ & 0,81 & 0,35 & 0,64 & $\mathrm{~ns}$ & No & $* *$ & No & No \\
\hline $\begin{array}{l}\text { Proporción de pastoreo herbáceo } \\
\text { sobre Cervunal }\end{array}$ & 0,04 & 0,21 & 0,73 & $* *$ & $* *$ & ns & $*$ & No \\
\hline $\begin{array}{l}\text { Cobertura de lecherina en el pasto } \\
\text { de Festuca-Agrostis utilizado }\end{array}$ & 0,14 & 0,16 & 0,65 & ns & No & $* * *$ & No & No \\
\hline $\begin{array}{l}\text { Diversidad de las comunidades } \\
\text { (Índice de Shannon) }\end{array}$ & 0,99 & 0,32 & 0,34 & ns & No & * & No & ns \\
\hline
\end{tabular}
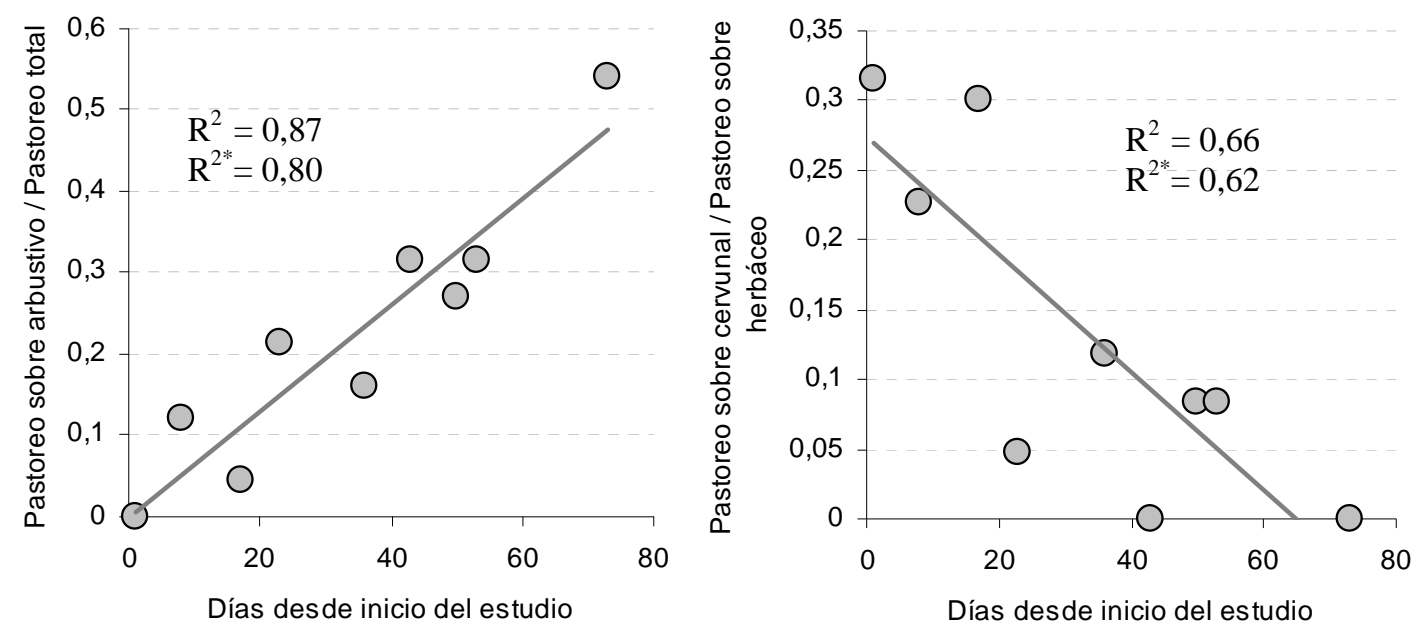

Figura 5.15. Evolución temporal de la utilización en pastoreo de dos tipos de pasto por las vacas tudancas (izquierda: utilización del pasto arbustivo respecto al pastoreo total; derecha: utilización del cervunal respecto al pastoreo sobre pasto herbáceo). El coeficiente de regresión $\mathbf{R}^{2^{*}}$ corresponde a la regresión lineal sin la observación del día 73.

\section{Selección de la vegetación por el ganado}

Como ya se decribió en el apartado 5.2.2, y a modo únicamente de recordatorio, la selección de la vegetación por el ganado se estimó a partir de la relación entre lo 
disponible, estimado en superficie (en las áreas disponibles) y lo utilizado, estimado en el tiempo (en las rutas de pastoreo).

La selección de los distintos tipos de pasto fue, en general, sensible a los factores especie y época de la estación de pastoreo (tabla 5.14). En concreto, la selección positiva del pasto herbáceo y negativa del arbustivo fue siempre más acusada en el ganado caballar que en el vacuno (figura 5.16 a y b), de forma similar a lo que ocurría con la utilización (como se vio en la figura 5.13).

Al profundizar en la selección del pasto herbáceo por las especies de ganado estudiadas, no se observaron diferencias significativas entre tipos de pasto herbáceo, excepto una tendencia a un mayor rechazo de los cervunales por parte del vacuno, de forma análoga a lo ya observado en los resultados de utilización (figura 5.13).

Por su parte, la época de la estación de pastoreo se mostró como un factor significativo en la selección de la mayoría de los tipos de pasto. La menor selección activa del pasto herbáceo y el menor rechazo del pasto arbustivo registrados en la parte intermedia de la estación de pastoreo fueron atribuibles a los bajos valores absolutos de selección encontrados en el ganado vacuno (figura 5.16a y b); en cambio el caballar mostró valores de estas variables muy similares en todas las épocas. A su vez, la selección del pasto herbáceo de Festuca-Agrostis fue siempre positiva para el vacuno, y nunca diferente de cero para el caballar (figura 5.16c), si bien las diferencias entre ambas especies no llegaron a ser significativas en caso alguno. Respecto a los cervunales, mientras que hasta la época intermedia de la estación de pastoreo su utilización fue proporcional a su disponibilidad, aunque muy variable, al final de la estación se detectó un fuerte rechazo a su pastoreo (figura 5.16d), coincidente también con su escasa utilización (figura 5.14). 
Tabla 5.14. Selección de los distintos tipos de pasto por el ganado en sus rutas de pastoreo diurnas. Nivel de significación estadística (P) de los efectos fijos especie (Esp: vacuno y caballar) y época (Ep: inicio, medio y final), de la covariable disponibilidad de los tipos de pasto analizados en las áreas disponibles (cov) y de sus interacciones.

\begin{tabular}{lcccccccccc}
\hline & Media & d.e. & $\mathrm{R}^{2}$ & Esp & Ep & Esp x Ep & Cov & Cov x Esp & $\begin{array}{c}\text { Cov } \\
\text { x Ep }\end{array}$ \\
\hline Selección de pasto herbáceo & $+0,81$ & 0,24 & 0,42 & $* * *$ & $\mathrm{t}$ & $\mathrm{ns}$ & No & No & No \\
Selección de pasto arbustivo & $-0,75$ & 0,31 & 0,48 & $* * *$ & $*$ & $\mathrm{t}$ & No & No & No \\
Selección de Festuca-Agrostis & $+0,27$ & 0,53 & 0,41 & $\mathrm{~ns}$ & $\mathrm{~ns}$ & $\mathrm{~ns}$ & $\mathrm{t}$ & $\mathrm{ns}$ & $\mathrm{ns}$ \\
Selección de cervunal & $-0,22$ & 0,66 & 0,35 & $\mathrm{t}$ & $* *$ & $\mathrm{~ns}$ & $\mathrm{No}$ & No & No \\
\hline
\end{tabular}

ns: no significativo; t: 0,10>P>0,05; *: $\mathrm{P}<0,05 ; * *: \mathrm{P}<0,01 ; * * *: \mathrm{P}<0,001 . \mathrm{R}^{2}$ : Coeficiente de determinación del modelo; d.e.: desviación estándar. No: no se incluyó ese término en el modelo, al resultar no significativo y disminuir el coeficiente de determinación del mismo.
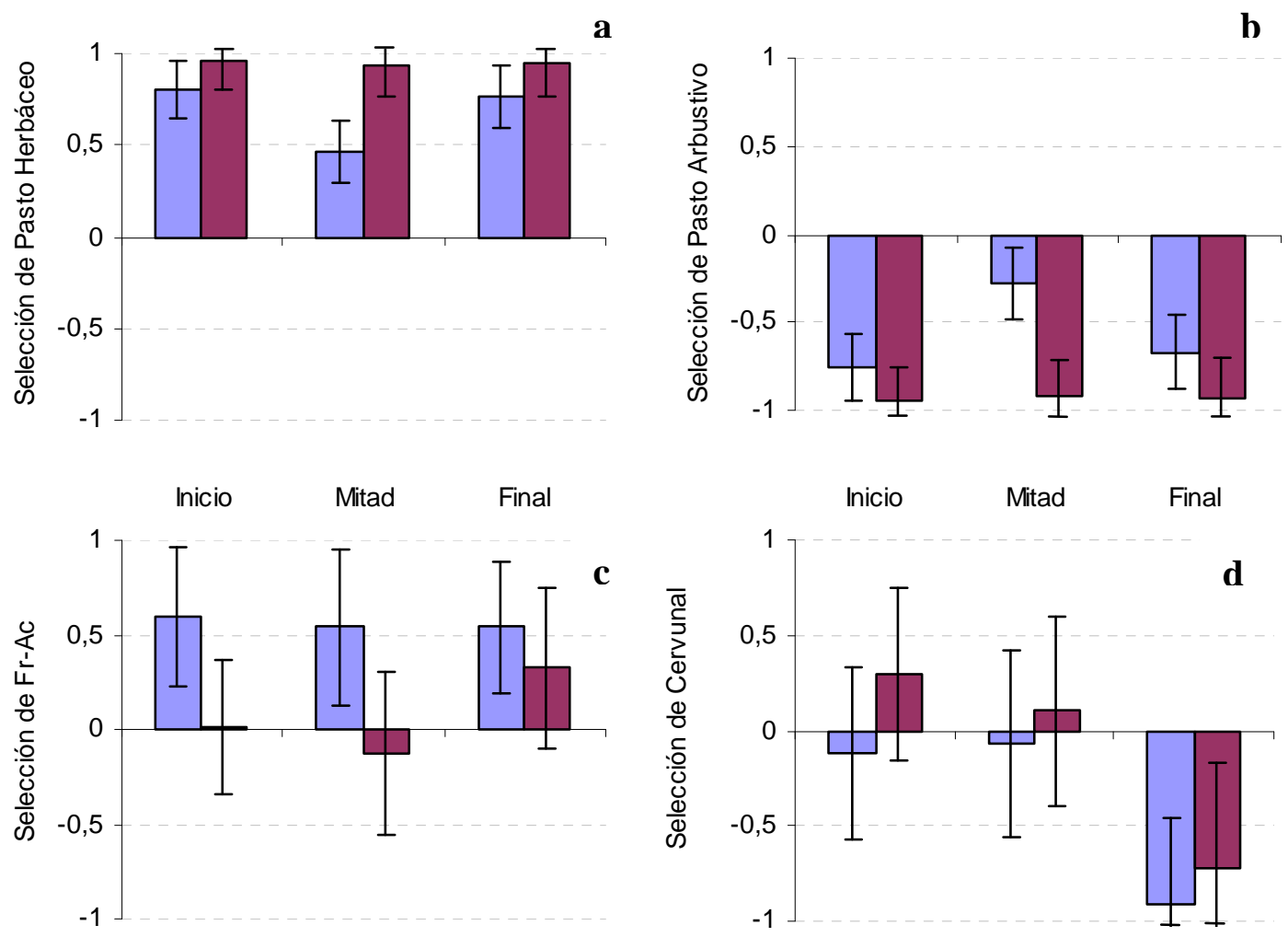

$\square$ Vacuno $\square$ Caballar

Figura 5.16. Selección de los distintos tipos de pasto según la especie (vacuno y caballar) y la época de la estación de pastoreo (inicio, medio y final) en sus rutas de pastoreo diurnas. Las barras verticales señalan los intervalos de confianza con $P=95 \%$.

En el análisis de la selección de los tipos de pasto estudiados por las dos razas de vacuno, la inclusión de la covariable días transcurridos desde el inicio del muestreo dio lugar en general a modelos más robustos (tabla 5.15). La selección de pasto herbáceo o arbustivo fue diferente entre razas una vez corregido por la covariable, mostrándose el ganado tudanco menos selectivo en ambos casos (figura 5.17). A su vez, la relación entre 
el índice de selección de Jacobs en estas categorías de pasto y la covariable fue especialmente alta $\left(\mathrm{R}^{2}=0,82\right)$ en el caso de las vacas de raza tudanca (figura 5.18). El efecto significativo de la raza sobre la selección de pasto de Festuca-Agrostis fue similar al encontrado en la disponibilidad de ese pasto, tal y como se mostraba en la figura 5.12.

Tabla 5.15. Selección de los distintos tipos de pasto por el ganado vacuno en sus rutas de pastoreo diurnas. Nivel de significación estadística (P) del efecto fijo raza (tudanca y otras razas), de la covariable días desde el comienzo de la prueba (días) y de su interacción.

\begin{tabular}{lcccccc}
\hline & Media & d.e. & $\mathrm{R}^{2}$ & Raza & Días & $\begin{array}{c}\text { Raza x } \\
\text { Días }\end{array}$ \\
\hline Selección de pasto herbáceo & $+0,64$ & 0,31 & 0,52 & $\mathrm{~ns}$ & $* *$ & $*$ \\
Selección de pasto arbustivo & $-0,52$ & 0,40 & 0,53 & $\mathrm{~ns}$ & $* *$ & $*$ \\
Selección de Festuca-Agrostis & $+0,50$ & 0,47 & 0,25 & $*$ & $\mathrm{~ns}$ & No \\
Selección de cervunal & $-0,38$ & 0,63 & 0,30 & $\mathrm{~ns}$ & $\mathrm{~ns}$ & No \\
\hline
\end{tabular}

ns: no significativo; t: $0,10>\mathrm{P}>0,05 ; *: \mathrm{P}<0,05 ; * *: \mathrm{P}<0,01 ; * * *: \mathrm{P}<0,001 . \mathrm{R}^{2}$ : Coeficiente de determinación del modelo; d.e.: desviación estándar. No: no se incluyó ese término en el modelo, al resultar no significativo y disminuir el coeficiente de determinación del mismo.
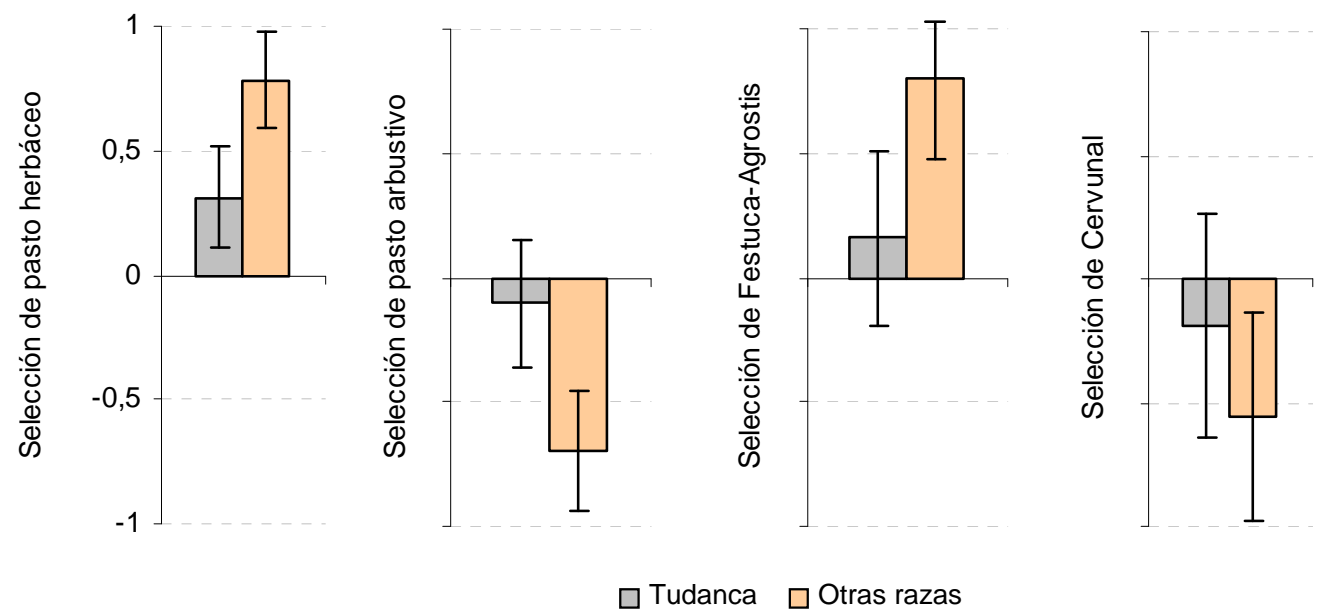

Figura 5.17. Selección de los distintos tipos de pasto según la raza de ganado vacuno (tudanca y otras razas) en sus rutas de pastoreo diurnas. Las barras verticales señalan los intervalos de confianza con $\mathbf{P}=95 \%$. 


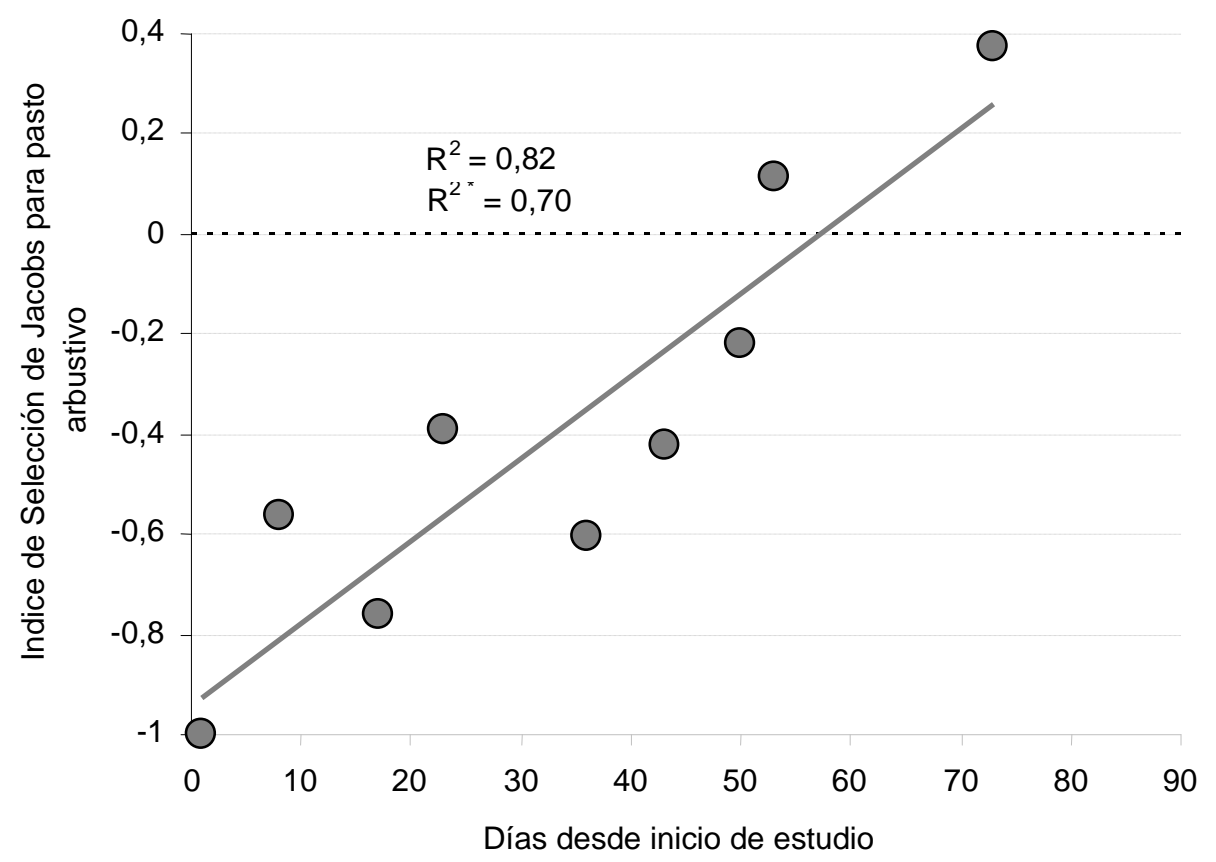

Figura 5.18. Evolución temporal de la selección del pasto arbustivo por las vacas de raza tudanca. El coeficiente de regresión $\mathbf{R}^{2^{*}}$ corresponde a la regresión lineal sin la observación del día 73 .

En el análisis de la selección de los pastos de Festuca-Agrostis según su grado de invasión de lecherina (tabla 5.16), se encontró una interacción significativa entre los efectos fijos especie y época en la selección de los pastos de Festuca-Agrostis con niveles bajos y medios de cobertura de lecherina. En el caso del vacuno, la selección no fue diferente de cero en ningún caso, aunque las gráficas parecen mostrar una ligera selección de los pastos con menos lecherina (figura 5.19). En cambio, en el ganado caballar, si bien en las épocas inicial e intermedia de la estación no se encontraron selecciones o rechazos activos muy marcados para ninguno de los percentiles, en el último tercio se observó una selección muy elevada del pasto de Festuca-Agrostis con menor cobertura de lecherina y un rechazo de las zonas con niveles medios y altos de invasión. También para los percentiles de cobertura baja y media de lecherina se encontró que la covariable proporción de pasto de Festuca-Agrostis sobre el total de pasto herbáceo en el área disponible afectó significativamente a la selección a lo largo de la estación de pastoreo, tanto por el vacuno como por el caballar. El análisis específico del ganado vacuno según su raza no mostró ninguna diferencia significativa $(\mathrm{P}>0,10)$. 
Tabla 5.16. Selección de los pastos de Festuca-Agrostis según su grado de cobertura de lecherina dividido en tres percentiles de igual superficie disponible (cobertura baja, media y alta; ver tabla 5.3). Nivel de significación estadística (P) de los efectos fijos especie (Esp: vacuno y caballar) y época (Ep: inicio, medio y final), de la covariable proporción de pasto de Festuca-Agrostis sobre el total de pasto herbáceo en el área disponible (cov) y de sus interacciones.

\begin{tabular}{lcccccccccc}
\hline & Media & d.e. & $\mathrm{R}^{2}$ & Esp & Ep & $\begin{array}{c}\text { Esp } \\
\text { x Ep }\end{array}$ & Cov & $\begin{array}{c}\text { Esp x } \\
\text { Cov }\end{array}$ & $\begin{array}{c}\text { Ep x } \\
\text { Cov }\end{array}$ & $\begin{array}{c}\text { Esp x Ep } \\
\text { x Cov }\end{array}$ \\
\hline $\begin{array}{l}\text { Percentil de } \\
\text { cobertura bajo }\end{array}$ & $+0,09$ & 0,61 & 0,24 & $\mathrm{~ns}$ & $*$ & $*$ & $\mathrm{~ns}$ & No & $*$ & No \\
$\begin{array}{l}\text { Percentil de } \\
\text { cobertura media }\end{array}$ & $-0,11$ & 0,56 & 0,41 & $\mathrm{~ns}$ & $* *$ & $* *$ & $\mathrm{~ns}$ & No & $* *$ & No \\
$\begin{array}{l}\text { Percentil de } \\
\text { cobertura alta }\end{array}$ & $-0,34$ & 0,54 & --- & $\mathrm{ns}$ & $\mathrm{ns}$ & $\mathrm{ns}$ & $\mathrm{ns}$ & No & No & No \\
\hline
\end{tabular}

ns: no significativo; t: 0,10>P>0,05; *: $\mathrm{P}<0,05 ; * *: \mathrm{P}<0,01 ; * * *: \mathrm{P}<0,001 . \mathrm{R}^{2}$ : Coeficiente de determinación del modelo; d.e.: desviación estándar. No: no se incluyó ese término en el modelo, al resultar no significativo y disminuir el coeficiente de determinación del mismo.

Cob. de lecherina baja

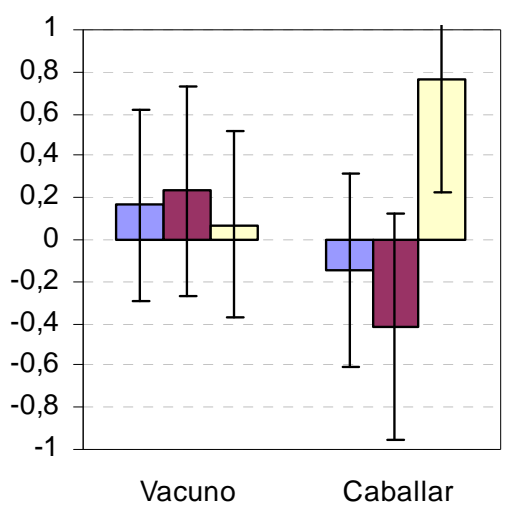

Cob. de lecherina media

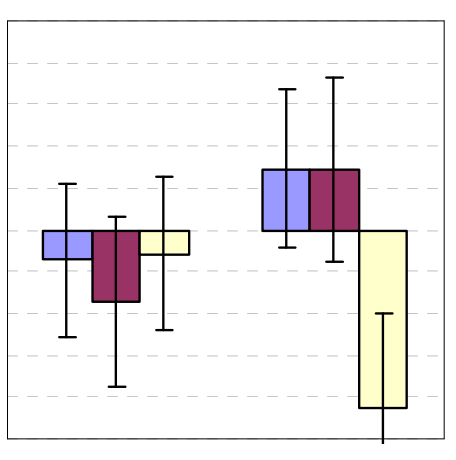

Vacuno Caballar
Cob. de lecherina alta

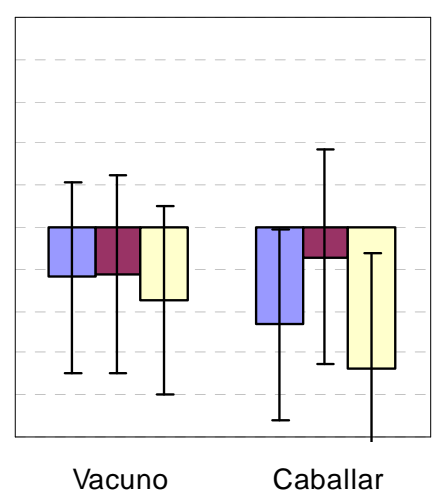

$\square$ Inicio $\square$ Medio $\square$ Final

Figura 5.19. Selección de los pastos de Festuca-Agrostis según su grado de cobertura de lecherina dividido en tres percentiles de igual superficie disponible (cobertura baja, media y alta).

\subsection{Discusión}

Los cambios radicales acaecidos en los sistemas ganaderos de la montaña cantábrica en las últimas décadas (ver capítulo 2) también han repercutido sobre el uso de los puertos: desaparición del pastoreo dirigido por vaqueros, cambio en los tipos de ganado y, en muchos casos, cambio y desconocimiento de las zonas de pastoreo por el ganado. Los resultados obtenidos en este estudio ponen de relieve la diversidad de patrones de uso pastoral encontrados en la actualidad en un puerto de montaña cantábrico. Esta diversidad es, en parte, fruto del distinto comportamiento mostrado por los tipos de ganado presentes, tanto a nivel de la especie animal (vacuno y caballar), como por las distintas razas, en este 
caso de vacuno. Además del tipo de ganado, también se ha puesto de relieve la existencia de importantes cambios temporales en ciertos patrones de uso a lo largo del verano. En este apartado se realiza un análisis de los resultados haciendo énfasis en la relación que puede existir entre los patrones de pastoreo observados y el sobrepastoreo de los pastos herbáceos de Festuca-Agrostis, proceso que conduce a su degradación e invasión por la lecherina.

\subsubsection{Características generales de las rutas diurnas}

Como era esperable, no se detectaron grandes diferencias en las características generales de las rutas diurnas de pastoreo del ganado vacuno y caballar, ya que ambas especies, aunque poseen distintos tipos de sistemas digestivos, están especializadas en el consumo de grandes cantidades de herbáceas y forrajes bastos (Janis, 1976). En este sentido, se sabe que el solapamiento de sus hábitats y de sus dietas en pastoreo libre puede ser elevado (Salter et al., 1980; Krysl et al., 1984; Aldezabal, 2001; Menard et al., 2002; Lamoot et al., 2005).

Las únicas diferencias observadas entre las características generales de las rutas de estas dos especies estuvieron relacionadas con la pendiente, seleccionando el ganado caballar las posiciones más suaves a las distintas escalas de análisis. Este resultado contrasta con lo sugerido por Ganskopp y Vavra (1987) en zonas de montaña del estado de Oregón (EE.UU), si bien hay que considerar que en su caso comparaban al ganado vacuno con caballos salvajes. En nuestro trabajo, el mayor tiempo de pastoreo del caballar y su mayor selección de pasto herbáceo (ver apartado 5.3.3), más abundante en las zonas de topografía más suave (tabla 5.17), podrían haber producido cierta separación espacial de los hábitats de las dos especies, donde el vacuno acabaría ocupando las zonas más desfavorecidas (Edwards y Hollis, 1982; Gordon, 1989b; Lamoot et al., 2005). Con respecto a la totalidad del puerto de Sejos, los valores medios de las pendientes en las áreas disponibles de las rutas y los correspondientes a los percentiles creados (valores medios de $7 \% ; 16 \%$; y $25 \%$, para los tres percentiles respectivamente) fueron notablemente inferiores a la pendiente media del puerto (37\%). Los valores de pendientes del percentil superior, que fue el único seleccionado activamente (figura 5.5), fueron también los que más se acercaron a los valores medios de pendiente de los pastos herbáceos del puerto, especialmente de aquéllos invadidos por lecherina (tabla 5.17). Parece pues que la utilización actual del puerto está marcadamente restringida en este aspecto. Las zonas con 
pendientes superiores al 35\% apenas son aprovechas por el ganado, siendo este un patrón general en zonas de pastoreo de vacuno y caballar en montaña y con escaso control humano (Ganskopp y Vavra, 1987). Esto conduce a un proceso de matorralización (Dullinger et al., 2003; Bartolomé et al., 2005), que en el puerto de Sejos se traduce en un predominio del matorral en pendientes por encima del 40\% (tabla 5.17). Por su parte, el ganado se concentra en las zonas con pendientes inferiores a la media del puerto, conduciendo al predominio de la vegetación herbácea y en ocasiones a su sobrepastoreo (Bailey et al., 2001).

En cuanto a la selección de altitudes, los percentiles establecidos para su cálculo en las áreas disponibles mostraron unos valores medios de los rangos (diferencia entre los valores máximo y mínimo) de 76, 38 y 85 metros para los percentiles inferior, medio y superior respectivamente. Estos valores indicarían la existencia dentro de las áreas disponibles de zonas más llanas en el rango de altitudes intermedias, siendo precisamente en estas zonas donde pareció concentrarse más el ganado al final de la estación de pastoreo (figura 5.4), lo que podría ser el resultado de la evolución temporal en la disponibilidad de pasto por cabeza de ganado, con valores aparentemente mayores al final de la estación (tabla 5.1). Otra posible causa de este patrón de selección sería la adopción de una estrategia de ahorro energético por los animales ante periodos prolongados con recursos forrajeros limitados, prefiriendo concentrar su actividad en las zonas más tendidas (Lachica et al., 1999; Armstrong y Robertson, 2000). Esta selección de los rangos intermedios de altitudes también ha sido descrita como patrón generalizado para el ganado vacuno en otros pastos de montaña de la Cordillera Cantábrica (Mandaluniz, 2003).

Tabla 5.17. Altitudes y pendientes medias de los tipos de vegetación analizados en el estudio (datos de la cartografía de vegetación de Sejos [Busqué et al., 2006]).

\begin{tabular}{lc|ccc|ccc}
\hline & Superficie (ha) & \multicolumn{3}{|c|}{ Altitud (m) } & \multicolumn{4}{c}{ Pendiente (\%) } \\
& & media & d.e. & $g_{1}$ & media & d.e. & $g_{1}$ \\
\hline TOTAL DEL PUERTO & $\mathbf{1 2 3 5}$ & $\mathbf{1 5 7 5}$ & $\mathbf{1 5 3}$ & $\mathbf{+ 0 , 3 7}$ & $\mathbf{3 7 , 1}$ & $\mathbf{1 5 , 7}$ & $\mathbf{+ 0 , 5 1}$ \\
\hline Pasto herbáceo & 650 & 1567 & 139 & $+0,07$ & 32,4 & 14,6 & $+0,67$ \\
Pasto arbustivo & 422 & 1567 & 159 & $+0,58$ & 41,2 & 13,9 & $+0,46$ \\
\hline Pasto de Festuca-Agrostis & 438 & 1576 & 136 & $+0,08$ & 31,3 & 14 & $+0,72$ \\
Cervunal & 77 & 1608 & 127 & $-0,16$ & 27,9 & 12,6 & $+0,69$ \\
\hline Lecherina & 57 & 1555 & 104 & $-0,08$ & 25,6 & 12 & $+0,99$ \\
Pasto de Festuca-Agrostis sin lecherina & 381 & 1579 & 139 & $+0,06$ & 32,2 & 14,1 & $+0,68$ \\
\hline
\end{tabular}




\subsubsection{Características de las actividades del ganado: pastoreo y descanso}

Aunque, al igual que en el resto de herbívoros ungulados domésticos, el pastoreo es la actividad en la que se invierte más tiempo diurno (Arnold y Dudzinski, 1978), en nuestro estudio se registró una diferencia significativa entre el ganado caballar y el vacuno (11,5 vs. 9,1 horas de tiempo medio de pastoreo diurno, respectivamente), que coincide con lo encontrado por otros autores (Arnold y Dudzinski, 1978; Menard et al., 2002; Lamoot et al., 2005). En el caso del vacuno, las estimaciones del tiempo diurno de pastoreo fueron ligeramente superiores a las 8,3 horas registradas por Mandaluniz (2003) o las 8,2 horas encontradas por Revilla (1997) y bastante superiores a las 7 horas registradas por Aldezabal et al. (1999); pero inferiores a lo observado por Menard et al. (2002) y Rittenhouse (1986) (10,8 y 11,0 horas, respectivamente) en seguimientos que incluían la actividad nocturna. Las diferencias entre especies se mantuvieron cuando se corrigió el tiempo dedicado a pastar en función de la duración de los seguimientos diarios: se observó que las vacas emplearon una menor proporción del tiempo diurno en pastar que las yeguas (con valores medios de 63,1 y 81,7\% para el vacuno y el caballar, respectivamente), de acuerdo también con lo consultado en la bibliografía (Pratt et al., 1986; Rittenhouse, 1986; Menard et al., 2002; Lamoot et al., 2005). La magnitud de estas diferencias es similar a la registrado por Pratt et al. (1986) y García-González (2008), pero está por debajo de lo señalado por otros autores en seguimientos que incluyeron la actividad nocturna (Rittenhouse 1986; Menard et al., 2002), donde pudieron captar en toda su extensión las diferencias entre especies (en concreto, registrando también un menor pastoreo nocturno en las vacas que en las yeguas). Respecto a estas últimas, Duncan (1983) y Menard et al. (2002) contabilizaron tiempos superiores a las 14 y 13 horas de pastoreo, respectivamente, en seguimientos que incluían la actividad nocturna.

También se encontraron diferencias para esta variable dentro del ganado vacuno estudiado en función de su raza (figura 5.8): la proporción de tiempo empleado en pastoreo fue inferior en la tudanca respecto a las otras razas. En este sentido, el menor peso corporal de los animales de esta raza autóctona sería el primer factor que podría explicar sus menores tiempos diurnos dedicados a pastar, ya que la ingestión potencial está ligada directamente con el tamaño del animal (Illius y Gordon, 1987). Además, aunque el tamaño del animal se ha relacionado directamente con el tamaño y peso del bocado en condiciones de pasto abundante (Demment et al., 1995), es posible que cuando las disponibilidades de pasto son muy reducidas, como ocurrió en este trabajo, los animales de mayor formato 
consigan tamaños de bocado proporcionalmente más pequeños (Clutton-Brock y Harvey, 1983) y, por tanto, se vean forzados a pastar durante más tiempo. Adicionalmente, en un trabajo previo (Mora et al., 2007c) encontramos que las vacas tudancas mostraron, posiblemente por ocupar áreas disponibles con mayor proporción de pasto arbustivo (figura 5.12) menos visitadas por otros tipos de ganado, una tendencia a aprovechar pastos herbáceos con mayor biomasa en pie respecto a las vacas de otras razas, lo cual también apoyaría los menores tiempos de pastoreo de la raza autóctona.

Por otro lado, no se encontró un efecto significativo de la época de la estación sobre la proporción del tiempo diurno empleado en pastar. Este resultado contrasta con el aumento de dicha proporción con el avance de la estación de pastoreo observado por otros autores (Senf et al., 1985; Mandaluniz, 2003) e interpretado como una compensación del descenso progresivo de la duración de los días. En nuestro caso, la variabilidad de las condiciones meteorológicas entre seguimientos pudo modificar los patrones diurnos de actividad, alterando la evolución previsible de esta variable. Por otro lado, es posible que el tiempo nocturno de pastoreo se incrementara con el avance de la estación (Van Rees y Hutson, 1983) aunque es algo que no se registró. No obstante, un indicio de ello fue que, según avanzaba el verano, se observó con más frecuencia al ganado pastando al finalizar los seguimientos diurnos.

El hecho de que en el vacuno se encontrara una utilización de zonas con pendiente menos pronunciada y menos variable para el descanso respecto al pastoreo (figura 5.6), también pudo deberse en parte a la variación en las condiciones meteorológicas durante la realización del estudio, y también a la distinta respuesta a ésta entre vacas y yeguas. Así, en días de calor y poco viento, y con el fin de evitar las picaduras de ciertas especies de moscas (González, 1995), las vacas dejan de pastar y buscan zonas aireadas (Arnold y Dudzinski, 1978; Senft et al., 1985), que suelen corresponder a cordales con pendientes inferiores y altitudes superiores a las de sus áreas colindantes. Las yeguas también resultan atacadas por las moscas (Duncan, 1983), pero parecen existir diferencias en las especies de moscas que parasitan los dos tipos de ganado, correspondiendo también a ciclos vitales de diferente estacionalidad (González, 1995).

La ausencia de diferencias significativas en el estudio de la variabilidad de la altitud utilizada en las rutas de pastoreo cuando la actividad del ganado no se tomó en cuenta (tabla 5.4), y la marcada influencia de la actividad y de la época (tabla 5.6 y figura 5.7) 
cuando sí se hizo, vuelven a poner de manifiesto la existencia de patrones bien diferenciados para el pastoreo y el descanso (Aldezabal et al., 1999).

Los rangos de pendientes seleccionados por el ganado para la actividad de pastoreo siguieron el mismo patrón descrito para las rutas completas (i.e. incluyendo todas las actividades), con valores similares en el caballar y más extremos en el vacuno (comparar figuras 5.5 y 5.10). De estos resultados destaca la alta selección del vacuno hacia el rango de pendientes más alto de sus áreas disponibles, aunque es necesario volver a remarcar que las pendientes de esas áreas disponibles fueron en su mayor parte más bajas que las del área total de pastoreo del puerto de Sejos (tabla 5.17), coincidiendo con lo registrado en otros estudios (Gillen et al., 1984; Aldezabal et al, 1999). Estos valores en el vacuno fueron similares a los observados en otras zonas de la Cordillera Cantábrica (Mandaluniz, 2003). Posiblemente la escasa disponibilidad de pasto herbáceo por unidad de superficie en la zona de estudio (ver tabla 5.1 y Mora et al., 2007b) fue más limitante para el vacuno, obligándolo a desplazarse a las zonas de mayor pendiente, mientras el equino mantuvo un pastoreo más homogéneo respecto a esta variable. Otros estudios comparativos de pastoreo mixto de vacuno y caballar en ecosistemas heterogéneos (Gordon, 1989b; Lamoot et al., 2005), ponen de manifiesto la menor utilización por parte del vacuno de este recurso pastable cuando su disponibilidad es escasa, mientras el caballar lo puede seguir utilizando como principal componente de su dieta hasta niveles de disponibilidad mucho más bajos.

Esta separación topográfica de los hábitats de pastoreo corresponde también a un alejamiento del vacuno de las zonas más intensamente utilizadas de los pastos de FestucaAgrostis, caracterizadas por mayores niveles de invasión de lecherina (zonas de pendientes comprendidas entre el 15 y el 25\%; tabla 5.17). En este sentido, se podría dedudir que el caballar, por su mayor presencia en zonas de pendiente más suave, y por el posible desplazamiento que ejercería sobre el vacuno (Arnold y Dudzinski, 1978), estaría contribuyendo en mayor medida que este al sobrepastoreo de las zonas con mayor susceptibilidad topográfica a invadirse por lecherina.

\subsubsection{Características del pastoreo en relación con el tipo de pasto}

\section{Pasto herbáceo vs. pasto arbustivo}

La primera clasificación de la vegetación pastoral realizada en este estudio consiste en la división entre pastos herbáceos y pastos arbustivos. Es importante tener en cuenta 
que, además de la existencia de manchas de vegetación mayoritariamente herbáceas y arbustivas, existe en Sejos un gradiente amplio de mosaicos herbáceo-arbustivo que enriquece la diversidad vegetal y complica también la naturaleza de las relaciones pastoherbívoro (Laca, 2008). En este sentido, la existencia de una correlación significativa entre las coberturas de herbáceas y de arbustivas y la diversidad de la vegetación estimada por el índice de Shannon $(-0,76$ y $+0,79$ respectivamente; $\mathrm{P}<0,001)$ va ligada al hecho de que los mosaicos de pasto herbáceo-arbustivo poseen una mayor diversidad vegetal (ver revisión de Plaixats y Bartolomé, 2001).

La aparente facilidad del ganado para elegir zonas del paisaje con una determinada composición vegetal a este nivel de grano grueso de la vegetación (herbáceo-arbustivo; Laca, 2008), podría explicar las diferencias observadas en la composición de las áreas disponibles en las rutas de pastoreo, tanto entre distintas especies (más pasto herbáceo en las áreas disponibles de las yeguas que en las de las vacas; figura 5.11), como entre distintos tipos de ganado vacuno (más arbustivo en las tudancas que en las vacas de otras razas; figura 5.12). La regularidad en el tipo de pasto presente en las distintas áreas disponibles a lo largo de la estación de pastoreo, a pesar de los cambios acusados en la carga ganadera que se observaron en la última época, parecen señalar la existencia de hábitats a nivel de la vegetación relativamente bien definidos para cada tipo de ganado, con independencia de posibles relaciones de competencia o dominancia territorial que pudieran existir entre tipos de ganado presentes en el mismo territorio (Arnold y Dudzinski, 1978; Pratt et al., 1986; Gordon, 1989c). En este sentido, el aprendizaje social entre los individuos de los rebaños (Launchbaugh y Howery, 2005; Provenza, 2007) y el control indirecto de los ganaderos, por ejemplo a través de la utilización de suplementos (Bailey et al, 2001), podrían influir en la definición de las zonas de pastoreo de cada rebaño.

Respecto a la utilización de pasto herbáceo y arbustivo, estimada por el tiempo relativo empleado en pastar sobre ellos, además de la relación existente con su grado de presencia en las áreas disponibles (i.e. a mayor presencia de cada tipo de pasto, mayor utilización), se observó una mayor utilización de los pastos herbáceos por el caballar que por el vacuno, a semejanza de lo observado tanto en otras zonas de montaña (Aldezabal, 2001; Mandaluniz, et al., 2005) como en zonas de altitudes inferiores (Putman et al., 1987; Menard et al, 2002; Lamoot et al., 2005). El consumo casi exclusivo por parte del caballar de pasto herbáceo podría estar relacionado con su previsible susceptibilidad a la ingestión de compuestos secundarios (Menard et al., 2002), generalmente más abundantes en los 
pastos arbustivos (Ramos et al., 1998). Por otro lado, en situaciones de escasez de pasto herbáceo, como ocurrió en Sejos, el caballar también encontraría en su morfología bucal una ventaja competitiva respecto al vacuno (Edwards y Hollis, 1982; Gordon, 1989b; Lamoot et al., 2005).

El vacuno de razas foráneas siempre empleó más del $80 \%$ de su tiempo de pastoreo a pastar sobre pastos herbáceos mientras que las tudancas mostraron una evolución muy clara a pastar cada vez más tiempo sobre arbustivas (figura 5.15), fundamentalmente ericáceas (Calluna vulgaris, Erica vagans, E. tetralix y Vaccinium myrtillus). Las diferencias observadas entre razas de vacuno en la utilización de pasto arbustivo se han explicado evolutivamente, como una adaptación a los distintos hábitats originarios de cada raza (Bailey et al., 2001). La baja utilización de matorral por las vacas de razas foráneas también podría explicarse por un rechazo hacia especies vegetales desconocidas, ante su escasa historia de aprovechamiento en ecosistemas pastorales similares (Provenza, 2007). En el caso del vacuno de raza tudanca, su área de distribución principal está restringida a la montaña occidental de Cantabria (Villegas, 2005), lo que facilita su adaptación a la vegetación del puerto. Los resultados encontrados en el vacuno tudanco concuerdan con los encontrados en otras zonas de la Cordillera Cantábrica con vacuno de raza pirenaica (Mandaluniz et al., 2000) y parecen reflejar la mayor flexibilidad mostrada por estos animales a variar cualitativamente su dieta en pastoreo con el tiempo, ante situaciones de escasez del recurso forrajero de mayor valor nutritivo (el pasto herbáceo). Mientras las diferencias interespecíficas en la utilización de ericáceas como la Calluna vulgaris están bien documentadas (Grant et al., 1987; Osoro et al., 2000), existe escasa información respecto a la variación intraespecífica entre razas de vacuno, especialmente entre razas autóctonas y razas importadas de mayor formato. Además, Wright et al. (2006) pusieron de manifiesto la dificultad adicional de atribuir las posibles diferencias entre razas autóctonas y foráneas a la diferente genética o al aprendizaje ligado a la cultura de los rebaños. En todo caso, la capacidad del vacuno de raza tudanca para consumir especies arbustivas podría estar relacionada con la adaptación evolutiva de su microbiota ruminal a la vegetación característica de su área de distribución (Cheeke y Palo, 1995; Duncan et al., 2000). Por otra parte, el aumento progresivo en la utilización del pasto arbustivo mostrado por estas vacas podría ser el resultado de una disminución en la oferta disponible de pasto herbáceo más apetecible (Milne et al., 1978; Grant et al., 1987; Fraser y Gordon, 1997), 
coincidiendo a su vez con un posible ligero descenso de los altos contenidos de taninos que caracterizan a las ericáceas (Hervás et al, 2003).

La adaptación del ganado tudanco a aprovechar pasto arbustivo en las proporciones documentadas en este trabajo (se alcanzaron valores superiores al 30\% de su tiempo diurno de pastoreo) tiene un enorme interés como mecanismo para el mantenimiento de una vegetación arbustiva joven, poco embastecida, en mosaicos con el pasto herbáceo de alta diversidad biológica y de bajo valor inflamable (Tews et al., 2004; Celaya et al., 2005; Isselstein et al., 2005). Adicionalmente, su menor selección, y por tanto presión, sobre el pasto herbáceo supone una menor contribución al sobrepastoreo de las zonas más susceptibles de invadirse por lecherina.

\section{Tipos de pasto herbáceo: pasto de Festuca-Agrostis y cervunales}

En un trabajo previo (Mora et al., 2007b) en el que comparamos los pastos de Festuca-Agrostis y los cervunales en los puertos de Sejos, no detectamos diferencias relevantes ni en la mayoría de las variables bromatológicas analizadas ni en su disponibilidad por unidad de superficie. En cambio, sí que observamos un descenso en los valores de estas variables a lo largo de la estación de pastoreo, coincidiendo con lo apuntado en el capítulo 4 para los pastos de Festuca-Agrostis y con otros estudios en pastos de puerto (García-González et al., 2005). Los pastos de Festuca-Agrostis y los cervunales son los dos tipos de pastos herbáceos mayoritarios en Sejos, con un $66 \%$ y un $12 \%$ del total de su superficie pastoral herbácea (ver capítulo 2). Además, es fundamental considerar su distinta susceptibilidad a invadirse por lecherina, siendo alta en el caso de los pastos de Festuca-Agrostis y muy baja en los cervunales (Busqué et al., 2003).

Los resultados de disponibilidad, utilización y selección de los pastos de FestucaAgrostis y de los cervunales pusieron de manifiesto la escasa diversidad aparente de la dieta de las vacas de razas foráneas, circunscritas la mayor parte de su tiempo de pastoreo a los pastos de Festuca-Agrostis. En este sentido, como ya se ha comentado anteriormente, el papel que puede jugar el aprendizaje social del ganado en cuanto a la dieta que pueden ingerir en pastoreo es esencial a la hora de determinar su diversidad y la forma de pastar en un paisaje heterogéneo (Provenza, 2007). Si no hay intervención exterior, bien por un pastoreo dirigido o por una interacción con animales conocedores del territorio, este patrón de pastoreo restringido se puede transmitir en el tiempo a los descendientes (Howery et al., 
1998). Además, este proceso puede también perdurar por las prácticas habituales de los ganaderos de bajar sus cabañas del puerto cuando comienzan a notar una pérdida de condición corporal en los animales. Esta práctica, que muestra su pico a principios de septiembre (figura 2.21), hace que los animales que abandonan el puerto no se vean forzados a buscar nuevos recursos y permite a los que se quedan disminuir su rango de búsqueda de dieta, tal como se muestra en este estudio con el rechazo de todos los tipos de ganado a utilizar los cervunales en los muestreos de septiembre. Este claro rechazo, asociado a una mayor selección de los pastos de Festuca-Agrostis, si bien no fue posible atribuirlo a diferencias significativas en los parámetros relacionados con su valor nutritivo (Mora et al., 2007b), pudo deberse a la mayor presencia de defensas físicas (pelos de sílice) en el cervuno (Thomas y Fairbairn, 1956) que le permitirían evadirse en mayor medida del pastoreo en una época en la que la carga ganadera en el puerto ya había descendido considerablemente.

La utilización homogénea de los pastos herbáceos por el caballar mientras la carga ganadera del puerto fue alta ratifica su preferencia por las especies de tipo graminoide en su pastoreo en puerto (Aldezabal, 2001), dado el predominio de este tipo de plantas tanto en los pastos de Festuca-Agrostis como en los cervunales (Busqué et al., 2003).

A pesar de que en la época final la carga ganadera descendió notablemente, el hecho de que en todos los tipos de ganado la selección de los pastos herbáceos se concentrara sobre los de Festuca-Agrostis estaría contribuyendo a que estos alcanzaran valores de utilización por encima de los considerados críticos (Rickert, 1996; Busque et al., 2007), favoreciendo por tanto su invasión por lecherina.

\section{Pastos de Festuca-Agrostis según su grado de invasión por lecherina}

Tal y como se ha mencionado ya previamente en diversas ocasiones, la invasión de lecherina en pastos de Festuca-Agrostis parece estar ligada a su sobrepastoreo (Busqué et al., 2003). Este fenómeno podría retroalimentarse de forma positiva ya que, a mayor nivel de invasión del pasto por la lecherina, menor cobertura del pasto original y, por tanto, a igualdad de carga ganadera, la defoliación de este último será mayor (Hodgson, 1990; Archer, 1996). En una situación de pastoreo de montaña con heterogeneidad en la vegetación disponible para el ganado, este proceso probablemente pierda fuerza a partir de un determinado umbral de cobertura de lecherina, por encima del cual al ganado le 
resultará menos interesante pastar en la mancha de pasto invadida, dado el gasto energético asociado a encontrar pasto original bien separado de las matas de lecherina (Owens et al., 1991; Milchunas y Noy-Meir, 2002). A partir de ese momento, se producirá un descenso en el pastoreo de esas manchas de pasto a favor de otras que aún no hayan alcanzado el umbral de rechazo (Smit et al., 2006). Este patrón de utilización de pasto herbáceo en mosaico ha sido también documentado en pastos similares a los del tipo Festuca-Agrostis en mosaicos con brezal-tojal (Mandaluniz et al., 2005).

Los resultados obtenidos en nuestro trabajo parecen avalar la hipótesis descrita. Así, las zonas más invadidas por lecherina, con valores de cobertura de esta euforbiácea superiores al $20 \%$, posiblemente en su mayoría por encima del umbral de rechazo comentado, fueron rechazadas activamente en la mayoría de las rutas y durante toda la estación de pastoreo. Este rechazo fue mayor por parte del caballar, posiblemente más sensible a la ingestión accidental de brotes de lecherina y, por tanto, más exigente a la hora de encontrar pasto libre de esta planta (Menard et al., 2002). Además, dicho rechazo se agudizó al final de la estación de pastoreo, cuando existió menor carga ganadera en el puerto y, por tanto, más superficie forrajera disponible por animal. Por su parte, las zonas con grado medio de invasión por la E. polygalifolia, en teoría más lejos del umbral de rechazo, fueron seleccionadas positivamente por el caballar hasta la época intermedia de la estación, rechazándose al final cuando la carga ganadera general del puerto fue mucho menor.

Considerando las elevadas utilizaciones de los pastos de Festuca-Agrostis por vacas (especialmente las de razas foráneas) y yeguas, junto con la alta selección por las yeguas de los pastos de Festuca-Agrostis menos invadidos por la lecherina en la época final, cabe esperar que se produzca una situación de sobrepastoreo (Rickert, 1996), favoreciéndose de esta manera el avance de la invasión de E. polygalifolia. Es decir, los pastos de FestucaAgrostis con niveles nulos o muy bajos de cobertura de lecherina, se estarían enfrentando a una preferencia excesiva por un ganado caballar con gran capacidad, gracias a su anatomía bucal (Gordon, 1989b; Lamoot et al., 2005), para apurar e incluso arrancar plantas en una época en la que el pasto podría encontrarse fisiológicamente debilitado (Dawson et al., 2000). Este debilitamiento favorecería el avance de las plantas de lecherina al aprovechar los huecos de suelo desnudo creados para expandirse (Archer, 1996). 


\subsubsection{Extrapolación de los resultados a todo el puerto}

La tabla 5.18 muestra el producto de un ejercicio de extrapolación de los resultados de este estudio a la situación general en el puerto de Sejos. Para su cálculo, se restringió el área de pastoreo del ganado a las zonas con pendientes menores de $35 \%$, ya que según nuestros resultados sólo un $2 \%$ de las áreas disponibles estuvieron por encima de ese valor. Además se tuvieron en cuenta los valores de los tiempos diurnos de pastoreo de cada tipo de ganado y la evolución de sus censos en el puerto a lo largo del verano (apartado 2.3.2). Quizás convenga señalar que, puesto que los valores mostrados y utilizados en los cálculos son únicamente medias, deben tomarse con cierta precaución.

Tabla 5.18. Selección de los principales tipos de vegetación estimados para toda el área del puerto de Sejos con utilización ganadera de vacuno y caballar (con pendientes menores a 35\%).

\begin{tabular}{l|ccc}
\hline & $\begin{array}{c}\text { IJ Pasto } \\
\text { arbustivo } \\
174 h a\end{array}$ & $\begin{array}{c}\text { IJ Pasto de } \\
\text { Festuca-Agrostis } \\
307(253) h a\end{array}$ & $\begin{array}{c}\text { IJ } \\
\text { Cervunal } \\
61 ~ h a\end{array}$ \\
\hline Inicio & $-0,79$ & $+0,72(+0,79)$ & $+0,15$ \\
Medio & $-0,56$ & $+0,52(+0,63)$ & $-0,16$ \\
Final & $-0,49$ & $+0,50(+0,62)$ & $-0,69$ \\
\hline Selección Global & $\mathbf{- 0 , 6 9}$ & $\mathbf{0 , 6 4}(\mathbf{0 , 7 3})$ & $\mathbf{0 , 0 2}$ \\
\hline
\end{tabular}

Los valores entre paréntesis corresponden a la superficie o a los índices de selección del pasto de Festuca-Agrostis quitando la superficie ocupada por la lecherina. IJ: Índice de selección de Jacobs.

Los resultados de esta estimación ponen en evidencia la fuerte presión a la que se someten los pastos de Festuca-Agrostis de forma global. Por el contrario, los pastos arbustivos son rechazados fuertemente, mientras la selección del cervunal fue nula (i.e., su utilización fue proporcional a su disponibilidad). La evolución de la selección a lo largo de la estación de pastoreo sigue en general la lógica que podría suponerse de la disminución del recurso más seleccionado inicialmente (el pasto de Festuca-Agrostis), la adaptación de parte del ganado (vacuno de raza tudanca) al consumo de arbustivas y la disminución progresiva de la carga ganadera en el puerto. Así, se observa una disminución en la selección del pasto de Festuca-Agrostis, en parte compensado por una disminución en el rechazo a la utilización de pasto arbustivo, y un rechazo creciente del cervunal, tipo de pasto que acabó siendo el menos seleccionado. 
Traduciendo los valores anteriores a tiempo de utilización diurno, este resulta ser de un $82 \%$ en los pastos de Festuca-Agrostis ( $\sin$ contar la lecherina, que no es consumida), de un $10 \%$ en los cervunales y de un $6 \%$ en el pasto arbustivo, para valores de disponibilidad de 42, 10 y 29\%, respectivamente. La acusada diferencia en las relaciones entre utilización y disponibilidad de los pastos de Festuca-Agrostis $(1,96)$ y los cervunales $(1,04)$ no se compensan con las diferencias existentes en sus productividades, con valores medios de producción anual de materia seca en zonas de montaña del norte de España, de $350 \mathrm{~g} \mathrm{~m}^{-2}$ para el pasto de Festuca-Agrostis y de $250 \mathrm{gm}^{-2}$ para los cervunales (Alonso, 1994; Busqué et al., 1995; Aldezabal et al., 1996; García-González et al., 2002; Taüll y Sebastiá, 2002; Busqué et al., 2003).

Se concluye, pues, que el pasto de Festuca-Agrostis está experimentando una presión de pastoreo muy fuerte, lo que posiblemente favorece el proceso de invasión de lecherina. Estos resultados son la base para el desarrollo de herramientas (ver p.ej. Busqué et al., 2007a) que puedan ser empleadas en la gestión de estos espacios pastorales con el objetivo de evitar los desequilibrios en la utilización de la vegetación por el ganado, contribuyendo así al desarrollo de un sistema de pastoreo para el control biológico de la invasión de lecherina.

\subsection{Conclusión e implicaciones}

Los resultados obtenidos verifican las hipótesis planteadas inicialmente. Los distintos tipos de ganado presentes en el puerto se comportaron de forma diferente, aunque fue necesario distinguir entre vacas tudancas y de razas foráneas para explicar mejor la diversidad de patrones de pastoreo existente. En primer lugar, el tiempo de pastoreo diurno difirió entre los distintos tipos de ganado, con valores menores en las vacas tudancas, intermedios en las vacas de otras razas y mayores en las yeguas. Por otro lado, el ganado caballar se diferenció de las vacas en la utilización del territorio del puerto según su topografía, ocupando las zonas de menor pendiente. Sin embargo, cuando se analizó la utilización y selección de la vegetación, el ganado caballar presentó en muchos aspectos comportamientos similares al vacuno de razas foráneas, especialmente en cuanto al rechazo de los pastos arbustivos, a diferencia de lo mostrado por el vacuno tudanco. En el caso específico de los pastos de Festuca-Agrostis, tanto el caballar como el vacuno de 
razas foráneas los utilizaron intensamente, en tanto que en las vacas tudancas esta utilización fue menor.

Respecto a la segunda hipótesis sobre la evolución temporal de la selección de los pastos de Festuca-Agrostis, se verificaron los valores altos de selección inicial por todos los tipos de ganado y algo menores en la época intermedia, aunque más altos de los esperados en el caso del caballar y del vacuno de razas foráneas. Las vacas de raza tudanca, en cambio, incrementaron notablemente su selección de pasto arbustivo, disminuyendo la del pasto de Festuca-Agrostis. Por último, el aumento final en la utilización y selección de este tipo de pasto al disminuir la carga ganadera sólo se produjo en el ganado caballar, estando asociado a un rechazo de los cervunales.

La intensa utilización de los pastos de Festuca-Agrostis que se deduce de este trabajo pone en evidencia su situación de sobreexplotación, causa más probable de la degradación observada en forma de invasión por lecherina. Además, los resultados advierten de que, en las condiciones actuales de pastoreo (considerando los índices de selección, el elevado tiempo diurno de pastoreo del ganado caballar y su comportamiento selectivo al final del verano), el peligro de degradación se extiende a los pastos de Festuca-Agrostis aún libres o con niveles bajos de cobertura de lecherina. 

6. PRUEBA 3. Degradación ruminal de pastos de puerto invadidos por lecherina en el ganado vacuno y ovino: efecto del pastoreo previo en zonas invadidas 



\subsection{Introducción}

Se sabe que el ganado vacuno presente en los puertos de Sejos rechaza el consumo de lecherina (Euphorbia polygalifolia). Este rechazo al consumo de euforbiáceas ha sido documentado ampliamente en Norte América, donde las vacas evitan pastar Euphorbia esula pese a su alto valor nutritivo (basado en estimaciones convencionales que incluyen composición química y pruebas de digestibilidad; Roberts y Olson, 1999). En el caso de la E. esula, el rechazo se ha relacionado con la presencia de compuestos secundarios, principalmente terpenoides, que provocarían el desarrollo de una aversión condicionada por el ganado vacuno hacia el consumo de esta especie (Kronberg y Walker, 1993; Kronberg et al., 1995; Halaweish et al., 2002). En cambio, existen trabajos que demuestran que las ovejas pueden consumir E. esula sin sufrir sus consecuencias tóxicas (Landgraf et al., 1984) y, de hecho, estos animales han sido utilizados durante décadas como agentes de control biológico contra las invasiones de euforbiáceas (ver referencias citadas por Bangsund et al., 2001). Tal y como ya se mencionó en el capítulo 4, en pruebas experimentales de pastoreo realizadas por nuestro grupo con ovejas que utilizaban zonas invadidas por E. polygalifolia (Mora et al., 2007a), no se apreciaron signos de intoxicación ni efectos negativos sobre el rendimiento productivo de estos animales, aunque se constató que las ovejas consumían lecherina de forma notable (desaparición de un promedio del $63 \%$ de los brotes de lecherina tras pastoreos semanales).

Estos resultados invitan a plantear la siguiente cuestión: ¿por qué existen estas diferencias tan notables en el consumo de euforbiáceas por estas dos especies de rumiantes? En este sentido, en un trabajo comparativo con ganado ovino y caprino, Kronberg y Walker (1993) señalaron que las diferencias entre especies en el consumo de euforbiáceas podrían explicarse, al menos parcialmente, por los procesos que ocurren en el rumen. Aunque todos los rumiantes son anatómicamente similares, los sistemas gastrointestinales pueden tener importantes diferencias funcionales capaces de influir en la eficiencia de utilización de diferentes dietas (Huston et al., 1986). En este sentido, se sabe que las comunidades microbianas del rumen de diferentes especies poseen distinta capacidad para tolerar o degradar toxinas o compuestos secundarios de las plantas (Duncan et al., 1997; Pell et al., 2000; Frutos et al., 2004b).

Además, diversos autores han demostrado que un incremento gradual de la ingestión de una planta que contiene compuestos secundarios puede permitir un incremento de la 
capacidad de los rumiantes que la consumen para tolerarla o degradarla (Domínguez-Bello, 1996; Duncan et al., 2000).

Por todo ello, este experimento se realizó para probar dos hipótesis. La primera era que la microbiota ruminal de las ovejas tiene una mayor capacidad para degradar los pastos de puerto invadidos por lecherina que la microbiota ruminal de las vacas. La segunda era que la degradación ruminal de este tipo de pasto por distintos rumiantes (en este caso ovino y vacuno) podría ser regulada, al menos parcialmente, por su consumo, a través de una adaptación de la población microbiana del rumen.

\subsection{Material y métodos}

El área de estudio se encuentra descrita en el capítulo segundo.

\subsubsection{Animales y diseño experimental}

Los animales seleccionados fueron 8 ovejas de raza merina y 6 vacas cruzadas de aptitud cárnica, sin experiencia previa en el consumo de lecherina. Todos ellos se distribuyeron en 4 tratamientos experimentales de acuerdo con un diseño factorial $2 \times 2$ : 2 especies (vacuno vs. ovino) $\times 2$ tratamientos de pastoreo previo (pastoreo en zonas invadidas vs. pastoreo en zonas no invadidas) ocupando durante 17 días 4 parcelas experimentales (de entre 4.000 y $10.000 \mathrm{~m}^{2}$ ) valladas con cinta y malla electrificadas.

\subsubsection{Sustratos}

En este trabajo se estudió la fermentación ruminal de dos sustratos: un pasto invadido por lecherina (que contenía un $46 \%$ de E. polygalifolia, estimado mediante la separación y posterior pesaje de la lecherina de una muestra representativa del pasto invadido) y un pasto libre de la invasión. Ambos fueron recogidos en el mes de agosto, mediante siega con cuchilla eléctrica de mano, secados en estufa a $50^{\circ} \mathrm{C}$ (Heraeus RTV-220, Alemania) hasta alcanzar un peso constante y molidos a un diámetro de criba de $1 \mathrm{~mm}$ (Retsch ZM 1000, Alemania). Su composición química (MO, PB, FND y FAD) se muestra en la tabla 6.1 . 
Tabla 6.1. Composición química de los sustratos pasto invadido por lecherina y pasto no invadido $(\mathrm{g} / \mathrm{kg}$ MS).

\begin{tabular}{lcccc} 
& MO & PB & FND & FAD \\
\hline Pasto invadido & 938 & 112 & 471 & 247 \\
Pasto no invadido & 919 & 131 & 570 & 252 \\
\hline
\end{tabular}

\subsubsection{Cultivos discontinuos de microorganismos ruminales: producción de gas y degradación ruminal in vitro}

Para estudiar la fermentación ruminal in vitro de los sustratos descritos se utilizaron cultivos discontinuos de microorganismos ruminales y una adaptación de la técnica de producción de gas descrita por Theodorou et al. (1994), con las modificaciones propuestas por Mauricio et al. (1999).

Al concluir el periodo de adaptación de 17 días de pastoreo en las parcelas experimentales y tras permanecer los animales la última noche en ayunas, se recogieron a primera hora de la mañana los inóculos ruminales mediante sonda esofágica. Los fluidos obtenidos de cada animal se mezclaron para preparar dos fluidos ruminales diferentes (réplicas) por tratamiento ( 8 en total: 2 especies $\times 2$ tratamientos de pastoreo $\times 2$ inóculos). Inmediatamente después, se conservaron en botes bien llenos y cerrados, se introdujeron en una nevera con hielo y agua y se transportaron al laboratorio en 4 horas. En este tiempo se aseguraba que no habría cambios significativos en la capacidad fermentativa de los inóculos (Hervás et al., 2005).

En el laboratorio, cada uno de los 8 fluidos ruminales se filtró a través de dos capas de gasa y, en condiciones de anaerobiosis (es decir, gaseando con $\mathrm{CO}_{2}$ ), se introdujo en un baño de agua a $39^{\circ} \mathrm{C}$ durante unos minutos, para que recuperara esta temperatura.

Aproximadamente $500 \mathrm{mg}$ de sustrato se pesaron en botellas de suero de $125 \mathrm{~mL}$, en las que posteriormente se dosificaron $10 \mathrm{~mL}$ de inóculo ruminal y $40 \mathrm{~mL}$ de medio de incubación (1:4, v:v; McDougall, 1948). Este medio de incubación contenía una solución de macrominerales, una solución tampón, una solución reductora, una solución de microminerales y una solución de resazurina como indicador del potencial redox.

Como se ha mencionado previamente, las incubaciones se realizaron con 2 inóculos ruminales (réplicas) de cada uno de los 4 tratamientos experimentales descritos anteriormente. Además, de cada sustrato estudiado, se prepararon 3 muestras (repeticiones) 
y para cada combinación de tratamiento $\times$ réplica se incubaron 3 blancos (es decir, botellas con medio de incubación e inóculo ruminal pero sin sustrato; 24 en total) para corregir la producción de gas no debida al sustrato. Esto hizo un total de 72 botellas ( 2 inóculos x 4 tratamientos $\mathrm{x} 2$ sustratos $\mathrm{x} 3$ repeticiones +24 blancos $)$.

Todas las incubaciones se llevaron a cabo en un incubador (Memmert BE 500, Alemania) a $39^{\circ} \mathrm{C}$, al igual que se explica en el capítulo cuarto.

La producción de gas se registró en cada una de las botellas a las 2, 4, 6, 9, 12, 15, 19, 24, 30, 36, 46, 56, 72, 96 y 120 horas post-incubación, mediante un transductor de presión (Bailey \& Mackey, Reino Unido) conectado a una salida visual (Data Track Process Instruments 223, Reino Unido). El volumen de gas producido se estimó, tal y como se detalla en el apartado 4.2.4 de la primera prueba, mediante una ecuación de regresión lineal entre el volumen y la presión. Tras la lectura final a las 120 horas postincubación, las botellas se introdujeron en agua con hielo para detener la fermentación. Posteriormente, el residuo se filtró en crisoles provistos de una placa porosa y el contenido de los crisoles se secó en una estufa durante 24 horas a $103^{\circ} \mathrm{C}$ para estimar la desaparición de MS (DMS).

De forma similar a las dos series de incubaciones que se describen en el capítulo cuarto, a la serie ya descrita se le añadió otra en la que por cada tratamiento y sustrato se incubaron 6 muestras más (2 réplicas [inóculo] x 3 botellas por réplica; 48 botellas en total) durante 24 horas. Tras este tiempo se detuvo la fermentación y se centrifugaron muestras del fluido (600 x $g, 4{ }^{\circ} \mathrm{C}, 15$ minutos) para eliminar cualquier partícula del sustrato. Seguidamente, una alicuota de $4 \mathrm{~mL}$ de cada sobrenadante fue acidificada con 4 $\mathrm{mL}$ de $\mathrm{HCl}$ para la determinación de amoniaco y otra de $0,8 \mathrm{~mL}$ sirvió para la determinación de ácidos grasos volátiles (AGV) previo añadido de una solución desproteinizante que contenía ácido metafosfórico y ácido crotónico (utilizado como estándar interno; ver apartado 4.2.4). Todas las muestras fueron almacenadas a $-30{ }^{\circ} \mathrm{C}$ hasta su análisis.

\subsubsection{Análisis químicos}

Los análisis de materia seca (MS), cenizas y nitrógeno Kjeldahl se realizaron de acuerdo con los procedimientos descritos por la AOAC (2000). Los contenidos de fibra neutro detergente (FND) y fibra ácido detergente (FAD) se determinaron en un analizador 
de fibra Ankom ${ }^{220}$ de acuerdo con los métodos de Van Soest et al. (1991) y Goering y Van Soest (1970), tal y como se describe en el apartado 4.2.3. De igual forma, las concentraciones de amoniaco se determinaron por el método colorimétrico descrito por Weatherburn (1967) y el contenido de AGV por cromatografía de gases (Carro et al., 1999) utilizando un cromatógrafo de gases y el ácido crotónico como estándar interno.

\subsubsection{Cálculos y análisis estadístico}

Los datos de producción de gas se ajustaron al modelo exponencial descrito por France et al. (2000):

$$
G=A \times\left(1-\mathrm{e}^{(-c \times(t-L a g))}\right),
$$

siendo $G(\mathrm{~mL} / \mathrm{g} \mathrm{MO}), t(\mathrm{~h}), A(\mathrm{~mL} / \mathrm{g} \mathrm{MO}), c\left(\mathrm{~h}^{-1}\right)$ y Lag $(\mathrm{h})$ los mismos parámetros definidos en el apartado 4.2.5. Para la realización de los ajustes matemáticos se utilizó el procedimiento NLIN (Nonlinear Regresion) del programa estadístico SAS (SAS, 1999).

La extensión de la degradación en el rumen $(\mathrm{ED}, \mathrm{g} / \mathrm{kg})$ y el ritmo medio de fermentación (RMF, $\mathrm{mL} / \mathrm{h}$ ) fueron calculados asumiendo un ritmo de paso $\left(\mathrm{K}_{\mathrm{p}}\right)$ de $0,028 \mathrm{~h}^{-}$ ${ }^{1}$, de acuerdo con las ecuaciones propuestas por France et al. (2000):

$$
\begin{aligned}
& \mathrm{DE}=\left(c \times \mathrm{DMS} /\left(c+\mathrm{K}_{\mathrm{p}}\right)\right) \times \mathrm{e}^{-(\mathrm{Kp} \times L a g)} \\
& \mathrm{RMF}=A \times c /(2 \times \ln 2+c \times \operatorname{Lag})
\end{aligned}
$$

La producción de metano $\left(\mathrm{CH}_{4} ; \mu \mathrm{mol}\right)$ se calculó en función de las cantidades de acético (A), propiónico (P) y butírico (B) producidas, siguiendo la ecuación propuesta por Blümmel et al. (1997), al igual que se hizo en el capítulo 4.

$$
\mathrm{CH}_{4}=0,5 \mathrm{~A}-0,25 \mathrm{P}+0,5 \mathrm{~B}
$$

Todos los datos se analizaron mediante el procedimiento GLM (General Linear Model) del paquete estadístico SAS (SAS, 1999). El modelo incluía los efectos de los dos factores principales: especie animal (vacuno vs. ovino) y tratamiento de pastoreo (pastoreo en pastos invadidos vs. pastoreo en pastos no invadidos) y su interacción. Se consideraron diferencias estadísticamente significativas aquellas con un valor de $\mathrm{P}<0,05$ y tendencias aquellas con $\mathrm{P}>0,05$ pero $<0,10$. Cuando el nivel de significación de la interacción 
"especie animal x tratamiento de pastoreo" fue $\mathrm{P}<0,10$, las medias se compararon utilizando una $t$ de Student (sentencia LSMEAN del SAS; SAS, 1999).

\subsection{Resultados}

Como se muestra en la figura 6.1, no se observaron diferencias atribuibles a la especie de rumiante (ovino vs. vacuno) o al tratamiento previo de pastoreo (pastoreo en parcelas invadidas vs. no invadidas) cuando se incubó el pasto no invadido por lecherina. Sin embargo, las diferencias fueron notables en el sustrato que contenía E. polygalifolia (pasto invadido).

Los resultados de la curva ajustada aparecen en la tabla 6.2. En todos ellos se alcanzó el criterio de convergencia, siendo la proporción de la varianza total explicada por el modelo del 99,7\% $\pm 0,04$ y la desviación estándar residual del 7,86\% $\pm 0,641$.

En las incubaciones del pasto invadido se encontró una interacción "especie $\mathrm{x}$ tratamiento de pastoreo" para el ritmo fraccional de producción de gas $(c ; \mathrm{P}<0,01)$ y el ritmo medio de fermentación $(\mathrm{RMF} ; \mathrm{P}<0,10)$. El valor más alto para los dos parámetros anteriores se encontró en las ovejas que habían utilizado previamente pastos invadidos, y el más bajo en vacas que no habían tenido la posibilidad de pastar lecherina con anterioridad. La producción asintótica de gas $(A)$ mostró una tendencia a ser mayor en las incubaciones con inóculo ruminal procedente de ovejas frente a aquellas en las que el inóculo se obtuvo de las vacas (253 vs. $218 \mathrm{~mL} \mathrm{~g}^{-1}$ MO para ovejas y vacas respectivamente).

En los pastos no invadidos, sólo el tiempo de retardo ( $\mathrm{Lag}$ ) mostró diferencias entre especies, siendo los valores superiores en las vacas. 

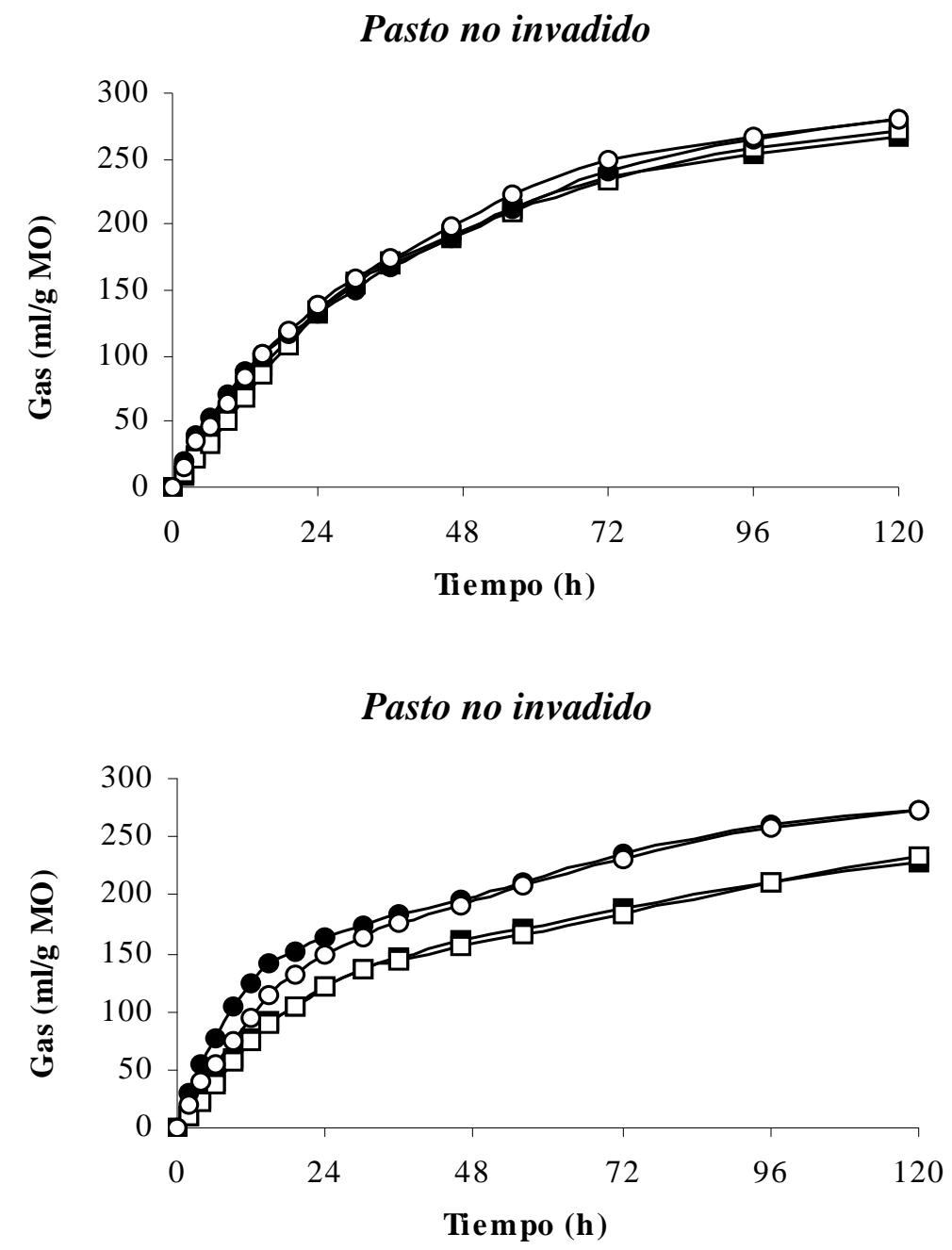

Vacuno con pastoreo previo en zonas invadidas

$\square$ Vacuno sin pastoreo previo en zonas invadidas
- Ovino con pastoreo previo en zonas invadidas Ovino sin pastoreo previo en zonas invadidas

Figura 6.1. Curvas de producción de gas de los pastos invadidos y no invadidos por lecherina en vacas y ovejas sometidas a pastoreo previo en zonas invadidas o libres de la invasión.

En concordancia con los resultados de ritmo de producción de gas y desaparición de MS (ver tabla 6.2), la extensión de la degradación en el rumen (ED) de los pastos que contenían lecherina fue significativamente superior en las ovejas y en los animales que habían pastado en parcelas invadidas. Por el contrario, no se observaron diferencias significativas cuando se incubaron sustratos no invadidos.

La tabla 6.3 muestra los resultados de concentración de amoniaco y de producción de ácidos grasos volátiles y metano. Las concentraciones de amoniaco fueron siempre más 
elevadas en las ovejas que en las vacas. Sin embargo, sólo se encontraron diferencias relacionadas con el tratamiento de pastoreo cuando se incubó el pasto invadido por lecherina, siendo los valores numéricamente más altos en los animales que habían pastado sobre las parcelas invadidas.

Las incubaciones de pasto invadido con fluido ruminal de vacuno produjeron menos AGV totales que las incubaciones con fluido ruminal de ovejas $(31,48$ vs. 35.78 mmol L-1 para el vacuno y el ovino respectivamente). Esto fue debido en gran medida a la menor producción de acético (20,94 vs. 24,39 $\mathrm{mmol} \mathrm{L}^{-1}$ ) y "otros" AGV (calculados como la suma de isobutírico, isovalérico y valérico; 0,36 vs. $0,73 \mathrm{mmol} \mathrm{L}^{-1}$ ). Ni el tratamiento de pastoreo previo ni la interacción "especie x tratamiento de pastoreo" afectaron significativamente a la producción de AGV.

En cuanto a la producción estimada de metano y a la relación $\mathrm{CH}_{4} / \mathrm{AGV}$ totales, la cual podría ser un indicador de la cantidad de energía obtenida en el rumen por unidad de sustrato fermentado, ninguna mostró variaciones significativas atribuibles a los tratamientos estudiados. 
Tabla 6.2. Producción asintótica de gas $\left(A, \mathrm{~mL} \mathrm{~g}^{-1} \mathrm{MO}\right)$, ritmo fraccional de producción de gas $\left(c, \mathrm{~h}^{-1}\right)$, tiempo de retardo $(\mathrm{Lag}$, $\mathbf{h})$, ritmo medio de fermentación $\left(\mathrm{RMF}, \mathrm{mL} \mathrm{h}^{-1}\right.$ ), desaparición de materia seca (DMS, $\mathrm{g} \mathrm{kg}^{-1}$ ) y extensión de la degradación en el rumen (ED, $\mathrm{g} \mathrm{kg}^{-1}$ ) de dos sustratos (pastos invadidos vs. no invadidos por lecherina) incubados in vitro durante 120 horas con inóculo ruminal de vacuno y ovino que habían pastado previamente (+EP) o no (-EP) en parcelas invadidas por lecherina.

\begin{tabular}{|c|c|c|c|c|c|c|c|c|c|}
\hline & & \multicolumn{2}{|c|}{ Vacuno } & \multicolumn{2}{|c|}{ Ovino } & \multirow[b]{2}{*}{ e.e.d. } & \multicolumn{3}{|c|}{ Nivel de significación (P) } \\
\hline & & $+\mathrm{EP}$ & $-\mathrm{EP}$ & $+\mathrm{EP}$ & $-\mathrm{EP}$ & & Especie & $\begin{array}{c}\text { Pastoreo } \\
\text { previo }\end{array}$ & $\begin{array}{c}\text { Especie } \times \\
\text { pastoreo previo }\end{array}$ \\
\hline \multirow[t]{2}{*}{$A$} & Invadido & 210 & 226 & 245 & 261 & 23,4 & $\mathrm{t}$ & $\mathrm{ns}$ & ns \\
\hline & No invadido & 272 & 282 & 283 & 288 & 14,5 & $\mathrm{~ns}$ & $\mathrm{~ns}$ & $\mathrm{~ns}$ \\
\hline \multirow[t]{2}{*}{$c$} & Invadido & $0,036^{\mathrm{b}}$ & $0,030^{\mathrm{c}}$ & $0,049^{\mathrm{a}}$ & $0,034^{\mathrm{b}}$ & 0,0013 & $* * *$ & $* * *$ & $* *$ \\
\hline & No invadido & 0,029 & 0,026 & 0,027 & 0,027 & 0,0019 & $\mathrm{~ns}$ & $\mathrm{~ns}$ & ns \\
\hline \multirow[t]{2}{*}{ Lag } & Invadido & 0,038 & 0,080 & 0,000 & 0,000 & 0,0625 & $\mathrm{~ns}$ & $\mathrm{~ns}$ & ns \\
\hline & No invadido & 0,786 & 0,862 & 0,000 & 0,000 & 0,4219 & $*$ & $\mathrm{~ns}$ & $\mathrm{~ns}$ \\
\hline \multirow[t]{2}{*}{ RMF } & Invadido & $5,45^{\mathrm{bc}}$ & $4,83^{\mathrm{c}}$ & $8,69^{\mathrm{a}}$ & $6,38^{\mathrm{b}}$ & 0,492 & $* *$ & $*$ & $\mathrm{t}$ \\
\hline & No invadido & 5,54 & 5,20 & 5,47 & 5,64 & 0,582 & $\mathrm{~ns}$ & $\mathrm{~ns}$ & ns \\
\hline \multirow[t]{2}{*}{ DMS } & Invadido & 741 & 747 & 736 & 769 & 14,7 & $\mathrm{~ns}$ & $\mathrm{~ns}$ & $\mathrm{~ns}$ \\
\hline & No invadido & 756 & 761 & 742 & 758 & 9,7 & $\mathrm{~ns}$ & $\mathrm{~ns}$ & $\mathrm{~ns}$ \\
\hline \multirow[t]{2}{*}{ ED } & Invadido & 418 & 386 & 468 & 421 & 6,9 & $* * *$ & $* *$ & ns \\
\hline & No invadido & 374 & 357 & 363 & 373 & 19,2 & $\mathrm{~ns}$ & $\mathrm{~ns}$ & $\mathrm{~ns}$ \\
\hline
\end{tabular}

ns: no significativo; t: $0,10>\mathrm{P}>0,05 ; *$ : $\mathrm{P}<0,05 ; * *: \mathrm{P}<0,01 ; * * *: \mathrm{P}<0,001$. e.e.d.: error estándar de la diferencia

$\mathrm{a}, \mathrm{b}, \mathrm{c}$ Valores medios con diferentes superíndices, en la misma fila, difieren significativamente 
Tabla 6.3. Concentración de amoniaco $\left(\mathrm{mg} \mathrm{L}^{-1}\right)$, producción de ácidos grasos volátiles (AGV, mmol $\mathbf{L}^{-1}$ ), relación acético:propiónico (A:P, mol:mol), producción estimada de metano $\left(\mathrm{CH}_{4}, \mu \mathrm{mol}\right)$ y relación $\mathrm{CH}_{4}$ : $\mathrm{AGV}$ totales $(\mu \mathrm{mol}: \mu \mathrm{mol})$ en incubaciones in vitro a 24 horas de dos sustratos (pastos invadidos vs. pastos no invadidos por lecherina) con inóculo ruminal de vacuno y ovino que habían pastado previamente (+EP) o no (-EP) en parcelas invadidas por lecherina.

\begin{tabular}{|c|c|c|c|c|c|c|c|c|c|}
\hline & & \multicolumn{2}{|c|}{ Vacuno } & \multicolumn{2}{|c|}{ Ovino } & \multirow[b]{2}{*}{ e.e.d. } & \multicolumn{3}{|c|}{ Nivel de significación (P) } \\
\hline & & $+\mathrm{EP}$ & $-\mathrm{EP}$ & $+\mathrm{EP}$ & $-\mathrm{EP}$ & & Especie & $\begin{array}{c}\text { Pastoreo } \\
\text { previo }\end{array}$ & $\begin{array}{c}\text { Especie } \times \\
\text { pastoreo previo }\end{array}$ \\
\hline \multirow[t]{2}{*}{ Amoniaco } & Invadido & 185 & 159 & 237 & 220 & 12,0 & $* *$ & $\mathrm{t}$ & ns \\
\hline & No invadido & 225 & 210 & 277 & 267 & 24,4 & $*$ & ns & ns \\
\hline \multirow[t]{2}{*}{ AGV totales } & Invadido & 31,34 & 31,62 & 34,87 & 36,69 & 2,229 & $\mathrm{t}$ & ns & $\mathrm{ns}$ \\
\hline & No invadido & 28,45 & 29,42 & 29,71 & 34,02 & 2,096 & ns & ns & ns \\
\hline \multirow[t]{2}{*}{ Acético } & Invadido & 20,55 & 21,32 & 22,75 & 26,03 & 2,171 & $\mathrm{t}$ & ns & ns \\
\hline & No invadido & 17,18 & 18,59 & 17,82 & 22,70 & 2,095 & ns & ns & ns \\
\hline \multirow[t]{2}{*}{ Propiónico } & Invadido & 8,20 & 7,65 & 8,69 & 7,81 & 0,590 & ns & ns & ns \\
\hline & No invadido & 8,26 & 7,78 & 8,53 & 8,14 & 0,562 & ns & $\mathrm{ns}$ & $\mathrm{ns}$ \\
\hline \multirow[t]{2}{*}{ Butírico } & Invadido & 2,25 & 2,28 & 2,64 & 2,19 & 0,224 & ns & ns & $\mathrm{ns}$ \\
\hline & No invadido & 2,35 & 2,34 & 2,28 & 2,21 & 0,209 & $\mathrm{~ns}$ & ns & ns \\
\hline \multirow[t]{2}{*}{$\operatorname{Otros}^{\ddagger}$} & Invadido & 0,34 & 0,37 & 0,81 & 0,65 & 0,139 & $*$ & $\mathrm{~ns}$ & $\mathrm{~ns}$ \\
\hline & No invadido & 0,67 & 0,70 & 1,08 & 0,97 & 0,194 & $\mathrm{t}$ & ns & $\mathrm{ns}$ \\
\hline \multirow[t]{2}{*}{$A: P$} & Invadido & 2,55 & 2,79 & 2,62 & 3,33 & 0,399 & ns & ns & ns \\
\hline & No invadido & 2,12 & 2,40 & 2,09 & 2,80 & 0,380 & ns & ns & ns \\
\hline \multirow[t]{2}{*}{$\mathrm{CH}_{4}$} & Invadido & 468 & 495 & 526 & 608 & 61,7 & $\mathrm{~ns}$ & ns & ns \\
\hline & No invadido & 385 & 426 & 396 & 521 & 60,1 & ns & ns & ns \\
\hline \multirow[t]{2}{*}{$\mathrm{CH}_{4}: \mathrm{AGV}$} & Invadido & 0,298 & 0,312 & 0,302 & 0,332 & 0,0203 & ns & ns & $\mathrm{ns}$ \\
\hline & No invadido & 0,270 & 0,288 & 0,267 & 0,306 & 0,0233 & ns & ns & $\mathrm{ns}$ \\
\hline
\end{tabular}

ns: no significativo; t: $0,10>\mathrm{P}>0,05 ; *$ : $\mathrm{P}<0,05 ; * *: \mathrm{P}<0,01 ; * * *: \mathrm{P}<0,001$. e.e.d.: error estándar de la diferencia, ${ }^{¥}$ Calculado como la suma de isobutírico, isovalérico y valérico. 


\subsection{Discusión}

La utilización del ganado ovino como una herramienta para el control sostenible de las invasiones por euforbiáceas ha sido planteada tanto en el caso de la E. esula (Bandsund et al., 2001) como en el de E. polygalifolia (Mora et al., 2007a). Al contrario de lo que sucede en las vacas, las ovejas parecen no desarrollar aversiones hacia estas euforbiáceas, lo cual podría estar relacionado con una ausencia de efectos tóxicos o antinutricionales y con una mejor fermentación ruminal de los pastos que contienen estas plantas.

Los efectos tóxicos y el desarrollo de aversiones en las vacas que consumen especies del género Euphorbia se han relacionado con la presencia de terpenoides. Entre los más implicados, destacarían el ingenol y algunos ésteres de ingenol o de forbol (Evans y Kinghorn, 1977; Kronberg et al., 1995), responsables de la activación de la proteína quinasa $\mathrm{C}$ (mediante sustitución de su activador natural), la cual participa en numerosos procesos bioquímicos y fisiológicos como son la regulación de las gonadotropinas, la permeabilidad vascular, la proliferación celular y la actividad neuronal (Kronberg et al., 1995). Si bien estos compuestos no fueron encontrados en la lecherina, en las condiciones analíticas utilizadas (ver capítulo 4), sí que se detectaron otros compuestos terpenoidales que bien directamente o a través de interacciones entre sí o con otros compuestos secundarios, podrían estar implicados en la generación de aversiones hacia su consumo. También se han encontrado taninos tanto en la E. esula (Roberts y Olson, 1999) como en la E. polygalifolia, tal y como se describió en la primera prueba.

Respecto a la fermentación ruminal de forma específica, los resultados de los parámetros de producción de gas, de la extensión de la degradación en el rumen y de la concentración de amoniaco y la producción de $\mathrm{AGV}$ de los pastos invadidos por $E$. polygalifolia indican una mejor fermentación de este sustrato en las ovejas que en las vacas. La ausencia de diferencias reseñables entre las dos especies de rumiantes cuando se incubaron los pastos sin lecherina sugiere que la mayor parte de la variación entre ovino y vacuno puede ser atribuida a la presencia de lecherina.

Es importante mencionar que el valor de $k_{\mathrm{p}}$ utilizado para estimar la extensión de la degradación en el rumen (ED) fue seleccionado de la literatura existente para ovejas (Carro, 1989) y vacas (Doreau y Diawara, 2003), en mantenimiento o moderada producción y alimentadas con dietas con una composición similar a los sustratos utilizados 
en este experimento. En ambos trabajos, los valores fueron ca 2,8 \% $\mathrm{h}^{-1}$. Algunas comparaciones directas han mostrado que el ritmo de paso de las partículas del rumen podría ser menor en las vacas que en las ovejas, para una misma dieta ingerida en cantidades similares (Poppi et al., 1980), aunque no siempre se ha observado esta tendencia (Colucci et al., 1990). El interés de usar el mismo valor de $k_{\mathrm{p}}$ (Doreau, comunicación personal) radica en que, de esta forma, las diferencias encontradas en la ED pueden ser atribuidas exclusivamente a diferencias potenciales en la degradación del alimento.

Diversos estudios han comparado la utilización digestiva de forrajes en ovejas y vacas, observándose resultados muy variables en función del forraje considerado. De este modo, los datos aparentemente contradictorios a favor del ovino (Blankenship et al., 1982; Gonçalves y Borba, 1996), a favor del vacuno (Poppi et al., 1980; Cone et al., 2002) o similares en ambas especies (Huston et al., 1986) pueden ser explicados por la interacción "especie x alimento" o incluso por el efecto de la dieta del animal donante sobre la actividad del fluido ruminal (Cone et al., 2002). Por otra parte, en muchos trabajos se han descrito diferencias entre especies de rumiantes en términos de susceptibilidad a las plantas que contienen compuestos secundarios (Wachenheim et al., 1992; Cheeke y Palo, 1995; Frutos et al., 2004b), siendo en general el vacuno menos resistente a las especies potencialmente tóxicas. Según Cheeke y Palo (1995), estas diferencias son un reflejo de la estrategia alimentaria y de la dieta con la que han evolucionado las diferentes especies animales. En este sentido, los rumiantes pastoreadores o consumidores de herbáceas y forrajes bastos, como las vacas, que han evolucionado sobre pastos herbáceos, han desarrollado de forma escasa sus sistemas de destoxificación ya que su dieta herbácea apenas contiene defensas químicas (i.e., compuestos secundarios o tóxicos).

Los valores más elevados del ritmo fraccional de producción de gas $(c)$ y del ritmo medio de fermentación se obtuvieron en las ovejas que habían pastado en parcelas invadidas, y los menores en las vacas mantenidas en pastos no invadidos. Además, los valores de ED se vieron afectados positivamente por el pastoreo previo en parcelas invadidas. Debido a que las vacas apenas incorporan euforbiáceas en sus dietas, gran parte de las diferencias observadas en este estudio entre vacuno y ovino podrían ser resultado de las diferencias de la composición de la dieta de los animales donantes del inóculo ruminal para llevar a cabo las incubaciones. En este sentido, una ingestión continuada y creciente de lecherina incrementaría la tolerancia del animal a la planta, probablemente a través de una adaptación de las comunidades microbianas del rumen (Domínguez-Bello, 1996), 
siendo evidente que la adaptación no puede ocurrir si el animal no ingiere la planta. El fenómeno de la adaptación de la microbiota ruminal a los compuestos potencialmente tóxicos ha sido descrito para varios metabolitos secundarios tales como el ácido oxálico (Duncan et al., 1997; Duncan et al., 2000), los alcaloides derivados de la pirrolozidina (Wachemhein et al., 1992), los taninos (Pell et al., 2000) o los terpenos (Oh et al., 1967).

De acuerdo con nuestras observaciones directas en el campo, las vacas que pastaron en la parcela que contenía lecherina muestrearon esta especie (es decir, ingirieron cantidades muy pequeñas con cierta frecuencia) a lo largo de la prueba, lo cual concuerda con el hecho conocido de que los rumiantes son capaces de ajustar su consumo de alimentos potencialmente nocivos para mantener la ingestión de compuestos tóxicos siempre por debajo de un nivel tolerable o umbral de toxicidad. Este comportamiento de muestreo cauteloso por parte de los herbívoros en pastoreo, les permite no sólo minimizar el riesgo de intoxicación por la ingestión de alimentos desconocidos, sino también incorporar gradualmente a la dieta alimentos que pueden resultar claramente beneficiosos por poseer un alto valor nutritivo (Duncan et al., 2003). Trabajando con E. esula, Kronberg et al. (1993) sugirieron que la microbiota ruminal de terneros que recibían E. esula podrían haber desarrollado una mejora en su capacidad metabólica para tolerar los fitoquímicos aversivos de esta planta, reduciéndose por ello las aversiones condicionadas en estos animales.

También se observaron diferencias debidas a la especie de rumiante y al tratamiento de pastoreo previo en otros parámetros de la fermentación ruminal (amoniaco y AGV) estudiados en este trabajo.

La concentración de amoniaco en el rumen es de especial interés de cara a la gestión de la proteína en los rumiantes. En este estudio, las concentraciones de amoniaco en el rumen fueron significativamente más bajas en el vacuno que en el ovino, independientemente del sustrato incubado, de acuerdo con lo ya apuntado en trabajos previos sobre la degradación ruminal de la proteína en ambas especies (Siddons y Paradine, 1983). Esta diferencia fue más pronunciada para el sustrato que contenía lecherina, lo cual coincide con los demás resultados de este estudio que sugieren una mejor fermentación de estos pastos en las ovejas que en las vacas. Todas las concentraciones de amoniaco observadas en esta prueba superaron el óptimo descrito en la bibliografía para la síntesis de aminoácidos y el crecimiento microbiano (como ya se había indicado también en la primera prueba; ver apartado 4.4.3). Sin embargo, de acuerdo con Mehrez et al., 
(1977), las concentraciones de amoniaco en las incubaciones del sustrato invadido podrían no haber sido las más adecuadas para un ritmo óptimo de degradación de la materia orgánica.

Por otra parte, podría especularse que la tendencia a una mayor concentración ruminal de amoniaco en los animales que habían permanecido en las parcelas invadidas $(\mathrm{P}=0,065)$ estaría relacionada con la presencia de taninos en la lecherina, aunque a priori parezca contradictorio, dado el conocido efecto negativo de los taninos sobre la proteolisis de los alimentos. Sin embargo, tras un periodo de pastoreo en pastos invadidos y una adaptación de la microbiota ruminal a la ingestión de E. polygalifolia, parece probable que los animales hubieran podido incrementar su capacidad para tolerar la planta (DomínguezBello, 1996; Makkar, 2003). Así, la adaptación de los microorganismos del rumen a la ingestión de taninos en la dieta podría haberse reflejado en una reducción de los efectos negativos de estos compuestos fenólicos sobre la proteolisis (Makkar, 2003; Frutos et al., 2004b) y, por lo tanto, en una consiguiente mayor concentración de amoniaco. Por otro lado, no puede descartarse la posibilidad de que alguna interacción entre los diversos compuestos secundarios de la lecherina pudiera haber ejercido algún efecto sobre estos parámetros, como ya se sospechó también en la primera prueba.

La fermentación ruminal de los sustratos que da lugar a los diferentes AGV, los cuales constituyen la mayor fuente de energía para los rumiantes, está condicionada en gran medida por los factores que favorecen o disminuyen la actividad de determinadas comunidades microbianas ruminales (Van Houtert, 1993). Los valores medios de la producción total de AGV cuando se incubaron los pastos invadidos por lecherina sugieren que la fermentación fue más eficiente en las ovejas que en las vacas. Las diferencias en AGV totales se explican mayoritariamente por la producción de acético y de "otros" AGV (isobutírico + isovalérico + valérico). La tendencia hacia una mayor producción de acético $(\mathrm{P}=0,0876)$ no fue suficiente para afectar significativamente a la relación acético/propiónico, lo cual sugeriría escasas divergencias en las vías de fermentación. Respecto a los "otros" AGV, los cuales proceden de la desaminación de algunos aminoácidos (Van Soest, 1994), las diferencias observadas fueron debidas básicamente a una mayor producción de valérico e isovalérico $(\mathrm{P}<0,05$; información no mostrada). Estos resultados (observados también en el sustrato no invadido) podrían reflejar una mayor degradación ruminal de la proteína en el ovino, que estaría de acuerdo con la mayor concentración de amoniaco encontrada en esta especie. La mayor producción de "otros" 
AGV encontrada en las incubaciones del sustrato que contenía lecherina con el inóculo ruminal procedente de las ovejas (con incrementos proporcionales, respecto al vacuno, del $103 \%)$ podría estar relacionada también con una fermentación más eficiente de los compuestos fenólicos (Silanikove et al., 1993).

Por otro lado, no se observaron diferencias significativas debidas al tratamiento de pastoreo previo en las proporciones molares de $\mathrm{AGV}$, con la excepción de la proporción molar de valerato, que fue significativamente superior en los animales que habían pastado previamente en las parcelas invadidas por lecherina ( 0,67 vs $\left.0,52 \mathrm{~mol} \mathrm{~mol}^{-1} ; \mathrm{P}=0,0226\right)$. Esto podría estar relacionado, como se especuló previamente para las concentraciones de amoniaco, con una adaptación de los microorganismos del rumen a la ingestión de taninos en la dieta.

En cuanto a la producción de metano, se sabe que esta representa una importante pérdida de energía del alimento en los rumiantes domésticos (Van Houtern, 1993). Como en el caso de la relación acético/propiónico, la tendencia hacia mayores cantidades de acético producidas en las ovejas no fue suficiente para compensar la ausencia de diferencias significativas en la producción de propiónico y butírico, con lo cual no se apreciaron diferencias significativas en la producción estimada de metano atribuibles a los tratamientos estudiados. No obstante, no puede descartarse que estas hayan podido producirse, pero el método de estimación no haya sido capaz de detectarlas.

\subsection{Conclusión e implicaciones}

Los resultados de las incubaciones in vitro realizadas en este estudio sugieren la confirmación de las dos hipótesis planteadas en la introducción: (1) la microbiota ruminal de las ovejas permite una mejor degradación ruminal de los pastos de Festuca-Agrostis invadidos por lecherina que la microbiota ruminal del vacuno y (2) la capacidad de los animales para degradar este tipo de pastos podría ser mejorada mediante su consumo previo, a través de una adaptación de las comunidades microbianas del rumen.

Estos resultados respaldarían el uso de ganado ovino como una herramienta biológica para restaurar los pastos de montaña invadidos por lecherina. Sin embargo, antes de hacer recomendaciones definitivas, sería necesario profundizar en el impacto del consumo de esta euforbiácea sobre la producción y sanidad de las ovejas, para asegurar que no existe 
ningún efecto tóxico para los animales y que su rendimiento productivo no se ve perjudicado. ${ }^{1}$

${ }^{1}$ Este capítulo se publicó en el Journal of the Science of Food and Agriculture:

Mora, M.J.; Hervás, G.; Mantecón, A.R.; Busqué, J.; Frutos, P. Ruminal degradation of mountain pastures infested by Euphorbia polygalifolia in cattle and sheep: effect of previous grazing in invaded areas. Journal of the Science of Food and Agriculture 86, 2153-2160 (2006). 


\section{CONCLUSIONES}





\section{$\underline{\text { Primera }}$}

La composición botánica de los pastos de Festuca-Agrostis se vio afectada significativamente por la invasión de Euphorbia polygalifolia (conocida comúnmente como lecherina), tanto directamente por su elevada presencia en los pastos invadidos $(44,5 \%)$, como indirectamente por su efecto sobre los demás componentes (leguminosas, graminoides $\mathrm{y}$ otras latifoliadas). Estas diferencias se tradujeron en variaciones significativas en la composición química, con contenidos superiores de materia orgánica e inferiores de proteína bruta y de fibra neutro detergente en los pastos invadidos respecto a los no invadidos. En cuanto a su utilización digestiva, los pastos invadidos mostraron valores significativamente inferiores de producción de gas, ritmos de fermentación y desaparición de la materia seca in vitro, así como de la extensión de su degradación en el rumen frente a los pastos libres de la invasión. No obstante, todas estas diferencias no justificarían por sí mismas el acusado rechazo del ganado hacia los pastos invadidos. En cambio, la presencia en la lecherina de taninos y terpenoides sí podría explicar dicho rechazo, mediante el desarrollo por el ganado de aversiones condicionadas hacia las plantas que contienen estos compuestos secundarios.

\section{$\underline{\text { Segunda }}$}

Los valores de selección de los pastos de Festuca-Agrostis susceptibles de ser invadidos por la Euphorbia polygalifolia fueron siempre positivos pero significativamente diferentes según el tipo de ganado presente en el puerto: los valores más altos se observaron en las yeguas y las vacas de razas foráneas (limusina y charolesa) y los más bajos en las vacas de raza tudanca. A su vez, las yeguas se concentraron en las zonas con pendientes menores del $25 \%$ (es decir, las de mayor riesgo de resultar invadidas por lecherina), mientras que las vacas pastaron en zonas de mayor pendiente. La evolución de la selección de los pastos de Festuca-Agrostis a lo largo de la estación de pastoreo también difirió dependiendo del ganado: en las vacas tudancas los valores fueron decreciendo, en contraposición al incremento en su preferencia por los pastos arbustivos, en tanto que no se observó ningún cambio significativo en las vacas de otras razas. En las yeguas, los valores aumentaron en la época final del verano, focalizándose especialmente sobre los pastos de Festuca-Agrostis con niveles de invasión de lecherina bajos. Estos valores de selección, junto al gradiente observado en el tiempo relativo de pastoreo diurno (56\% en las vacas tudancas, $69 \%$ en las de otras razas y $82 \%$ en las yeguas) y el número de animales de cada 
tipo de ganado, dieron lugar, en el conjunto del puerto, a una presión de pastoreo muy alta en los pastos de Festuca-Agrostis con riesgo de invasión.

\section{$\underline{\text { Tercera }}$}

Los resultados de producción de gas, extensión de la degradación en el rumen, concentración de amoniaco y producción de ácidos grasos volátiles de las incubaciones in vitro de los pastos de Festuca-Agrostis invadidos por lecherina, con inóculo ruminal procedente de ganado ovino o vacuno, sugieren una mejor fermentación de este sustrato en las ovejas que en las vacas. El pastoreo previo de los animales donantes del inóculo ruminal en zonas invadidas por Euphorbia polygalifolia afectó significativa y positivamente a los ritmos de producción de gas in vitro y a la extensión de la degradación en el rumen de los pastos invadidos, lo cual sugiere que la capacidad de los rumiantes para degradar estos pastos podría ser mejorada a través de su consumo previo, mediante la adaptación de la microbiota ruminal. 
8. BIBLIOGRAFÍA 

Aldezabal, A.; Garín, I.; García-González, R., 1996. Comparación de varios métodos para la estima de la producción primaria aérea en comunidades herbáceas subalpinas del pirineo central. Actas de la XXXVI Reunión Científica de la Sociedad Española para el Estudio de los Pastos, 167-170. La Rioja (España).

Aldezabal, A.; Garín, I.; García-González, R., 1999. Activity rhythms and the influence of some environmental variables on summer ungulate behaviour in Ordesa-Monte Perdido National Park. Pirineos, 153-154, 145-157.

Aldezabal, A., 2001. El sistema de pastoreo del Parque Nacional de Ordesa y Monte Perdido. Interacción entre la vegetación supraforestal y los grandes herbívoros. Consejo de Protección de la Naturaleza de Aragón. Zaragoza (España).

Allen, L.J.S.; Allen, E.J.; Kunst, C.R.G.; Sosebee, R.E., 1991. A diffusion model for dispersal of Opuntia imbricata (cholla) on rangeland. Journal of Ecology, 79, 1123 1135 .

Alonso, M.A., 1994. Estudio ecológico y valoración de un sistema pastoral de la montaña de León. Tesis Doctoral. Universidad de León. León (España).

Álvarez del Pino, M.C.; Hervás, G.; Mantecón, A.R.; Giráldez, F.J.; Frutos, P., 2005. Comparison of biological and chemical methods, and internal and external standards, for assaying tannins in Spanish shrub species. Journal of the Science of Food and Agriculture, 85, 583-590.

Ammar, H.; López, S.; Bochi-Brum, O.; García, R.; Ranilla M.J., 1999. Composition and in vitro digestibility of leaves and stems of grasses and legumes harvested from permanent mountain meadows at different stages of maturity. Journal of Animal and Feed Sciences, 8, 599-610.

Ammar, H.; López, S.; González, J.S.; Ranilla, M.J., 2004. Chemical composition and in vitro digestibility of some Spanish browse plant species. Journal of the Science of Food and Agriculture, 84, 197-204.

Anderson, G.L.; Delfosse, E.S.; Spencer, N.R.; Prosser, C.W.; Richard, R.D., 2003. Lessons in developing successful invasive weed control programs. Journal of Range Management, 56, 2-12. 
Ansquer, P.; Duru, M.; Theau, J.P.; Cruz, P.; Al Haj Khaled, R.; Viegas, J., 2004. Caractérisation de la diversité fonctionnelle des prairies à flore complexe: vers la construction d'outils de gestion. Fourrages, 179, 353-368.

AOAC, 2000. Official Methods of Analysis of the Association of Official Agricultural Chemists (17 $7^{\text {th }}$ Edn.). AOAC International Gaithersburg (Estados Unidos).

Archer, S.; Smeins, F.E., 1991. Ecosystem-level processes. En: Grazing management. An ecological perspective. R.K. Heitschmidt; J.W. Stuth (Eds.), pp. 109-139. Timber Press. Portland (Estados Unidos).

Archer, S., 1996. Assesing and interpreting grass-woody plant dynamics. En: The Ecology and Management of Grazing Systems. J. Hodgson; A.W. Illius (Eds.), pp. 101-134. CAB International. New York (Estados Unidos).

Armstrong, H.M.; Robertson, A., 2000. Energetics of free-ranging large herbivores: when should costs affect foraging behaviour? Canadian Journal of Zoology, 78, 16041615.

Arnold, G.W.; Dudzinski, M.L., 1978. Daily maintenance behaviour. En: Ethology of freeranging domestic animals, pp. 1-50. Elsevier. New York (Estados Unidos).

Bailey, D.W.; Rittenhouse, L.R.; Hart, D.M.; Swift, D.M.; Richards, R.W., 1989. Association of relative food availabilities and locations by cattle. Journal of Range Management, 42, 480-482.

Bailey, D.W.; Gross, J.E.; Laca, E.A.; Rittenhouse, L.R.; Coughenour, M.B., Swift, D.M.; Sims, P.L., 1996. Mechanisms that result in large herbivore grazing distribution patterns. Journal of Range Management, 49, 386-400.

Bailey, D.W.; Sims, P.L., 1998. Association of food quality and locations by cattle. Journal of Range Management, 51, 2-8.

Bailey, D.W.; Welling, R., 1999. Modification of cattle grazing distribution with dehydrated molasses supplement. Journal of Range Management, 52, 575-582.

Bailey, D.W.; Kress, D.D.; Anderson, D.C.; Boss, D.L.; Miller, E.T., 2001. Relationship between terrain use and performance of beef cows grazing foothill rangeland. Journal of Animal Science, 79, 1883-1891. 
Bailey, D.W.; Keil, M.R.; Rittenhouse, L.R., 2004. Research observation: daily movement patterns of hill climbing and bottom dwelling cows. Journal of Range Management, 57, 20-28.

Bangsund D.A.; Nudell, D.J.; Sell, R.S.; Leistritz, F.L., 2001. Economic analysis of using sheep to control leafy spurge. Journal of Range Management, 54, 322-329.

Bartholomew, G.A., 1964. The roles of physiology and behaviour in the maintenance of homeostasis in the desert environment. En: Homeostasis and Feedback Mechanisms. G.M. Hughes (Ed.), pp. 7-29. Cambridge University Press. Cambridge (Reino Unido).

Bartolomé, J.; Plaixats, J.; Fanlo, R.; Boada, M., 2005. Conservation of isolated Atlantic heathlands in the Mediterranean region: effects of land-use changes in the Montseny biosphere reserve (Spain). Biological Conservation, 122, 81-88.

Beeskow, A.M.; Elissalde, N.O.; Rostagno, C.M., 1995. Ecosystem changes associated with grazing intensity on the Punta Ninfas rangelands of Patagonia, Argentina. Journal of Range Management, 48, 517-522.

Belcher, J.W.; Wilson, S.D., 1989. Leafy spurge and the species composition of a mixedgrass prairie. Journal of Range Management, 42, 172-175.

Belsky, A.J., 1986. Does herbivory benefit plants? A review of the evidence. The American Naturalism, 127, 870-892.

Biondini, M.E.; Patton, B.D.; Nyren, P.E., 1998. Grazing intensity and ecosystem processes in a Northern mixed-grass prairie, USA. Ecological Applications, 8, 469479.

Blankenship, L.H.; Varner, L.W.; Lynch, G.W., 1982. In vitro digestibility of south Texas range plants using inoculum from four ruminant species. Journal of Range Management, 35, 664-666.

Blümmel, M.; Makkar, H.P.S.; Becker, K., 1997. In vitro gas production: a technique revisited. Journal of Animal Physiology and Animal Nutrition, 77, 24-34.

Bovolenta, S.; Spanghero, M.; Dovier, S.; Orlandi, D.; Clementel, F., 2008. Chemical composition and net energy content of alpine pasture species during the grazing season. Animal Feed Science and Technology, 140, 164-177. 
Box, E.O., 1981. Microclimate and plant forms: an introduction to predictive modelling in plant phytogeography. W. Junk Publishers. La Haya (Holanda).

Briske, D.D., 1986. Plant response to defoliation: morphological considerations and allocation priorities. En: Rangelands: a Resource Under Siege. P.J. Joss; P.W. Lynch; O.B. Williams (Eds.), pp. 425-427. Australian Academy of Science. Canberra (Australia).

Briske, D.D., 1996. Strategies of plant survival in grazed systems: a functional interpretation. En: The Ecology and Management of Grazing Systems. J. Hodgson and A.W. Illius (Eds.), pp. 37-67. CAB International. New York (Estados Unidos).

Bullock, J.M., 1996. Plant competition and population dynamics. En: The Ecology and Management of Grazing Systems. J. Hodgson and A.W. Illius (Eds.), pp. 69-100. CAB International. New York (Estados Unidos).

Busqué, J.; Fernández, B.; Alfageme, A.; Sarmiento, M.; Gutiérrez, A., 1995. Comportamiento ecológico y productivo de dos tipos de pastizales de montaña en Cantabria”. Actas de la XXXV Reunión Científica de la Sociedad Española para el Estudio de los Pastos, 295-300. Tenérife (España).

Busqué, J.; Méndez, S.; Fernández, B., 2003. Estructura, crecimiento y aprovechamiento de pastos de puerto cantábricos invadidos o no por lecherina (Euphorbia polygalifolia). Pastos, 33, 283-303.

Busqué, J.; Fernández, N.; Fernández, B., 2006. A decision support tool to design rangeland sustainable grazing systems. En: Sustainable Grassland Productivity. Grassland Science in Europe. J. Lloveras, A. González-Rodríguez, O. VázquezYáñez, J. Piñeiro, O. Santamaría, L. Olea, M.J. Poblaciones (Eds.), pp. 682-684. European Grassland Federation. Badajoz (España).

Busqué, J.; Mora, M.J.; Bedia, J.; Fernández, B., 2007a. Sobrepastoreo y degradación de pastos de puerto: quién, cuándo, dónde. Respuestas del modelo de simulación "Puerto". Actas de la XLVI Reunión Científica de Sociedad Española para el Estudio de los Pastos, 32-37. Vitoria (España).

Busqué, J.; Mora, M.J.; Frutos, P., 2007b. Un sistema de pastoreo ovino para recuperar pastos de montaña invadidos por lecherina (Euphorbia polygalifolia). Ganadería, $50,38-43$. 
Busqué, J.; González, G.; Agote, L.; Benoit, S.; Gutiérrez, J.M.; Bedia, J., 2008. Teratogénesis en vacuno en los pastos de puerto de Áliva (Picos de Europa). Análisis de encuestas a los ganaderos. Actas de la XLVII Reunión Científica de la Sociedad Española para el Estudio de los Pastos, 589-595. Córdoba (España).

Carlson, J.R.; Breeze, R.G., 1984. Ruminal metabolism of plant toxins with emphasis on indolic compounds. Journal of Animal Science, 58, 1040-1049.

Carro, M.D., 1989. Utilización digestiva e ingestión voluntaria de diferentes henos por el ganado ovino. Tesis Doctoral. Universidad de León. León (España).

Carro, M.D.; López, S.; Valdés, C.; Ovejero, F.J., 1999. Effect of DL-malate on mixed ruminal microorganism fermentation using the rumen simulation technique (RUSITEC). Animal Feed Science and Technology, 79, 279-288.

Celaya, R.; Jaúregui, B.M; García, U.; Osoro, K., 2005. Efectos de la raza y la carga ganadera sobre la cubierta vegetal en brezales-tojales pastados por caprino. Actas de la XLV Reunión Científica de la Sociedad española para el Estudio de los pastos, 323-330. Gijón (España).

Cendrero Uceda, A.; Díaz de Terán Mira, J.R.; Flor Pérez, E.; Francés Arriola, E.; González Lastra, J.R.; Martínez Incera, J.M., 1986. Guía de la Naturaleza de Cantabria. Estudio. Santander (España).

Chaves, A.V.; Burke, J.L.; Waghorn, G.C.; Brookes, I.M., 2006. Digestion kinetics of leaf, stem and inflorescence from five species of mature grasses. Journal of the Science of Food and Agriculture, 86, 816-825.

Cheeke, P.R., 1988. Toxicity and metabolism of pyrrolizidine alkaloids. Journal of Animal Science, 66, 2343-2350.

Cheeke, P.R.; Palo, R.T., 1995. Plant toxins and mammalian herbivores: co-evolutionary relationships and antinutritional effects. En: Recent Developments in the Nutrition of Herbivores. Proceedings of the IV th International Symposium on the Nutrition of Herbivores. M. Journet, E. Grent, M.H. Farce, M. Thériez, C. Demarquilly, (Eds.), pp. 437-459. INRA Editions. París (Francia). 
CIFA, 2004. Memoria Anual del Centro de Investigación y Formación Agrarias de Cantabria. Consejería de Ganadería, Agricultura y Pesca del Gobierno de Cantabria. Santander (España).

Clements, F., 1916. Plant Succession : an Analysis of the Development of Vegetation. Carnegie Inst. Publ. 242. Washington (Estados Unidos).

Cone, J.W.; Van Gelder, A.H.; Bachmann, H., 2002. Influence of inoculum source on gas production profiles. Animal Feed Science and Technology, 99, 221-231.

Cook, C.W., 1966. Factors affecting utilization of mountain slopes by cattle. Journal of Range Management, 19, 200-2004.

Cole, D.N., 1995. Experimental trampling of vegetation. I. Relationship between trampling intensity and vegetation response. Journal of Applied Ecology, 32, 203-214.

Coley, P.D., 1983. Herbivory and defensive characteristics of tree species in a lowland tropical forest. Ecological Monographs, 53, 209-234.

Colucci, P.E.; Macleod, G.K.; Grovum, W.L.; McMillan, I.; Barney, D.J., 1990. Digesta kinetics in sheep and cattle fed diets with different forage to concentrate ratios at high and low intakes. Journal of Dairy Science, 73, 2143-2156.

Corbera, M., 2006. Resistencia de un sistema milenario de trashumancia ganadera de corto recorrido en el Valle de Cabuérniga (Cantabria). Scripta Nova: Revista Electrónica de Geografía y Ciencias Sociales, 10, 218.

Coughenour, M.B., 1991. Spatial components of plant-herbivore interactions in pastoral, ranching, and native ungulate ecosystems. Journal of Range Management, 44, 530542.

Clutton-Brock, T.H.; Harvey, P.H., 1983. The functional significance of variation in body size among mammals. American Society of Mammologists Special Publication, 7, 632-663.

Cymbaluk, N.F., 1990. Comparison of forage digestion by cattle and horses. Canadian Journal of Animal Science, 70, 601-610.

Dawson, L.A.; Grayston, S.J.; Paterson, E., 2000. Effects of grazing on the roots and rhizosphere of grasses. En: Grassland Ecophysiology and Grazing Ecology. G. 
Lemaire, J. Hodgson, A. de Moraes, G. Nabinger, F. de Carvalho, (Eds.), pp. 61-85. CABI. Oxon (Reino Unido).

Demment, M.W.; Van Soest, P.J., 1985. A nutritional explanation for body-size patterns of ruminant and nonruminant herbivores. The American Naturalism, 125, 641-672.

Demment, M. W.; Peyraud, J.L.; Laca, E.A., 1995. Herbage intake at grazing: a modelling approach. En: Recent Developments in the Nutrition of Herbivores. Proceedings of the IV th International Symposium on the Nutrition of Herbivores. M. Journet, E. Grent, M.H. Farce, M. Thériez, C. Demarquilly, (Eds.), pp. 121-141. INRA Editions. París (Francia).

Díaz, T.E.; Fernández-Prieto, J.A.; 1994. La vegetación de Asturias. Itinera Geobotánica, $8,243-529$.

Dijkstra, J., 1994. Production and absorption of volatile fatty acids in the rumen. Livestock Production Science, 39, 61 - 69.

DiTomaso, J.M., 2000. Invasive weeds in rangelands: Species, impacts, and management. Weed Science, 48, 255-265.

Doescher, P.S.; Svejcar, T.J.; Jaindl, R.G., 1997. Gas exchange of Idaho fescue in response to defoliation and grazing history. Journal of Range Management, 50, 285-289.

Doane, P.H.; Schofield, P.; Pell, A.N., 1997. Neutral detergent fiber disappearance and gas and volatile fatty acid production during the in vitro fermentation of six forages. Journal of Animal Science, 75, 3342-3352.

Domínguez-Bello, M.G., 1996. Detoxification in the rumen. Annales de Zootechnie, 45, Suppl., 323-327.

Doreau, M.; Diawara, A., 2003. Effect of level of intake on digestion in cows: influence of animal genotype and nature of hay. Livestock Production Science, 81, 35-45.

Driedger, A.; Hatfield, E. 1972. Influence of tannins on the nutritive value of soybean meal for ruminants. Journal of Animal Science, 34, 465-468.

Dullinger, S.; Dirnböck, T.; Greimler, J.; Grabherr, G., 2003. A resampling approach for evaluating effects of pasture abandonment on subalpine plant species diversity. Journal of Vegetation Science, 14, 243-252. 
Duncan, A.J.; Hartley, S.E.; Iason, G.R., 1994. The effect of monoterpene concentrations in Sitka spruce (Picea sitchensis) on the browsing behaviour of red deer (Cervus elaphus). Canadian Journal of Zoology, 72, 1715-1720.

Duncan, A.J.; Frutos, P.; Young, S.A., 1997. Rates of oxalic acid degradation in the rumen of sheep and goats in response to different levels of oxalic acid administration. Animal Science, 65, 451-455.

Duncan, A.J.; Frutos, P.; Young, S.A., 2000. The effect of rumen adaptation to oxalic acid on selection of oxalic acid-rich plants by goats. British Journal of Nutrition, 83, 5965.

Duncan, A.J.; Mayes, R.W.; Young, S.A.; Lamb, C.S.; MacEachern, P., 2001. Choice of foraging patches by hill sheep given different opportunities to seek shelter and food. Animal Science, 73, 563-570.

Duncan, A.J.; Ginane, C.; Gordon, I.J.; Orskov, E.R., 2003. Why do browsing herbivores select mixed diets? En: Matching Herbivore Nutrition to Ecosystems Biodiversity. L. Mannetje, L. Ramírez-Avilés, C.A. Sandoval-Castro, J.C. Ku-Vera (Eds.), pp. 195-209. Universidad Autónoma de Yucatán. Yucatán (México).

Duncan, P., 1983. Determinants of the use of habitat by horses in a Mediterranean wetland. Journal of Applied Ecology, 52, 93-109.

Duncan, P.; Foose, T.J.; Gordon, I.J.; Gakahu, C.G.; Lloyd, M., 1990. Comparative nutrient extraction from forages by grazing bovids and equids: a test of the nutritional model of equid/bovid competition and coexistence. Oecologia, 84, 411418.

Edwards, P.J.; Hollis, S., 1982. The distribution of excreta on New Forest grassland used by cattle, ponies and deer. Journal of Applied Ecology, 19, 953-964.

Evans, F.J.; Kinghorn, A.D., 1977. A comparative phytochemical study of the diterpenes of some species of the genera Euphorbia and Elaeophorbia (Euphorbiaceae). Botanical Journal of the Linnean Society, 74, 23-35.

Ferrer i Marco, F.; Fernández, J.M.; Francés, E., 2006. Mapa Efafológico de Cantabria. Consejería de Ganadería, Agricultura y Pesca de Cantabria. Santander (España). 
Fischer, S.F.; Poschlod, P.; Beinlich, B., 1996. Experimental studies on the dispersal of plants and animals on sheep in calcareous grasslands. Journal of Applied Ecology, $33,1206-1222$.

Fox, D.; Kirby, D.; Lym, R.G.; Caton, J.; Krabbenhoft, K., 1991. Chemical composition of leafy spurge and alfalfa. North Dakota Farm Research Bimonthly Bulletin, 48, 7-9.

France, J.; Dijkstra, J.; Dhanoa, M.S.; López, S.; Bannink, A., 2000. Estimating the extent of degradation of ruminant feeds from a description of their gas production profiles observed in vitro: derivation of models and other mathematical considerations. British Journal of Nutrition, 83, 143-150.

Fraser, M.D.; Gordon, I.J., 1997. The diet of goats, red deer and South American camelids feeding on three contrasting Scottish upland vegetation communities. Journal of Applied Ecology, 34, 668-686.

Freeland, W.J.; Janzen, D.J., 1974. Strategies in herbivory by mammals: the role of plant secondary compounds. The American Naturalist, 108, 269-289.

Frutos, P.; Duncan, A.J.; Kyriazakis, I.; Gordon, I.J., 1998. Learned aversion towards oxalic acid-containing foods by goats: does rumen adaptation to oxalic acid influence diet choice? Journal of Chemical Ecology, 24, 383-397.

Frutos, P.; Hervás, G.; Giráldez, F.J.; Mantecón, A.R., 2001. La selección de la dieta: papel de los compuestos secundarios de las plantas. Ovis, 74, 81-101.

Frutos, P.; Hervás, G.; Ramos, G.; Giráldez, F.J.; Mantecón, A.R. 2002. Condensed tannin content of several shrub species from a mountain area in northern Spain, and its relationship to various indicators of nutritive value. Animal Feed Science and Technology, 95, 215-226.

Frutos, P.; Hervás, G.; Giráldez, F.J.; Mantecón, A.R., 2004a. Review. Tannins and ruminant nutrition. Spanish Journal of Agricultural Research, 2, 191-202.

Frutos, P.; Hervás, G.; Giráldez, F.J.; Mantecón, A.R., 2004b. An in vitro study on the ability of polyethylene glycol to inhibit the effect of quebracho tannins and tannic acid on rumen fermentation in sheep, goats, cows and deer. Australian Journal of Agriculture Research, 55, 1125-1132. 
Ganskopp, D.; Vavra, M., 1987. Slope use by cattle, feral horses, deer, and Bighorn sheep. Nothwest Science, 61, 74-81.

García-González, R.; García-Serrano, A.; Revilla, R., 1992. Comparación del régimen alimentario de vacas pardo alpinas y pirenaicas en un puerto del Pirineo Occidental. Actas de la XXXII Reunión Científica de la Sociedad Española para el Estudio de los Pastos, 299-305. Pamplona (España).

García-González, R.; Marinas, A.; Gómez, D.; Aldezabal, A., 2002. Revisión bibliográfica de la producción primaria neta aérea de las principales comunidades pascícolas pirenaicas". Actas de la XXXII Reunión Científica de la Sociedad Española para el Estudio de los Pastos, 245-249. Lérida (España).

García-González, R.; Aldezabal, A.; Garín, I.; Marinas, A., 2005. Valor nutritivo de las principales comunidades de pastos de los Puertos de Góriz (Pirineo Central). Pastos, 35, 77-103.

García-González, R., 2008. La utilización de los pastos por los grandes herbívoros: principios básicos y casos de estudio. En: Pastos del Pirineo. F. Fillat; R. GarcíaGonzález; D. Gómez; R. Reiné (Eds.), pp. 205-227. CSIC y Diputación de Huesca. Madrid (España).

García-Ruiz, J.M.; Lasanta, T.; Ruiz-Flano, P.; Ortigosa, L.; White, S.; González, C.; Martí, C., 1996. Land-use changes and sustainable development in mountain areas: a case study in the Spanish Pyrenees. Lanscape Ecology, 11, 267-277.

Gibbs, P.G.; Potter, G.D.; Schelling, G.T.; Kreider, J.L.; Boyd, C.L., 1988. Digestion of hay protein in different segments of the equine digestive tract. Journal of Animal Science, 66, 400-406.

Gillen, R.L.; Krueger, W.C.; Miller, R.F., 1984. Cattle distribution on mountain rangeland in Northeastern Oregon. Journal of Range Management, 37, 549-553.

Gillen, R.L.; Krueger, W.C.; Miller, R.F., 1985. Cattle use of riparian meadows in the Blue Mountains of Northeastern Oregon. Journal of Range Management, 38, 205-209.

Goering, M.K.; Van Soest, P.J., 1970. Forage fiber analysis (apparatus, reagents, procedures and some applications). Agriculture Handbook No 379. Agricultural Research Service, USDA. Washington (Estados Unidos). 
Gómez, 2008. Métodos para el estudio de los pastos, su caracterización ecológica y valoración. En: Pastos del Pirineo. F. Fillat; R. García-González; D. Gómez; R. Reiné (Eds.), pp. 75-110. CSIC y Diputación de Huesca. Madrid (España).

Gómez-Sal, A.; Rodríguez, E.; Busqué, J.; Rodríguez, M., 1995. Cuadernos de la Trashumancia-Nº.17. Pernía-Páramos-Alto Campoo. ICONA. Madrid (España).

Gonçalves, L.M.B.O.; Borba, E.S., 1996. Study of gas production capacity by three sources of inocula. Journal of Agricultural Science Cambridge, 127, 511-515.

González, M.J. (1995). Biología de las principales especies de múscidos asociadas al ganado vacuno en Asturias. Tesis Doctoral. Universidad de Oviedo. Oviedo (España).

Gordon, I.J.; Illius, A.W., 1988. Incisor arcade structure and diet selection in ruminants. Functional Ecology, 2, 15-22.

Gordon, I.J., 1989a. Vegetation community selection by ungulates on the Isle of Rhum. I. Food Supply. Journal of Applied Ecology, 26, 35-51.

Gordon, I.J., 1989b. Vegetation community selection by ungulates on the Isle of Rhum. II. Vegetation community selection. Journal of Applied Ecology, 26, 53-64.

Gordon, I.J., 1989c. Vegetation community selection by ungulates on the Isle of Rhum. III. Determinants of vegetation community selection. Journal of Applied Ecology, 26, 65-79.

Gordon, I.J.; Illius, A.W., 1989. Resource partitioning by ungulates on the Isle of Rhum. Oecologia, 79, 383-389.

Grant, S.A.; Suckling, D.E.; Smith, H.K.; Torvell, L.; Forbes, T.D.A.; Hodgson, J., 1985. Comparative studies of diet selection by sheep and cattle: the hill grasslands. Journal of Ecology, 73, 987-1004.

Grant, S.A.; Torvell, L.; Smith, H.K.; Suckling, D.E.; Hodgson, J., 1987. Comparative studies of diet selection by sheep and cattle: blanket bog and heather moor. Journal of Ecology, 75, 947-960.

Grant, S.A.; Maxwell, T.J., 1988. Hill vegetation and grazing animals: the biology and definition of management options. En: Ecological Change in the Uplands. M.B. 
Usher, D.B.A. Thompson (Eds.), pp. 201-214. Blackwell Scientific Publications, Oxford (Reino Unido).

Grime, J.P., 1979. Plant strategies and vegetation processes. John Wiley \& Sons. Chichester (Reino Unido).

Grime, J.P., 2001. Plant Strategies and Vegetation Processes and Ecosystem Properties. John Wiley \& Sons. Chichester (Reino Unido).

Gutiérrez, J.M.; Cofiño, A.; Alonso del Val, F.J.; Fernández, J.M.; Ferrer i Marco, F., Francés, E., 2005. Mapas climáticos de Cantabria. Consejería de Ganadería, Agricultura y Pesca de Cantabria. Santander (España).

Hagerman, A.E.; Robbins, C.T.; Weerasuriya, Y.; Wilson, T.C.; McArthur, C. 1992. Tannin chemistry in relation to digestion. Journal of Range Management, 45, 5762.

Halaweish, F.T.; Kromberg, S.; Hubert, M.B.; Rice, J.A., 2002. Toxic and aversive diterpenes of Euphorbia esula. Journal of Chemical Ecology 28, 1559-1611.

Hanley, T.A., 1982. The nutritional basis for food selection by ungulates. Journal of Range Management, 35, 146-151.

Hansen, R.M.; Clark, R.C.; Lawhorn, W., 1977. Foods of wild horses, deer, and cattle in the Douglas Mountain Area, Colorado. Journal of Range Management, 30, 116119.

Hatfield, R.D.; Weimer, P.J., 1995. Degradation characteristics of isolated and in situ cell wall Lucerne pectic polysaccharides by mixed ruminal microbes. Journal of the Science of Food and Agriculture, 69, 185-196.

Heemstra, J.M.; Kronberg, S.L.; Neiger, R.D.; Pruitt, R.J., 1999. Behavioral, nutritional, and toxicological responses of cattle to ensiled leafy spurge. Journal of Animal Science. 77, 600-610.

Hein, D.G.; Miller, S.D., 1992. Influence of leafy spurge on forage utilization by cattle. Journal of Range Management. 45, 405-407.

Herbel, C.H.; Nelson, A.B., 1966. Activities of Hereford and Santa Gertrudis cattle on a southern New Mexico range. Journal of Range Management, 19, 173-176. 
Hervás, G.; Mandaluniz, N.; Oregui, L.M.; Mantecón, A.R.; Frutos, P. 2003. Evolución anual del contenido de taninos del brezo (Erica vagans) y relación con otros parámetros indicativos de su valor nutritivo. ITEA, 99A, 69-84.

Hervás, G.; Frutos, P.; Giráldez, F.J.; Mora, M.J.; Fernández, B.; Mantecón A.R., 2005. Effect of preservation on the fermentative activity of the fluid used as inoculum for the in vitro gas production technique. Animal Feed Science and Technology, 123$124,107-118$.

Hill, G. M.; Utley, P. R.; Newton, G.L., 1986. Digestibility and utilization of ammoniatreated an urea-supplemented peanut skin diets fed to cattle. Journal of Animal Science, 63, 705-714.

Hodgson, J., 1990. Grazing Management. Science into Practice. Longman. Essex (Reino Unido).

Hodgson, J.G.; Wilson, P.J.; Hunt, R; Grime, J.P.; Thompson, K., 1999. Allocating C-S-R functional types; a soft approach to a hard problem. Oikos, 85, 282-294.

Hoffman, R.R. 1988. Anatomy of the gastro-intestinal tract. En: The Ruminant Animal Physiology and Nutrition. D.C. Church (Ed.), pp.14-43. Prentice Hall. New Yersey (Estados Unidos).

Holechek, J.L.; Pieper, R.D.; Herbel, C.H., 2004. Range Management. Principles and Practices ( $5^{\text {th }}$ Edn.). Prentice Hall. New Yersey (Estados Unidos).

Hongo, A.; Akimoto, M., 2003. The role of incisors in selective grazing by cattle and horses. Journal of Agriculture Science, 140, 469-477.

Howery, L.D.; Provenza, F.D.; Banner, R.E.; Scott, C.B., 1996. Differences in distribution patterns among individuals in a cattle herd. Applied Animal Behaviour Science, 49, 305-320.

Howery, L.D.; Provenza, F.D.; Banner, R.E.; Scott, C.B., 1998. Social and environmental factors influence cattle distribution on rangeland. Applied Animal Behaviour Science, 55, 231-244.

Hunter, R.F., 1962. Hill sheep and their pasture: a study of sheep grazing in South East Scotland. Journal of Ecology, 50, 651-680. 
Huston, J.E.; Rector, B.S.; Ellis, W.C.; Allen, M.L., 1986. Dynamics of digestion in cattle, sheep, goats and deer. Journal of Animal Science, 62, 208-215.

Illius, A.W.; Gordon, A.J., 1987. The allometry of food intake in grazing ruminants. Journal of Applied Ecology, 56, 989-999.

Illius, A.W.; Gordon, A.J., 1992. Modelling the nutritional ecology of ungulate herbivores: evolution of body size and competitive interactions. Oecologia, 89, 428-434.

Irving, B.D.; Rutledge, P.L.; Bailey, A.W.; Naeth, M.A.; Chanasyk, D.S., 1995. Grass utilization and grazing distribution within intensively managed fields in Central Alberta. Journal of Range Management, 48, 358-361.

Isselstein, J.; Jeangros, B.; Pavlu, V., 2005. Agronomic aspects of biodiversity targeted management of temperate grasslands in Europe: a review. Agronomy Research, 3, 139-151.

Jacobs, J., 1974. Quantitative measurement of food selection. A modification of the forage ratio and Ivlev's electivity index. Oecologia, 14, 413-417.

Janis, C., 1976. The evolutionary strategy of the equidae and the origins of rumen and cecal digestion. Evolution, 30, 757-774.

Jauffret, S.; Lavorel, S., 2003. Are plant functional types relevant to describe degradation in arid, southern Tunisian steppes? Journal of Vegetation Science, 14, 399-408.

Jewell, P.L.; Güsewell, S.; Berry, N.R.; Käuferle, D.; Kreuzer, M.; Edwards, P.J., 2005. Vegetation patterns maintained by cattle grazing on a degraded mountain pasture. Botanica Helvetica, 115, 109-124.

Kaitho, R.J.; Nsahlai, I.V.; Williams, B.A.; Umunna, N.N.; Tamminga, S.; Van Bruchem, J., 1998. Relationships between preference, rumen degradability, gas production and chemical composition of browses. Agroforestry Systems, 39, 129-144.

Kemp, D.R., 1999. Managing grassland composition with grazing. Proceedings of the Bushcarce Grassy Landscapes Conference. T. Barlow; R. Thorburn (Eds.), pp. 145-152. Clare (Australia).

Kilcher, M.R., 1981. Plant development, stage of maturity and nutrient composition. Journal of Range Management, 46, 410-415. 
Kirby D.R.; Hanson T.P.; Sieg, C.H., 1997. Diets of Angora goats grazing leafy spurge (Euphorbia esula) infested rangeland. Weed Technology, 11, 734-738.

Kronberg, S.L.; Walker, J.W., 1993. Ruminal metabolism of leafy spurge in sheep and goats: a potential explanation for differential foraging on spurge by sheep, goats, and cattle. Journal of Chemical Ecology, 19, 2007-2017.

Kronberg, S.L.; Multifering, R.B.; Ayers, E.L.; Marlow, C.B., 1993. Cattle avoidance of leafy spurge: A case of conditioned aversion. Journal of Range Management, 46, 364-366.

Kronberg, S.L.; Lynch, W.C.; Cheney, C.D.; Walker, J.W., 1995. Potential aversive compounds in leafy spurge for ruminants and rats. Journal of Chemical Ecology, 21, 1387-1399.

Krysl, L.J.; Hubbert, M.E.; Sowell, B.F.; Plumb, G.E.; Jewett, T.K.; Smith, M.A.; Waggoner, J.W., 1984. Horses and cattle grazing in the Wyoming Red Desert. I. Food habits and dietary overlap. Journal of Range Management, 37, 72-76.

Laca, E.A., 2008. Foraging in a heterogeneous environment. Intake and diet choice. En: Resource Ecology. Spatial and Temporal Dynamics of Foraging. H.T. Prins; F. van Langevelde (Eds.), pp. 81-100. Springer. Wageningen (Holanda).

Lacey, J.R.; Marlow, C.B.; Lane, J.R., 1989. Influence of spotted knapweed (Centaurea maculosa) on surface runoff and sediment yield. Weed Technology, 3, 627-631.

Lachica, M.; Prieto, C.; Aguilera, J.F., 1997. Estimation of the energy costs of walking on the level and on negative and positive slopes in the Granadina goat (Capra hircus). British Journal of Nutrition, 77, 73-81.

Lachica, M.; Somlo, R.; Barroso, F.G.; Boza, J.; Prieto, C., 1999. Goats locomotion energy expenditure under range grazing conditions: seasonal variation. Journal of Range Management, 52, 431-435.

Lamoot, I.; Meert, C.; Hoffmann, M., 2005. Habitat use of ponies and cattle foraging together in a coastal dune area. Biological Conservation, 122, 523-536.

Landgraf, B.K.; Fay, F.K.; Havstad, K.M., 1984. Utilization of leafy spurge (Euphorbia esula) by sheep. Weed Science, 32, 348-352. 
Langenheim, J.H., 1994. Higher plant terpenoids: a phytocentric overview of their ecological roles. Journal of Chemical Ecology, 20, 1223-1281.

Launchbaugh, K.L.; Howery, L.D., 2005. Understanding lanscape use patterns of livestock as a consequence of foraging behavior. Rangeland Ecology \& Management, 58, 99108.

Lawrence, A.B., 1990. Mother-daughter and peer relationships of Scottish hill sheep. Animal Behaviour, 39, 481-486.

López, S.; Carro, M.D.; González, J.S.; Ovejero, F.J., 1991. Rumen degradation of the main forage species harvested from permanent mountain meadows in NorthWestern Spain. Journal of Agricultural Science, Cambridge, 117, 363-369.

López, S.; Davies, D.R.; Giráldez, F.J.; Dhanoa, M.S.; Dijkstra, J.; France, J., 2005. Assessment of nutritive value of cereal and legume straws based on chemical composition and in vitro digestibility. Journal of the Science of Food and Agriculture.

Loucougaray, G.; Bonis, A.; Bouzillé, J., 2004. Effects of grazing by horses and/or cattle on the diversity of coastal grasslands in western France. Biological Conservation, $116,59-71$.

Luick, R., 1998. Ecological and socio-economic implications of livestock-keeping systems on extensive grasslands in South-Western Germany. Journal of Applied Ecology, $35,979-982$.

Lym, R.G.; Kirby, D.R., 1987. Cattle foraging behavior in Leafy Spurge (Euphorbia esula) infested Rangeland. Weed Technology, 1, 314-318.

Lyman, T.D.; Provenza, F.D.; Villalba, J.J., 2008. Sheep foraging behavior in response to interactions among alkaloids, tannins and saponins. Journal of the Science of Food and Agriculture, 88, 824-831.

Makkar H.P.S.; Blümmel, M.; Borowy, N.K.; Becker, K., 1993. Gravimetric determination of tannins and their correlations with chemical and protein precipitation methods. Journal of the Science of Food and Agriculture, 61, 161-165. 
Makkar, H.P.S., 2003. Effects and fate of tannins in ruminant animals, adaptation to tannins, and strategies to overcome detrimental effects of feeding tannin-rich feeds. Small Ruminant Research, 49, 241-256.

Malechek, J.C.; Smith, B.M., 1976. Behaviour of range cows in response to winter weather. Journal of Range Management, 29, 9-12.

Mandaluniz, N.; Aldezabal, A.; Oregui, L.M., 2000. Comparación interanual de la estrategia alimentaria del ganado vacuno en pastos comunales del macizo de Gorbea (Bizkaia). Actas de la XL Reunión Científica de la Sociedad Española para el Estudio de los Pastos, 571-577. Lugo (España).

Mandaluniz, N., 2003. Pastoreo del ganado vacuno en zonas de montaña y su integración en los sistemas de producción de la CAPV. Tesis doctoral. Universidad de Zaragoza. Zaragoza (España).

Mandaluniz, N.; Igarzabal, A.; Pérez de Arenaza, A.; Oregui, L.M., 2005. Pastoreo en el parque natural de Gorbeia. 2. Cargas ganaderas. Actas de las XI Jornadas sobre Producción Animal ITEA, 201-203. Zaragoza (España).

Mantecón, A.R.; Frutos, P.; Lavín, P.; Giráldez, F.J., 1998. Prácticas en ganadería extensiva. Actas de la XXXVIII Reunión Científica de la Sociedad Española para el Estudio de los Pastos, 205-217. Soria (España).

Marinas, A.; García-González, R.; Fondevila, M., 2003. The nutritive value of five pasture species occurring in the summer grazing ranges of the Pyrenees. Animal Science, 76, 461-469.

Mattson, W.J.J., 1980. Herbivory in relation to plant nitrogen content. Annual Review on Ecology and Systematics, 11, 119-161.

Mauricio, R.M.; Mould, F.L.; Dhanoa, M.S.; Owen, E.; Channa, K.S.; Theodorou, M.K., 1999. A semi-automated in vitro gas production technique for ruminant feedstuff evaluation. Animal Feed Science Technology, 79, 321-330.

Mbugua, D.M; Kiruiro; E.M.; Pell, A.N., 2008. In vitro fermentation of intact and fractionated tropical herbaceous and tree legumes containing tannins and alkaloids. Animal Feed Science and Technology, 146, 1-20. 
McDougall, E.I., 1948. Studies of ruminant saliva. I. The composition and output of sheep's saliva. Biochemical Journal, 43, 99-109.

McNaughton, S.J., 1983. Compensatory plant growth as a response to herbivory. Oikos, 40, 329-336.

Mehrez, A.Z.; Ørskov, E.R.; McDonald, I., 1977. Rate of rumen fermentation in relation to ammonia concentration. British Journal of Nutrition, 38, 437-443.

Menard, C.; Duncan, P.; Fleurance, G.; Georges, J.; Lila, M., 2002. Comparative foraging and nutrition of horses and cattle in European wetlands. Journal of Applied Ecology, 39, 120-133.

Meyer, G.A., 1998. Mechanisms promoting recovery from defoliation. Canadian Journal of Botany, 76, 450-459.

Milchunas, D. G.; Noy-Meir, I., 2002. Grazing refuges, external avoidance of herbivory and plant diversity. Oikos, 99, 113-130.

Milne, J.A.; MacRae, J.C.; Spence A.; Wilson, S., 1978. A comparison of the voluntary intake and digestion of forages at different times of the year by the sheep and red deer (Cervus elaphus). British Journal of Nutrition, 40, 347-357.

Mlambo, V.; Makkar, H.P.S., 2005. Calibration and validation of the ${ }^{14}$ C-labelled polyethylene glycol-binding assay for tannins in tropical browse. Animal Feed Science and Technology, 122, 29-40.

Molinillo, M; Lasanta, T.; García-Ruiz, J.M., 1997. Managing mountainous degraded landscapes alter farmland abandonment in the Central Spanish Pyrenees. Environmental Management, 21, 587-598.

Montserrat, P.; Fillat, F., 1977. La ganadería extensiva y las culturas rurales montañesas. Anales del Instituto de Estudios Agropecuarios, 3, 83-120.

Montserrat, P., 1978. El incendio de pastizales y sus peligros. Pastos, 8, 31-36.

Mora, M.J.; Busqué, J.; Hervás, G.; Mantecón, A.R.; Fernández, B.; Frutos, P., 2007a. Evaluation of sheep grazing as a tool to restore mountain pastures invaded by Euphorbia polygalifolia. Options Méditerranéennes, 74, 273-278. 
Mora, M.J.; Frutos, P.; Sarmiento, M.; Mantecón, A.R.; Busqué, J., 2007b. ¿Podría la disponibilidad y el valor nutritivo de los pastos de puerto de la Cordillera Cantábrica explicar su invasión por la lecherina (Euphorbia polygalifolia L.)? Actas de la XLVI Reunión Científica de la Sociedad Española para el Estudio de los Pastos, 101-106. Vitoria (España).

Mora, M.J.; Frutos, P.; Fernández, B.; Busqué, B., 2007c. Comportamiento en pastoreo en zonas de montaña de la Cordillera Cantábrica: comparación entre razas de ganado vacuno autóctonas (Tudanca) y foráneas (Limusina y Charolesa). Actas de la XLVI Reunión Científica de Sociedad Española para el Estudio de los Pastos, 397-402. Vitoria (España).

Mote, T.E.; Villalba, J.J.; Provenza, F.D., 2007. Relative availability of tannin and terpene containing foods affects food intake and preference by lambs. Journal of Chemical Ecology, 33, 1197-1206.

Mueggler, W.F., 1965. Cattle distribution on steep slopes. Journal of Range Management, $18,255-257$.

Noy-Meir, I.; Gutman, M.; Kaplan, Y., 1989. Responses of mediterranean grassland plants to grazing and protection. Journal of Applied Ecology, 77, 290-310.

Núñez-Hernández, G.; Wallace, J.D.; Holechek, J. L.; Galyean M. L.; Cardenas, M., 1991. Condensed tannins and nutrient utilization by lambs and goats fed low-quality diets. Journal of Animal Science, 69, 1167-1177.

O’Connor, T.G., 1991. Local extinction in perennial grasslands: a life-history approach. The American Naturalism, 137, 753-773.

Oh, H.K.; Sakai, T.; Jones, M.B.; Longhhurst, W.M., 1967. Effect of various essential oils isolated from Douglas fir needles upon sheep and deer rumen microbial activity. Applied microbiology, 15, 777-784.

Orr, D.M.; Evenson C.J.; Lehane, J.K.; Bowly, P.S.; Cowan, D.C., 1993. Dynamics of perennial grasses with sheep grazing in Acacia aneura woodlands in south-west Queensland. Tropical grasslands, 27, 87-93. 
Osoro, K.; Oliván, M.; Celaya, R.; Martínez, A., 1999. Effects of genotype on the performance and intake characteristics of sheep grazing contrasting hill vegetation communities. Animal Science, 69, 419-426.

Osoro, K.; Celaya, R.; Martínez, A.; Zorita, E., 2000. Pastoreo de las comunidades vegetales de montaña por rumiantes domésticos: producción animal y dinámica vegetal. Pastos, 30, 3-50.

Owens, M.K.; Launchbaugh, K.L.; Holloway, J.W., 1991. Pasture characteristics affecting spatial distribution of utilization by cattle in mixed brush communities. Journal of Range Management, 44, 118-123.

Panter, K.E.; James, L.F.; Gardner, D.R.; Ralphs, M.H.; Pfister, J.A.; Stegelmeier, B.L.; Lee, S.T., 2002. Reproductive losses to poisonous plants: influence of management strategies. Journal of Range Management, 55, 301-308.

Parmenter, R.R.; MacMahon, J.A., 1983. Factors determining the abundance and distribution of rodents in a shrub-steppe ecosystem - the role of shrubs. Oecologia, $59,145-156$.

Parsons, C.T.; Momont, P.A.; Delcurto, T.; McInnis, M.; Porath, M.L., 2003. Cattle distribution patterns and vegetation use in mountain riparian areas. Journal of Range Management, 56, 334-341.

Peco, B.; Sánchez, A.M.; Azcárate, F.M., 2006. Abandonment in grazing systems: Consequences for vegetation and soil. Agriculture Ecosystems and Environment, $113,284-294$.

Pell, A.N.; Woolston, T.K.; Nelson, K.E.; Schofield, P., 2000. Tannins: biological activity and bacterial tolerance. ACIAR Proc, 92, 111-116.

Pinchak, W.E.; Smith, M.A.; Hart, R.H.; Waggoner, J.W., 1991. Beef cattle distribution patterns on foothill range. Journal of Range Management, 44, 267-275.

Plaixats, J.; Bartolomé, J. 2001. Dinámica de la cubierta vegetal. Interacción planta-animal. Ovis, 74, 31-48.

Poppi, D.P.; Minson, D.J.; Ternouth, J.H., 1980. Studies of cattle and sheep eating leaf and stem fractions of grasses. I. The voluntary intake, digestibility and retention time in the reticulo-rumen. Australian Journal of Agricultural Research, 32, 99-108. 
Pratt, R.M.; Putman, R.J.; Ekins, J.R.; Edwards, P.J., 1986. Use of habitat by free-ranging cattle and ponies in the New Forest, Southern England. Journal of Applied Ecology, 23, 539-557.

Pritz, R.K.; Launchbaugh, K.L.; Taylor, C.A., 1997. Effects of breed and dietary experience on juniper consumption by goats. Journal of Range Management, 50, 600-606.

Provenza, F.D.; Balph, D.F., 1987. Diet learning by domestic ruminants: theory, evidence and practical implications. Applied Animal Behaviour Science, 18, 211-232.

Provenza, F.D.; Pfister, J.A.; Cheney, C.D., 1992. Mechanisms of learning in diet selection with reference to phytotoxicosis in herbivores. Journal of Range Management, 45, $36-45$.

Provenza, F.D., 1995. Postingestive feedback as an elementary determinant of food preference and intake in ruminants. Journal of Range Management, 48, 2-17.

Provenza, F.D. 1996. Acquired aversions as the basis for varied diets of ruminants foraging on rangelands. Journal of Animal Science, 74, 2010-2020.

Provenza, F.D., 2007. Social organization, culture and use of landscapes by livestock. Options Méditerrannéenes, 74, 307-316.

Putman, R.J.; Pratt, R.M.; Ekins, J.R.; Edwards, P.J., 1987. Food and feeding behaviour of cattle and ponies in the New Forest, Hampshire. Journal of Applied Ecology, 24, 369-380.

Ralphs, M.H.; Bowns, J.E.; Manners, G.D., 1991. Utilization of larkspur by sheep. Journal of Range Management, 44, 619-622.

Ralphs, M.H.; Graham, D.; James, L.F., 1994. Social facilitation influences cattle to graze locoweed. Journal of Range Management, 47, 123-126.

Ramos, G.; Frutos, P.; Giráldez, F.J.; Mantecón, A.R., 1998. Los compuestos secundarios de las plantas en la nutrición de los herbívoros. Archivos de Zootecnia, 47, 597620.

Ramos, M.E.; Robles, A.B.; Ruiz-Mirazo, J.; Cardoso, J.A.; González-Rebollar, J.L., 2005. Dispersión endozoócora por ganado ovino de cuatro leguminosas herbáceas de 
interés forrajero. Actas de la XLV Reunión Científica de la Sociedad Española para el Estudio de los Pastos, 923-929. Gijón (España).

Revesado, P., 1994. Valor nutritivo de pastos de montaña e intensidad de selección ejercida sobre los mismos por dos razas ovinas (Churra y Merina). Tesis Doctoral. Universidad de León. León (España).

Revilla, R., 1997. Comportamiento de animales domésticos en pastos de zonas de montaña. En: Aprovechamiento Agroambiental de Pastos Comunales. A.A. Rodríguez Castañón (Ed.), pp. 191-221. Asociación Española de criadores de vacuno selecto de raza Asturiana de los Valles. Oviedo (España).

Rickert, K.G., 1996. Stocking rate and sustainable grazing systems. Wageningen Agricultural University Papers, 96, 29-67.

Riedel, J.L., 2007. Bases para la gestión sostenible del Parque de la Sierra y Cañones de Guara: interacciones entre la ganadería y la dinámica de la vegetación. Tesis Doctoral. Universidad de Zaragoza. Zaragoza (España).

Ríos y Ríos, A., 1878. Memoria sobre las antiguas y modernas comunidades de pastos entre los valles de Campoo de Suso, Cabuérniga y otros de la provincia de Santander. J.M. Martínez. Santander (España).

Rittenhouse, L.R., 1986. The relative efficiency of rangeland use by ruminants and nonruminant herbivores. En: Grazing Research at Northern Latitudes. O. Gudmundsson (Ed.), pp. 179-193. Plenum Press. New York (Estados Unidos).

Rivas-Martínez, S.; Díaz, T. E.; Fernández-González; Izco, F. J.; Loidi, J.; Lousã, M.; Penas, A., 2002. Vascular plant communities of Spain and Portugal. Addenda to the syntaxonomical checklist of 2001. Part I. Itinera Geobotanica, 15, 5-432.

Roath, L.R.; Krueger, W.C., 1982. Cattle grazing influence in a mountain riparian zone. Journal of Range Management, 35, 100-104.

Roberts, J.L.; Olson, B.E., 1999. Effect of Euphorbia esula on sheep rumen microbial activity and mass in vitro. Journal of Chemical Ecology, 25, 297-314.

Rogosic, J.; Estell, R.E.; Ivankovic, S.; Kezic, J.; Razov, J., 2008. Potential mechanisms to increase shrub intake and performance of small ruminants in Mediterranean shrubby ecosystems. Small Ruminant Research, 74, 1-15. 
Roura-Pascual, N.; Pons, P.; Etienne, M.; Lambert, B., 2005. Transformation of a rural lanscape in the Eastern Pyrenees between 1953 and 2000. Mountain Research and Development, 25, 252-261.

Salter, R.E.; Hudson, R.J., 1980. Range relationships of feral horses with wild ungulates and cattle in Western Alberta. Journal of Range Management, 33, 266-271.

SAS, 1999. SAS OnlineDoc ${ }^{\circledR}$, Version 8. SAS Institute Inc. Cary (Estados Unidos).

Scott, N.A.; Saggar, S.; McIntosh, P.D., 2001. Biogeochemical impact of Hieracium invasion in New Zealand's grazed tussock grasslands: sustainability implications. Ecological Applications, 11, 1311-1322.

Seath, D.M.; Miller, G.D., 1946. Effect of warm weather on grazing performance of milking cows. Journal of Dairy Science, 39, 921-925.

Senft, R.L.; Rittenhouse, L.R.; Woodmansee, R.G., 1985. Factors influencing patterns of cattle grazing behaviour on shortgrass steppe. Journal of Range Management, 38, 82-87.

Senft, R.L.; Coughenour, M.B.; Bailey, D.W.; Rittenhouse, L.R.; Sala, O.E.; Swinft, D.M., 1987. Large herbivore foraging and ecological hierarchies: landscape ecology can enhance traditional foraging theory. Bioscience, 37, 789-799.

Severson, K.E.; Debano, L.F., 1991. Influence of Spanish goats on vegetation and soils in Arizona chaparral. Journal of Range Management, 44, 111-117.

Sheley, R.L.; Jacobs, J.S.; Carpinelli, M.F., 1998. Distribution, biology, and management of diffuse knapweed (Centaurea diffusa) and spotted knapweed (Centaurea maculosa). Weed Technology, 12, 353-362.

Siddons, R.C.; Paradine, J., 1983. Protein degradation in the rumen of sheep and cattle. Journal of the Science of Food and Agriculture, 34, 701-708.

Silanikove, N.; Tagari, H.; Shkolnik, A., 1993. Comparison of rate of passage, fermentation rate and efficiency of digestion of high fiber diet in desert Bedouin goats compared to Swiss Saanen goats. Small Ruminant Research, 12, 45-60.

Smit, C.; den Ouden, J.; Müller-Schärer, H., 2006. Unpalatable plants facilitate tree sapling survival in wooded pastures. Journal of Applied Ecology, 43, 305-312. 
Smith, G.S., 1992. Toxification and detoxification of plant compounds by ruminants: an overview. Journal of Range Management, 45, 25-30.

Smith, M.A.; Rodgers, J.D.; Dodd, J.L.; Skinner, Q.D., 1992. Declining forage availability effects on utilization and community selection by cattle. Journal of Range Management, 45, 391-395.

SPSS, 1999. SPSS Base 10.0 Applications guide. SPSS Inc. Chicago (Estados Unidos).

Steinauer, E.M.; Collins, S.L., 1995. Effects of urine deposition on small-scale patch structure in prairie vegetation. Ecology, 76, 1195-1205.

Sternberg, M.; Gutman, M.; Perevolotsky, A.; Ungar, E.D.; Kigel, J., 2000. Vegetation response to grazing management in a Mediterranean herbaceous community: a functional group approach. Journal of Applied Ecology, 37, 224-237.

Taüll, M.; Sebastiá, M.T., 2002. Estructura y productividad de diversas comunidades en el pirineo central según el tipo de pastoreo. Actas de la XLVII Reunión Científica de la Sociedad Española para el Estudio de los Pastos, 183-188. Lérida (España).

Teague, W.R.; Dowhower, S.L.; Waggoner, J.A., 2004. Drought and grazing patch dynamics under different grazing management. Journal of Arid Environments, 58, 97-117.

Terradas, J., 2001. Ecología de la vegetación. De la ecofisiología de las plantas a la dinámica de comunidades y paisajes. Omega. Barcelona (España).

Tews, J.; Brose, U.; Grimm, V.; Tielbörger, K.; Wichmann, M.C.; Schwager, M.; Jeltsch, F., 2004. Animal species diversity driven by habitat heterogeneity/diversity: the importance of keystone structures. Journal of Biogeography, 31, 79-92.

Theodorou, M.K.; Williams, B.A.; Dhanoa, M.S.; McAllan, A.B.; France, J., 1994. A simple gas production method using a pressure transducer to determine the fermentation kinetics of ruminant feeds. Animal Feed Science and Technology, 48, 185-197.

Thomas, B.; Fairbairn, C.B., 1956. The white bent (Nardus stricta): its composition, digestibity and probable nutritive value. Grass \& Forage Science, 11, 230-234.

Tramell, M.A.; Butler, J.L., 1995. Effects of exotic plants on native ungulate use of habitat. Journal of Wildlife Management, 59, 808-816. 
Treskonova, M., 1991. Changes in the structure of tall tussock grasslands and infestation by species of Hieracium in the Mackenzie country. New Zealand Journal of Ecology, $15,65-79$.

Ugherughe, P.O., 1986. Relationship between digestibility of Bromus inermis and plant parts. Journal of Agronomy and Crop Science, 157, 136-143.

Van Houtert, M.F.J., 1993. The production and metabolism of volatile fatty acids by ruminants fed roughages: a review. Animal Feed Science and Technology, 43, 189225.

Van Rees, H.; Hutson, G.D., 1983. The behaviour of free-ranging cattle on an alpine range in Australia. Journal of Range Management, 36, 740-743.

Vander Noot, G.W.; Gillbreath, E.B., 1970. Comparative digestibility of components of forages by geldings and steers. Journal of Animal Science, 31, 351-355.

Van Soest, P.J.; Robertson J.B.; Lewis, B.A., 1991. Methods for dietary fiber, neutral detergent fiber, and nonstarch polysacharides in relation to animal nutrition. Journal of Dairy Science, 74, 3583-3597.

Van Soest, P.J., 1994. Nutritional Ecology of the Ruminant ( $2^{\text {nd }}$ Edn.). Cornell University Press. Ithaca (Estados Unidos).

Villegas, R., 2005. En el País de la Vaca Tudanca. Cantabria Tradicional. Santander (España)

Voth, K., 2007. Livestock for Lanscapes, [Web en línea]. $<$ http://www.livestockforlandscapes.com/>. [Consulta: 10-12-2007].

Wachenheim, D.E.; Blythe, L.L.; Craig, A.M., 1992. Characterization of rumen bacterial pyrrolizidine alkaloid biotransformation in ruminants of various species. Veterinary and Human Toxicology, 34, 513-517.

Wade, M.H.; Peyraud, J.L.; Lemaire, G.; Comeron, E.A., 1989. The dynamics of daily area and depth of grazing and herbage intake of cows in a five day paddock system. Proceedings of the $16^{\text {th }}$ International Grassland Congress, 1111-1112. Niza (Francia). 
Walker, J.W.; Hansen, R.M.; Rittenhouse, L.R., 1981. Diet selection of Hereford, AngusxHereford and CharolaisxHereford cows and calves. Journal of Range Management, 34, 243-245.

Weatherburn, M.W., 1967. Phenol-hypochlorite reaction for determination of ammonia. Analytical Chemistry, 39, 971-974.

Wezel A.; Bender, S., 2004. Degradation of agro-pastoral village land in semi-arid southeastern Cuba. Journal of Arid Environments, 59, 299-311.

Wise, M.J.; Abrahamson, W.G., 2005. Beyond the compensatory continuum: environmental resource levels and plant tolerance of herbivory. Oikos, 109, 417428.

Wright, I.A.; Pakeman, R.J.; Dennis, P.; Dalziel, A.J.; Milne, J.A., 2006. The effects of cattle on the natural heritage of Scotland. Scottish Natural Heritage Commisioned Report No. 203 (ROAME No. F04AA103).

Yokoyama, M.T.; Johnson, K.A. 1988. Microbiology of the rumen and intestine. En: The Ruminant Animal: Digestive Physiology and Nutrition. D.C. Church (Ed.), pp. 125144. Prentice-Hall. New Jersey (Estados Unidos).

Zervas, G., 1998. Quantifying grazing regimes in Greek Mountain Systems. Journal of Applied Ecology, 35, 983-986. 